Marcelo Lucas

\title{
Sensor Virtual Inteligente Para Estimação de Composições em Colunas de Destilação
}

Dissertação de Mestrado apresentada à Escola de Engenharia de São Carlos da Universidade de São Paulo, sendo parte dos requisitos para obtenção do título de Mestre em Ciências, Programa de Engenharia Elétrica, Ârea de Concentração em Sistemas Dinâmicos.

Orientador: Prof. Dr. Ivan Nunes da Silva 
Ficha catalográfica preparada pela Seção de Tratamento da Informação do Serviço de Biblioteca - EESC/USP

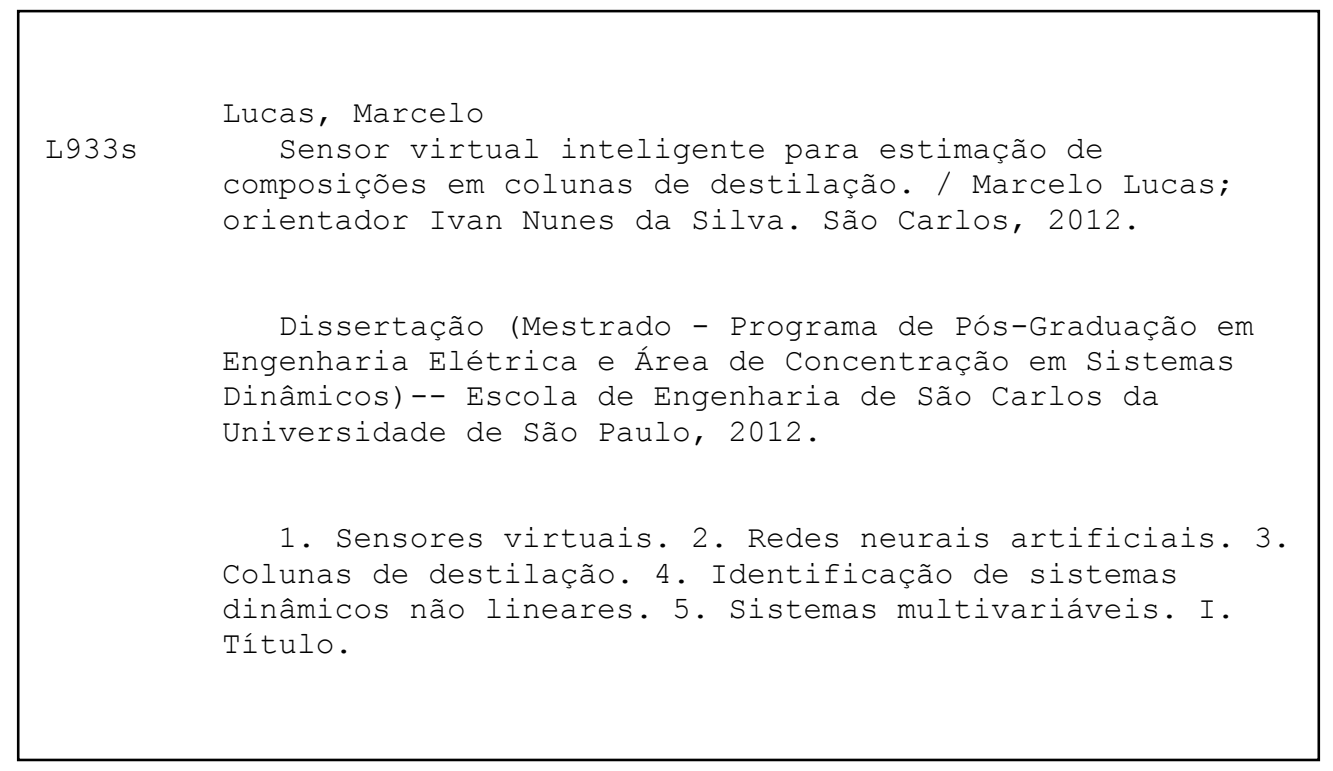




\section{FOLHA DE JULGAMENTO}

Candidato: Engenheiro MARCELO LUCAS.

Título da dissertação: "Sensor virtual inteligente para estimação de composições em colunas de destilação".

Data da defesa: 30/05/2012

Comissão Julgadora:

Prof. Associado Ivan Nunes da Silva (Orientador)

(Escola de Engenharia de São Carlos/EESC)

Prof. Dr. Edilberto Pereira Teixeira

(Universidade de Uberaba/UNIUBE)

Prof. Dr. Dennis Brandão

(Escola de Engenharia de São Carlos/EESC)
Resultado:
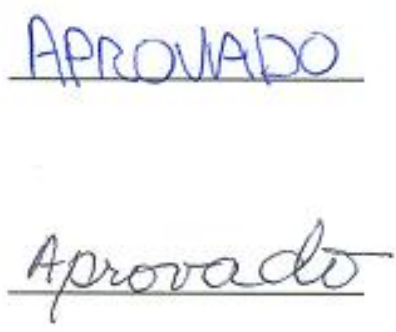

apronado

Coordenador do Programa de Pós-Graduação em Engenharia Elétrica:

Prof. Titular Denis Vinicius Coury

Presidente da Comissão de Pós-Graduação:

Prof. Associado Paulo Cesar Lima Segantine 

"Aquele que habita no esconderijo do Altíssimo, à sombra do Todo Poderoso descansará."

SALMOS 91,1 



\section{Dedicatória}

Dedico este trabalho primeiramente aos meus pais, pelo amor, compreensão, incentivo, educação e pelos ensinamentos que muito me auxiliaram, dando-me a base necessária para vencer esta e todas as demais etapas que estão por vir. Aos meus irmãos, amigos e toda minha família, pela amizade, carinho, força e atenção. Em especial, aos meus filhos, minha eterna inspiração. 



\section{Agradecimentos}

Primeiramente, a Deus pela oportunidade de estar presente aqui hoje, pelas bênçãos derramadas, de forma incondicional, todos os dias em nossas vidas. Por ter me dado força ao longo dessa dura jornada, não deixando que as dificuldades diárias me abalassem de tal maneira que pudessem me impedir de continuar. Pela saúde e por ter conseguido atingir meus objetivos. A todos de minha família que me auxiliaram a atingir meus objetivos, em particular meus pais José Heli e Maria Ercilia, que me ensinaram grandes sabedorias, e pelo apoio em todos os momentos da minha vida. Minha eterna gratidão, pelo amor, colo, torcida, companheirismo e por terem suportado com tanta paciência minha ausência. Amo vocês! A todas as minhas irmãs que direta ou indiretamente contribuíram para este momento, aos meus tios, tias e avós que já foram chamados por Deus, fica aqui minha homenagem.

Agradeço profundamente ao Prof. Doutor Ivan Nunes da Silva, orientador, professor, conselheiro, meu muito obrigado pela paciência, compreensão, profissionalismo, pelas longas horas dedicadas à orientação, a fim de tornar possível a concretização desse sonho.

Agradeço também a todos do Laboratório de Automação Inteligente de Processos e Sistemas (LAIPS) pela infraestrutura fornecida, aos colegas de laboratório, que presenciaram todo o desenvolvimento aqui realizado, principalmente ao Doutor Ricardo Augusto Souza Fernandes, pelas importantes discussões filosóficas que ajudaram a semear este trabalho, especialmente ao Mestre Luciano Carli.

A todos os funcionários e docentes do programa de pós-graduação da Escola de Engenharia de São Carlos - USP, cuja dedicação, competência e conhecimento possibilitaram o desenvolvimento desse trabalho.

Aos meus amigos, aos quais sempre pude contar e pelos momentos de diversão que compartilhamos. Em especial, aos meus amigos Anderson Morais, Prof. Doutor Edilberto, 
Florisvaldo, Marcelo Barreiro, Antônio Manuel, José Roberto, Luiz Pessoa, André de Souza, Ricardo Naufel e Virgílio.

À grande amiga Melina, por toda ajuda, que, sem dúvida foi essencial no decorrer desta jornada.

Agradeço aqueles que me transmitiram seus conhecimentos e experiências profissionais e de vida com dedicação e carinho. Também agradeço aos que me guiaram para além das teorias, das filosofias e das técnicas, expresso meus maiores agradecimentos e profundo respeito, que sempre serão poucos, diante do muito que me foi oferecido.

Finalmente, a todos que direta ou indiretamente ajudaram na realização e na conclusão desse trabalho, lembrando que posso ter cometido omissões e, portanto, gostaria de pedir sinceras desculpas àqueles que eu possa ter deixado sem o devido reconhecimento.

Dedico esta obra a todos aqueles que insistem no sonho e fazem com que este se torne realidade por meio da perseverança e do esforço sincero. 


\section{Sumário}

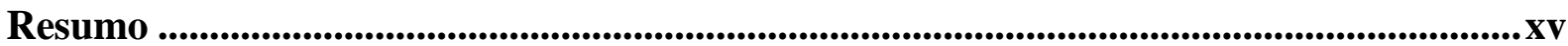

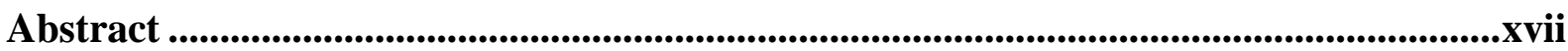

Lista de Siglas e Abreviaturas ................................................................................................xix

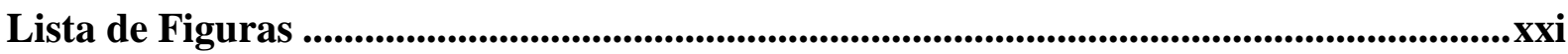

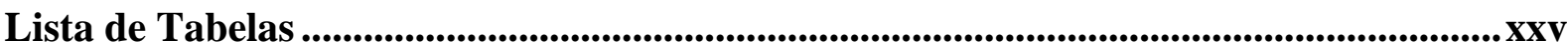

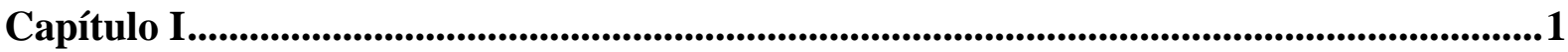

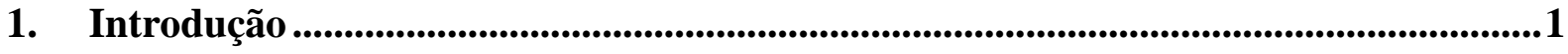

1.1. Motivação e Relevância do Trabalho......................................................................... 1

1.2. Proposta e Justificativa da Dissertação ..................................................................... 8

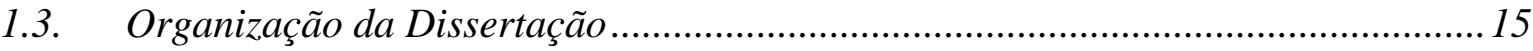

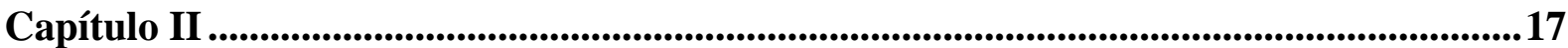

2. Fundamentação Teórica .........................................................................................................17

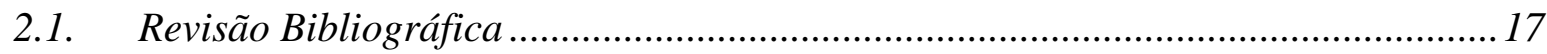

2.1.1. Aplicação de Rede Neural Artificial como Estimador Dinâmico não Linear ..............................22

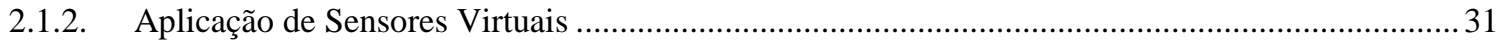

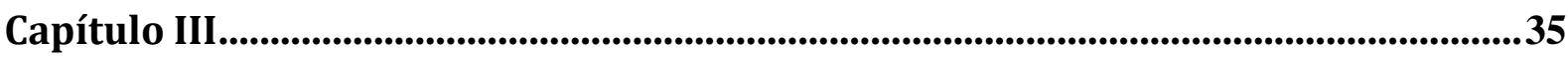

3. Aspectos de Redes Neurais Artificiais ....................................................................35

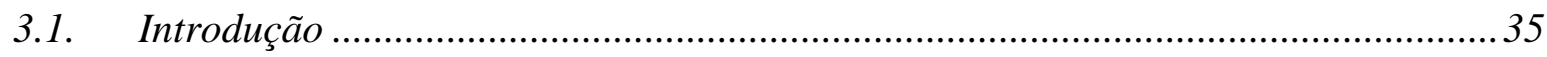

3.2. Relação entre Neurônio Biológico e Artificial ......................................................... 38

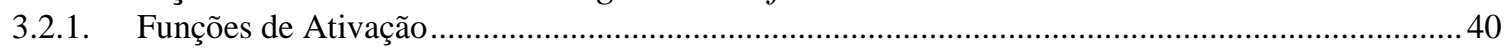

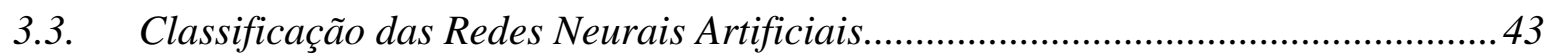

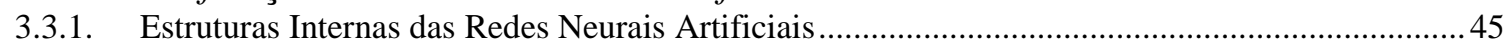

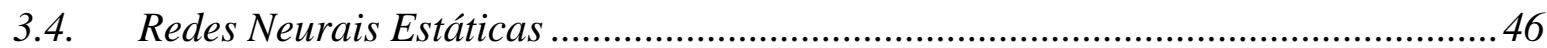

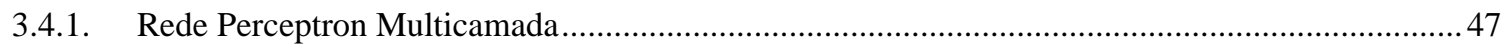

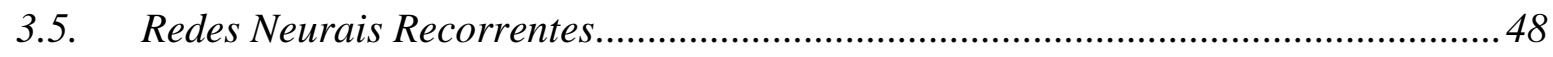

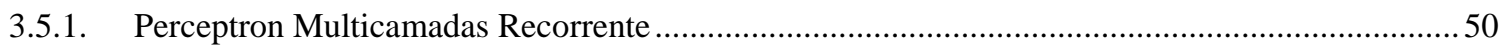

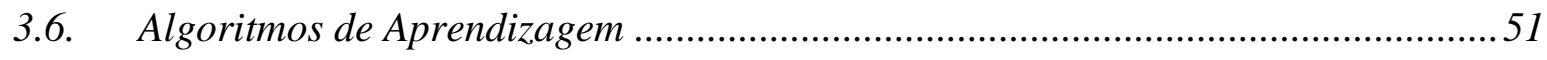

3.7. Aplicação de Redes Neurais na Identificação de Sistemas Dinâmicos.................... 54

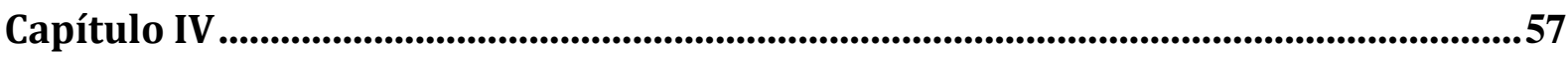




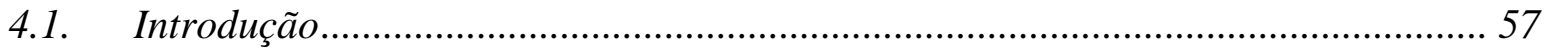

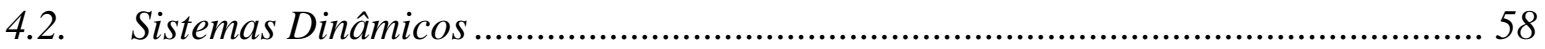

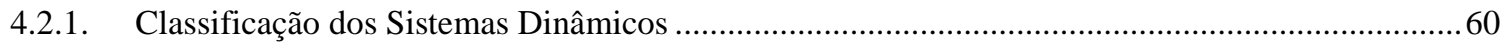

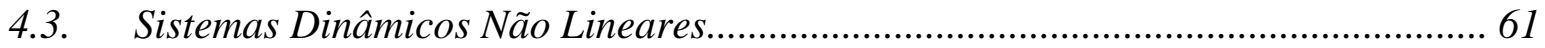

4.4. Modelagem de Sistemas Dinâmicos Não Lineares ............................................... 63

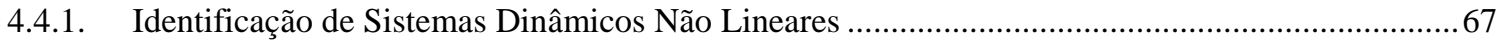

4.5. Etapas Usadas na Identificação de Sistemas Dinâmicos ....................................... 70

4.6. Representação de Sistemas Não Lineares ............................................................ 74

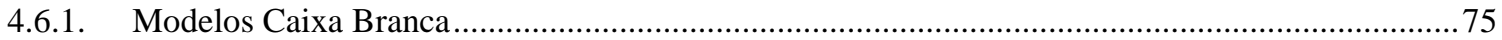

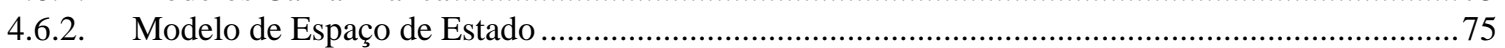

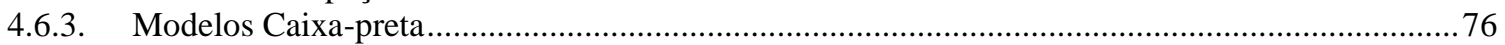

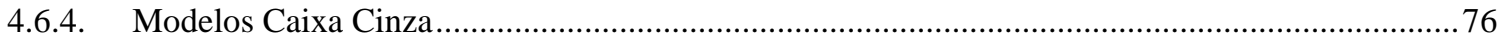

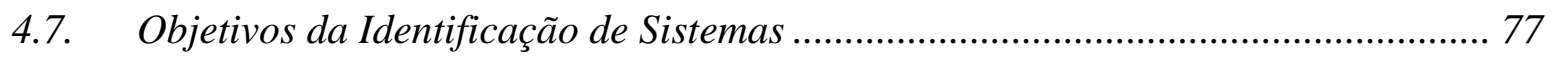

Capítulo V

5. Aspectos de Colunas de Destilação e Sensores Virtuais .......................................... 79

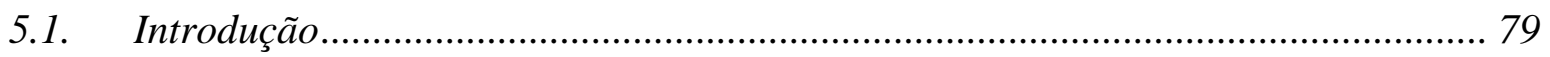

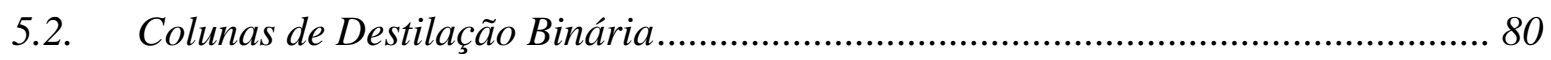

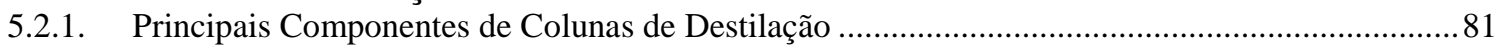

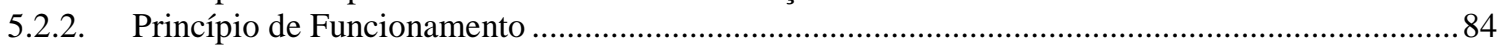

5.3. Estudo da Produção do Álcool Hidratado em Destilarias de Etanol....................... 87

5.3.1. Procedimento de Destilação do Álcool Hidratado ....................................................................... 89

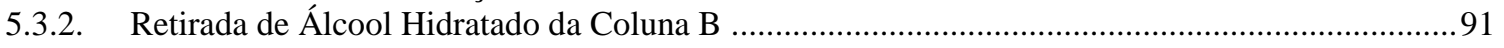

5.4. Sensores Virtuais Aplicados em Colunas de Destilação ........................................ 92

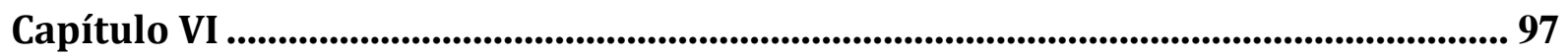

6. Materiais, Métodos e Discussão dos Resultados........................................................ 97

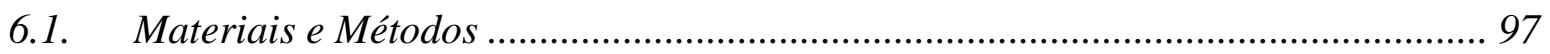

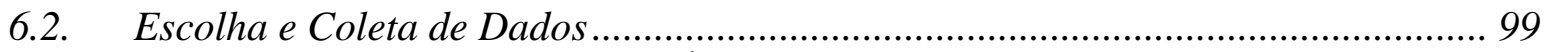

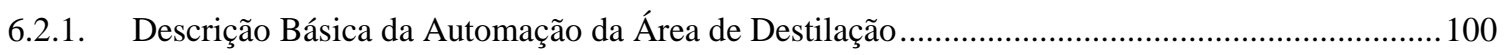

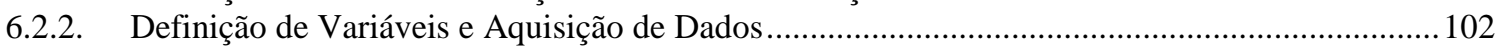

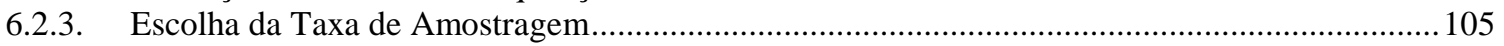

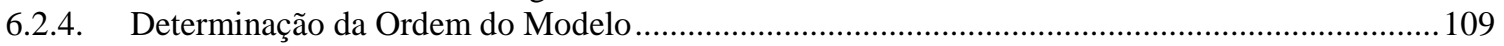

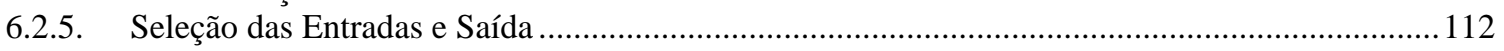

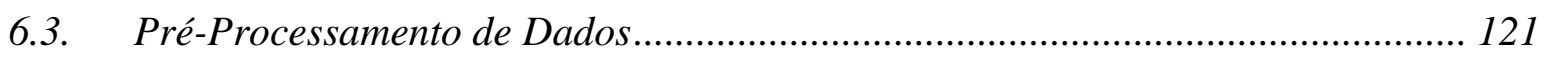

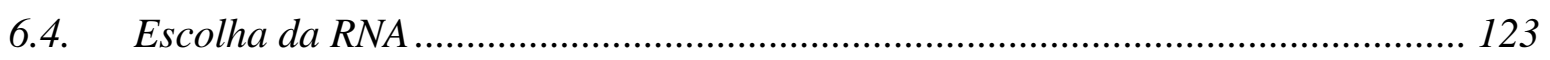

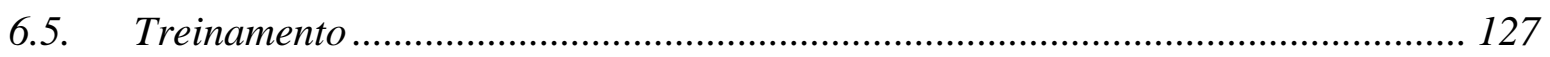

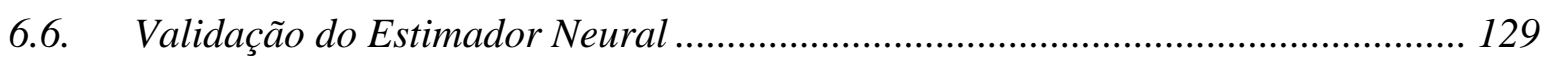

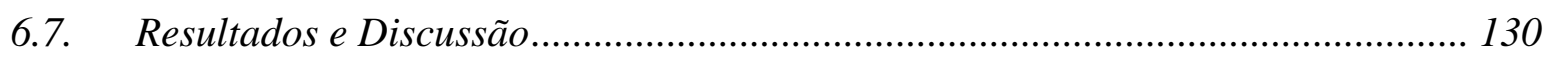

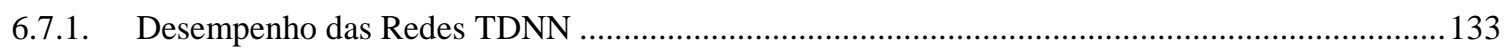




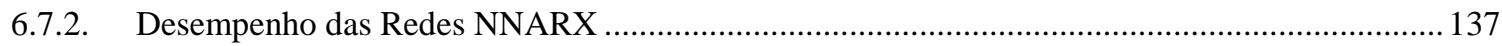

6.7.3. Comparação entre a Rede NNARX e a Representação no Espaço de Estados .....

Capítulo VII...............................................................................................................................................163

7. Conclusões Gerais e Trabalhos Futuros..............................................................163

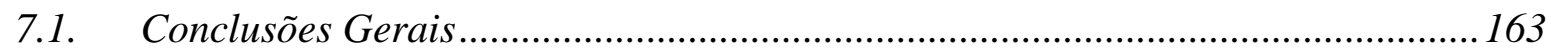

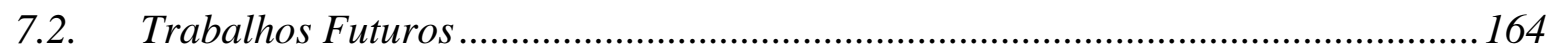

Referência Bibliográfica............................................................................................................................165

ANEXOS

ANEXO A

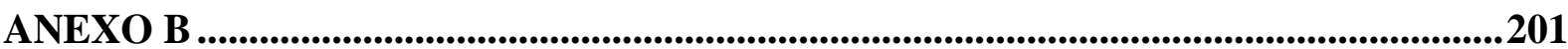





\section{Resumo}

Lucas, M.; (2012). Sensor Virtual Inteligente Para Estimação de Composições em Colunas de Destilação. Dissertação (Mestrado) - Escola de Engenharia de São Carlos, Universidade de São Paulo, 2012.

Um problema-chave envolvendo processos químicos industriais é controlar, de forma confiável, eficiente e barata, a evolução dinâmica do sistema. Numa coluna de destilação, por exemplo, o objetivo do controle é manter a composição do destilado e do produto de fundo em torno de um valor desejado. As dificuldades operacionais e o alto custo dos analisadores industriais, existentes no mercado, usados na medição da composição têm motivado o projeto de sensores virtuais (soft sensors) para que, a partir de outras medições disponíveis, seja possível inferir de maneira online os valores das variáveis desejadas. Por outro lado, as redes neurais artificiais têm sido utilizadas em diversas aplicações práticas de engenharia, sendo possível usá-las para resolver problemas industriais complexos. Elas possuem diversas características que as fazem particularmente atrativas em aplicações envolvendo sistemas multivariáveis não lineares. Nesse trabalho, um estimador dinâmico virtual baseado em redes neurais é usado para inferir a composição de etanol destilado com base na temperatura e na pressão no interior da coluna, além das vazões de refluxo, do vapor no refervedor e da alimentação. Os resultados desse estudo poderão ser utilizados no desenvolvimento de futuros projetos envolvendo sensores virtuais aplicados ao controle e à otimização de processos industriais.

Palavras Chave: Sensores virtuais, redes neurais artificiais, colunas de destilação, identificação de sistemas dinâmicos não lineares, sistemas multivariáveis. 



\begin{abstract}
Lucas, M.; (2012). Intelligent Virtual Sensor for Composition Estimation in Distillation Columns. Dissertation Text (Master's Degree) - Escola de Engenharia de São Carlos, Universidade de São Paulo, 2012.
\end{abstract}

A key problem involving industrial chemical processes is to control the dynamic evolution of the system in a reliable, efficient and low cost way. In a distillation column, for example, the control objective is to keep the composition of both distillate and bottom product around a desired value. The operational difficulties and high cost of concentration analyzers, used for measuring the composition, have motivated the design of virtual sensors (soft sensors). They are used, in an online way, to infer the values of the desired variables from other available measurements. On the other hand, artificial neural networks have been used for solving many practical engineering applications involving complex industrial problems. They have several features, making them particularly attractive to applications involving nonlinear multivariable systems. In this work, a virtual estimator based on a dynamic neural network is used to infer the composition of distilled ethanol. Temperature and pressure within the column, and the flows of steam and reflux are used as inputs for the neural network. The results of this study can be used to develop future projects involving virtual sensors applied in control and optimization of industrial processes.

Keywords: Virtual sensors, neural networks, distillation columns, identification of nonlinear dynamical systems, multivariable systems. 



\section{Lista de Siglas e Abreviaturas}

\begin{tabular}{|c|c|}
\hline AG & Algoritmos Genéticos \\
\hline ANN & Artificial Neural Network \\
\hline ARMAX & Auto Regressive Moving Average model with eXogenous inputs \\
\hline ARX & Auto Regressive model with eXogenous input \\
\hline $\mathrm{CE}$ & Computação Evolutiva \\
\hline CPBUM & Chebyshev Polynomials Based Unified Model \\
\hline $\mathrm{DBN}$ & Deep Belief Networks \\
\hline DMNN & Dynamic Multilayer Neural Networks \\
\hline DNN & Dynamic Neural Network \\
\hline EM & Expectation Maximization \\
\hline ERR & Error Reduction Ratio \\
\hline FBPN & Functional Basis Perceptron Network \\
\hline FFN & Feedforward Neural Network \\
\hline FIR & Finite Duration Impulse Response \\
\hline FLANN & Functional Link Artificial Neural Networks \\
\hline FNN & False Nearest Neighbor \\
\hline GRNN & Generalized Regression Neural Network \\
\hline IA & Inteligência Artificial \\
\hline LN & Lógica Nebulosa \\
\hline LTI & Linear Time-Invariant \\
\hline MAE & Mean Absolute Error \\
\hline MDL & Minimum Description Length \\
\hline MIMO & Multiple Input Multiple Output \\
\hline MISO & Multiple Input Single Output \\
\hline MLP & Multilayer Perceptron \\
\hline MMQ & Método dos Mínimos Quadrados \\
\hline MPC & Model Predictive Control \\
\hline MSE & Mean Squared Error \\
\hline MV & Variável Manipulada \\
\hline NARMAX & Nonlinear Auto Regressive Moving Average \\
\hline NARX & Nonlinear Auto Regressive model with eXogenous input \\
\hline NNBJ & Nonlinear Box-Jenkins model structure Neural Network \\
\hline NNARMAXN & $\begin{array}{l}\text { Nonlinear AutoRegressive Moving Average model structure with } \\
\text { eXogenous inputs Neural Network }\end{array}$ \\
\hline NNARX & $\begin{array}{l}\text { Nonlinear AutoRegressive model structure eXogenous inputs Neural } \\
\text { Network }\end{array}$ \\
\hline NNFIR & Nonlinear Finite Impulse Response model Neural Network \\
\hline NNOE & Nonlinear Output Error model Neural Network \\
\hline NLS & Nonlinear Systems \\
\hline PCA & Principal Component Analysis \\
\hline PI & Controle Proporcional e Integral \\
\hline PID & Controle Proporcional Integral e Derivativo \\
\hline PLS & Partial Least Squares \\
\hline PNN & Probabilistic Neural Network \\
\hline PV & Variável de Processo \\
\hline
\end{tabular}




$\begin{array}{ll}\text { RBF } & \text { Radial Basis Function } \\ \text { RLS } & \text { Recursive Least Square } \\ \text { RMLP } & \text { Recurrent Multilayer Perceptron } \\ \text { RNA } & \text { Redes Neurais Artificiais } \\ \text { RNN } & \text { Recurrent Neural Networks } \\ \text { S/N } & \text { Relação Sinal-Ruído } \\ \text { SH } & \text { Sistemas Híbridos } \\ \text { SI } & \text { Sistemas Inteligentes } \\ \text { SN } & \text { Sistemas Nebulosos } \\ \text { TDNN } & \text { Distributed Time-Delay Neural Network } \\ \text { UD-RLS } & \text { Unit Upper Triangular Matrix Covariance Factorization - Recursive Least }\end{array}$




\section{Lista de Figuras}

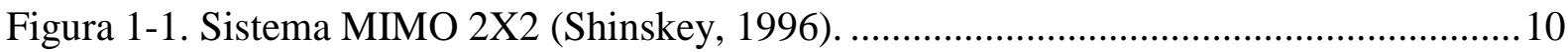

Figura 2-1. Esquema de modelagem caixa-preta de um sistema desconhecido real................20

Figura 3-1. Ilustração do neurônio biológico. (fonte: adaptação de Ferneda, 2006).................38

Figura 3-2. Modelo não linear de um neurônio artificial. (fonte: adaptação de Silva et al.,

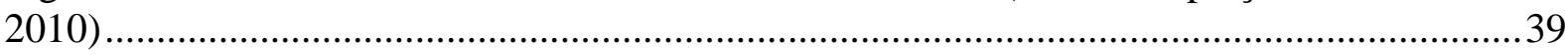

Figura 3-3. Representação gráfica das principais funções de ativação. .................................41

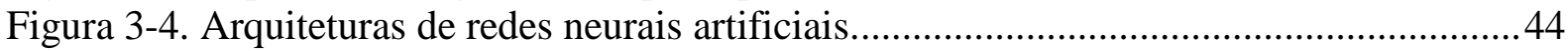

Figura 3-5. Ilustração da estrutura do MLP com duas camadas ocultas. .................................47

Figura 3-6. Rede neural de Elman. (fonte: Segatto et al., 2006) ............................................48

Figura 3-7. Estrutura geral de um Perceptron Multicamadas Recorrente. (fonte: adaptação de

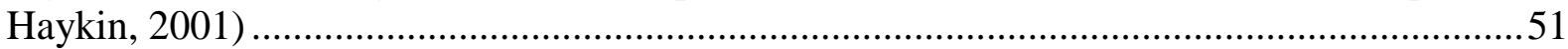

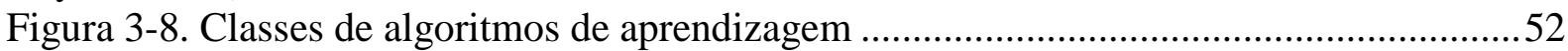

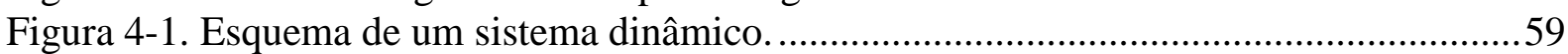

Figura 4-2. Princípio da superposição aplicado em um sistema linear. .................................63

Figura 4-3. Resposta típica de (a) um sistema linear e (b) um sistema não linear para uma

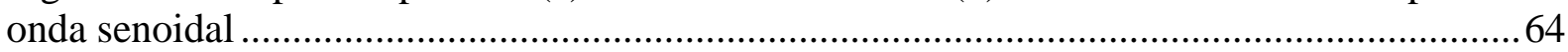

Figura 4-4. Esquema representando a modelagem de Sistemas.............................................66

Figura 4-5. Diagrama de blocos para identificação de sistemas dinâmicos. .............................68

Figura 4-6. Procedimentos básicos usado na identificação de sistemas dinâmicos (adaptação

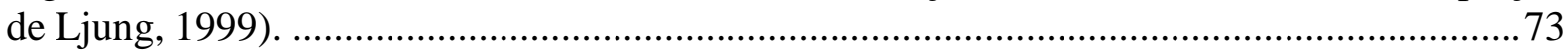

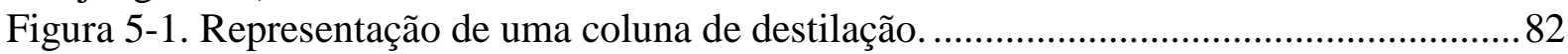

Figura 5-2 - Vista esquemática de uma unidade de destilação alcoólica.................................88

Figura 5-3 - Processo simplificado de destilação de álcool................................................. 91

Figura 6-1 - Diagrama de blocos das etapas envolvidas no projeto do sensor virtual $\left(1^{\mathrm{a}}\right.$ a $5^{\mathrm{a}}$

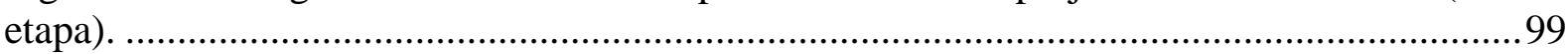

Figura 6-2 - Dados de entrada (a) e saída (b) aquisitados para a determinação do tempo de

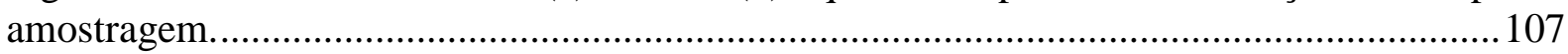

Figura 6-3 - (a) Autocovariância linear. (b) Autocovariância não-linear. ............................. 108

Figura 6-4- Resultado do algoritmo FNN (percentual de falsos vizinhos x ordem). ............112

Figura 6-5 - Funções de correlação cruzada entre a variável candidata F com a saída XD . .115

Figura 6-6 - Funções de correlação cruzada entre a variável candidata DL com a saída XD.

Figura 6-7 - Funções de correlação cruzada entre a variável candidata PM com a saída XD.

Figura 6-8 - Funções de correlação cruzada entre a variável candidata TB com a saída XD.

Figura 6-9 - Funções de correlação cruzada entre a variável candidata PC com a saída XD.

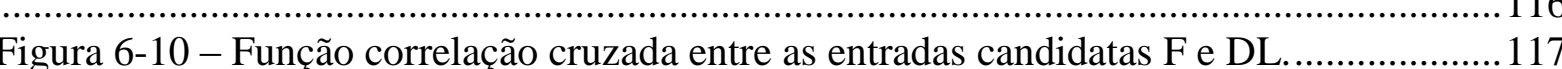

Figura 6-11 - Função correlação cruzada entre as entradas candidatas F e PM. ...................117

Figura 6-12 - Função correlação cruzada entre as entradas candidatas F e TB....................118

Figura 6-13 - Função correlação cruzada entre as entradas candidatas F e PC. ....................118

Figura 6-14 - Função correlação cruzada entre as entradas candidatas DL e PM.................118

Figura 6-15 - Função correlação cruzada entre as entradas candidatas DL e TB..................119

Figura 6-16 - Função correlaçãa cruzada entre as entradas candidatas DL e PC..................119 
Figura 6-17 - Função correlação cruzada entre as entradas candidatas PM e TB................ 119

Figura 6-18 - Função correlação cruzada entre as entradas candidatas PM e PC................ 120

Figura 6-19 - Função correlação cruzada entre as entradas candidatas TB e PC.................. 120

Figura 6-20 - Esquema TDNN para identificação de sistemas. .......................................... 125

Figura 6-21 - Esquema NNARX para Identificação de sistemas: (a) modelo série-paralelo e

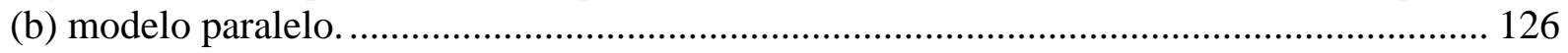

Figura 6-22 - Gráfico da saída (XD em ${ }^{\circ}$ INPM) real e estimada para a rede TDNN de melhor desempenho, sendo a entrada a vazão de retirada do destilado DL em $\mathrm{m}^{3} / \mathrm{h}$. ...................... 133

Figura 6-23 - Histograma do erro MSE para a rede TDNN de melhor desempenho............ 134

Figura 6-24 - Gráfico da performance (treinamento, validação e teste) para a rede TDNN de

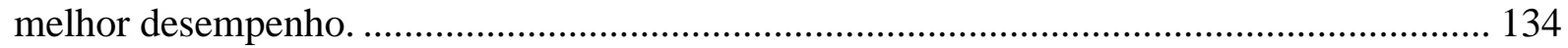
Figura 6-25 - Gráfico da correlação entre entrada DL e o erro para a rede TDNN de melhor

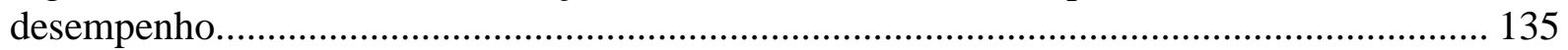

Figura 6-26 - Gráfico da autocorrelação do erro para a rede TDNN de melhor desempenho.

Figura 6-27 - Gráfico da regressão linear entre a saída estimada e a real para a rede TDNN de melhor desempenho. 136 Figura 6-28 - Gráfico da resposta e do erro, obtidos durante o treinamento, para a rede TDNN

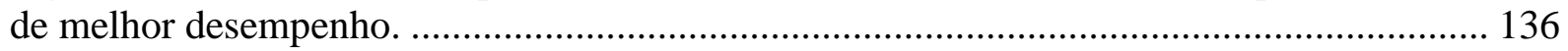
Figura 6-29 - Gráfico da saída (XD em ${ }^{\circ}$ INPM) real e estimada para a rede NNARX (15 neurônios e 6 regressores) de melhor desempenho, sendo a entrada a vazão de retirada do

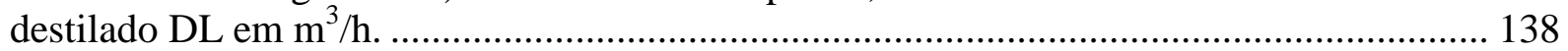
Figura 6-30 - Histograma do erro MSE para a rede NNARX (15 neurônios e 6 regressores) de

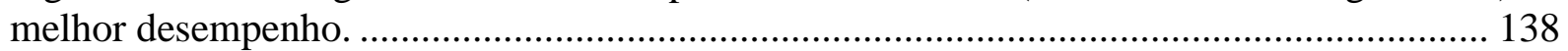
Figura 6-31 - Gráfico da performance (treinamento, validação e teste) para a rede NNARX (15 neurônios e 6 regressores) de melhor desempenho. ...................................................... 139 Figura 6-32 - Gráfico da correlação entre entrada DL e o erro para a rede NNARX (15 neurônios e 6 regressores) de melhor desempenho................................................................ 139 Figura 6-33 - Gráfico da autocorrelação do erro para a rede NNARX (15 neurônios e 6

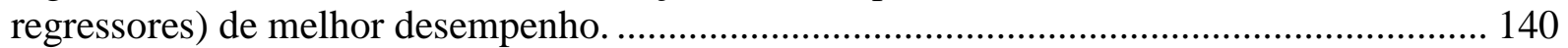
Figura 6-34 - Gráfico da regressão linear entre a saída estimada e a real para a rede NNARX (15 neurônios e 6 regressores) de melhor desempenho. ..................................................... 140 Figura 6-35 - Gráfico da resposta e do erro, obtidos durante o treinamento, para a rede NNARX (15 neurônios e 6 regressores) de melhor desempenho. ......................................... 141 Figura 6-36 - Gráfico da saída (XD em ${ }^{\circ}$ INPM) real e estimada para a rede NNARX (15 neurônios e 12 regressores) com $2^{\circ}$ melhor desempenho, sendo a entrada a vazão de retirada

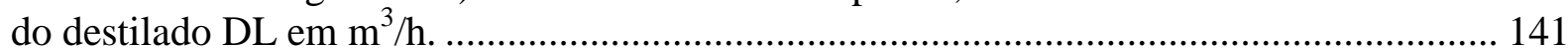

Figura 6-37 - Histograma do erro MSE para a rede NNARX (15 neurônios e 12 regressores)

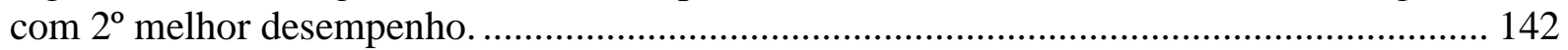
Figura 6-38 - Gráfico da performance (treinamento, validação e teste) para a rede NNARX (15 neurônios e 12 regressores) com $2^{\circ}$ melhor desempenho............................................... 142 Figura 6-39 - Gráfico da correlação entre entrada DL e o erro para a rede NNARX (15 neurônios e 12 regressores) com $2^{\circ}$ melhor desempenho. ................................................. 143 Figura 6-40 - Gráfico da autocorrelação do erro para a rede NNARX (15 neurônios e 12 regressores) com $2^{\circ}$ melhor desempenho..................................................................... 143 Figura 6-41 - Gráfico da regressão linear entre a saída estimada e a real para a rede NNARX (15 neurônios e 12 regressores) com $2^{\circ}$ melhor desempenho.............................................. 144 Figura 6-42 - Gráfico da resposta e do erro, obtidos durante o treinamento, para a rede NNARX (15 neurônios e 12 regressores) com $2^{\circ}$ melhor desempenho................................. 144 
Figura 6-43 - Gráfico da saída (XD em ${ }^{\circ}$ INPM) real e estimada para a rede NNARX (15 neurônios e 6 regressores), sendo a entrada a vazão de alimentação da coluna " $A$ " em m3/h.

Figura 6-44 - Histograma do erro MSE para a rede NNARX (15 neurônios e 6 regressores).

Figura 6-45 - Gráfico da performance (treinamento, validação e teste) para a rede NNARX (15 neurônios e 6 regressores).

Figura 6-46 - Gráfico da correlação entre entrada DL e o erro para a rede NNARX (15 neurônios e 6 regressores).

Figura 6-47 - Gráfico da autocorrelação do erro para a rede NNARX (15 neurônios e 6 regressores).

Figura 6-48 - Gráfico da regressão linear entre a saída estimada e a real para a rede NNARX (15 neurônios e 6 regressores).

Figura 6-49 - Gráfico da resposta e do erro, obtidos durante o treinamento, para a rede NNARX (15 neurônios e 6 regressores).

Figura 6-50 - Gráfico da saída (XD em ${ }^{\circ}$ INPM) real e estimada para a rede NNARX (15 neurônios e 2 regressores), sendo a entrada a temperatura na bandeja B4 da coluna "B"..... 149 Figura 6-51 - Histograma do erro MSE para a rede NNARX (15 neurônios e 2 regressores).

Figura 6-52 - Gráfico da performance (treinamento, validação e teste) para a rede NNARX (15 neurônios e 2 regressores).

Figura 6-53 - Gráfico da correlação entre entrada DL e o erro para a rede NNARX (15 neurônios e 2 regressores).

Figura 6-54 - Gráfico da autocorrelação do erro para a rede NNARX (15 neurônios e 2 regressores).

Figura 6-55 - Gráfico da regressão linear entre a saída estimada e a real para a rede NNARX (15 neurônios e 2 regressores).

Figura 6-56 - Gráfico da resposta e do erro, obtidos durante o treinamento, para a rede NNARX (15 neurônios e 2 regressores).

Figura 6-57 - Gráficos que mostram o desempenho do modelo de espaço de estado para as entradas F e DL e ordem do sistema $=12$.

Figura 6-58 - Gráficos que mostram o desempenho do modelo de espaço de estado para a entrada TB e ordem do sistema $=12$.

Figura 6-59 - Gráficos que mostram o desempenho do modelo de espaço de estado para as entradas $\mathrm{F}$ e $\mathrm{TB}$ e ordem do sistema $=12$.

Figura 6-60 - Gráficos que mostram o desempenho do modelo de espaço de estado para as entradas $\mathrm{F}$ e $\mathrm{TB}$ e ordem do sistema $=11$.

Figura 6-61 - Gráficos que mostram o desempenho do modelo de espaço de estado para as entradas $\mathrm{F}$ e $\mathrm{TB}$ e ordem do sistema $=9$. 



\section{Lista de Tabelas}

Tabela 3-1 - Lista de RNAs e suas aplicabilidades (Fonte: Meireles at al., 2003)................56

Tabela 5-1 - Estruturas de controle empregadas nas colunas de destilação. ............................86

Tabela 6-1 - Lista de variáveis secundárias medidas de forma online do processo. ..............104

Tabela 6-2 - Valores correspondentes do $1^{\circ}$ mínimo, $\tau m$ e a faixa viável de valores para o período de amostragem.

Tabela 6-3 - Aplicação do algoritmo FNN nas entradas e saída para obter a ordem do modelo.

Tabela 6-4 - Tabela com informações básicas sobre as variáveis secundárias e primária do processo.

Tabela 6-5 - Matriz correlação Cruzada.

Tabela 6-6 - Lista de variáveis candidatas selecionadas.

Tabela 6-7 - Informações básicas sobre os dados aquisitados.

Tabela 6-8 - Definição dos atrasos e número de neurônios utilizados no treinamento. .........128

Tabela 6-9 - Os 15 melhores resultados da simulação para a rede TDNN. ...........................131

Tabela 6-10 - Os 15 melhores resultados da simulação para a rede NNARX.......................132

Tabela 6-11 - Modelos de espaços de estados com melhor desempenho. ..............................153

Tabela 6-12 - Matrizes de estado estimadas para as entradas F e DL e ordem do sistema = 12 .

Tabela 6-13 - Matrizes de estado estimadas para a entrada TB e ordem do sistema $=12 . \ldots 155$

Tabela 6-14 - Matrizes de estado estimadas para as entradas F e TB e ordem do sistema = 12 .

156

Tabela 6-15 - Matrizes de estado estimadas para as entradas F e TB e ordem do sistema $=11$.

157

Tabela 6-16 - Matrizes de estado estimadas para as entradas F e TB e ordem do sistema $=9$. 



\section{Capítulo I}

\section{Introdução}

\subsection{Motivação e Relevância do Trabalho}

Um problema-chave no processo químico é controlar, de maneira confiável e barata, a evolução dinâmica do sistema, ou seja, composições de produtos, reagentes, temperaturas, pressões, vazões, etc. Numa coluna de destilação, por exemplo, o objetivo do controle é manter a composição do produto em torno do valor ótimo. Em grande parte das colunas de destilação de etanol, a medição da composição para controlar a qualidade do produto está disponível de forma offline, sendo realizada em laboratório.

Instrumentos de medição da composição são geralmente caros e de difícil manutenção; no entanto, mesmo quando é admissível sua instalação, eles podem introduzir atrasos de transporte indesejáveis na malha de controle. A falta ou o alto custo dos analisadores industriais para medição da composição tem motivado o projeto de sensores virtuais (soft sensors), baseado no modelo dinâmico do processo, para que, a partir das medições disponíveis, seja possível inferir de forma online os valores das variáveis desejadas (Bauer et al., 1998).

As colunas de destilação são conhecidas pelas dificuldades encontradas no projeto dos controladores presentes em suas malhas de controle e pelo alto custo de operação. Quando comparadas a outros processos químicos, essas dificuldades são resultantes das complexidades inerentes ao processo, podendo ser destacadas as não linearidades envolvidas, as fortes interações entre as malhas de controle, as restrições de projeto e a presença de 
elevadas constantes de tempo e atrasos, podendo-se ainda ser influenciada pela formação de transientes na qualidade da mistura a ser destilada, entre outros (Klir \& Folger, 1988).

Do ponto de vista operacional, uma coluna de destilação pode ser considerada como um problema de otimização composto de função objetivo e restrições. O constante estudo das técnicas de otimização e controle das colunas de destilação é muito importante, visto que esse processo de separação é um dos que mais demandam energia dentre os processos químicos.

Por outro lado, é de conhecimento dos engenheiros e projetistas que antes de se projetar e operar qualquer sistema é fundamental a sua compreensão. Para o entendimento dos sistemas, o ser humano utiliza-se de modelos que descrevem o comportamento dos sistemas em estudo. A maioria são modelos mentais, isto é, são aqueles onde as relações entre as entradas e as saídas do sistema são obtidas por meio das experimentações observadas durante a manipulação do sistema (Aguirre, 2007). O problema encontrado nesse tipo de modelagem é que a precisão do modelo mental obtida está diretamente relacionada com a experiência do projetista ou operador. Além do mais, existe uma grande dificuldade na transmissão do conhecimento acumulado ao longo do tempo para dispositivos automáticos.

Uma solução para esse tipo de problema é a utilização de modelos matemáticos durante a etapa de projeto e simulação do sistema. Um modelo matemático pode ser definido como sendo uma representação por meio de equações que descrevem a forma de operação de um sistema qualquer. Uma maneira de se obter esse modelo é por intermédio das leis físicas que regem seu comportamento dinâmico, obtido através dos balanços de massa, energia e quantidade de movimento.

Ao longo do tempo, os modelos matemáticos têm sido utilizados para diversos fins. Dentre eles, pode-se destacar a compreensão dos fenômenos naturais, no projeto de sistemas de controle, na predição de estados, na simulação de sistemas, etc. A busca por um modelo 
pode ser considerada como uma condição básica para que uma estrutura de controle possa ser projetada e colocada em operação (Unberhauem \& Roa, 1998).

Para o projetista de sistemas de controle, o aumento da viabilidade técnica e econômica é a principal motivação para a utilização de modelos matemáticos em vez de sistemas reais durante a fase de projeto. Esses modelos descrevem, segundo algum objetivo, o mundo real e para sua obtenção é necessária a utilização de técnicas de modelagem física e experimental como, por exemplo, estimador de mínimos quadrados, estimadores recursivos, filtros de Kalman, dentre outras.

No entanto, uma das principais limitações na utilização da modelagem matemática no estudo de sistemas dinâmicos está no fato da grande complexidade existente nas equações que determinam o comportamento do modelo em análise, necessitando-se assim de um considerável esforço computacional no processamento dos cálculos envolvidos. Assim, quando a construção destes modelos, a partir de leis físicas, for consideravelmente difícil, custosa ou até mesmo impossível, a identificação de sistemas se faz necessário.

Segundo Aguirre (2007), a identificação de sistemas é a área do conhecimento que estuda a obtenção de modelos matemáticos para sistemas dinâmicos a partir do estudo das relações existentes entre as variáveis de entrada e saída, podendo estas ser lineares ou não lineares e, a partir destes modelos, realizar experimentos que reproduzam o comportamento dos sistemas reais.

A estimação do modelo dinâmico pode ser realizada em tempo real ou em batelada (offline). Uma boa parte dos processos químicos industriais apresenta, normalmente, grandes tempos de respostas e parâmetros que variam lentamente, sendo então possível a identificação offline, mesmo quando o objetivo é a síntese de controladores adaptativos ou preditivos. Nesse caso, a identificação offline dá ao projetista a possibilidade de conhecer e entender a 
dinâmica de um determinado sistema por meio de um conjunto de dados experimentais, visando-se com isto replicar seu comportamento real.

Devido à sua simplicidade e versatilidade, os modelos dinâmicos lineares têm sido muito utilizados na representação de sistemas, porém, essa não é a forma mais adequada de descrever grande parte das plantas industriais devido às não linearidades inerentes aos processos industriais.

Com o advento de problemas cada vez mais complexos, aliado ao crescente interesse pelos pesquisadores na busca de novas soluções baseadas nos sistemas inteligentes, tem-se viabilizado o surgimento de novas alternativas, por meio das técnicas de inteligência computacional, aplicadas na identificação e no controle de sistemas dinâmicos reais, os quais são difíceis de serem modelados matematicamente, principalmente aqueles envolvendo não linearidades.

A busca por novas técnicas de identificação ocorre devido ao fato de que as equações envolvidas no funcionamento de um determinado sistema real normalmente não são obtidas de forma simples. Dessa forma, ficam impraticáveis, por limitações de tempo e de recursos, a obtenção dessas equações e a estimativa de seus respectivos parâmetros.

A aplicação de Sistemas Inteligentes (SI) vem de encontro com a necessidade, cada vez mais crescente, de aumento da eficiência dos processos industriais, da exigência por parte do mercado consumidor por produtos de qualidade, pela redução das perdas ocorridas nas plantas industriais a fim de maximizar seu rendimento, pelas questões ambientais envolvidas no processo de fabricação, além de outros fatores que estão vinculados ao aprimoramento dos métodos de identificação e controle de processos.

Com base na capacidade humana em desenvolver habilidades a partir de exemplos e experiências, a comunidade técnico-científica tem buscado desenvolver procedimentos computacionais onde a máquina aprende como determinar a saída desejada em função de uma 
dada entrada. As técnicas de inteligência computacional são capazes de aliar tanto os conhecimentos objetivos, definidos mediante equações matemáticas, quanto os conhecimentos subjetivos, baseados em informações linguísticas e experimentações, com a finalidade de solucionar problemas reais.

Os SI possibilitam a implementação de soluções onde o computador desempenha funções que são próprias dos seres humanos, envolvendo experimentação, conhecimento e raciocínio. Alguns sistemas são inspirados em modelos biológicos, outros, em sistemas que produzem algum tipo de comportamento próximo ao observado em sistemas naturais (Morales, 1997).

Pesquisadores têm contribuído de forma significativa nessa área do conhecimento e três linhas de pesquisas têm se destacado, isto é, as Redes Neurais Artificiais (RNA), inspiradas no modelo do neurônio biológico; a Lógica Nebulosa (LN), dirigida ao raciocínio humano explorando informações qualitativas, e a Computação Evolutiva (CE), baseada no processo de seleção natural como um paradigma de solução de problemas (Morales, 1997; Fogel \& Michalewicz, 1997).

Os Sistemas Nebulosos (SN) ou sistemas fuzzy têm sido propostos na solução de problemas envolvendo identificação devido à sua capacidade de descrever as relações entre os sinais de entrada e de saída de um determinado sistema com base em informações incertas e imprecisas.

As RNAs também têm sido propostas como uma solução alternativa para os problemas envolvendo a identificação e o controle de sistemas multivariáveis (Multiple Input Multiple Output - MIMO) e não lineares. Por essa razão, assim como pelas vantagens apresentadas pelas RNAs na representação de sistemas não lineares, muitos pesquisadores têm sido levados a realizar estudos sobre sua aplicação em identificação de sistemas dinâmicos não lineares. 
Um dos principais pontos que deve ser abordado no projeto da rede neural é o modelo da arquitetura a ser utilizada. Diversos modelos de redes neurais podem ser aplicados na identificação e no controle de sistemas dinâmicos (Jin-Tsong et al., 1999; Sanchez, et al., 1999; Barto, 1989). Alguns exemplos de modelos de redes convencionais são as Multilayer Perceptron (MLP), as redes Radial Basis Function (RBF) e as redes de Hopfield (Dimopoulos et al., 1999). Além destes, alguns modelos propostos recentemente, como as redes CPBUM (Chebyshev Polynomials Based Unified Model), também foram utilizadas no problema de identificação e de controle (Lo et al., 2001; Baruch, et al., 2001).

Uma aplicação prática que tem recebido grande atenção por parte dos pesquisadores, acerca da utilização de inteligência computacional na identificação de sistemas dinâmicos, é o projeto de instrumentos virtuais. Sensores virtuais têm sido desenvolvidos com o objetivo de complementar as medições online e são empregados no controle e na supervisão de processos industriais.

Outro ponto a ser observado é o fato de que durante a fase de projeto de um sistema de controle, muitas vezes, o projetista não se preocupa com o local de instalação dos instrumentos onde as saídas do sistema serão geradas. Utilizando sensores virtuais, as saídas do sistema podem ser geradas através da simulação do modelo inferido a partir de sensores reais que, em grandes projetos, pode corresponder a custos elevados. O uso de simulações, durante a etapa de projeto dos sistemas de controle, possibilita a realização de repetidos testes sob condições similares àquelas encontradas na prática. Além disso, permitem a investigação de diversos cenários impossíveis de serem conseguidos num ambiente real devido à falta de componentes não determinísticos, por vezes, tão necessários no teste da robustez das ações propostas.

As pesquisas iniciais sobre sensores virtuais basearam-se na disponibilidade do modelo do processo em estudo. Joseph et al. (1978) desenvolveram um modelo inferencial 
usando filtro de Kalman. Entretanto, existem situações onde não é possível determinar analiticamente o modelo do processo e, nesses casos, modelos baseados em redes neurais (Qin \& Mcavoy, 1992; Radhakrishnan \& Mohamed, 2000) e métodos estatísticos podem ser usados com objetivo de obter um modelo de regressão não linear (Kresta et al., 1994; Park \& Han, 2000; Zhao, 2003). Um sensor virtual baseado em modelo pode ser criado se os princípios fundamentais da física puderem descrever o processo com certo grau de precisão. No entanto, as modernas técnicas de medição existentes, que possibilitam a coleta e o armazenamento de uma grande quantidade de dados operacionais, fazem com que o desenvolvimento de sensores virtuais seja hoje uma alternativa viável.

No projeto de um sensor virtual, para atender os requisitos de desempenho de uma coluna de destilação, é necessária a compreensão de seu comportamento, sendo que isso pode ser obtido mediante experimentações práticas realizadas diretamente na coluna de destilação ou por meio de um modelo matemático preciso do processo.

Nas técnicas que usam medições experimentais grande parte dos problemas pode ser atribuída ao estado dos dados utilizados no projeto de sensores virtuais. Muitas vezes, estes dados apresentam uma qualidade variável, o que torna difícil a aplicação de métodos convencionais de estimação. Os problemas mais comuns que podem ser observados nos dados, coletados experimentalmente na indústria de processo, são os seguintes (Zanata, 2005):

- inconsistência dos dados;

- falta de informações no conjunto de dados;

- ruídos de medição;

- colinearidade entre os dados do conjuntos de amostras;

- flutuação nos dados amostrados.

Apesar dos vários estudos apresentados na literatura a respeito das aplicações práticas envolvendo sensores virtuais utilizados na automação de processos, ainda existem algumas 
questões a serem resolvidas acerca do projeto e manutenção de instrumentos virtuais. Na grande maioria dos casos são essas as questões que impedem um maior número de aplicações práticas que façam uso de sensores virtuais no controle e na otimização de plantas industriais.

Hoje, em consequência dos avanços tecnológicos, principalmente da tecnologia da informação, é possível por meio de simulação dinâmica usando modelos de inferência, analisar vários fatores de um processo industrial, como:

- seleção de sensores e atuadores;

- interfaceamento com a estrutura de controle;

- otimização do controle;

- $\quad$ segurança operacional;

- instalação de algoritmos de controle avançado;

- otimização de paradas e partidas;

- treinamento de operadores e,

- otimização em linha.

\subsection{Proposta e Justificativa da Dissertação}

Na indústria, muitos processos químicos são intrinsecamente não lineares. Em muitos casos, o comportamento não linear do processo acontece devido à complexidade das relações termodinâmicas ou da cinética de reação existente nesses sistemas.

Identificação e controle de sistemas dinâmicos são áreas da engenharia vastamente exploradas por técnicas convencionais. As técnicas clássicas são baseadas principalmente na teoria de sistemas lineares. Nesse tipo de abordagem, a álgebra linear e as equações diferenciais lineares ordinárias são as principais ferramentas utilizadas na solução de problemas (Aguirre, 2007). 
A partir da década de 80, observou-se aqui um aumento no interesse pela identificação de modelos não lineares. Os estudos iniciam-se pela busca de formas de representar o comportamento dinâmico dos sistemas não lineares por meio de equações matemáticas, assim como o desenvolvimento de algoritmos para a estimação dos parâmetros desses modelos e de técnicas para validá-los (Ljung et al., 1987).

No entanto, as dificuldades encontradas na obtenção de modelos para as plantas industriais estão intimamente relacionadas ao fato do comportamento apresentado por tais sistemas não ser bem compreendido, sendo de difícil modelagem, principalmente aqueles detentores de não linearidades e possuidores de comportamento dinâmico complexo, como é o caso das colunas de destilação.

No processo de destilação, o comportamento de dinâmica não linear ocorre devido à não linearidade da curva de equilíbrio líquido-vapor, à complexidade das configurações do processo e à extração de produto de alta pureza (Luyben, 1987).

As colunas de destilação são consideradas uma das mais importantes operações unitárias em Engenharia Química, sendo um dos processos mais estudados em termos de controle. Esta é usada para separar os componentes de uma mistura por meio da aplicação e remoção de calor, ocorrendo dessa forma um grande consumo energético em ambas as operações de aquecimento e resfriamento. Elas contribuem também em mais de 50 por cento dos custos operacionais das unidades de destilação (Skogestad, 1992; Tham, 1991).

Tais equipamentos caracterizam-se por manipular altas vazões, além de apresentar elevados gradientes de temperatura e atraso de transporte na etapa de aquecimento. Tudo isso, aliado às fortes interações com alto grau de acoplamento entre as variáveis manipuladas e controladas, torna então o controle e a otimização desses aparelhos um grande problema a ser resolvido (Moura, 2003). 
A crescente demanda por processos químicos com alto nível de integração, com rígidas especificações de qualidade do produto final e com rigorosas regulamentações ambientais, exigem que os sistemas de controle das torres de destilação possuam alto grau de controlabilidade e desempenho. Frequentemente encontrada como elemento central de uma planta petroquímica, a torre de destilação está presente em cerca de 90 por cento dos processos de separação na indústria de refino de produtos químicos (Riggs et al., 2006).

Conforme observado em vários estudos (Rademaker et al., 1975; Shinskey, 1984; Buckley et al., 1985; Skogestad, 1992), a maioria das colunas de destilação tem sido tratadas como um sistema $5 \times 5$ conforme abordado na Seção 5.2.2. Para atender a estas especificações, diversos pares de variáveis de processo (PV) e manipulada (MV) são possíveis.

A escolha dos pares (PV-MV) deve ser realizada com base em quais variáveis podem ser medidas e controladas com máxima precisão. Outro fator decisivo consiste na interação entre as malhas de controle. Em muitos casos, assume-se que a pressão e os níveis (balanço de massa) podem ser controlados desconsiderando as interações existentes, pois essas são mais fracas do que as que ocorrem no controle da qualidade dos produtos da coluna. Assim, o sistema que era $5 \times 5$ passa a ser considerado apenas $2 \times 2$, conforme pode ser visto no diagrama da Figura 1-1. (Shinskey, 1996).

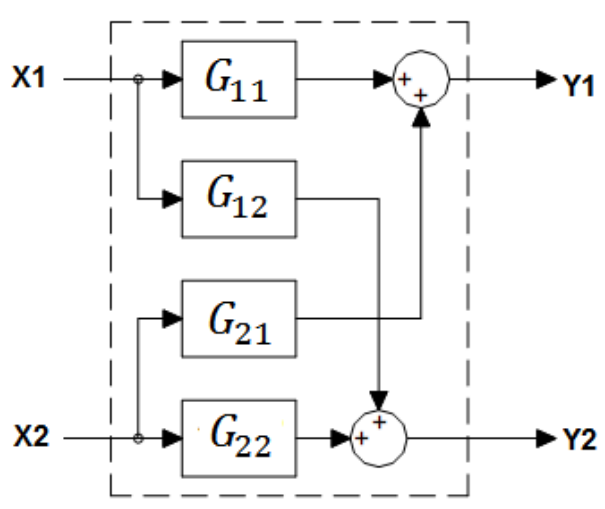

Figura 1-1. Sistema MIMO 2X2 (Shinskey, 1996).

A automação atualmente utilizada em destilarias de álcool considera dois os pontos principais do controle operacional, ou seja, a pressão na base das colunas e a temperatura no 
topo das colunas. A automação envolve também o controle escravo de alimentação do vinho, controle da composição do álcool hidratado e desidratante, controle do nível na retirada da vinhaça, a retirada da flegmaça e do álcool anidro.

Nesses equipamentos, a eliminação das variabilidades do processo contribui de forma significativa com uma redução no custo total dos produtos fabricados. De forma mais objetiva, a redução de variabilidade significa manter a planta operando de maneira ótima, ou seja, permitir que o produto final seja fabricado exatamente dentro da faixa de especificação, sem necessidade de reprocessamentos e gastos adicionais de energia e matéria prima (Campos \& Teixeira, 2006).

Uma das formas de solucionar esse problema é a otimização das malhas de controle pré-existentes, visto que, qualquer planta industrial altera suas características dinâmicas com o passar do tempo, podendo ser citadas ainda as mudanças no ponto de operação em função da demanda do mercado consumidor. Isso afeta diretamente a variabilidade das malhas de controle e, portanto, implica em ajustes constantes nos parâmetros de sintonia dos controladores.

Para a definição e o projeto de um sistema de controle adequado é necessário o conhecimento da dinâmica do processo. Os sistemas que envolvem técnicas de controle avançados, tais como preditivo e adaptativo, utilizam o modelo dinâmico do processo a ser controlado em sua estrutura. O modelo matemático obtido da identificação pode ser utilizado também na simulação ou no controle. O primeiro passo consiste na definição de quais variáveis do processo devem ser mantidas num ponto de operação constante e quais podem ser ajustadas dentro de uma faixa.

A identificação de plantas ou sistemas desconhecidos é um tópico intensamente estudado na teoria de controle clássico. Diversos métodos e algoritmos para a identificação têm sido investigados e muitos procedimentos têm sido também propostos e utilizados na 
modelagem de sistemas lineares monovariáveis, embora sua aplicabilidade em sistemas não lineares multivariáveis seja muito limitada.

Diante das dificuldades encontradas na modelagem e no controle dos sistemas dinâmicos multivariáveis e não lineares, as RNA e os SN, devido à capacidade de modelar processos complexos, passaram a ser tratados como possíveis soluções para esse tipo de problema.

Buscando contribuir para superar as dificuldades acima citadas, diversos estudos sobre a utilização de SN e RNA, como alternativas para solução de problemas envolvendo identificação e controle de processos industriais, têm sido apresentadas, principalmente aqueles que envolvem não linearidades (Morales, 1997; Sanchez et al., 1999).

Quando comparadas às técnicas clássicas desenvolvidas na solução de problemas de identificação, o emprego de sistemas inteligentes pode ser considerado como uma abordagem muito mais flexível, inclusive por não requerer informação prévia do modelo. No entanto, quando da utilização isolada de sistemas inteligentes na identificação de sistemas, o projetista deve especificar as topologias e implementar as etapas necessárias para descrever o mapeamento das relações entre entradas e saídas.

Identificação nebulosa é um exemplo típico de técnica que faz uso do conhecimento humano e do processo dedutivo. Takagi \& Sugeno (1985) foram os primeiros pesquisadores a explorar sistematicamente a lógica nebulosa na modelagem de sistemas dinâmicos. Como resultado desses estudos, inúmeras aplicações práticas têm sido então sugeridas em controle convencional, preditivo e inferencial.

Todavia, a implementação das etapas de fuzzificação, regras de inferência e defuzzificação dependem do conhecimento de um especialista, que pode não estar disponível, tornando-se assim seu ajuste mais difícil. Dessa forma, a utilização de sistemas nebulosos na identificação de processos dinâmicos multivariáveis não lineares pode apresentar algumas 
dificuldades à medida que cresce seu nível de complexidade. Dentre elas pode-se citar a inexistência de metodologias padronizadas para transformar o conhecimento humano, ou sua experiência adquirida, em uma base de regra de um sistema de inferência nebulosa. Além do mais, necessita-se de métodos eficazes a fim de ajustar as funções de pertinência do SI com o objetivo de minimizar o erro de estimação ou maximizar o desempenho do modelo. Para essas aplicações, o uso de redes neurais tem se mostrado muito promissor.

As RNAs possuem diversas propriedades que as fazem particularmente atrativas nas aplicações envolvendo sistemas multivariáveis não lineares. Essas estruturas dinâmicas não lineares têm sido exploradas na estimação de sistemas dinâmicos pela sua habilidade universal de aproximar funções, pela sua estrutura paralela e pela disponibilidade de métodos de aprendizagem online e offline para determinação dos pesos.

Por outro lado, devido ao fato de haver um elevado consumo energético concentrado numa única operação unitária, diversos pesquisadores tem empregado seus esforços na busca de alternativas para minimização dos custos envolvidos no processo de destilação por meio da otimização desses processos industriais.

Entretanto, um problema antigo apresentado pelas empresas do setor sucroalcooleiro é a obtenção, de forma rápida e precisa, das medidas da composição dos produtos de topo e de fundo em uma coluna de destilação de etanol. Dada a complexidade e o alto custo de instalação e manutenção, além da baixa confiabilidade e elevado tempo de resposta das análises em laboratório utilizadas na determinação da qualidade do produto, a grande maioria das unidades produtoras de etanol utilizam a análise laboratorial para realizar essa tarefa.

Portanto, mesmo nos processos onde houver a disponibilidade de analisadores industriais instalados para a medição das composições, o emprego de instrumentação virtual pode colaborar de forma significativa pela melhoria na operação das colunas de destilação. 
As estruturas de modelagem baseadas em redes neurais, apropriadas para identificação de sistemas não lineares, são generalizações das estruturas de modelagem linear. Elas são caracterizadas pelo seu vetor de regressão, ou seja, pelo vetor que contém os valores passados das variáveis usadas para se estimar a saída do sistema.

Dependendo da escolha do vetor de regressão, diferentes estruturas de modelo neural emergem. Se o vetor de regressão for selecionado de forma similar àquela utilizada pelo modelo ARX (Auto Regressive model with eXogenous input), a estrutura de modelagem é chamada NNARX (Nonlinear AutoRegressive model structure eXogenous inputs Neural Network).

Uma rede TDNN (Distributed Time-Delay Neural Network) é um arranjo em avanço de neurônios com memória e neurônios não lineares. A memória de curto prazo existente na rede TDNN está localizada somente na camada de entrada. Uma característica interessante dessas redes é sua capacidade de capturar a informação presente no sinal de entrada.

No decorrer deste trabalho serão apresentadas as estruturas NNARX e TDNN, redes temporais e dinâmicas respectivamente, como base para a realização da inferência do sistema aqui proposto. Essas estruturas possuem em suas entradas valores passados das variáveis secundárias (TDNN e NNARX) e primárias (NNARX) do processo.

Com base nesse contexto, este trabalho tem como propósito avaliar a eficiência de um estimador dinâmico destinado à aproximação de funções, com a finalidade de inferir a saída de sistemas multivariáveis não lineares reais, baseado em redes neurais, passível de ser usado como sensor virtual e podendo ser aplicado na operação, manutenção, otimização e controle de processos industriais. Nessa dissertação, um estimador é proposto para inferir a composição de etanol destilado, tendo-se como base variáveis como temperatura e pressão no interior da coluna, vazão de refluxo, vazão de vapor no refervedor, vazão de alimentação, etc. 


\subsection{Organização da Dissertação}

Esta dissertação está dividida em 7 capítulos. A organização dos capítulos é feita como segue:

No Capítulo 2, uma revisão bibliográfica sobre os principais temas abordados nessa dissertação é apresentada.

No Capítulo 3, a fundamentação sobre as RNA e sua aplicação em identificação de sistemas dinâmicos não lineares é descrita.

No Capítulo 4, os conceitos sobre identificação de sistemas dinâmicos multivariáveis não lineares são introduzidos.

No Capítulo 5, os conceitos básicos sobre colunas de destilação e aplicação de sensores virtuais na supervisão e controle desses equipamentos são apresentados.

No Capítulo 6 é apresentada a avaliação de desempenho do sensor virtual neural estudado frente à representação no espaço de estados.

Finalmente, no Capítulo 7, as conclusões sobre a utilização do sistema neural proposto são apresentadas e também as sugestões para trabalhos futuros. 



\section{Capítulo II}

\section{Fundamentação Teórica}

\subsection{Revisão Bibliográfica}

Atualmente, as plantas industriais têm sido operadas em condições limites devido à alta competitividade do mercado mundial, tornando-se cada vez mais difícil a manutenção dos processos industriais em seus pontos de máxima lucratividade. Com a crescente preocupação em melhorar a qualidade do produto, aliado ao aumento no número de leis ambientais mais rígidas, e ainda devido à necessidade de operar os processos em condições cada vez mais seguras, os engenheiros estão sendo levados a buscar soluções rápidas e de baixo custo, com a finalidade de tornar os processos cada vez mais eficientes. As tomadas de decisão durante a operação do processo e a detecção de possíveis modificações ocorridas no sistema requerem conhecimento sobre o estado real da unidade fabril.

Segundo Luyben (1987), o processo de destilação é uma das mais importantes operações unitárias presentes nas indústrias química e petroquímica. Responsável pela separação de compostos químicos, esta é amplamente utilizada na indústria sucroalcooleira na produção do etanol. A precisão e a rapidez no controle da composição dos produtos, em uma torre de destilação, são problemas antigos. As colunas de destilação exigem sistemas de controle apropriados para se obter a especificação desejada do produto e uma operação estável no processo. Em virtude dos volumes processados e dos custos operacionais envolvidos, há a necessidade que os sistemas de controle estejam sempre bem ajustados para que as perturbações sejam compensadas rapidamente. $\mathrm{O}$ controle confiável e preciso da composição, ou de alguma propriedade dos produtos, é uma das principais dificuldades em se 
tratando de torres de destilação. Dessa forma, a habilidade em obter modelos consistentes, a partir de dados reais do processo, pode trazer muitos benefícios para o gerenciamento dessas unidades com alto nível de complexidade.

Um grande problema na identificação de sistemas não lineares tem sido encontrar um conjunto de modelos com boa capacidade de representação, onde efetivamente não seja necessário o conhecimento da arquitetura do sistema a ser modelado. Embora existam vários algoritmos de modelagem aplicados a sistemas lineares, muitos outros têm sido propostos para identificação de sistemas não lineares onde sua estrutura é conhecida, como por exemplo, o filtro de Kalman estendido; contudo, pode ser ainda verificada a falta de uma metodologia genérica e eficiente para ser aplicada na identificação de sistemas não lineares. Uma forma de melhorar a robustez do modelo encontrado é fazer uso de técnicas que combinem as informações auxiliares com base no conhecimento operacional e no conjunto de dados do processo obtidos durante a etapa de identificação. Por exemplo, pode ser usado o conhecimento do processo para decompor toda região de operação em várias regiões operacionais locais. Dentro de cada região local, um modelo linear com ordem reduzida pode ser usado para aproximar o comportamento em torno desse ponto operacional do processo.

Pesquisadores têm proposto diversas metodologias para identificação, cada uma com suas vantagens e limitações, as quais estão sendo usadas pela comunidade científica ou até mesmo aplicadas na identificação e no controle de diversos processos industriais (Ljung, 1999). Muitas vezes, a aplicação dessas técnicas fica limitada pelas não linearidades presentes no sistema em questão, pelas características dos insumos utilizados no processo de produção, pela flexibilidade exigida no ciclo produtivo, pelas exigências de qualidade do produto ou pelo ambiente no qual ele está inserido. Para esses casos, as técnicas convencionais usadas no estudo de sistemas lineares podem não satisfazer completamente aos requisitos do sistema em questão. 
Uma possível solução seria a utilização de técnicas específicas para o projeto de sistemas não lineares. Entretanto, os métodos existentes são muito específicos e, em alguns casos, intrínsecos ao processo analisado. Diante das dificuldades encontradas na modelagem de sistemas complexos, a busca por novas soluções tem crescido de forma significativa, sendo grande o potencial para o estudo de novas técnicas aplicadas na identificação de sistemas não lineares.

Dentre as técnicas de SI utilizadas na automação de processos industriais, pode-se destacar os SN, as RNA, os Sistemas Híbridos (SH) e os Algoritmos Genéticos (AG). Essas técnicas computacionais buscam criar modelos de sistemas com algum tipo de inteligência semelhante à apresentada por determinados sistemas biológicos. Os SI não são inspirados $a$ priori em nenhum sistema natural, mas sim no comportamento observado em sistemas naturais (Iyoda, 2000).

Diversas aplicações usando SN, RNA e SH visando à solução de problemas nas mais diversas áreas são apresentadas na literatura (Nguyen \& Widrow, 1990; Nerrand et al., 1993; Lin \& Cunningham III, 1995; Brouwer, 2000). As técnicas de identificação baseadas em inteligência computacional vêm sendo desenvolvidas por meio de modelos que fazem uso da linguagem natural, regras, redes semânticas ou modelos qualitativos. Quando comparado às técnicas convencionais desenvolvidas para o tratamento de problemas de identificação não linear, o emprego de SI pode ser considerado como uma abordagem mais flexível, inclusive por não requerer informação prévia do modelo. Utilizando-se dessas técnicas na modelagem de sistemas, o trabalho do projetista está então em encontrar a arquitetura necessária para descrever o mapeamento da entrada-saída (Lima, 2000).

Para identificação de sistemas não lineares, o modelo nebuloso Takagi-Sugeno tem recebido muita atenção, visto que ele é um aproximador universal e apresenta uma boa característica de interpolação e generalização. Contudo, existem alguns aspectos básicos 
pertinentes à aplicação dessa técnica que necessitam de uma melhor compreensão. Dentre eles, pode-se citar a inexistência de nenhuma metodologia padronizada para transformar o conhecimento humano, ou sua experiência adquirida, em base de regra de um $\mathrm{SN}$, além da necessidade por métodos eficazes para ajustar as funções de pertinência do SN com o objetivo de minimizar o erro de estimação ou maximizar o desempenho do modelo.

Os conjuntos nebulosos fornecem meios apropriados para a definição dessas regiões operacionais, tendo-se em vista que a definição de regiões operacionais locais na natureza é um processo relativamente complexo, e normalmente existe algum tipo de sobreposição entre as diferentes regiões. Esta é uma grande vantagem de se utilizar a LN na identificação de sistemas.

Por outro lado, devido à sua notável capacidade de aprendizagem, as redes neurais estão sendo aplicadas em muitas áreas da engenharia e da ciência. As redes neurais têm também encontrado grande aplicação na identificação de sistemas dinâmicos não lineares, sendo que sua utilização tem como resultado um modelo caixa-preta que pode ser visualizado no diagrama da Figura 2-1 seguinte.

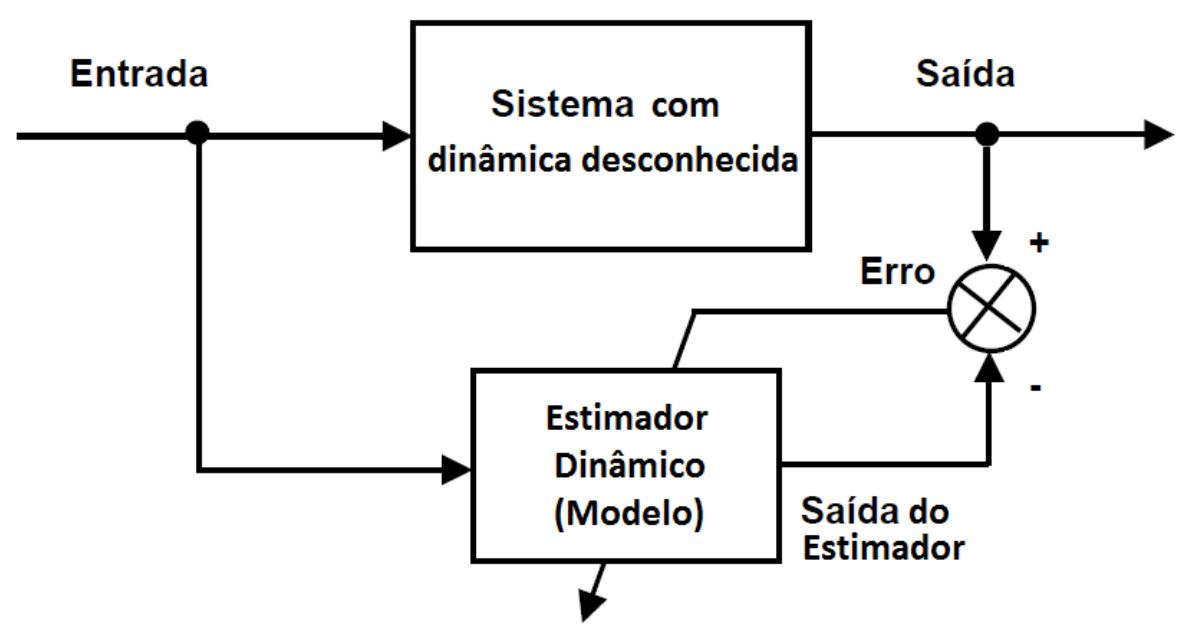

Figura 2-1. Esquema de modelagem caixa-preta de um sistema desconhecido real.

As RNAs podem ser divididas basicamente em três classes, de acordo com suas conexões em estrutura e da existência de realimentação, isto é, recorrentes, por exemplo, as redes neurais de Hopfield (Hopfield et al., 1986); localmente recorrentes, por exemplo, as 
redes Cellular Neural Networks (Chua et al., 1988) e as não recorrentes, por exemplo, Perceptrons (Widrow et al., 1990). Um tipo especial de RNA não recorrente é a Feedforward Neural Network (FFN). Além da grande capacidade de aprendizagem, as redes neurais têm sido também aplicadas na identificação de sistemas dinâmicos não lineares devida à sua capacidade em realizar complexos mapeamentos não lineares e por possuírem a habilidade de fazer a aproximação desses mapeamentos (Narendra et al., 1990; Chen et al., 1992a; 1999; Iyoda, 2000).

Várias pesquisas têm mostrado que as redes neurais são ótimos aproximadores universais de função e que sua aplicação na modelagem de sistemas tem sido sugerida por vários pesquisadores. Diversos trabalhos foram publicados a respeito de identificação de sistemas não lineares usando redes MLP (Bhat \& McAvoy, 1990; Yang \& Tseng, 1996) e redes RBF (Chen et al., 1992b). Bhat \& McAvoy (1990) estão entre os pioneiros a utilizar as redes neurais na identificação de processos químicos não lineares.

Passado cerca de 50 anos da apresentação do perceptron por Rosenblatt (1962) e do algoritmo LMS por Widrow \& Hoff (1960), que resultou no trabalho publicado por Werbos (1974), onde pela primeira vez foi apresentado o algoritmo de treinamento backpropagation, diversos outros algoritmos de aprendizagem foram então estudados e comparados entre si.

À medida que novos estudos foram sendo realizados, observou-se que redes neurais com arquitetura mais complexa tendem a ser mais promissoras na aprendizagem dos mapeamentos funcionais, no entanto, são mais difíceis de serem treinadas. Nas últimas décadas, verificou-se o desenvolvimento e aplicação de várias técnicas de controle baseado no uso de modelos dinâmicos, como parte integrante do sistema de controle.

Com o aumento da complexidade dos processos produtivos, passou-se então a ser grande o interesse pela otimização das estratégias utilizadas nas malhas de controle de muitos processos industriais. O conhecimento do comportamento dinâmico de tais processos é 
fundamental quando se deseja obter melhores resultados econômicos e de competitividade, que via de regra, requer uma melhora no projeto dos controladores industriais (McAvoy et al., 1989).

\subsubsection{Aplicação de Rede Neural Artificial como Estimador Dinâmico não Linear}

Muitas aplicações têm mostrado que a identificação de sistemas não lineares por meio de redes neurais tem se tornado uma importante ferramenta na área de modelagem de sistemas dinâmicos. Hornik et al. (1989) mostram em seu trabalho que uma rede MLP, formada por estrutura composta por uma camada de entrada, uma camada oculta contendo um número suficiente de neurônios com funções de ativação não linear e uma camada de saída formada por neurônio com funções de ativação linear, tem a capacidade de atuar como um aproximador universal. Narendra et al. (1990) e Chen et al. (1992a; 1992b) propuseram a utilização de RNAs convencionais feedforward e recorrentes na identificação e no controle de sistemas não lineares. No entanto, o método proposto apresentou algumas limitações devido ao baixo desempenho do algoritmo de aprendizagem, além de não oferecer uma metodologia sistematizada na obtenção da topologia desejada. Para o caso de identificação e controle de sistemas com severas não linearidades, a metodologia apresentada proporcionou resultados pouco satisfatórios.

Todavia, no estudo e aplicação da teoria de controle avançado em processos químicos industriais, existe ainda uma grande distância devido à complexidade e diversidade dos processos atuais, cada qual com suas próprias características. Poucos estudos teóricos e investigações práticas têm sido realizados a respeito da estabilidade e da robustez dos sistemas de controle em malha fechada. Sadegh (1993) propôs a estrutura de um controlador neural, baseado numa estrutura chamada Rede Perceptron Base Funcional (FBPN), que também pode ser aplicada na modelagem de sistemas não lineares. O autor descreve inicialmente a estrutura básica da rede FBPN e sua lei de formação, sendo que, em seguida, 
propõe uma nova estratégia de controle. A estrutura apresentada é uma rede Probabilistic Neural Network (PNN) empregada na identificação do modelo dinâmico reverso do processo, ao passo que o modelo encontrado foi usado no projeto da estratégia de controle proposta. $\mathrm{O}$ controlador desenvolvido pode ser aplicado tanto em processos discretos como em contínuos. A estabilidade e a robustez do controlador neural, operando em condições ideais, são rigorosamente analisadas pelo pesquisador.

Outro estudo interessante foi aquele desenvolvido por Isik \& Cakmakci (1993). Em seu trabalho, os autores discutem os aspectos práticos envolvidos na utilização de redes neurais feedforward na identificação de sistemas MIMO não lineares. Os autores observaram que, em processos onde os sinais medidos são ruidosos, é então difícil quantificar a precisão do modelo. Esforços para minimizar o erro quadrático médio podem comprometer a estabilidade do modelo e levar a rede neural a seguir o ruído. Nesse trabalho é mostrado que a rede MLP constitui-se de uma promissora ferramenta para identificação de sistemas MIMO não lineares, com baixa relação sinal-ruído $(\mathrm{S} / \mathrm{N})$, quando se tem um número mínimo de entradas, saídas e variáveis internas. Ao final, é sugerido um estudo mais aprofundado na obtenção de modelos em tempo real, tais como monitoramento e controle de sistemas, validação de dados provenientes de sensoriamento e no projeto de múltiplos sensores.

Straub \& Schroder (1996) realizam um estudo comparativo entre diferentes redes neurais utilizadas na identificação e no controle de sistemas. Nesse trabalho, são comparadas as redes neurais de regressão geral (GRNN), perceptrons de múltiplas camadas, redes de Hopfield, dentre outros, além de importantes algoritmos de aprendizado. Também é realizado um estudo sobre observadores de estado usados na inferência de variáveis de processo em malhas de controle, bem como sua aplicação na estimação de variáveis não mensuráveis, extração de características não lineares e no projeto de controladores baseados em conhecimentos anteriores. 
Já Xiaoou Li \& Wen Yuo (2002) descrevem a aplicação de redes MLP recorrentes (RMLP) na identificação de sistemas não lineares. Partindo-se da capacidade das redes MLP em aproximar funções, os autores concluíram que um RMLP recorrente pode aproximar qualquer sistema dinâmico com determinado grau de precisão. Por meio dos funcionais de Lyapunov-Krasovskii, empregados na análise de estabilidade de sistemas com atraso, foi então possível criar um algoritmo de aprendizagem estável usado no treinamento da rede recorrente proposta.

Narendra \& Parthasarathy (2003) apresentam uma nova abordagem, baseada numa estrutura MLP treinada pelo algoritmo backpropagation, para ser usada na identificação de sistemas dinâmicos não lineares. Outro relato interessante foi aquele apresentado por Zhu (2003), em que se propõe modificações no algoritmo backpropagation usado no treinamento de redes MLP. A nova estrutura proposta estima os parâmetros de uma classe de modelos racionais dinâmicos não lineares durante o processo de identificação.

A identificação de sistemas não lineares baseados em modelos de espaço de estado também tem desempenhado um papel importante em muitas aplicações, como rastreamento, sistemas de identificação, análise de séries temporais e robótica. Gorji \& Menhaj (2008) usaram a rede MLP para modelar um sistema não linear de espaço de estado. A rede MLP foi escolhida para descrever a estrutura global e a saída de um modelo de transição de estado não linear discreto no tempo. Os autores utilizaram o algoritmo Expectation Maximization (EM) para estimar estados internos do sistema e os parâmetros da rede. Para provar a superioridade do método proposto, a rede sugerida foi então utilizada na estimativa de séries temporais e os resultados da simulação confirmaram sua aplicabilidade na identificação de modelos de espaço de estado não lineares.

Jang \& Sun (1993) apresentaram uma nova metodologia para definição da estrutura e das regras de aprendizagem para redes neurais de função de base radial e para os SN. Os 
autores demostram que, embora sejam técnicas baseadas em diferentes princípios, as redes $\mathrm{RBF}$, na fisiologia do cérebro humano, e os $\mathrm{SN}$, na ciência cognitiva, elas possuem características comuns, tanto na forma com que realizam as manipulações de dados como no processo de aprendizagem utilizado para obter os mapeamentos desejados. Essa proximidade funcional possibilita que todo conhecimento adquirido num modelo seja aplicado de forma direta no outro, e vice-versa. Observou-se também que ambos os modelos são de fato bons aproximadores universais quando os neurônios da camada escondida da rede e as funções de pertinência do SN forem funções Gaussianas. O uso de redes RBF em aplicações industriais de controle baseada em modelo já foi amplamente estudado, em decorrência de suas habilidades na manipulação e incorporação de restrições envolvendo variáveis de entrada e saída.

Zhang et al (1996) propõem um algoritmo híbrido para treinamento de redes RBF usadas na identificação de sistemas não lineares. Um novo algoritmo de agrupamento $K$ Means é usado para selecionar os centros das funções de base radial e um algoritmo de fatoração U-D, baseado no algoritmo Recursive Least Squares (UD-RLS), é aplicado no ajuste dos pesos da RBFN. O novo algoritmo apresentou um desempenho superior com relação à convergência, estabilidade e precisão do sistema quando comparado com o algoritmo Recursive Least Square (RLS) convencional, sendo que essa nova estrutura foi utilizada na identificação de sistemas não lineares. Um novo algoritmo de treinamento também foi proposto e empregado no treinamento de uma rede MLP. Os autores também realizaram um estudo comparativo, através de simulações, entre o desempenho da rede RBF hibrida e a rede MLP. Os resultados encontrados mostram que o algoritmo de treinamento híbrido sugerido é bem mais rápido e apresenta erro quadrático médio menor quando comparado ao algoritmo convencional, o que torna a RBFN proposta mais adequada em aplicações de tempo real. 
A abordagem usada na maioria dos trabalhos, desenvolvidos e apresentados pela comunidade cientifica até então, sobre identificação e controle de sistemas não lineares, foi o emprego de redes neurais estáticas na aproximação das equações não lineares do modelo dinâmico. Essas estruturas de rede apresentam como grande desvantagem o fato de que durante o treinamento não ser utilizada a saída gerada pelo sistema nas atualizações dos pesos, ficando a aproximação funcional sensível somente aos dados de treinamento.

As redes neurais recorrentes tiveram grande desenvolvimento a partir de importantes pesquisas realizadas ao longo dos anos 90. Redes recorrentes são redes neurais com realimentações das conexões. Exemplos incluem Memória Associativa Bidirecional, Hopfield, Máquina de Boltzmann e redes Backpropagation Recorrentes. Essas redes têm sido aplicadas em uma ampla variedade de problemas. Srinivasan et al. (1994) apresentam uma nova abordagem para avaliação do desempenho do algoritmo backpropagation aplicado no treinamento de redes recorrentes. Os autores descrevem várias configurações com crescentes níveis de complexidade computacional para ajuste dos pesos da rede.

Com a evolução dos sistemas computacionais, tem havido um interesse crescente no uso de redes neurais dinâmicas (DNN - Dynamic Neural Network) na identificação de sistemas não lineares. Vários algoritmos de treinamento aplicados nessa classe de redes neurais têm sido propostos na literatura. A maioria destes métodos utiliza a técnica do gradiente, que envolve o cálculo de derivadas parciais, no treinamento das redes neurais. Embora esse algoritmo de treinamento tenha sido utilizado com sucesso em vários estudos empíricos, a sua desvantagem está na incapacidade em obter resultados de forma analítica sobre sua convergência e sua estabilidade. Leondes (1997) aborda o uso de redes MLP recorrentes na síntese e na implementação de controladores adaptativos aplicados em sistemas não lineares com dinâmica desconhecida. Em seu trabalho é enfocado o estudo de diversas estruturas da rede neural buscando obter sistemas práticos e eficientes. 
Sanchez et al. (1999) em sua pesquisa, também na área de identificação e controle de sistemas não lineares, propuseram um novo algoritmo de aprendizagem aplicado às redes neurais multicamadas dinâmicas (Dynamic Multilayer Neural Networks - DMNN) na identificação online de sistemas. Usando as funções de Lyapunov, os autores então observaram a estabilidade no treinamento das camadas ocultas e de saída. Os pesquisadores concluíram que o método apresentado se mostrou muito promissor. Eles propuseram a extensão e aplicação desse estudo em uma nova abordagem a ser aplicada no controle de sistemas não lineares e em problemas envolvendo observadores de estado.

As redes neurais convencionais feedforward e recorrentes, usadas na identificação e no controle de sistemas não lineares, foram bastante pesquisadas e apresentadas em várias publicações científicas. Jin-Tsong Jengt \& Tsu-Tain Lee (1999) apresentam uma estrutura neural baseada no Modelo Unificado, com base nos polinômios de Chebyshev (CPBUM Chebyshev Polynomials Based Unified Model), aplicado em aproximação de funções. A técnica apresentada extrai as relações existentes entre redes neurais de uma única camada e redes perceptron multicamadas. É mostrado também que a rede neural equivalente apresentada pode ser representada por um conjunto funcional baseado nos polinômios de Chebyshev. A nova estrutura neural proposta não só apresentou o mesmo comportamento de aproximador universal, mas também uma velocidade de aprendizagem superior quando comparada como as redes neurais convencionais feedforward e recorrentes.

Em projetos envolvendo sistemas de identificação e controle, existe um grande universo de possibilidades onde é possível aplicar RNA na identificação de processos não lineares. Yamada \& Yabuta (1993) apresentam um procedimento prático usado na identificação de funções de transferência direta e reversa de sistemas dinâmicos através de redes neurais. Os resultados obtidos por meio da simulação de um processo de segunda ordem mostram que a identificação de sistemas dinâmicos usando redes neurais pode ser realizada de 
forma satisfatória. Em seu trabalho, os autores observaram que estimadores neurais podem representar muito bem as características não lineares dos processos industriais. O projeto de um controlador neural também foi proposto e implementado, sendo que a função de transferência reversa foi obtida pelo estimador neural.

Kuschewski et al. (1993), buscando aqui solucionar problemas envolvendo a identificação e o controle usando redes neurais, propuseram duas metodologias com base nas redes ADALINE de duas e três camadas. Foram apresentados dois estudos sobre a aplicabilidade de redes FFN na identificação e no controle de processos. Nesse trabalho, primeiramente, foi realizada a identificação da malha de realimentação e da dinâmica inversa do processo a ser controlado. Em seguida, é apresentada uma estratégia de controle para o sistema proposto. Observando os resultados obtidos nas simulações verificou-se a viabilidade do método.

Nechyba \& Yangsheng (1994) também investigaram o potencial de aplicação e eficiência de aprendizagem de uma arquitetura neural aplicada na solução de problemas de identificação e de controle do sistema. Nesse trabalho, durante o processo de aprendizagem, é ajustado dinamicamente o tamanho da rede. A arquitetura proposta possibilita que as diversas camadas de neurônios tenham funções de ativação diferentes, tendo-se como resultado uma aprendizagem mais rápida, aproximações mais suaves e um número menor de neurônios na camada oculta. A validação da metodologia apresentada foi realizada por meio da identificação de dois sistemas, um estático e outro dinâmico, e também no projeto de um controlador não linear para o sistema pêndulo invertido.

Apesar da capacidade de aprendizagem e de aproximação apresentada pelas redes neurais ter levado sua aplicação na identificação e no controle de sistemas não lineares, elas são incapazes de realizar com boa precisão o mapeamento desses sistemas quando suas entradas não são uniformemente distribuídas na região de interesse. Isto implica em grandes 
dificuldades quando se deseja fazer a identificação e o controle em torno de pontos de operação instáveis, uma vez que geralmente nessas regiões é difícil a obtenção do conjunto de amostras adequadas para o treinamento. Sung-Woo Kim et al. (1994) estudaram a aplicação de redes neurais na identificação e no controle de sistemas instáveis. Buscando superar as dificuldades impostas pela instabilidade do sistema, eles então apresentaram uma estrutura composta por um sistema supervisor cuja função é fazer o treinamento das redes neurais nas regiões específicas de interesse. Depois de realizada a identificação do sistema em torno das regiões de instabilidade, outra rede neural foi projetada para minimizar as não linearidades nessas regiões. Mesmo sendo não linear, o sistema proposto pôde ser controlado por meio de controladores PI ou PID simples.

Em muitos ramos da ciência e da engenharia, obter o modelo matemático de sistemas desconhecidos por meio de um conjunto de dados empíricos é de fundamental importância. Infelizmente, essas condições nem sempre são possíveis na prática. A complexidade do problema a ser resolvido depende de uma série de fatores, como o conhecimento a priori do sistema a ser modelado, da qualidade e da integridade do conjunto de dados utilizado e da forma e precisão do modelo desejado. Suykens et al. (1996), em sua obra, realizaram o estudo e a análise de diversas arquiteturas de rede e algoritmos de aprendizagem aplicados na modelagem e no controle de sistemas não lineares.

O controle robusto e preciso dos processos produtivos é requisito básico para atingir as condições ideais de funcionamento de toda a planta industrial. A aplicação de técnicas de inteligência artificial na identificação e controle de processos industriais tem se mostrado eficaz em algumas aplicações de controle e automação, tendo-se em vista as limitações existentes na aplicação de estratégias convencionais. O controle preditivo, baseado em modelo (MPC), tem se mostrado uma importante ferramenta de controle criada para lidar com diversos tipos de sistemas, podendo ser aplicada em sistemas Single Input Single Output 
(SISO) e Multiple Input Multiple Output (MIMO). Consolidada na última década, essa tem sido então uma das poucas técnicas de controle avançado a apresentar significativos impactos na indústria de controle de processos. Benne et al. (2000) mostram em seu artigo a confiabilidade apresentada pelas RNA aplicadas na identificação e no controle de processos industriais. Usando MCP, os autores desenvolveram uma metodologia de controle robusta aplicada em um evaporador industrial. Como a estratégia MCP requer o modelo do sistema a ser controlado, um estimador de vários passos à frente baseado em redes neurais foi usado na modelagem da planta.

Yong et al. (2000), em seu artigo, abordam de maneira objetiva os aspectos relativos à utilização de redes wavelet-neural ortogonais aplicadas à identificação de modelos de Wiener. A combinação de redes neurais e transformadas wavelet, formando estruturas neurowavelet, com objetivo de realizar a identificação de sistemas, especialmente para os processos dinâmicos e não lineares, também tem sido investigado em diversas aplicações.

Recentemente, Yang \& Tseng (1996) relataram um estudo sobre aproximação de função empregando uma estrutura ANN (Artificial Neural Networks) ortogonal usando funções de Legendre no projeto de seus parâmetros (Functional Link Artificial Neural Networks - FLANN). Além de sua aplicação na identificação de sistemas não lineares, a estrutura FLANN foi usada na solução de problemas envolvendo comunicação digital. Patra et al. (1999) também utilizaram uma estrutura FLANN com expansão polinomial na solução de problemas envolvendo aproximação funcional. Mashor (2004) descreve em seu trabalho o uso de RNA na modelagem e identificação de sistemas não lineares. Ele aborda o problema envolvendo a identificação de processos contendo não linearidades usando uma rede MLP e uma rede RBF. Depois de estudos comparativos, os autores relataram ter obtidos resultados satisfatórios com essas duas estruturas neurais. 


\subsubsection{Aplicação de Sensores Virtuais}

Sensores virtuais permitem aos profissionais de engenharia melhorar a rentabilidade do negócio por meio do aumento da produtividade e do uso mais eficiente da energia utilizada pela unidade fabril. Um grande problema presente nas indústrias (química, petroquímica, de papel e celulose, etc.) é a falta de medição, em tempo real, de variáveis que estão associadas com as características que definem a qualidade do produto e o rendimento do processo. Esta indisponibilidade em processos críticos pode levar à fabricação de produtos fora de especificação. Este problema pode ser superado usando um sistema inferencial ou um sensor virtual.

Sensores virtuais fornecem informações em tempo real, necessárias para a realização do controle ou da supervisão de plantas industriais, eliminando-se dessa forma gastos adicionais com energia e custos complementares associados à fabricação de produtos fora de especificações. Esses dispositivos são capazes de realizar estimativas precisas das variáveis desejadas usando um conjunto de medições disponíveis de forma online. Por causa da maior facilidade encontrada em seu projeto, devido à sua implementação por software, aliado à sua capacidade de operar de forma online, o emprego de sensores virtuais como estimadores dinâmicos tem sido mais interessante do que os filtros estocásticos ou observadores determinísticos. Portanto, esse tipo de sensor tem sido amplamente aplicado na inferência de medições de qualidade que, normalmente, são obtidas por meio de amostragem, onde muitas vezes sua análise é realizada de forma offline, tais como a composição do produto de topo de uma coluna de destilação (Zamprogna et al., 2005) e a distribuição granulométrica num equipamento de moagem (Casali et al., 1998).

Algumas aplicações envolvendo sensores virtuais são baseadas apenas em métodos estatísticos. Um exemplo típico é uma combinação dos métodos envolvendo Principal Component Analysis (PCA) e Partial Least Squares (PLS). Na análise usando PCA, tem-se 
aqui uma visão geral dos dados e, estabelecendo as correlações entre as variáveis, pode-se modelá-los. Ao contrário dos métodos denominados caixa-preta, tais como as redes neurais, essa abordagem proporciona uma melhor compreensão sobre o comportamento do processo, revelando-se ao projetista as inter-relações entre as diferentes variáveis do modelo. O método PLS possibilita a criação de modelos preditivos. Um bom modelo preditivo implica na separação das variáveis que mais contribuem para o comportamento do sistema. A combinação dos métodos PCA e PLS tem sido eficaz na previsão e seleção das variáveis mais significativas do sistema, melhorando o processo de diagnóstico e aquisição de conhecimento (Zamprogna et al., 2005).

As RNAs e o modelo de regressão por mínimos quadrados parciais (PLS) têm sido amplamente utilizados, sendo que inúmeros pesquisadores têm relatado várias aplicações bem sucedidas de sensores virtuais utilizados na inferência da composição do produto em diferentes processos. Qin et al. (1992) e Wilson et al. (1997) propuseram o uso de uma rede neural RBF para ser usada em conjunto com modelo PLS na análise e modelagem de dados altamente correlacionados e contaminado por ruído. Baffi et al. (2000) revisaram a metodologia proposta por Wilson et al. (1997) e desenvolveram um procedimento aperfeiçoado para atualização dos pesos das entradas, que não são ajustados pela estratégia PLS aplicada em problemas não linear. Esta nova metodologia, chamada de procedimento de atualização dos pesos de entrada baseado no erro, aumenta a capacidade de previsão da estratégia PLS não linear.

Diversas aplicações sobre o projeto de sensores virtuais aplicados em colunas de destilação têm sido também relatadas na literatura. Especificamente, na área de estimação de estado, muitos trabalhos têm sido dedicados na estimação da composição do produto em colunas de destilação. Brosilow (1978) foi considerado o pioneiro no desenvolvimento de estimadores ótimos para inferir a composição do produto numa coluna de destilação contínua, 
por meio de medições de temperatura e vazão do vapor. Desde então, vários autores têm estudado este tema.

Baratti et al. (1995) usaram um filtro de Kalman não linear estendido para inferir as composições dos produtos de fundo e topo, em colunas de destilação contínua, a partir de medições de temperatura. $\mathrm{O}$ desempenho do estimador foi comparado com o comportamento dinâmico de uma coluna experimental composta por 30 bandejas. Os autores observaram que, para conseguir um bom desempenho do estimador, a descrição precisa do equilíbrio líquidovapor nas colunas é importante.

Estudos realizados na literatura indicaram uma crescente tendência em combinar métodos estatísticos, tais como análise de componentes principais, com métodos de inteligência computacional, como as redes neurais artificiais. Quando se trata de processos que contém um grande número de variáveis, uma análise por meio do método PCA pode ser usada para determinar quais das variáveis de processo disponíveis têm maior influência sobre as variáveis a serem inferidas. Isto permite uma redução no número de variáveis, sem perder informações importantes. Além disso, permite uma seleção adequada das saídas, ou seja, as variáveis que realmente tem um efeito sobre o valor a ser estimado. Essas variáveis são então utilizadas como as entradas para o sensor virtual, que irá inferir o valor a ser estimado. Ao combinar essas técnicas de análise de dados com um sensor virtual, as entradas que têm o maior impacto sobre a saída são então selecionadas, e a implementação do algoritmo do sensor virtual fica muito simplificada, já que o número das variáveis de entrada fica reduzido (Zamprogna et al., 2005; Qin et al., 1997). 



\section{Capítulo III}

\section{Aspectos de Redes Neurais Artificiais}

\subsection{Introdução}

Nas últimas décadas, estabeleceu-se um novo ramo na ciência computacional composto por um conjunto de técnicas inspiradas nos sistemas biológicos, cujo objetivo é resolver problemas relacionados ao mundo real, oferecendo soluções robustas e de fácil implementação (Widrow et al. 1990).

Esta nova abordagem, também chamada de Soft Computing, inclui a lógica nebulosa, redes neurais, raciocínio aproximado, algoritmos genéticos, teoria do caos e teoria da aprendizagem, etc. Dentre esses métodos, as RNAs têm causado maior impacto devido à sua extraordinária aplicabilidade prática. Elas têm sido utilizadas principalmente em duas grandes áreas: (a) aproximação de funções e (b) reconhecimento/classificação de Padrões (Haykin, 2001).

As RNAs são modelos simplificados de redes biológicas e estão inseridas no grupo dos sistemas inteligentes, dentre os quais estão todas as técnicas que buscam modelar o conhecimento e o aprendizado humano. Elas podem ser definidas como um agregado de elementos básicos de cálculo que possuem capacidade de aprender, com certo grau de precisão, a relação causa e efeito entre suas variáveis de entrada e saída.

Uma importante característica apresentada pelas redes neurais é sua capacidade de generalização do conhecimento a partir de um conjunto de dados de treinamento. Isto permite que ela seja capaz de lidar com ruídos e distorções, além de responder corretamente a novos padrões, ou seja, padrões que não foram apresentados durante seu aprendizado. 
Como sistema conexionista, a rede neural é capaz de resolver paradigmas que a computação linear não consegue. Em um sistema conexionista, o processamento não é sequencial, mas sim paralelo. Nesses sistemas, suas unidades de processamento podem ser operadas simultaneamente. Dessa forma, sob essas condições e com a topologia adequada, uma rede neural será capaz de generalizar o problema em estudo.

Todavia, para haver a generalização do problema abordado é indispensável ter algum conhecimento prévio do sistema que se deseja representar, conforme observado por Russell (1948) e Goodman (1954; 1983) e rigorosamente provado por Wolpert (1995a; 1996a; 1996b). Em qualquer aplicação prática, é preciso saber quais entradas são relevantes para o mapeamento do sistema. Em muitos casos não é conveniente usar todas as entradas do sistema original. É preciso determinar uma classe restrita de entradas e saídas que proporcionem uma aproximação adequada para o aprendizado da função a ser mapeada. Assim, existem três condições básicas que são normalmente necessárias, embora não suficientes, para uma boa generalização:

- Deve ser aplicado nas entradas da rede informações suficiente sobre o sistema, de modo que exista uma função matemática que relacione corretamente as saídas e entradas com a precisão desejada. A coleta de dados de treinamento e a seleção das entradas que permitem uma boa representação do sistema, em muitos casos, tomam mais tempo e esforço do que o treinamento da rede.

- A função a ser mapeada deve apresentar um comportamento suave, ou seja, composta por componentes de baixa frequência. Pequenas mudanças nas entradas da rede devem, na maioria das vezes, provocar uma pequena mudança nas saídas. Algumas redes neurais possuem a capacidade de aprender descontinuidades, desde que a função seja composta por um número finito de intervalos contínuos. Funções com grande variabilidade, como aquelas produzidas pelos geradores de 
números pseudoaleatórios e algoritmos de criptografia, não podem ser generalizadas por meio de redes neurais. Muitas vezes, uma transformação não linear do espaço de entrada pode aumentar a suavidade da função, melhorando também sua generalização.

- O subconjunto de treinamento dever ser suficientemente grande e representativo, composto de todas as situações que pretende-se generalizar. A importância desta condição está relacionada ao fato de haver basicamente dois tipos diferentes de generalização: interpolação e extrapolação. Interpolação se aplica em situações onde os dados estão ao redor do conjunto de treinamento. A extrapolação é necessária onde os dados estão fora desse intervalo ou ocorra à existência de buracos no conjunto de dados. Interpolação muitas vezes pode ser realizada de forma confiável, mas a extrapolação é notoriamente não confiável. Dessa forma, é muito importante ter uma quantidade suficiente de dados de treinamento e com boa representatividade para evitar a necessidade da extrapolação.

Nos últimos anos, tem sido grande o número de aplicações de RNA nas mais diversas áreas do conhecimento. $\mathrm{Na}$ área de controle automático, as redes neurais têm sido usadas principalmente como modelos na identificação e controle de sistemas. Identificação de sistemas dinâmicos consiste no ajuste dos parâmetros do modelo proposto, de forma que seu comportamento se aproxime do sistema ou planta estudada. Assim, as redes neurais têm aplicação direta no campo de identificação de sistemas devido à sua capacidade de generalização a partir das entradas e saídas do sistema.

Recentemente, com o surgimento da eletrônica moderna e o avanço alcançado pela ciência da computação, tem-se aumentado o interesse por parte da comunidade científica na modelagem e representação computacional do cérebro humano, dando um novo impulso no ramo da inteligência artificial (IA). 


\subsection{Relação entre Neurônio Biológico e Artificial}

Os seres humanos e outros animais processam as informações por meio de redes neurais. Os neurônios (células nervosas) são também responsáveis pelo pensamento humano e podem ser vistos como os principais elementos na formação do sistema nervoso central. A única limitação apresentada pelo sistema nervoso é que, após o nascimento, os neurônios perdem a capacidade de se dividir e de formar novas células. Todavia, sistemas neurais biológicos apresentam uma alta tolerância a falhas. Estruturalmente, um neurônio pode ser dividido em três partes principais: corpo celular (soma), dendritos e axônio, conforme pode ser visto na Figura 3-1 a seguir.

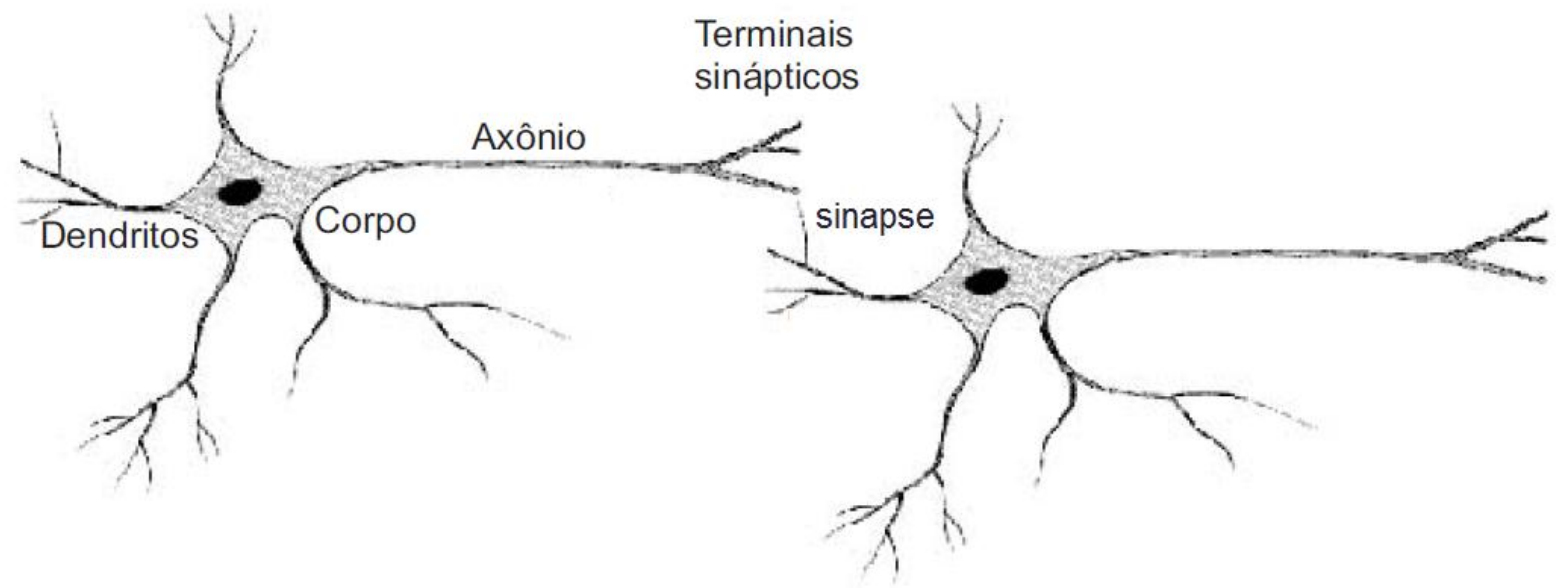

Figura 3-1. Ilustração do neurônio biológico. (fonte: adaptação de Ferneda, 2006)

Embora exista muito a ser descoberto de como é feito a aprendizagem pelo cérebro, as atuais teorias dizem que isso é resultado da modificação das conexões sinápticas entre os neurônios. Respostas diferentes do indivíduo perante uma mesma situação caracterizam seu aprendizado por meio da prática. Normalmente, o processo de aprendizagem também requer um professor para sugerir como realizar bem uma determinada tarefa. Após um processo de treinamento, por tentativa e erro, o indivíduo consegue executar corretamente a tarefa que antes não era capaz de resolver. 
Toda teoria envolvendo rede neural artificial é inspirada na estrutura e funcionamento do sistema nervoso, onde o neurônio é elemento fundamental e foi desenvolvido buscando modelar o neurônio biológico. Os algoritmos de computador que tentam simular essas estruturas biológicas são chamados de RNAs.

Contudo, na representação de uma simples célula nervosa é grande a complexidade da estrutura e dos processos envolvidos. Até os mais sofisticados modelos de neurônios artificiais ainda são muito limitados quando comparados aos neurônios biológicos. A abordagem mais utilizada é baseada no modelo proposto por McCulloch \& Pitts (1943). Fundamentalmente, o neurônio artificial ilustrado na Figura 3-2 é composto pelas seguintes partes:

- Um conjunto de sinapses, que são as entradas do neurônio ponderadas por um peso. Identifica-se o peso conectando a entrada $x_{j}$ do neurônio $i$ pelo símbolo $w_{i j}$. Faz parte desse conjunto um peso $w_{i 0}$, denominado bias. Essa entrada é constante para o neurônio $i$ cujo valor é definido como \pm 1 .

- Um somador $(\Sigma)$ que simula o corpo do neurônio biológico e determina o nível de excitação do neurônio artificial.

- Uma função de ativação $\varphi($.$) que produz um valor na saída se o nível de excitação$ atingir um determinado limiar e restringe esse nível caso contrário, evitando-se assim a saturação da rede.

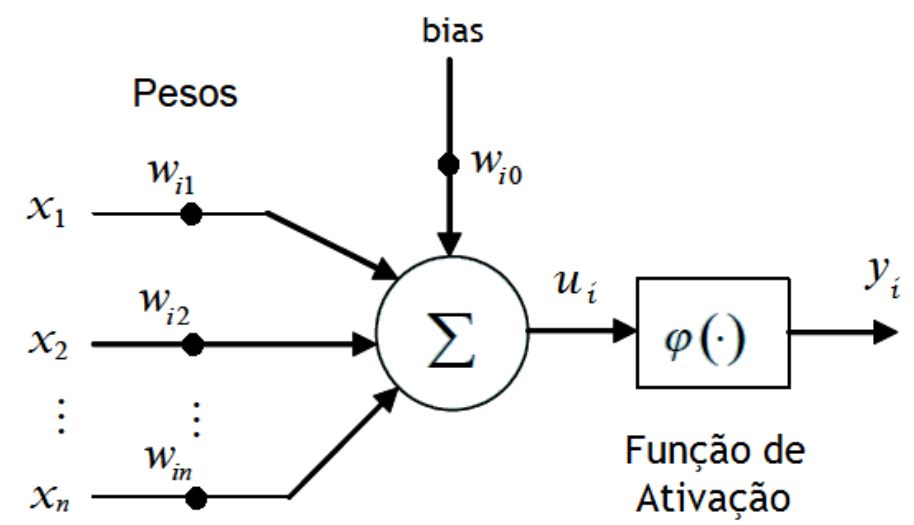

Figura 3-2. Modelo não linear de um neurônio artificial. (fonte: adaptação de Silva et al., 2010) 
Matematicamente, a saída do $i$-ésimo neurônio é dada pelas seguintes expressões:

$$
\begin{gathered}
u_{i}=\sum_{j=1}^{n} w_{i j} x_{j} \\
b_{i}=w_{i 0} \\
y_{i}=f\left(u_{i}-b_{i}\right)
\end{gathered}
$$

onde $n$ indica o número de entradas; $x_{1}, x_{2}, \cdots, x_{n}$ são os valores das entradas; $w_{i 1}, w_{i 2}, \cdots, w_{i n}$ são os pesos sinápticos correspondentes às entradas do neurônio $i ; b_{i}$ é o limiar e $\varphi($.$) é a função de ativação.$

Os pesos $w_{i j}$ com valores positivos correspondem às sinapses excitatórias e os negativos às inibitórias. Este é o modelo chamado Perceptron de Rosenblatt proposto em 1959. A saída $y_{i}$ pode ser expressada numa outra forma equivalente, conforme mostrado na equação (3-4):

$$
y_{i}=f\left(W^{T} X\right)
$$

donde $X \equiv\left[x_{1}, x_{2}, \cdots, x_{n}\right]^{T}$ e $W \equiv\left[w_{i 1}, w_{i 2}, \cdots, w_{i n}\right]^{T}$

\subsubsection{Funções de Ativação}

A função de ativação modela o comportamento do neurônio artificial, definindo o valor da saída em função da associação das entradas. Ela faz com que não exista sinal na saída do neurônio quando seu argumento ficar abaixo de um determinado valor de referência; caso contrário, a saída apresentará uma magnitude específica. As funções de ativação frequentemente utilizadas são mostradas na Figura 3-3 a seguir. As funções de ativação $\varphi(\cdot)$ podem classificadas em duas categorias: (a) funções de ativação totalmente diferenciáveis; (b) funções de ativação parcialmente diferenciáveis. 


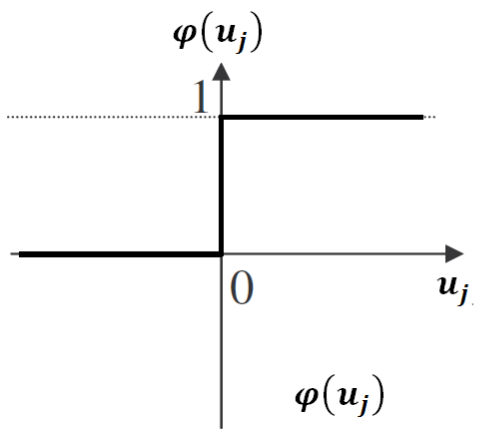

(a)

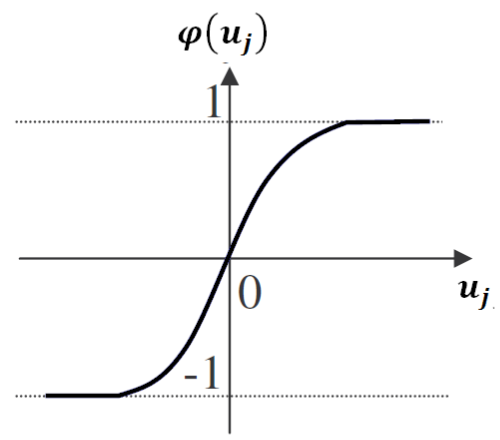

(d)

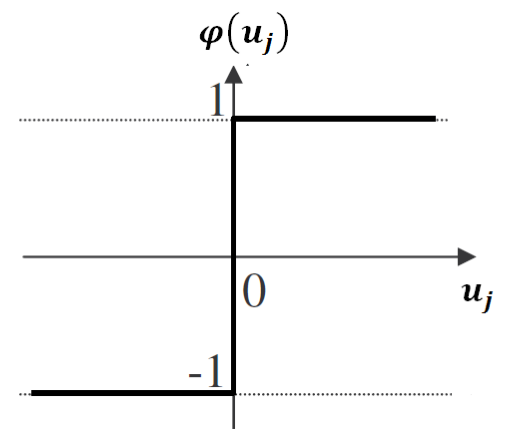

(b)

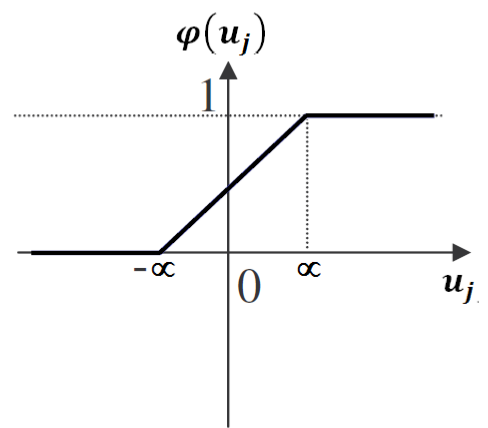

(e)

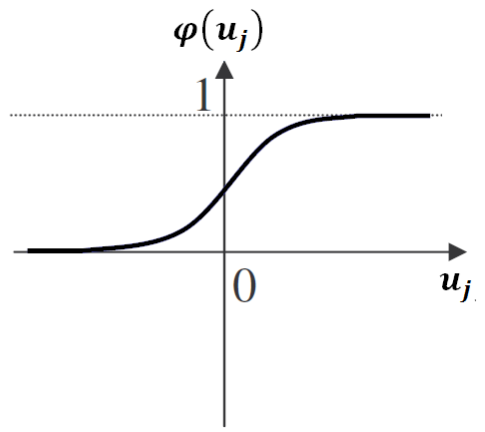

(c)

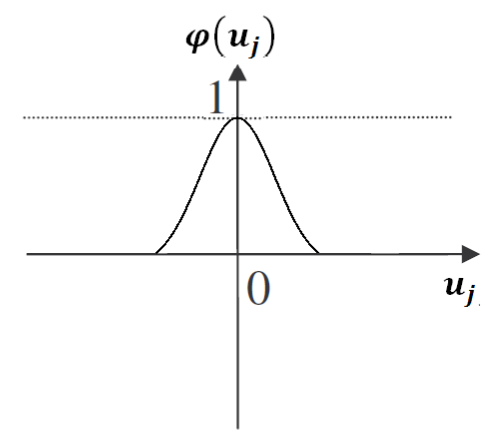

(f)

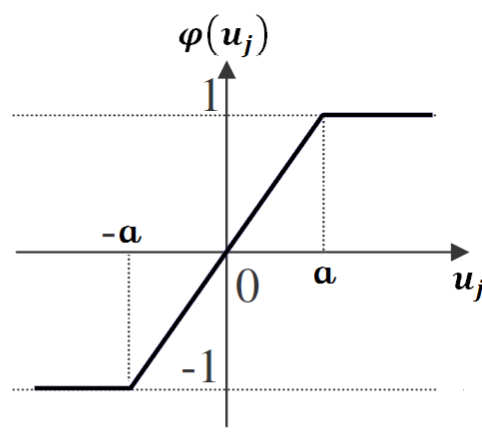

(g)

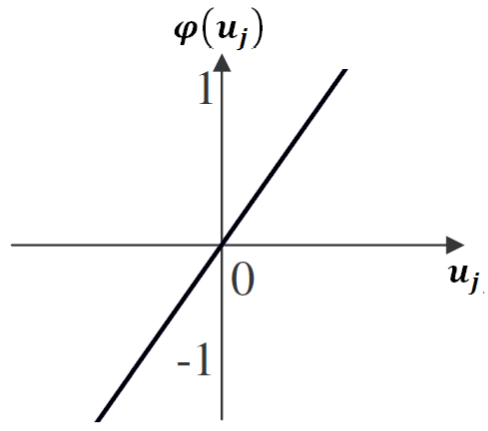

(h)

Figura 3-3. Representação gráfica das principais funções de ativação.

A primeira categoria é composta por funções que possuem uma não linearidade suave, ou seja, função diferenciável em todo seu domínio. As funções logística (c), tangente hiperbólica (d), gaussiana (f) e linear (h) fazem parte desse grupo, sendo que elas são necessárias na utilização de algoritmos de treinamento adaptativos como o Backpropagation. A segunda é constituída por funções parcialmente diferenciáveis, isto é, funções que apresentam pontos de descontinuidade. Fazem parte desse grupo as funções degrau (a), 
degrau bipolar (b), além das funções rampa (e) e rampa simétrica (g), sendo que elas são comumente usadas no perceptron de camada única.

A função de ativação linear é definida pela equação da reta dada pela equação (3-5) a seguir, onde $\alpha$ representa um número real que define a inclinação da curva vista na Figura 3-3(h).

$$
\varphi\left(u_{j}\right)=\alpha \cdot u_{j}
$$

A função de ativação rampa é caracterizada por apresentar intervalos distintos em sua representação, um linear e outros dois constantes, iguais a $\alpha$ e zero, conforme pode ser visto na equação (3-6) a seguir. Na Figura 3-3(e) pode ser visto a representação gráfica da função rampa.

$$
\varphi\left(u_{j}\right)=\left\{\begin{array}{c}
\alpha, \text { se } u_{j}>\alpha \\
u_{j}, \text { se }-\alpha \leq u_{j} \leq \alpha \\
0, \text { se } u_{j}<\alpha
\end{array}\right.
$$

A equação (3-7) a seguir representa a função de ativação rampa simétrica e seu aspecto pode ser visto na Figura 3-3(f)

$$
\varphi\left(u_{j}\right)=\left\{\begin{array}{c}
a, \text { se } u_{j}>a \\
u_{j}, \text { se }-a \leq u_{j} \leq a \\
-a, \text { se } u_{j}<a
\end{array}\right.
$$

A função de ativação degrau produz um valor constante positivo para valores de $u_{j}$ maiores que zero e zero para valores menores. Sua expressão matemática é dada pela seguinte equação.

$$
\varphi\left(u_{j}\right)=\left\{\begin{array}{l}
1, \text { se } u_{j} \geq 0 \\
0, \text { se } u_{j}<0
\end{array}\right.
$$

A Figura 3-3(b) exibe o gráfico da função de ativação degrau bipolar, sendo que esta produz um valor constante negativo para valores de $u_{j}$ menores que zero, conforme pode ser visto na equação (3-9) a seguir. 


$$
\varphi\left(u_{j}\right)=\left\{\begin{array}{c}
+1, \text { se } u_{j}>0 \\
0, \text { se } u_{j}=0 \\
-1, \text { se } u_{j}<0
\end{array}\right.
$$

Função de ativação logística caracteriza-se por apresentar um intervalo dinâmico quase linear, sendo possível obter várias funções logísticas dependendo do valor de $\beta$. Essas funções são utilizadas na construção de diversos modelos de redes neurais aplicadas às diferentes áreas do conhecimento. Sua representação é dada pela equação (3-10) a seguir. Seu padrão geométrico é mostrado na Figura 3-3(c).

$$
\varphi\left(u_{j}\right)=\frac{1}{1+e^{-\beta u_{j}}}
$$

Em situações onde se deseja que a função de ativação assuma também valores negativos, emprega-se a forma correspondente da função sigmoidal, isto é, função de ativação tangente hiperbólica que é definida pela equação (3-11) a seguir. A Figura 3-3(d) mostra de forma gráfica a função tangente hiperbólica.

$$
\varphi\left(u_{j}\right)=\frac{1+e^{-\beta u_{j}}}{1-e^{-\beta u_{j}}}
$$

Por fim, tem-se as funções de ativação gaussianas que podem ser representadas pela expressão (3-12) a seguir. Sua representação gráfica é mostrada na Figura 3-3(g).

$$
\varphi\left(u_{j}\right)=e^{\frac{\left(u_{j}-c\right)^{2}}{2 \sigma^{2}}}
$$

A função de ativação tem como objetivo limitar a amplitude dos neurônios de saída, além de fornecer um comportamento não linear à rede para que ela possa ser usada como aproximador universal de funções.

\subsection{Classificação das Redes Neurais Artificiais}

Arquitetura e topologia são conceitos distintos em RNAs. Arquitetura está diretamente relacionada com a maneira em que os neurônios estão arranjados. Já topologia define suas características intrínsecas que as diferenciam dentro de uma mesma arquitetura, 
por exemplo, o número de neurônios na primeira camada neural, número de neurônios na camada de saída, número de camadas, etc (Silva et al., 2010).

Segundo Narendra et al. (1990), as redes neurais podem ser classificadas, do ponto de vista estrutural, em estruturas estáticas ou dinâmicas. A principal desvantagem apresentada pelas redes estáticas ou não recorrentes é que durante a atualização dos pesos não ocorre a utilização das informações produzidas na saída da estrutura, ou seja, nessa arquitetura as saídas dependem somente do valor atual das entradas, por isso são chamadas também de redes sem memória. Isso torna essas redes mais sensíveis aos dados de treinamento em aplicações envolvendo aproximação de funções que as redes recorrentes. Em contrapartida, além das redes dinâmicas ou recorrentes possuírem uma representação simples e capacidade de tratar o problema de memorização devido à realimentação existente em sua estrutura, elas ainda proporcionam outra vantagem, que é apresentar bom desempenho mesmo em situações onde os dados disponíveis não proporcionam uma boa representação dinâmica.

As RNAs podem ser classificadas em quatro arquiteturas básicas conforme pode ser visto na Figura 3-4 a seguir.

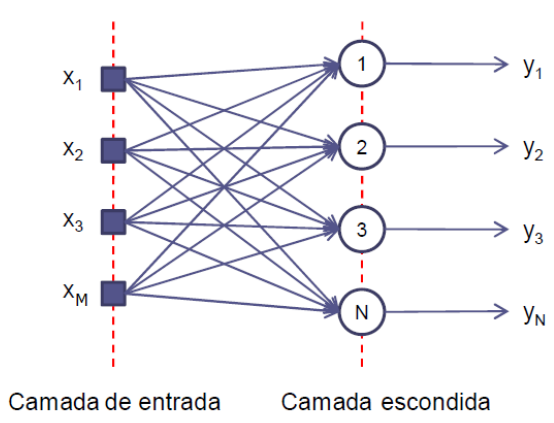

(a)

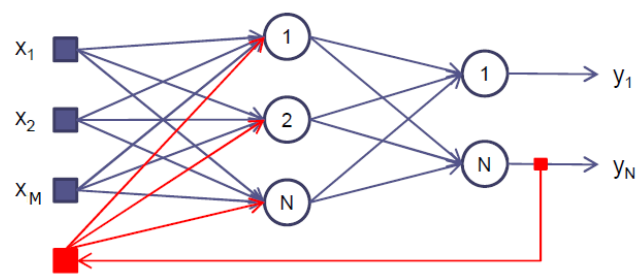

(c)

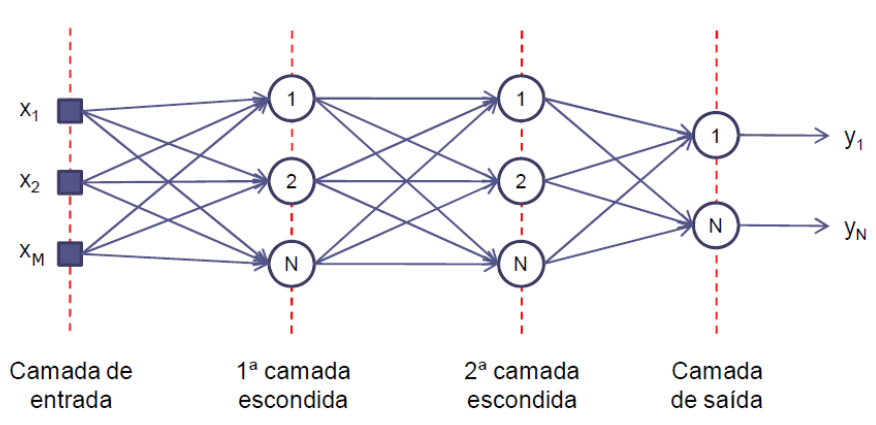

(b)

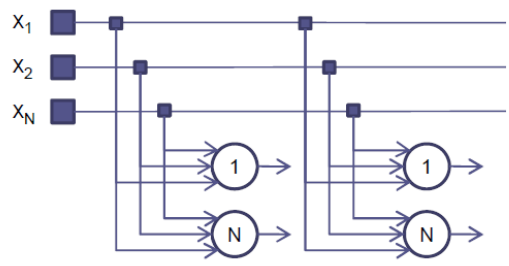

(d)

Figura 3-4. Arquiteturas de redes neurais artificiais. 
Dois tipos de redes neurais têm recebido muita atenção em recentes trabalhos, ou seja, as redes neurais feedfoward multicamadas e redes neurais recorrentes. Do ponto de vista teórico, as redes feedfoward multicamadas representam um mapeamento estático não linear, enquanto as redes recorrentes representam sistemas realimentados dinâmicos com comportamento não linear.

As redes feedforward podem ser divididas em dois grupos: O primeiro grupo que pode ser visto na Figura 3-4(a), também chamado de redes de camada única, possui além da entrada, uma única camada de neurônios que é a própria saída, por exemplo, tem-se aqui o perceptron e as redes ADALINE. O segundo é composto pelas redes de múltiplas camadas, que diferem da anterior pela presença de uma ou mais camadas escondidas de neurônios, conforme pode ser observado na Figura 3-4(b). As redes MLP e RBF são exemplos dessa arquitetura.

Redes recorrentes (Figura 3-4(b)) são estruturas que contêm retroalimentação entre neurônios de camadas diferentes. A retroalimentação de informação permite a criação de representações internas de dispositivos de memória capazes de processar e armazenar informações temporais e sinais sequenciais. Dentre as diversas arquiteturas existentes, tem-se o perceptron multicamadas com realimentação e as redes de Hopfield.

\subsubsection{Estruturas Internas das Redes Neurais Artificiais}

Internamente, uma RNA tem seus neurônios organizados em camadas bem definidas, tais como:

- Camada de entrada: sua função é receber os dados vindos do meio exterior. Esta camada normalmente não processa os sinais recebidos, mas os enviam para a próxima camada. $\mathrm{O}$ número de entradas a ser utilizada depende especificamente do problema a ser tratado. 
- Camada oculta: nessa camada os neurônios processam os sinais recebidos antes de enviá-los para os neurônios da camada de saída ou outra camada oculta, quando for usada uma arquitetura multicamadas. O ajuste dos pesos dos neurônios nesta camada depende de um algoritmo de aprendizagem.

- Camada de saída: tem a função de enviar para o meio exterior (saída) o sinal processado pela camada oculta. Os neurônios nesta camada realizam uma nova transformação nos sinais recebidos antes de enviá-los à saída.

\subsection{Redes Neurais Estáticas}

Como visto na seção anterior, se a resposta de uma RNA depende apenas de suas entradas e independe de sinais anteriores no tempo, essa rede é então classificada como rede neural estática; desse modo, a resposta apresentada pela rede é invariante no tempo. Essas são muito úteis em problemas de classificação de padrões e aproximação de funções, pois constroem funções não lineares entre os espaços de entrada e saída das variáveis envolvidas. Uma rede neural feedfoward com uma camada oculta não linear e camada de saída linear possui a capacidade de aproximar qualquer função com certo grau de precisão desejado, como mostrado em várias publicações (Hornik et al., 1989).

O tipo de rede neural feedfoward mais estudada na literatura é a rede neural multicamada com função de ativação de tipo sigmoidal. Essas redes têm-se revelado uma importante ferramenta aplicada em problemas de reconhecimento de padrões e identificação de sistemas dinâmicos, enquanto que as redes recorrentes têm sido empregadas na identificação e controle de sistemas dinâmicos, previsão de séries temporais, memórias associativas e também em problemas de otimização. 


\subsubsection{Rede Perceptron Multicamada}

Em função das limitações apresentadas pela rede Perceptron, fizeram-se então surgir as redes conhecidas como Multilayer Perceptron (MLP). Redes MLP são arquiteturas feedforward ou cascata, pois os sinais se propagam da entrada para a saída num único sentido. São compostas por um conjunto de neurônios agrupados em 3 ou mais camadas, uma camada de entrada, uma ou mais camadas ocultas e uma camada de saída, conforme pode ser visto na Figura 3-5 a seguir. Os neurônios da camada de entrada são responsáveis por transmitir o sinal de entrada para a camada oculta mais próxima. As camadas ocultas transmitem as informações recebidas da camada de entrada para a camada de saída, sendo que suas funções de ativação devem ser crescentes e diferenciáveis, as quais são geralmente usadas funções sigmóides. As saídas geradas pela última camada intermediária são processadas pelos neurônios da camada de saída, produzindo dessa forma os sinais na saída da rede.

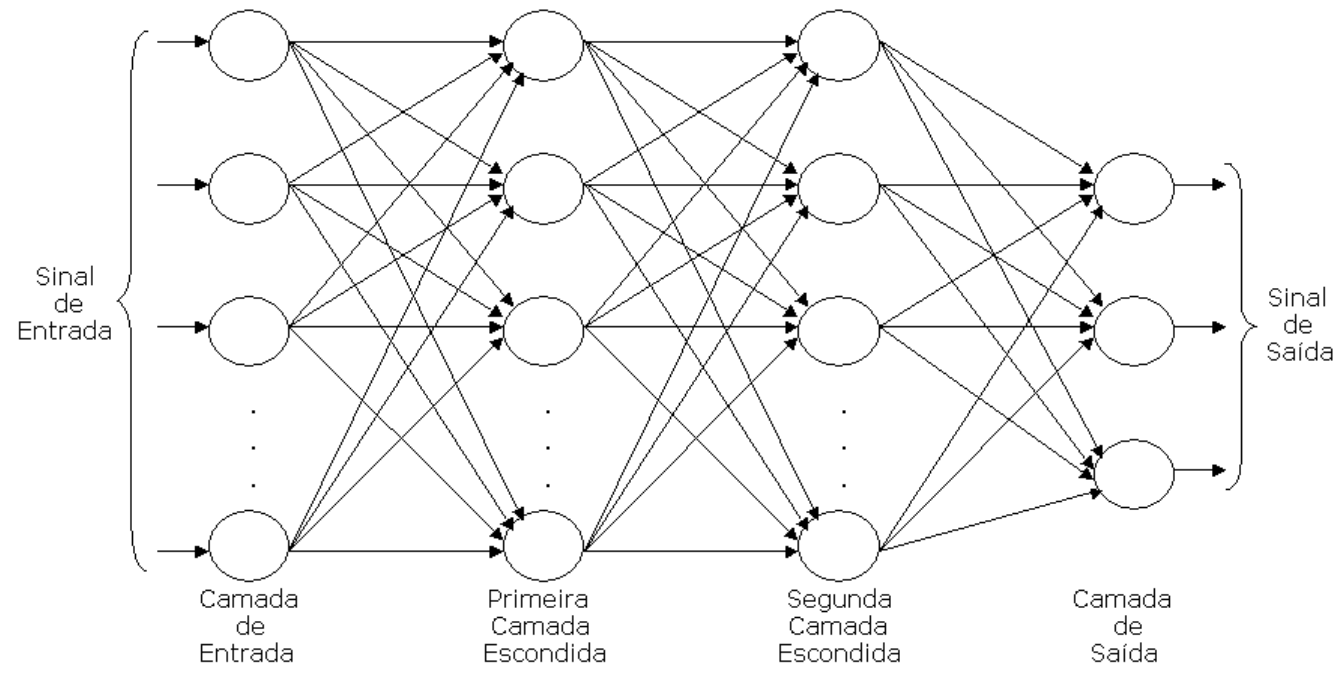

Figura 3-5. Ilustração da estrutura do MLP com duas camadas ocultas.

Observando a Figura 3-5, como acontece nos neurônios biológicos, as conexões entre os diversos neurônios das camadas da rede são chamadas de sinapses. Cada sinapse possui um peso que representa a intensidade da conexão. Esses pesos são ajustados por um algoritmo de treinamento supervisionado chamado backpropagation, ou algoritmo de retropropagação de erro, ou ainda, regra Delta generalizada. 


\subsection{Redes Neurais Recorrentes}

Como as redes estáticas, as redes neurais recorrentes (RNN - Recurrent Neural Networks) representam uma grande e variada classe de modelos computacionais que foram concebidos pela analogia, mais ou menos detalhada, do cérebro humano. Em uma RNN, numerosos neurônios artificiais, também chamados de unidades ou elementos de processamento, são interligados por conexões sinápticas também artificiais, que permitem a propagação dos potenciais de ação por meio da rede. A principal característica que distingue as RNNs das redes feedforward é a presença de uma realimentação em sua topologia, como pode ser observado na Figura 3-6 a seguir. A existência de realimentação tem uma grande influência em seu funcionamento.

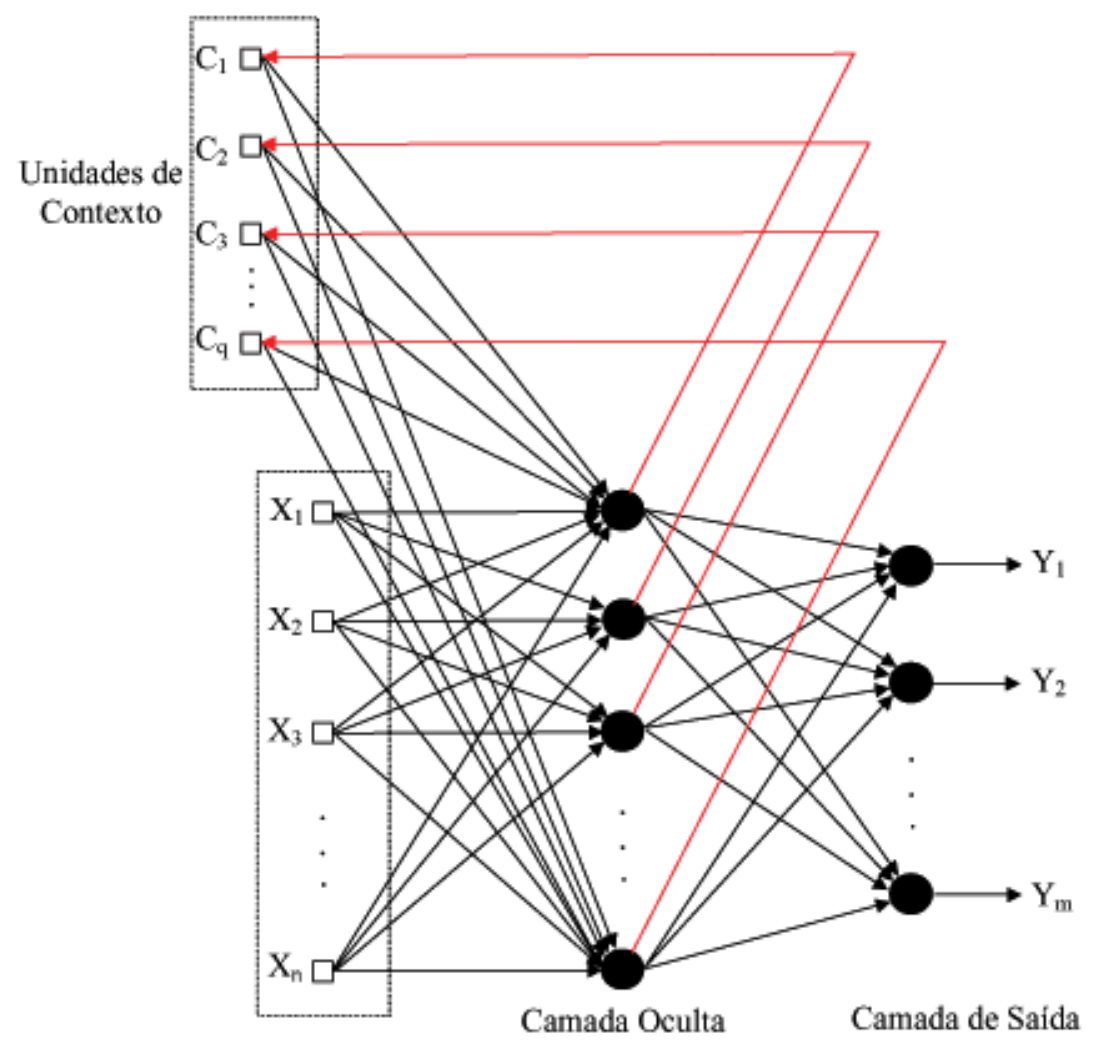

Figura 3-6. Rede neural de Elman. (fonte: Segatto et al., 2006)

Devido à essa realimentação, uma RNN possui a capacidade de manter o comportamento dinâmico das ativações das sinapses entre seus neurônios, mesmo na ausência de sinais de entrada. Matematicamente, isto torna a RNN um sistema realimentado, enquanto 
as redes feedforward são sistemas com realimentação direta. Além do mais, quando a entrada de uma RNN é estimulada, ela conserva internamente em sua estrutura um histórico das transformações não lineares de suas entradas, em outras palavras, ela tem uma memória dinâmica, sendo capaz de processar informações de contexto temporal.

As redes neurais recorrentes apresentam um comportamento dinâmico não linear, podendo ser simuladas por meio de software ou implementadas em hardware digital. Os sistemas no qual elas estarão inseridas podem ser classificados, conforme sua representação temporal, em dois grupos distintos, sistemas de tempo contínuo ou de tempo discreto. A segunda propriedade diz respeito quanto à forma do sinal tratado pelo sistema, podendo ser classificado como analógico (valor real) ou digital (valor quantizado). Um sistema é de valor real, se implementado em hardware analógico. Todas as implementações digitais usam valores quantizados, uma vez que os valores são armazenados em um número finito de bits. No entanto, uma implementação digital muitas vezes é analisada como se fosse um valor real, quando o erro introduzido pela quantização é pequeno demais para ser observado, por exemplo, quando números de ponto flutuante são usados.

As propriedades do sistema acima citadas não dizem muito sobre qual será a aplicação pretendida para a RNN. Essas redes são usadas para diversos fins científicos e existem pelo menos duas grandes classes de modelos de RNN, isto é, elas são usadas para fins de modelagem do cérebro humano ou como ferramenta no desenvolvimento de aplicações para engenharia. O primeiro grupo está inserido no campo da neurociência computacional, enquanto o segundo pertence à aprendizagem de máquina, teoria da computação, processamento de sinais não lineares e controle.

Do ponto de vista dos sistemas dinâmicos, existem basicamente duas classes de RNNs. Os modelos da primeira classe são caracterizados por ter seu comportamento dinâmico descrito por uma função de energia e por apresentarem conexões simétricas. Os melhores 
exemplos desses modelos são redes de Hopfield (Hopfield, 1986), máquinas de Boltzmann (Hinton, 2007), e a recém-criada Deep Belief Networks (DBN) (Hinton et al., 2006).

Estas redes em sua maioria são treinadas por um algoritmo de treinamento não supervisionado. Devido ao seu funcionamento específico, elas são aplicadas tipicamente nos campos de memórias associativas, compressão de dados, modelagem não supervisionada de dados e classificação de padrões estáticos, onde o modelo é executado por intervalos de tempo sucessivos para cada conjunto de entrada até convergir ou atingir o equilíbrio. Toda fundamentação matemática usada na modelagem dessas redes é baseada na física estatística. Em contrapartida, o segundo grupo de RNNs normalmente apresenta uma dinâmica de atualização determinística e conexões direcionadas. Esses sistemas respondem como filtros não lineares, que transformam uma série temporal aplicada em uma entrada numa série temporal de saída. Toda fundamentação matemática dessa classe é baseada na teoria de sistemas dinâmicos não lineares e, nesse caso, a técnica padrão usada na aprendizagem da rede baseia-se em algoritmo de treinamento supervisionado.

\subsubsection{Perceptron Multicamadas Recorrente}

O Perceptron Multicamadas Recorrente (RMLP) é uma rede híbrida neural (feedforward/feedback), com a realimentação representada por conexões recorrentes e cruzamentos apropriados. Usada na identificação da dinâmica de sistemas não lineares desconhecidos, ela é composta basicamente por uma camada de entrada, várias camadas ocultas e uma camada de saída. Nessa arquitetura existem conexões do tipo feedback/feedforward entre os neurônios das camadas vizinhas, além de cruzamentos e recorrência nas camadas ocultas (ver Figura 3-7 a seguir). 


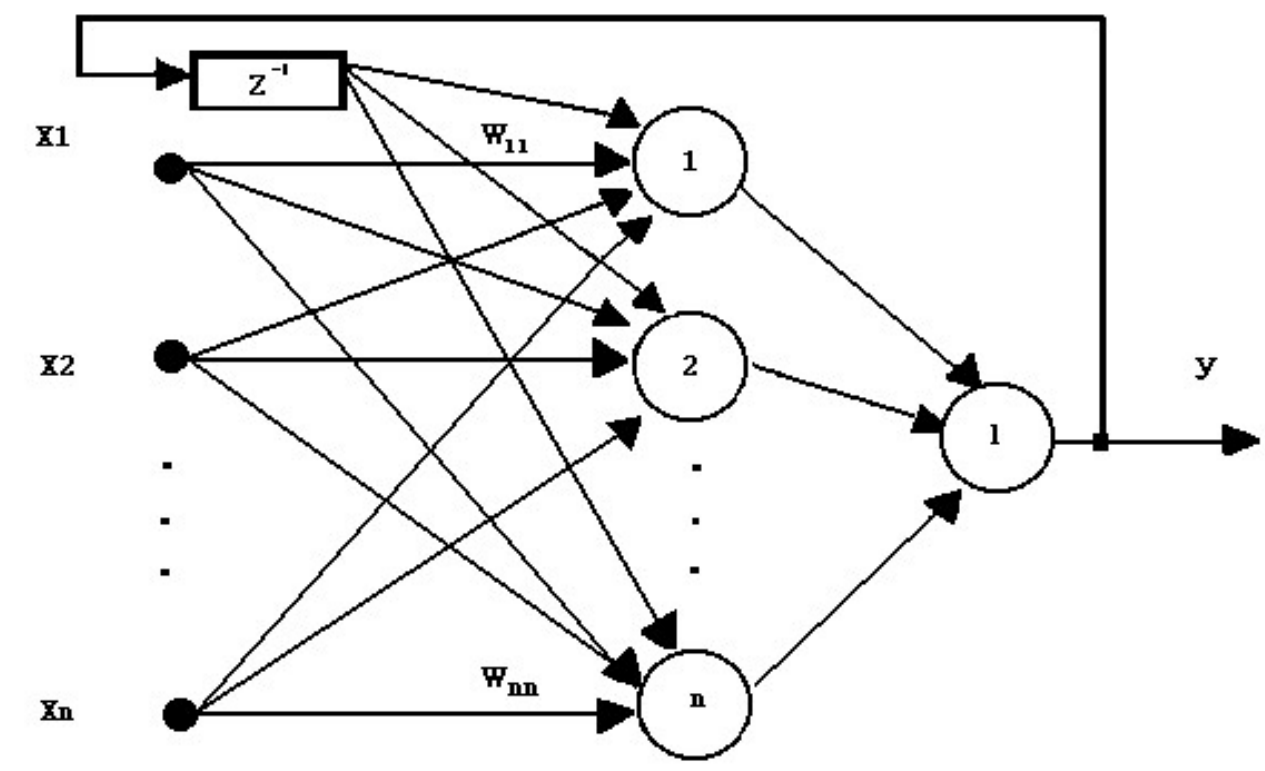

Figura 3-7. Estrutura geral de um Perceptron Multicamadas Recorrente. (fonte: adaptação de Haykin, 2001)

O uso de realimentação permite que as redes recorrentes adquiram representações dos estados do sistema, sendo que seu uso pode reduzir significativamente as exigências de memória, quando comparado com as redes estáticas. As redes recorrentes se mostram bastante úteis em diversas aplicações, principalmente, na modelagem e identificação de sistemas não lineares.

\subsection{Algoritmos de Aprendizagem}

Algoritmos de aprendizagem são métodos de adaptação pela qual uma rede ajusta seus parâmetros internos (pesos) de acordo com padrões de eventos ocorridos anteriormente, ou seja, baseado em experiências anteriores, até atingir uma solução adequada, se esta existir.

Os algoritmos de aprendizagem podem ser classificados conforme mostrado na Figura 3-8. $\mathrm{Na}$ aprendizagem supervisionada, o desvio (erro) produzido pela diferença entre a saída produzida pela rede e o valor real do sistema é utilizado para corrigir ou modificar os pesos das conexões sinápticas entre os neurônios da rede, de acordo com uma regra definida pelo algoritmo de aprendizagem. O aprendizado não supervisionado é utilizado quando, para cada amostra do vetor de entrada, não se conhece o valor da saída. 


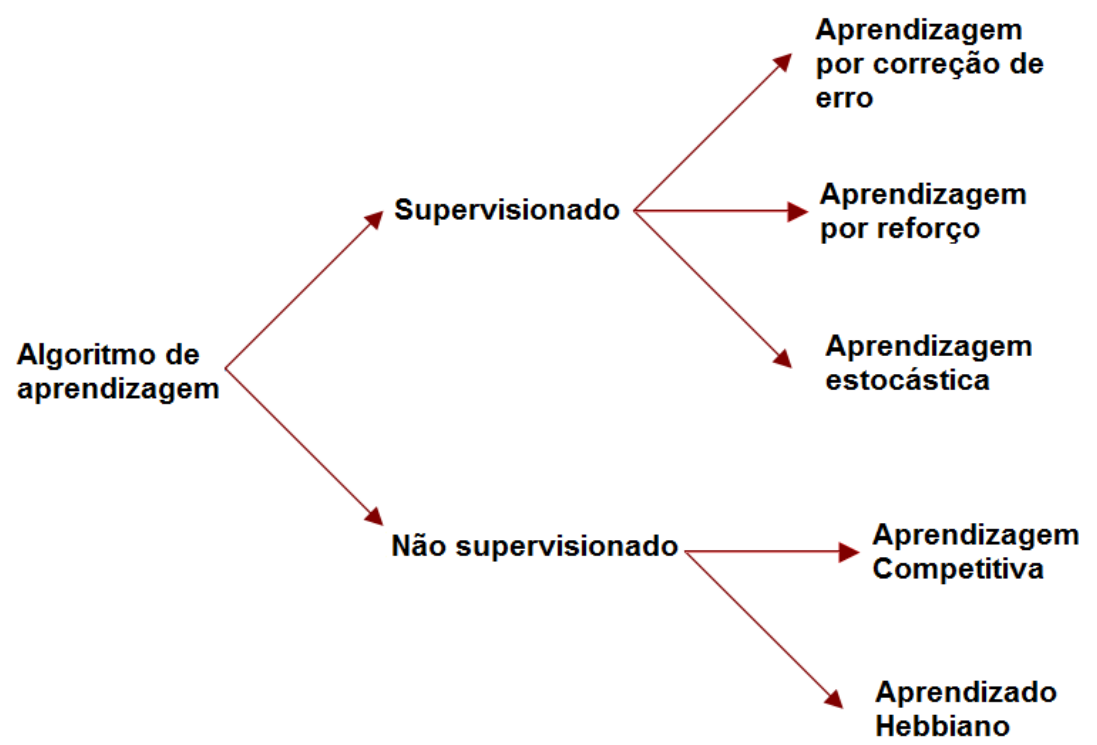

Figura 3-8. Classes de algoritmos de aprendizagem

A diferença fundamental entre essas duas classes de algoritmos está na existência de um agente externo chamado supervisor, usado para controlar o processo de aprendizagem da rede. Há quatro regras básicas de aprendizagem:

- Regra de Hebb: A primeira e mais conhecida regra de aprendizagem. Introduzido por Donald Hebb, foi descrito no livro The Organization of Behavior (Hebb, 1949). Tem como base o seguinte postulado: Quando o axônio de um neurônio $A$ estiver perto o suficiente para excitar um neurônio $B$ e, repetidamente, ou persistentemente, continuar fazendo com que esse neurônio esteja ativado, apresentando matematicamente o mesmo sinal, um processo de crescimento ou mudança metabólica então ocorrerá em um ou ambos os neurônios, de forma a aumentar a eficiência do neurônio $A$ em fazer com que o neurônio $B$ seja ativado, isto é, os pesos entre os neurônios são reforçados.

- Regra Delta: Essa regra é uma variação da regra de Hebb, e é uma das mais utilizadas. Esta regra baseia-se na ideia de modificar continuamente as conexões de entrada da rede (pesos) para reduzir a diferença (delta) entre a saída real desejada e o valor atual gerado pela saída do neurônio. Esta regra modifica os 
pesos de forma a minimizar o erro quadrático médio da rede. Após ajustar os pesos da rede, com base na diferença entre os valores desejados e os obtidos na saída da rede, o erro é então propagado para as camadas anteriores, uma a uma até atingir a primeira camada.

- Aprendizagem Competitiva: Nessa técnica, cada neurônio da rede aprende e se especializa por meio de conjuntos de dados similares, tornando-se um detector de padrões. Esse algoritmo possui um mecanismo que permite aos neurônios competirem pelo direito de responder às excitações das entradas, de modo que apenas um neurônio possa vencer a competição. Esse neurônio é chamado de vencedor, sendo que sua saída é então atualizada. A aprendizagem consiste no deslocamento dos pesos sinápticos dos nós inativos para os ativos. Se o neurônio ganha uma competição, cada peso de cada entrada tem seu valor alterado de acordo com a regra de aprendizagem competitiva padrão.

- Aprendizagem por Máquina de Boltzmann: Esse método de aprendizagem tem suas origens na teoria da computação e considerações termodinâmicas. Em uma máquina de Boltzmann são empregados neurônios probabilísticos que formam uma estrutura recursiva operando de forma binária (+1/-1), sendo conhecidos como estados on/off. Além disso, é caracterizada por uma função de energia, cujo valor é definido pelos estados ocupados por cada neurônio na máquina. Seu funcionamento consiste em selecionar um neurônio aleatoriamente e alterar seu estado numa temperatura $T$ com certa probabilidade. Convém observar que $T$ é uma pseudo temperatura, indicando apenas que em altas temperaturas o sistema tende a aceitar melhor as mudanças de estado que em temperaturas mais baixas. 


\subsection{Aplicação de Redes Neurais na Identificação de Sistemas Dinâmicos}

Sistemas de controle convencionais são tradicionalmente projetados usando modelos matemáticos dos sistemas físicos. Os modelos que descrevem o comportamento dinâmico do sistema são desenvolvidos inicialmente para que, em seguida, sejam aplicadas técnicas de projeto para a concepção dos controladores apropriados para esse sistema. Além disso, os modelos matemáticos devem ser simples o suficiente para serem analisados com os métodos atualmente disponíveis, mas devem ser suficientes precisos para descrever com exatidão o comportamento dinâmico do sistema. No entanto, em aplicações práticas, muitas vezes o modelo e seus parâmetros são desconhecidos. Além disso, as mudanças no ponto de operação e a presença de dinâmicas não modeladas, não linearidades e incertezas dificultam o controle do sistema usando controladores convencionais, visto que, esses não são capazes de aprender ou adaptar às novas situações.

Na maioria das publicações envolvendo identificação de sistemas não lineares são utilizadas redes neurais estáticas, como por exemplo, MLP. Essas estruturas atuam como aproximador universal de funções e são usadas como estimador de modelos dinâmicos não lineares. As principais desvantagens do uso de estruturas não realimentadas são a não utilização das informações da própria estrutura na atualização dos pesos durante o processo de treinamento, bem como o fato de que quando usadas em aproximação de função elas são sensíveis à qualidade dos dados usados no treinamento (Haykin, 2001). Redes neurais dinâmicas podem superar com vantagens estas limitações, além de responder adequadamente em situações envolvendo a ocorrência de dinâmicas não modeladas, sendo que isso é possível devido à sua estrutura incorporar realimentações da saída.

Todavia, usando técnicas tradicionais de identificação de sistemas dinâmicos pode ser possível obter erros de aproximação relativamente pequenos para uma ampla gama de funções não lineares, no entanto, não é possível garantir a estabilidade do erro de identificação. Os 
modelos obtidos com RNAs podem ser usados no lugar dos modelos convencionais e sua precisão pode ser alterada por meio de modificações estruturais ou ajustes nos parâmetros internos. A capacidade de mapeamento de processos não lineares apresentada pelas RNAs está intimamente ligada ao tipo da função de processamento não linear incluída em sua estrutura, ou seja, na escolha adequada de sua função de ativação e pela estrutura utilizada. Devido à possibilidade de poder ajustar o conjunto de pesos, em aplicações envolvendo RNAs a arquitetura e topologia usada afeta sua capacidade de adaptação e generalização.

As limitações observadas no emprego de RNAs na modelagem de sistemas dinâmicos são devidas à dificuldade que poderá existir na compreensão das relações entre as entradas e saídas do modelo e, em aplicações práticas, pode não ser obtida a robustez desejada. Uma forma de melhorar a robustez do modelo encontrado é fazer uso de técnicas que combinem as informações auxiliares com base no conhecimento operacional do processo e no conjunto de dados do processo obtidos durante a etapa de identificação. Por exemplo, pode ser usado o conhecimento do processo para decompor toda região de operação em várias regiões operacionais locais. Dentro de cada região local, um modelo linear com ordem reduzida pode ser usado para aproximar o comportamento em torno desse ponto do processo.

Segundo Meireles et al. (2003), há várias aplicações de RNAs para resolução de problemas na indústria, como diagnóstico de falhas, controle de qualidade, classificação de padrões, controle adaptativo e modelagem de processos. Estudos mostram que o porcentual de utilização das redes neurais se divide, em aproximadamente, da seguinte maneira: MLP, 81,2\%; Kohonen, 8,3\%; Hopfield, 5,4\%; e outros 5,1\% (Haykin, 2001). Na Tabela 3-1 estão listadas as principais aplicações para as diversas estruturas propostas. 
Tabela 3-1 - Lista de RNAs e suas aplicabilidades (Fonte: Meireles at al., 2003).

\begin{tabular}{|l|l|}
\hline \multicolumn{1}{|c|}{ Função } & \multicolumn{1}{c|}{ Estrutura } \\
\hline Reconhecimento de padrões & MLP, Hopfield, Kohonen, PNN \\
\hline Memória associativa & Hopfield, MLP recorrente, Kohonen \\
\hline Otimização & Hopfield, ART, CNN \\
\hline Aproximação de função & MLP, CMAC, RBF \\
\hline Modelagem e controle & MLP, MLP recorrente, CMAC, FLN, FPN \\
\hline Processamento de Imagem & CNN, Hopfield \\
\hline Classificação & MLP, Kohonen, RBF, ART, PNN \\
\hline
\end{tabular}

Com o aparecimento de novos problemas em sistemas de controle, resultante dos avanços tecnológicos e científicos, sugere-se a necessidade de novas ferramentas para solucioná-los. Dentre elas estão os sensores virtuais baseados em RNAs inspiradas no sistema neural humano. 


\section{Capítulo IV}

\section{Identificação de Sistemas Dinâmicos}

\subsection{Introdução}

Atualmente, tem havido no cotidiano das empresas uma busca constante pelo aumento na produtividade dos processos industriais. Devido às grandes inovações tecnológicas pelas quais tem passado os processos produtivos, aliada às constantes mudanças ocorridas nas condições do mercado globalizado, os operadores têm sido obrigados a trabalhar em condições extremas de operação, procurando manter as plantas nos pontos de máxima lucratividade. Isso tem exigido cada vez mais que o projeto das malhas de controle seja baseado em rigorosos requisitos de desempenho e robustez.

Os ganhos de qualidade e produtividade alcançados na fabricação do produto final, proporcionado pela introdução constante dessas novas tecnologias, têm possibilitado uma melhor utilização dos recursos financeiros, implicando na implementação de melhorias e funcionalidades por parte dos engenheiros de processo, de forma a garantir uma melhor posição estratégica no mercado por parte das corporações.

Por outro lado, o desenvolvimento da ciência e tecnologia está diretamente ligado à construção e análise de modelos que reproduzam, com a maior precisão possível, o comportamento dos sistemas reais observados na natureza. Conceitualmente, um modelo matemático é a representação de um sistema real ou imaginário por meio de relações matemáticas, sendo muito importante a relação simplicidade versus fidelidade na obtenção de tais modelos. 
A modelagem e a identificação de sistemas dinâmicos são campos de estudos com diversas aplicações em engenharia de controle, principalmente na análise da estabilidade dos sistemas de controle em geral. Tais modelos possibilitam validar o comportamento funcional do sistema por intermédio da correlação entre causa e efeito (Aguirre, 2007), possibilitada pela análise dos dados observados. Os conhecimentos adquiridos sobre o processo por meio de modelagem matemática auxiliam no projeto do sistema de controle utilizado na automação da planta industrial.

A identificação de sistema pode ser então definida como sendo a modelagem matemática de sistemas dinâmicos utilizando dados reais obtidos do processo e, portanto, um método inerentemente experimental. O processo de identificação por sua vez é composto de várias etapas. Primeiramente, é recomendado a realização de uma simples análise do sistema observando suas propriedades básicas. Em seguida, com base nas informações obtidas, um modelo ou estrutura que represente o sistema dever ser escolhida. Nesse instante, a escolha adequada do modelo é muitas vezes definida mediante um compromisso entre precisão e simplicidade. Na prática, um modelo muito preciso nem sempre é o desejado se sua complexidade for muito alta. Em seguida, deve-se fazer a estimativa dos parâmetros do modelo a partir das medições efetuadas no sistema. Finalmente, deve ser realizada a validação do modelo estimado, sendo que essa etapa indica se o modelo obtido descreve o sistema modelado corretamente ou não.

\subsection{Sistemas Dinâmicos}

O estudo e análise de sistemas dinâmicos têm por objetivo representar, por meio de modelos matemáticos, fenômenos observados e sistemas de interesse com a finalidade de entender e controlar processos do mundo real. A teoria de sistemas surgiu da necessidade dos pesquisadores e cientistas em compreender o comportamento do meio a sua volta. 
Sistema é um conjunto de elementos interdependentes e combinados, de modo a formar um todo de maior complexidade, que apresentam certas relações de causa e efeito, possuindo determinado objetivo e realizando determinada função. Está presente em diversas áreas como engenharia, biologia, medicina, direito, sociologia, antropologia, história, ciências políticas, informática, administração, economia e finanças, etc.

Consequentemente, a teoria de sistemas é o estudo comportamental das interações entre os elementos que formam o sistema em análise quando sujeito a certas condições ou excitações. A natureza abstrata da teoria de sistemas ocorre devido ao fato de estar relacionado mais com propriedades matemáticas do que com a forma física ou conceitual das partes que o compõem. Seu objetivo é buscar soluções que possam ser implementadas por meio de ações apropriadas com a finalidade de alterar de maneira adequada o desempenho do modelo do sistema avaliado.

Sistemas dinâmicos são regidos por equações diferenciais cuja variável independente é o tempo e são representados na forma de blocos, como visto na Figura 4-1. Em aplicações reais, é mais fácil registrar as taxas de variação dos elementos observáveis e isso sugere o uso desse tipo de equação. Esse fato mostra que essas equações exerceram um papel fundamental no desenvolvimento da Engenharia e da Ciência. A compreensão, simplificação e solução de diversos problemas reais somente foi possível graças a essa promissora ferramenta matemática.

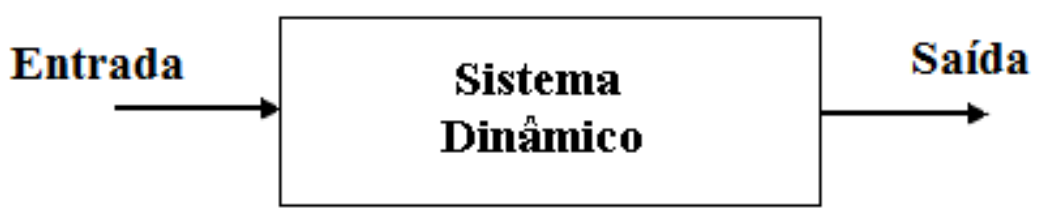

Figura 4-1. Esquema de um sistema dinâmico.

Nas últimas décadas, a teoria de sistemas lineares tem sido exaustivamente pesquisada. Os resultados obtidos têm influenciado de forma significativa o desenvolvimento das técnicas de controle empregadas na maioria das aplicações industriais. Aqui, muita 
atenção tem sido dada aos sistemas cuja representação pode ser feita por meio de equações lineares, sendo que vários métodos analíticos têm sido desenvolvidos para resolver os sistemas compostos por esse tipo de equação. Embora os sistemas físicos sejam intrinsecamente não lineares, técnicas aplicadas a sistemas lineares têm sido empregadas por meio de métodos de linearização desenvolvidos ou considerando o sistema operando numa região linear.

Por outro lado, devido à evolução dos sistemas computacionais, tem-se recentemente havido um grande interesse na análise de sistemas não lineares com foco na síntese e aplicação de estratégias de controle de processos inerentemente não lineares. Sua análise por intermédio da teoria de sistemas envolve em geral o estudo de modelos descritos por equações diferenciais não lineares no domínio do tempo. Para tais sistemas, os modelos são mais restritivos e são mais dependentes da aplicação. Além disso, a utilização dos métodos de estimação disponíveis nem sempre é trivial.

\subsubsection{Classificação dos Sistemas Dinâmicos}

Os sistemas podem ser classificados quanto à sua evolução no tempo em estáticos e dinâmicos. Conceitualmente, sistema dinâmico é aquele em que seu comportamento varia com o tempo, por exemplo, num capacitor o fluxo de carga entre seus terminais depende tanto do tempo como da fonte de alimentação. Em um sistema dinâmico, a saída atual depende da entrada atual e das passadas. Já o sistema é considerado estático quando suas propriedades são descritas independentemente do tempo, podendo variar espacialmente, por exemplo, numa resistência elétrica o fluxo de carga em seus terminais não depende do tempo, mas somente da fonte que a alimenta. Em um sistema estático, a saída atual depende apenas da entrada atual. Do ponto de vista da engenharia de controle, o estudo de sistemas dinâmicos abrange a modelagem, análise, síntese e simulação de sistemas físicos de interesse, tais como sistemas elétricos, mecânicos, hidráulicos, pneumáticos e térmicos, ou ainda, a combinação destes. 
Entretanto, o uso de técnicas e conceitos envolvendo esses sistemas não se restringe a uma área específica do conhecimento, podendo ser aplicados em outros tipos de sistemas, tais como sistemas biológicos, econômicos, de informação, de trânsito, etc. É importante destacar que os sistemas dinâmicos não são necessariamente de natureza física; porém, neste trabalho serão abordados somente os sistemas de interesse da engenharia.

No estudo de modelos matemáticos devem-se considerar algumas propriedades muito importantes apresentadas pelos sistemas dinâmicos e que influenciam diretamente no tipo de modelo a ser obtido. Dessa forma, os sistemas dinâmicos podem ser classificados de diversas formas, dentre elas:

- lineares ou não lineares;

- contínuos ou discretos;

- de parâmetros concentrados ou distribuídos;

- causais ou não causais;

- invariantes ou variantes no tempo;

- de equações homogêneas ou não homogêneas;

- autônomos e não autônomos;

- conservativos e dissipativos;

- estáveis ou instáveis.

Uma característica muito importante a ser observada no estudo de sistemas dinâmicos é a linearidade. Em sistemas não lineares não se pode aplicar o princípio da superposição, ficando mais difícil estabelecer uma relação causa e efeito entre sua entrada e saída.

\subsection{Sistemas Dinâmicos Não Lineares}

As não linearidades apresentadas pelo sistema em estudo influenciam diretamente na forma como este é analisado. Sistemas lineares podem ser estudados por métodos de análise 
de sistemas dinâmicos mais simples, os quais fazem uso de transformadas, como as de Laplace ou Fourier.

Em muitas plantas industriais, as estratégias de controle utilizadas baseiam-se em modelos de processos lineares, de primeira ordem ou em integradores puro, com tempo morto (Nikolaou \& Misra, 2003). Ao longo de décadas, as técnicas utilizadas na solução de problemas envolvendo sistemas lineares e invariantes no tempo (LTI) têm sido amplamente estudadas (Ljung, 1999). Portanto, a estimação dos parâmetros de qualquer sistema LTI desconhecido, dado suas entradas e saídas, já se tornou um problema de solução conhecida.

Visto que a grande maioria dos processos apresenta não linearidades, os controladores projetados, a partir de modelos lineares, não apresentam bom desempenho quando mudanças nas condições de funcionamento do processo acontecem. No caso de pequenas não linearidades, uma aproximação linear pode ser usada. No entanto, se as não linearidades forem significativas, essa aproximação não oferece uma boa resposta e o sistema deve ser descrito por meio de um modelo não linear.

Tal característica tem feito com que engenheiros e projetistas de sistemas de controle busquem novas metodologias para lidar com esta situação. O projeto de controladores não lineares, baseado no modelo do processo a ser controlado, têm se mostrado ao longo dos anos como uma solução viável. Dessa forma, as técnicas de identificação aplicadas em sistemas dinâmicos não lineares se tornaram uma ferramenta importante quando o objetivo é o controle e otimização dos processos industriais, tendo-se como resultado uma considerável melhora no desempenho das malhas de controle e, consequentemente, uma considerável redução de custos. Entretanto, o desenvolvimento de um modelo adequado aplicado na identificação de processos não lineares é fundamental e tem se tornado uma das atividades que mais demandam tempo no desenvolvimento de controladores não lineares baseados em modelo. Exemplos de sistemas não lineares são os seguintes: 
- sistemas com histerese;

- sistemas com descontinuidades;

- $\quad$ sistemas com zonas mortas;

Como visto nos parágrafos anteriores, matematicamente, um sistema dinâmico linear deve satisfazer o princípio da superposição. O princípio da superposição estabelece que, para um sistema dinâmico linear $\mathbf{h}(\mathbf{t})$, a resposta a diversas excitações aplicadas na entrada do sistema pode ser calculada mediante o somatório da resposta dos sinais aplicados individualmente, conforme pode ser observado na Figura 4-2. Essa característica possibilita simplificar a solução de equações diferenciais lineares complexas a partir de soluções mais simples.

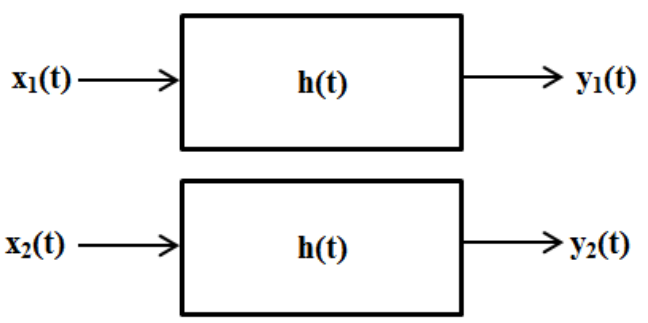

(a)

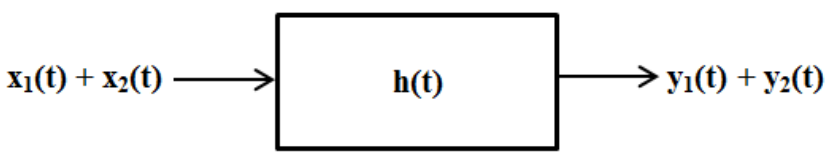

(b)

Figura 4-2. Princípio da superposição aplicado em um sistema linear.

Atualmente, em função da evolução das tecnologias de automação, existe uma quantidade significativa de dados disponíveis nos processos industriais, sendo que isso tem levado ao aumento no número de pesquisas de técnicas baseadas num conjunto de dados empíricos. Dentre as diferentes técnicas de identificação aplicadas a esses sistemas, os métodos baseados em redes neurais estão gradativamente se estabelecendo, não só no meio acadêmico, mas também na prática por intermédio de várias aplicações industriais.

\subsection{Modelagem de Sistemas Dinâmicos Não Lineares}

Modelagem matemática de um sistema dinâmico é a definição de um conjunto de equações que descrevem seu comportamento estático e dinâmico. Provavelmente, a maneira 
mais simples de avaliar um sistema não linear é usando uma onda senoidal como sinal de excitação. Com base na teoria de Sistemas Não Lineares (NLS), aplica-se uma onda senoidal pura na entrada de um sistema NLS, conforme mostrada na seguinte expressão:

$$
x(t)=A_{0} \cos \left(2 \pi f_{0} t+\theta_{0}\right)
$$

A Figura 4-3 mostra a saída de um sistema linear (a) e não linear (b) para uma excitação senoidal. A saída do sistema linear consiste numa onda senoidal, provavelmente com amplitude e fase modificadas. Por outro lado, o espectro de saída do sistema não linear conterá componentes espectrais adicionais, harmonicamente correlacionadas com a onda senoidal de entrada. Assim, a quantidade e forma dessas componentes indicam o nível de não linearidade do sistema analisado.

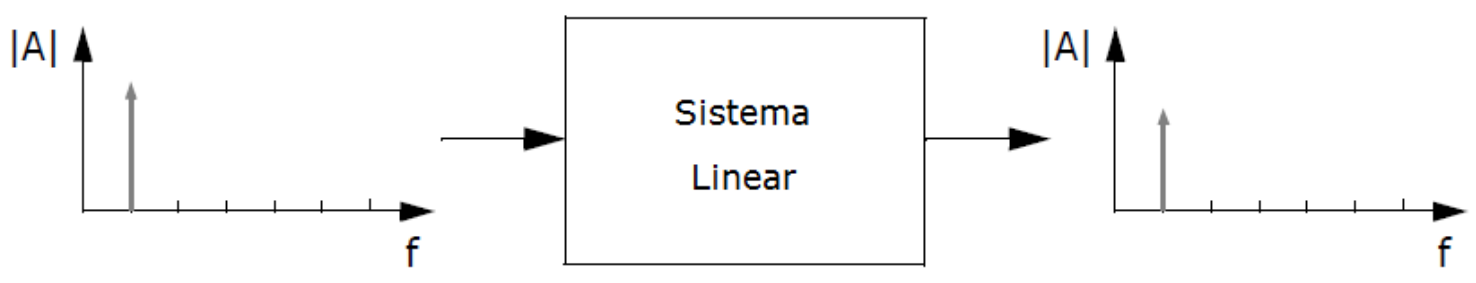

(a)

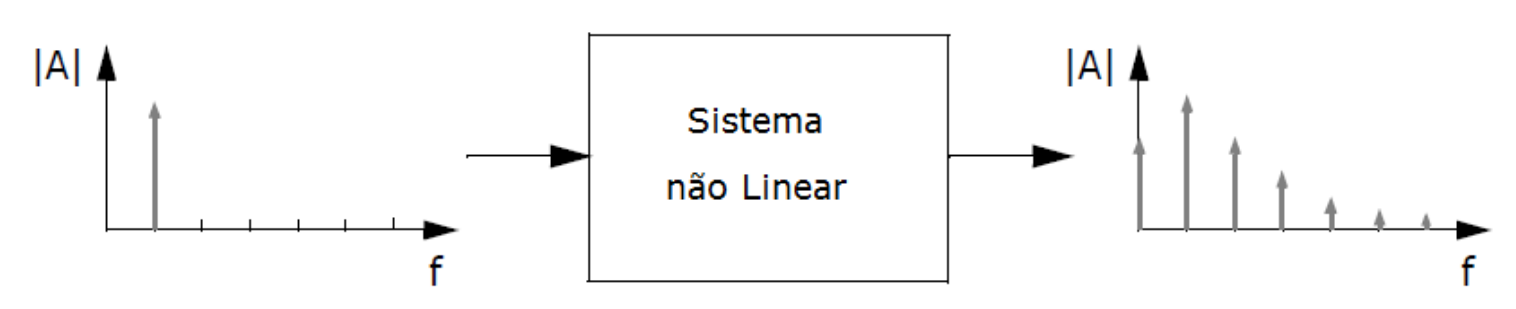

(b)

Figura 4-3. Resposta típica de (a) um sistema linear e (b) um sistema não linear para uma onda senoidal

A resposta do sistema não linear será a soma de todos os componentes harmônicos de acordo com a expressão (4-2), ou seja:

$$
y(t)=C_{0}+\sum_{n=1}^{\infty} C_{n} \cos \left(2 n \pi f_{0} t+\varphi_{n}\right)
$$


Nesse caso, o procedimento completo de identificação do sistema consiste na estimativa das amplitudes $\boldsymbol{C}_{\boldsymbol{n}}$ e fases $\boldsymbol{\varphi}_{\boldsymbol{n}}$ que estão relacionadas com a amplitude, frequência e fase do sinal de entrada. Este método de análise produz resultados extremamente precisos, no entanto, não é muito eficaz devido ao grande número de componentes necessárias para compor a saída $\mathbf{y}(\mathbf{t})$, além das variações de frequência e amplitudes apresentadas pelo sinal de entrada. Além disso, se considerado a distorção provocada pela intermodulação, esta análise se torna ainda mais complicada. Nesse caso, outro enfoque na solução do problema não linear deve ser usado.

Quando se estuda um sistema não linear, duas diferentes abordagens metodológicas podem ser consideradas. A primeira é baseada no estudo fenomenológico de cada evento não linear que interfere no comportamento global do sistema. As leis físicas não lineares que regem todos esses fenômenos devem ser obtidas. Essas leis podem ser usadas para criar um modelo teórico não linear do sistema. No entanto, para alguns processos reais, essa abordagem pode levar a um modelo muito complicado devido ao comportamento não linear complexo apresentado e, nesse caso, outra metodologia deve ser buscada.

A segunda abordagem consiste numa modelagem mais ampla, considerado o sistema não linear como um todo. Duas diferentes metodologias podem ser definidas em relação ao conhecimento disponível sobre as propriedades físicas do sistema. Primeiramente, tem-se o caso onde algumas propriedades físicas são conhecidas a priori. Então, a modelagem pode ser realizada utilizando esse conhecimento e o sistema é dito ser uma caixa cinza. Num segundo caso, não se tem conhecimento das propriedades físicas que definem o comportamento do sistema e, nessa situação, tal sistema é dito ser uma caixa-preta. Em ambos os casos, um modelo não linear generalizado é usado na identificação desse sistema. Vários modelos não lineares universais foram desenvolvidos nas últimas décadas. Tais modelos não lineares estão disponíveis em diversos trabalhos, por exemplo, modelo de Hammerstein, filtragem estendida 
de Kalman, modelo de Volterra, modelo Non-Linear Auto-Regressive Moving Average (NARMAX), modelo de Wiener, modelo MISO, modelo baseado em rede neural, modelo de filtragem de partículas, e algoritmo genético híbrido.

Billings et al. (1978) classificaram os modelos não lineares em três classes básicas: (a) modelos baseados em estruturas de blocos orientados não lineares (modelo de Wiener, modelo de Hammerstein, modelo Multiple Input Single Output - MISO), (b) modelos não paramétricos (modelo de Volterra) e (c) modelos paramétricos (NARMAX). No entanto, esta é apenas uma classificação preliminar, pois, os métodos de identificação baseados em blocos orientados, usando abordagem não paramétrica, foram divididos em três outras categorias. Todos estes modelos envolvem blocos, núcleos ou parâmetros que precisam ser estimados.

Em síntese, o modelamento matemático de sistemas dinâmicos pode ser dividido de duas formas, conforme pode ser visto na Figura 4-4: (a) modelagem por meio da descrição matemática do comportamento físico do sistema (Doebelin, 1980; Klamkim, 1987), ou (b) identificação de sistemas (Ljung et al., 1987). A grande vantagem do uso de modelos matemáticos na análise de sistemas dinâmicos é a facilidade de estudar esses sistemas sem ter que interagir fisicamente com os mesmos. Seu comportamento pode ser reproduzido com determinado grau de precisão por meio de métodos algébricos ou computacionais.

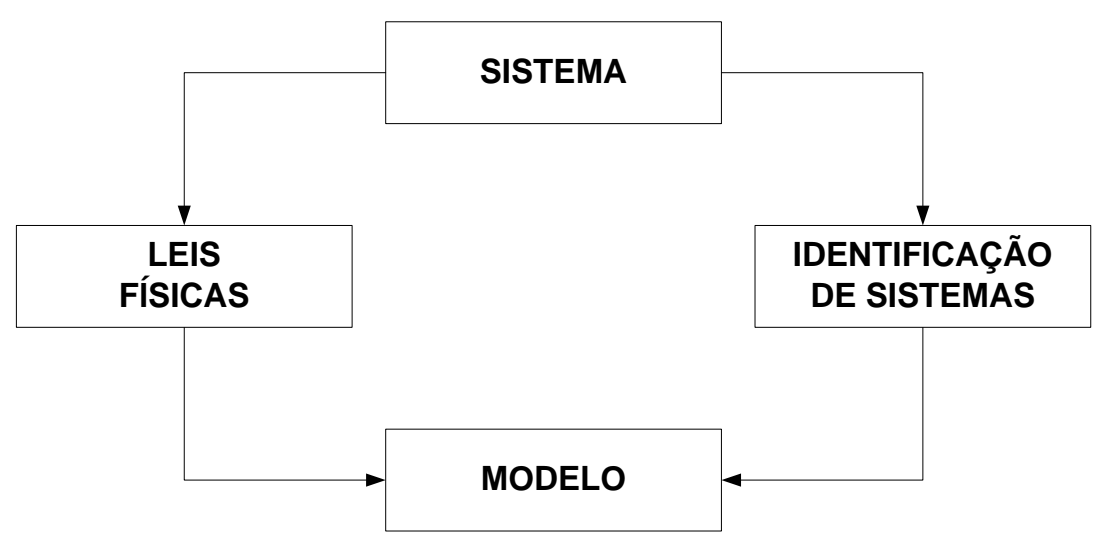

Figura 4-4. Esquema representando a modelagem de Sistemas.

De uma forma geral, os objetivos a serem alcançados com a modelagem de sistemas são os seguintes: 
- projeto de sistema de controle;

- predição;

- simulação;

- diagnóstico;

- otimização.

Em se tratando de novos desafios, a principal finalidade da modelagem de sistemas é possibilitar ao engenheiro de projetos um conhecimento mais profundo das características do sistema analisado, descobrindo-se as relações existentes entre as diversas variáveis envolvidas no problema, além de detectar a influência dessas variáveis no comportamento do sistema. Dessa forma, tornar-se-á possível abordar o problema em estudo como um todo, sendo permitido analisar simultaneamente as interações entre as variáveis.

\subsubsection{Identificação de Sistemas Dinâmicos Não Lineares}

Em muitas situações práticas, não está disponível aos engenheiros, projetistas e operadores um modelo matemático que descreva as relações entrada/saída do sistema. Em tais situações, uma possível alternativa seria obter um conjunto de dados das respectivas entradas e saídas do sistema desconhecido, para que de posse desses dados se inferir seu modelo dinâmico, realizando-se assim sua identificação. Pode-se então conceituar a identificação de sistemas como o campo que estuda a modelagem de sistemas dinâmicos a partir de dados experimentais.

De forma geral, a identificação é feita excitando a entrada do sistema, por exemplo, com um sinal aleatório, e observando o comportamento de sua saída ao longo do tempo. As etapas mínimas necessárias na identificação de um sistema dinâmico são as seguintes: (a) escolha do modelo paramétrico usado para estimar sua saída com base nos dados de entrada, (b) um critério de erro e (c) um algoritmo estatístico com a função de ajustar os parâmetros do 
modelo buscando a melhor aproximação possível. A Figura 4-5 mostra os principais blocos envolvidos na identificação de sistemas dinâmicos.

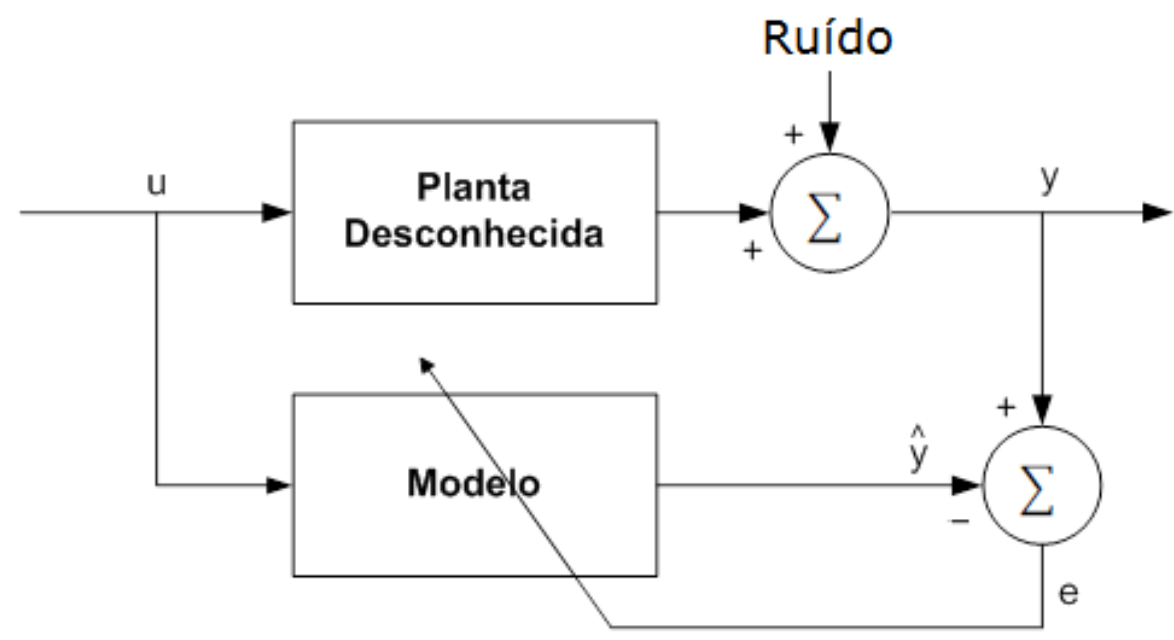

Figura 4-5. Diagrama de blocos para identificação de sistemas dinâmicos.

O modelo é colocado em paralelo com a planta e uma excitação $u$ é aplicada tanto na planta como no modelo a ser ajustado. Normalmente, na prática, os processos industriais possuem não linearidades e, em muitos casos, um ruído branco gaussiano é adicionado na saída do processo representando o ruído de medição. A saída desejada y é comparada com a saída estimada $\hat{y}$ pelo modelo, gerando-se assim um sinal de erro $e$. Esse erro é usado por um algoritmo para ajustar os parâmetros do modelo e, ao final desta fase, o sinal de erro deve ser o menor possível. Para fins de validação, novas amostras são então aplicadas tanto na planta como no modelo e suas respostas são comparadas.

É possível inferir propriedades importantes de um sistema dinâmico desconhecido observando os dados produzidos experimentalmente em sua saída. Takens (1981) provou em sua pesquisa que, em sistemas dinâmicos autônomos livres de ruído, o conjunto de amostras visto na equação (4-3) pode ser usado para criar uma trajetória num espaço euclidiano de tamanho $N$, capaz de conservar as constantes dinâmicas do sistema original, caso $N$ seja suficientemente grande. 


$$
X(n)=[x(n), x(n-\tau), \ldots x(n-(N-1) \tau)]
$$

onde $\tau$ é o atraso normalizado e $N>2 D_{e}$, onde $D_{e}$ é a dimensão do atrator. Embora tenha sido demonstrado primeiramente para sistemas autônomos, mais tarde foi estendido para sistemas não autônomos. Sistemas não autônomos são regidos por equações diferenciais, ou equações de diferenças, que dependem explicitamente do tempo $t$. Esse sistema pode ser transformado num sistema autônomo por meio da substituição de variáveis, onde o tempo é transformado em mais uma variável de estado.

Identificação de sistemas dinâmicos é o ajuste dos parâmetros de um sistema dinâmico a partir dos valores de entrada e saída atrasados no tempo. Fundamentalmente, a identificação de sistemas é composta de duas etapas. Primeiramente ocorre à incorporação, pelo modelo, do comportamento dado pelo histórico da entrada e saída, formando-se assim uma trajetória no espaço reconstruído e, em seguida, determina-se uma função $f$ que represente a trajetória reconstruída. Como não existe para sistemas não lineares uma forma algorítmica de encontrar essa função, esta tem de ser tratada no âmbito de aproximação de funções (Haykin, 2001).

Existem duas opções para realizar a aproximação de funções acima mencionadas, podendo-se usar um único mapeamento $f$ para representar todos os pontos no espaço de estados reconstruídos (modelagem global). Esse mapeamento normalmente é feito por meio do ajuste polinomial da trajetória. Existem muitos exemplos na literatura onde redes neurais têm sido aplicadas com sucesso na modelagem global, devido à sua capacidade de mapeamento universal (Haykin, 2001). Alternativamente, pode-se usar um mapeamento $\hat{f}$, composto por uma família de mapas, sendo que cada mapa ajusta apenas os agrupamentos de pontos inseridos em seu espaço de reconstrução (modelagem local), ao passo que o mapeamento completo será obtido por meio da concatenação desses mapas. Basicamente, esta metodologia divide o espaço de estado global em regiões locais e, em seguida, é obtido os 
modelos dinâmicos individuais de cada uma dessas sub-regiões. Em geral, os modelos obtidos possuem uma estrutura mais simples, com diferentes parâmetros entre as regiões. Esta estratégia que consiste em dividir para conquistar recebeu considerável atenção no passado.

Existem várias aplicações listadas na literatura que fazem uso desta estratégia. Por exemplo, os modelos baseados em múltiplos filtros de Kalman foram avaliados buscando melhorar a precisão na estimação de estados e em problemas de controle. Narendra et al. (1995; 1997) propuseram uma estrutura composta por múltiplos modelos variáveis e ajustáveis, aplicada em situações onde o sistema precisa agir em diversas condições de operação. Mudanças bruscas no ponto de operação do sistema, falhas nos sensores ou subsistemas e perturbações externas são exemplos de situações práticas. Nestes casos, a necessidade do uso de múltiplos modelos surge naturalmente, já que diferentes modelamentos matemáticos podem ser necessários para representar o comportamento da planta em cada um desses casos.

Recomenda-se para estudo mais detalhado, o uso das literaturas (Ljung et al., 1987) e (Aguirre, 2007) como referências na área de Identificação de Sistemas.

\subsection{Etapas Usadas na Identificação de Sistemas Dinâmicos}

Independentemente da metodologia usada, a identificação de sistemas é composta pelas seguintes etapas (Aguirre, 2007):

- Aquisição de dados: é nesta etapa que se realiza a geração ou obtenção dos dados de entrada e saída do sistema que serão usados na construção do modelo. Pode-se dividir essa etapa nos seguintes passos:

- Escolha apropriada dos sinais (estímulos) que serão aplicados na entrada do processo e definição adequada do tempo de amostragem.

- Realização da parte experimental com o objetivo de coletar os dados. 
- A definição de boas condições experimentais é crucial na determinação da qualidade final dos dados aquisitados e, consequentemente, do modelo produzido.

- Escolha do modelo representativo: Após uma análise criteriosa das características e comportamento do sistema a ser identificado, por exemplo, sua linearidade, determina-se o modelo representativo mais adequado para simular esse sistema. Existe uma diversidade muito grande de representações capazes de executar essa função, como exemplo, têm-se as equações diferenciais ordinárias ou parciais, funções de transferência, modelos ARX, ARMAX, NARX, NARMAX, modelos de espaço de estado, Redes Neurais, Sistemas Fuzzy, Neurofuzzy, etc.

- Escolha da estrutura do modelo: Nesse ponto, definida o modelo de representação, o próximo passo é definir uma estrutura para essa representação. Dependendo da estrutura escolhida, vários parâmetros devem ser definidos. Por exemplo, a dimensão do modelo, o número de pólos e zeros da função de transferência se for usado uma representação contínua, ou o número de termos para uma representação do NARMAX, ou ainda, a quantidade de neurônios e de camadas de uma rede neural, dentre outros. A escolha do modelo representativo e sua estrutura são muito importantes para que se consiga um modelo com boa precisão, sendo portanto fundamentais para o processo de identificação;

- Estimação de parâmetros: Nesta etapa determinam-se os valores adequados dos parâmetros que compõem o modelo, baseado nas informações obtidas nos passos anteriores. Nessa fase acontece, por parte dos projetistas, a seleção e uso dos algoritmos cuja função é realizar a estimação desses parâmetros. É importante observar que a grande maioria dos algoritmos utilizados com esse objetivo é 
baseada no método dos mínimos quadrados (MMQ) e suas variantes. Essa etapa se resume na determinação de um modelo por meio da estimação de seus parâmetros, dentre um conjunto de modelos candidatos, que represente adequadamente o sistema em estudo;

- Validação do modelo: Após a determinação do modelo para o sistema na etapa anterior, é fundamental proceder sua verificação observando se o mesmo é adequado, ou seja, se o modelo proposto agrupa as propriedades mais relevantes do sistema original. O resultado a ser obtido nessa avaliação depende da aplicação desejada para o modelo estimado e da quantidade dos dados obtidos do sistema original. Buscando realizar uma melhor avaliação a respeito da qualidade do modelo estimado, empregam-se normalmente nessa etapa e na anterior, conjuntos de dados diferentes. Uma maneira muito empregada na validação dos modelos é a comparação dos resultados obtidos na simulação do modelo com dados reais do sistema.

Pode-se dizer que, de maneira geral, o processo de identificação de sistemas envolve os seguintes fatores: um sistema, uma condição experimental, uma estrutura de modelo, um método de identificação e um critério de validação.

A Figura 4-6, a seguir, mostra um esquema resumido das etapas da identificação de sistemas (Ljung, 1999): 


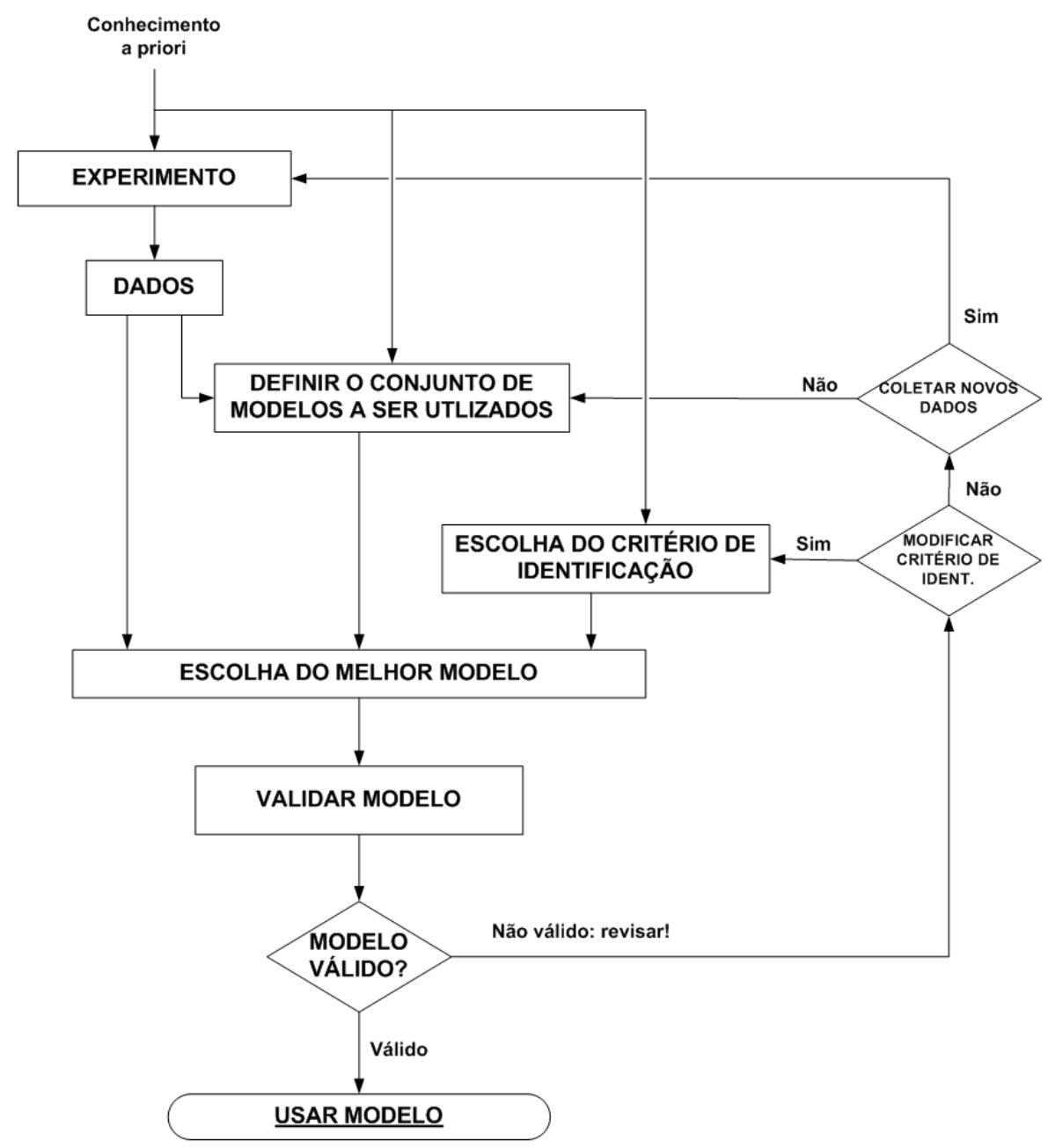

Figura 4-6. Procedimentos básicos usado na identificação de sistemas dinâmicos (adaptação de Ljung, 1999).

Analisando a Figura 4-6, pode-se descrever resumidamente o processo de identificação de sistemas dinâmicos da seguinte forma: (a) inicialmente, deve-se providenciar a realização da experimentação prática para aquisição dos dados de entrada e saída do sistema; de posse dos dados coletados, define-se o conjunto de modelos candidatos a ser utilizado na representação do sistema em estudo. O próximo passo é determinar qual o modelo dentro do conjunto de modelos candidatos que melhor atende às especificações desejadas. De posse do modelo escolhido, realizam-se então os testes para sua validação. Caso os resultados apresentados não sejam satisfatórios, providencia-se então a revisão dos passos anteriormente descritos. 
Atualmente, existe uma busca constante por métodos de identificação que sejam capazes de modelar sistemas dinâmicos não lineares usando dados reais de entradas e saída e que sejam robustos na presença de ruídos de medição na entrada, saída ou preferencialmente nos dois.

\subsection{Representação de Sistemas Não Lineares}

A tarefa mais difícil enfrentada pelos projetistas e pesquisadores em se tratando de sistemas não lineares consistem em lidar com o problema da dimensionalidade, também conhecido como curse of dimensionality. Esse fenômeno consiste em determinar tanto o número de elementos de treinamento requeridos para que um classificador tenha um bom desempenho, como uma função monotonicamente crescente da dimensão do espaço de características. Esta é uma característica comum das estruturas de modelos não lineares, uma vez que sistemas não lineares geralmente apresentam uma grande variedade de comportamentos dinâmicos complexos. Tal comportamento complexo apresentado pelos sistemas não lineares, aliado ao fato de que geralmente não é possível incorporar algum conhecimento a priori sobre a dinâmica do sistema no procedimento de identificação, tornase quase impossível estimar de forma satisfatória o modelo não linear de um processo físico.

De forma geral, o que pode ser obtido é um modelo adequado para atuar em torno do ponto de operação da aplicação de interesse. Esse fato reduz o problema envolvendo modelagem de sistema não linear num simples problema de ajuste de curva (Ljung, 2001).

Outro aspecto relativamente importante, envolvendo a modelagem matemática, é que a mesma pode se realizar em três maneiras de acordo com o nível de conhecimento utilizado na seleção de sua estrutura (Ljung et al., 1987), isto é, modelagem caixa branca, caixa cinza e caixa-preta. 


\subsubsection{Modelos Caixa Branca}

Modelagem a priori baseia-se na análise das leis fundamentais que regem o comportamento do sistema, no conhecimento de sua estrutura, e na descrição funcional de todos os subsistemas, com objetivo de criar modelos com capacidade de representar em todos os níveis de detalhes o sistema original. Esses modelos são frequentemente referidos como modelos morfológicos, já que os elementos individuais e suas interconexões estão muitas vezes relacionados diretamente à estrutura do sistema que está sendo modelado. Tipicamente, tais modelos incorporam um grande número de parâmetros que devem ser determinados experimentalmente.

Os modelos caixa-branca têm suas estruturas completamente definidas a partir de informações conhecidas a priori. Nesse caso, a forma da função matemática que descreve o comportamento dinâmico do sistema original é previamente conhecida. Os modelos caixacinza são identificados utilizando algum conhecimento a priori para simplificar os algoritmos de seleção de estrutura. Modelos de caixa-branca são derivados do primeiro princípio (First Principles) aplicados em seus respectivos campos científicos, e levando em conta a conexão entre os componentes do sistema. Exemplos típicos são os sistemas mecânicos e elétricos, onde as leis físicas podem ser usadas para prever a relação causa e efeito.

\subsubsection{Modelo de Espaço de Estado}

O modelo de espaço de estado de um sistema de tempo contínuo dinâmico pode ser obtido a partir do modelo de um dado sistema no domínio do tempo por uma equação diferencial ou pela função de transferência. Esses modelos são uma família de modelos flexíveis que podem ser utilizados na modelagem de diversos sistemas.

Considere o modelo de um sistema dinâmico de ordem $n$ representado por uma equação diferencial de enésima ordem vista na equação (4-4) a seguir: 


$$
\begin{gathered}
\frac{d^{n} y(t)}{d t^{n}}+a_{n-1} \frac{d^{n-1} y(t)}{d t^{n-1}}+\cdots+a_{1} \frac{d y(t)}{d t}+a_{0} y(t)= \\
\frac{d^{m} u(t)}{d t^{m}}+b_{m-1} \frac{d^{m-1} u(t)}{d t^{m-1}}+\cdots+b_{1} \frac{d u(t)}{d t}+b_{0} u(t) n>m
\end{gathered}
$$

A fim de se obter um processo sistemático para transformar equações diferenciais de ordem $n$ num espaço de estado representado por equações diferenciais de primeira ordem, assume-se que todas as condições iniciais da equação (4-4) sejam iguais a zero. Caso não existam derivadas presentes no lado direito de (4-4), tem-se uma versão simplificada do sistema descrito pela equação (4-5).

$$
\frac{d^{n} y(t)}{d t^{n}}+a_{n-1} \frac{d^{n-1} y(t)}{d t^{n-1}}+\cdots+a_{1} \frac{d y(t)}{d t}+a_{0} y(t)=u(t)
$$

\subsubsection{Modelos Caixa-preta}

Em contraste, na abordagem a posteriori, realizam-se tentativas para modelar o sistema sem fazer suposições sobre sua estrutura. Muitas vezes, essa abordagem é também chamada de modelagem caixa-preta, uma vez que o modelo resultante é simplesmente uma estrutura que transcreve o comportamento do sistema. Esta classe de modelos descreve a relação entre as entradas e saídas do sistema, mas não fornecem informações estruturais ou funcionais sobre o sistema ou seus componentes. No entanto, eles podem atuar como uma referência na qual os modelos morfológicos podem ser validados. Assim, a modelagem caixapreta pode fornecer os meios necessários para validar modelos morfológicos, fornecendo-se assim a visão funcional quando esse for o objetivo final.

\subsubsection{Modelos Caixa Cinza}

Essa classe é composta por modelos híbridos que possui, numa mesma estrutura, as duas abordagens descritas nas classes anteriores. Esses modelos híbridos não possibilitam um 
conhecimento tão grande do comportamento da planta quanto os modelos caixa branca, mas fornecem informações suficientes para não pertencerem à classe caixa-preta.

Estimadores híbridos têm por objetivo estimar tanto parâmetros como estados, por meio da combinação do conhecimento do modelo do processo com a habilidade e a capacidade do mapeamento dos dados de entrada/saída.

\subsection{Objetivos da Identificação de Sistemas}

Em geral, há duas funções básicas para os modelos obtidos por meio de técnicas de identificação de sistema: entendimento e controle. No projeto de sistemas de controle, particularmente em sistemas de controle preditivo, os modelos são necessários para prever a resposta da planta a uma entrada específica, com objetivo de projetar um controlador. Geralmente, é desejável obter o modelo mais simples possível capaz de descrever a dinâmica da planta a ser controlada.

A outra aplicação da identificação de sistemas dinâmicos é adquirir conhecimento sobre a operação de um sistema. Neste caso, deseja-se extrair o máximo de informações possíveis a partir dos dados de entrada/saída. Muitas vezes, os modelos identificados com objetivo de adquirir conhecimento sobre o processo são muito mais complexos do que aqueles usados no controle.

Uma boa revisão sobre a aplicação de estruturas caixa-preta usados na identificação dos sistemas não lineares é relatado em Sjöberg et al. (1994; 1995) e Juditsky et al. (1995). Em particular, em Juditsky et al. (1995), os fundamentos matemáticos das técnicas descritas no Sjöberg et al. (1995) são abordados. A teoria da identificação de sistemas não lineares utilizando modelos polinomiais é introduzida em Chen \& Billings (1989), enquanto Narendra \& Parthasarathy (1990) em seu trabalho, tratam de forma objetiva a aplicação de RNAs na identificação de sistemas dinâmicos não lineares. 



\section{Capítulo V}

\section{Aspectos de Colunas de Destilação e Sensores Virtuais}

\subsection{Introdução}

Eficiente no processo de separação de uma mistura líquido-líquido, a destilação é uma operação unitária muito importante na indústria de processos químicos, principalmente nas indústrias do setor sucroenergético e petroquímico. Ela consiste na separação de uma mistura (líquido-líquido) em duas correntes de diferentes composições, uma rica em componentes com menor ponto de ebulição (mais volátil) chamado destilado, e outra rica em componentes com maior ponto de ebulição (menos volátil) chamado resíduo ou produto de fundo; pelo fornecimento de calor, que irá vaporizar a substância mais volátil primeiro. Esse processo para ser realizado exige grandes quantidades de energia e, em muitas plantas industriais, essa operação pode envolver cerca de 30 a $40 \%$ do total de recursos usados com investimentos e gastos com energia (Yang et al., 1997). Os requisitos de energia numa planta de destilação podem ser reduzidos por meio do projeto ótimo da coluna ou quando existe um sistema de controle capaz de mantê-la nas condições ideais.

Um controle pobre da composição do destilado pode implicar em grandes períodos operando em condições críticas, levando à produção de produtos com uma pureza acima do necessário e, consequentemente, provocando um consumo excessivo de energia, ou ainda, obtendo produtos que não atenda aos valores mínimos de qualidade. Dessa forma, o controle preciso e robusto da coluna de destilação tem como finalidade aumentar a rentabilidade da planta por meio da economia de energia e da melhora na recuperação do produto final. 
Uma interessante alternativa, mas ainda pouco utilizada, são os sensores ou analisadores virtuais, também conhecidos como soft sensors. Esses analisadores virtuais são algoritmos matemáticos, utilizando-se de variáveis mais fáceis e/ou mais rápidas de serem medidas, os quais inferem ou estimam o valor de outras variáveis. Existem várias formas de se obter o modelo representativo do comportamento dinâmico da composição numa coluna de destilação em função de um determinado fluxo de alimentação. Esse modelo pode ser baseado num estudo fenomenológico rigoroso, numa rede neural, ou ainda, por meio de um estimador determinístico ou estocástico.

\subsection{Colunas de Destilação Binária}

Destilação binária é usada para separar uma mistura binária em dois produtos com diferentes composições. O conceito básico dessa operação unitária consiste em poder separar uma mistura composta de dois líquidos puros, com diferentes pontos de ebulição (diferença de volatilidade), por meio do seu aquecimento, devendo-se a temperatura ficar entre os respectivos pontos de ebulição. Esse processo consiste no aquecimento da mistura líquida até seu componente mais volátil passar para a fase vapor e então, por condensação, resfriá-lo para que este componente retorne à fase líquida.

A separação ocorre numa coluna onde o calor é adicionado ao sistema no refervedor (base da coluna) e removido pelo condensador (topo da coluna). Partindo-se do refervedor, um fluxo de vapor se desloca na direção do condensador, e um fluxo de líquido que é armazenado no tambor de refluxo localizado na parte superior da coluna desloca-se na direção do refervedor. Ocorrendo o contato entre essas duas correntes, o componente volátil é enriquecido na fase de vapor e o componente mais pesado é concentrado na fase líquida (Lundström, 1995). Ao contrário da evaporação e secagem, onde geralmente deseja-se concentrar o componente menos volátil, descartando-se o componente mais volátil que 
geralmente é a água, na destilação o principal objetivo é obter o componente mais volátil na sua forma mais pura. Por exemplo, a remoção da água na purificação (destilação) do etanol.

Entre as vantagens apresentadas pela coluna de destilação binária, as mais importantes são: (a) operação simples; (b) baixo investimento inicial quando comparada com outros processos de separação, tais como a absorção, sublimação, filtração, evaporação; (c) muitas vezes é considerado um processo com baixo risco operacional. Para a separação de componentes com volatilidade relativa acima de 1,2, o processo de destilação torna-se difícil de ser superado pelos métodos de separação acima mencionados. Entretanto, como desvantagem, o processo de destilação apresenta uma baixa eficiência energética, além da necessidade de estabilidade térmica por parte dos componentes em seus pontos de ebulição. Esse método não é eficiente na separação de componentes com alto ponto de ebulição presentes em baixas concentrações e em grandes volumes.

\subsubsection{Principais Componentes de Colunas de Destilação}

Colunas de destilação são compostas por vários componentes, cada um dos quais é usado para transferir energia térmica ou melhorar a transferência de material. Uma coluna típica contém vários componentes, dentre os quais se podem destacar:

- vaso vertical onde é realizada a separação dos componentes líquidos;

- componentes internos da coluna, tais como bandejas e/ou embalagens que são utilizadas para aumentar a separação de componentes;

- refervedor para proporcionar a vaporização necessária para o processo de destilação;

- condensador para resfriar e condensar o vapor que deixa o topo da coluna;

- tambor de refluxo para segurar o vapor condensado a partir do topo da coluna de modo que o líquido (refluxo) pode ser reciclado para a coluna. 
O diagrama de uma unidade de destilação típica, com alimentação única e duas correntes de produto, é mostrado na Figura 5-1.

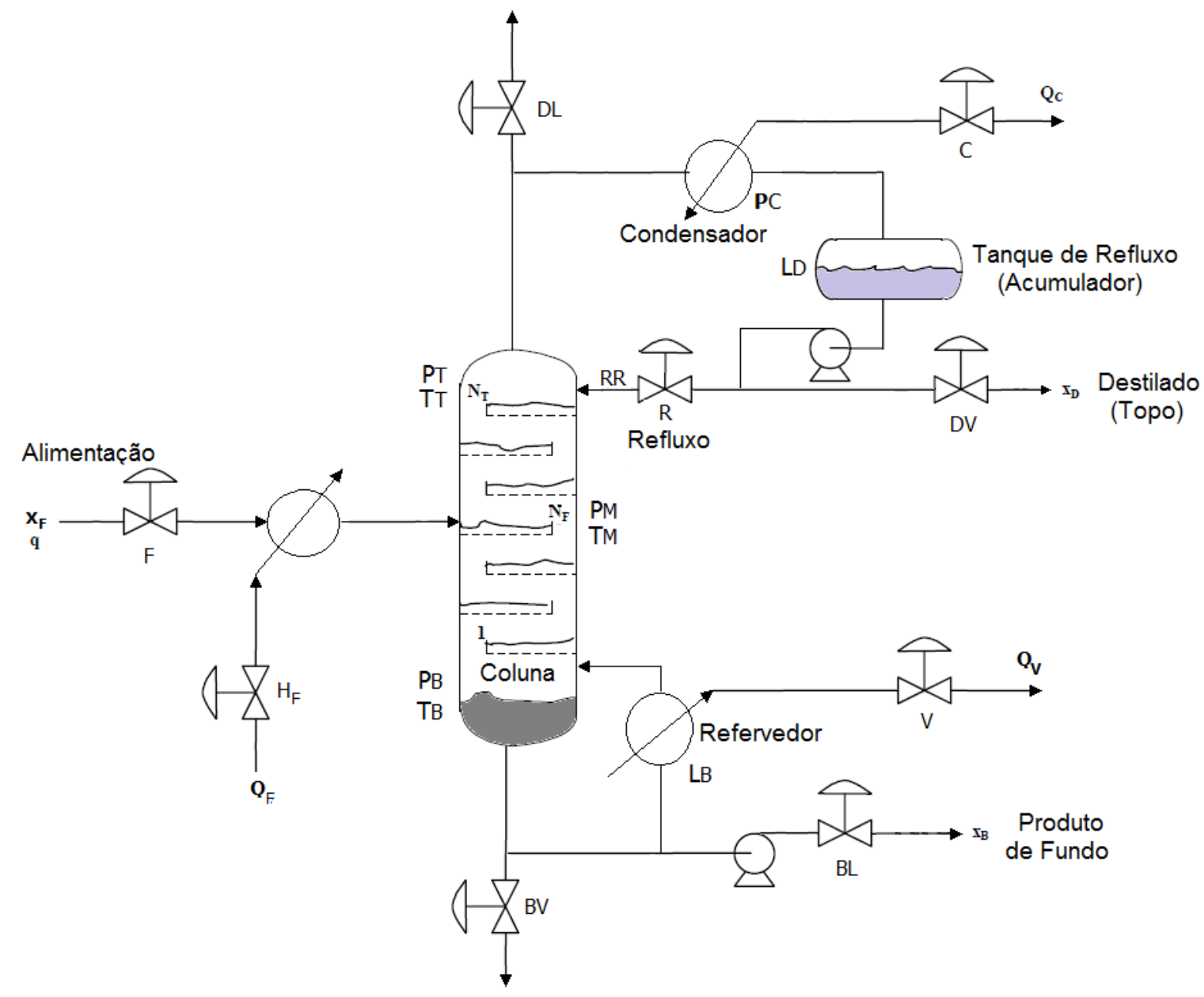

Figura 5-1. Representação de uma coluna de destilação.

onde:

$\mathrm{B}_{\mathrm{L}} \quad$ é a vazão de produto de fundo na fase líquida

$\mathrm{B}_{\mathrm{V}} \quad$ é a vazão de produto de fundo na fase vapor

C é a vazão do fluido de resfriamento no condensador

$\mathrm{D}_{\mathrm{L}} \quad$ é a vazão de destilado na fase líquida

$\mathrm{D}_{\mathrm{V}} \quad$ é a vazão de destilado na fase vapor

F é a vazão de alimentação

$\mathrm{H}_{\mathrm{F}} \quad$ é a vazão fluido aquecimento da alimentação 
$\mathrm{L}_{\mathrm{B}} \quad$ é o nível no refervedor

$\mathrm{L}_{\mathrm{D}} \quad$ é o nível no tambor de refluxo

$\mathrm{N}_{\mathrm{F}} \quad$ é o número do prato de alimentação

$\mathrm{N}_{\mathrm{T}} \quad$ é o número total de pratos

$\mathrm{P}_{\mathrm{B}} \quad$ é a pressão no fundo da coluna

$\mathrm{P}_{\mathrm{C}} \quad$ é a pressão no condensador

$\mathrm{P}_{\mathrm{M}} \quad$ é a pressão intermediaria da coluna

$\mathrm{P}_{\mathrm{T}} \quad$ é a pressão no topo da coluna

q é a condição termodinâmica da alimentação ( 0 para vapor saturado, 1 para líquido saturado)

$\mathrm{Q}_{\mathrm{C}} \quad$ é a carga térmica do condensador

$\mathrm{Q}_{\mathrm{F}} \quad$ é a carga térmica do aquecedor

$\mathrm{Q}_{\mathrm{V}} \quad$ é a carga térmica do refervedor

R é a vazão de refluxo

$\mathrm{R}_{\mathrm{R}}$ é a razão de refluxo, $\mathrm{R}_{\mathrm{R}}=\mathrm{R} / \mathrm{D}_{\mathrm{V}}$

$\mathrm{T}_{\mathrm{B}}$ é a temperatura no fundo da coluna

$\mathrm{T}_{\mathrm{M}}$ é a temperatura intermediaria da coluna

$\mathrm{T}_{\mathrm{T}}$ é a temperatura no topo da coluna

V é a vazão do fluido de aquecimento do refervedor

$\mathrm{X}_{\mathrm{B}}$ é a fração molar da substância residual

$\mathrm{X}_{\mathrm{D}}$ é a fração molar da substância destilada

$\mathrm{X}_{\mathrm{F}}$ é a fração molar do componente da alimentação 


\subsubsection{Princípio de Funcionamento}

Seja uma coluna de destilação, conforme representado na Figura 5-1, composta por N bandejas. Através da bandeja $\mathrm{N}_{\mathrm{F}}$, a coluna é então alimentada por uma mistura binária com fluxo molar F e composição $X_{Z}$, gerando fluxos de efluentes $D$ e B com composições $X_{D}$ e $\mathrm{X}_{\mathrm{B}}$, respectivamente. A mistura de alimentação da coluna de destilação pode estar na forma líquida, de vapor, ou mistura líquido-vapor. Além de estar localizada em qualquer ponto da coluna, embora exista uma localização ideal para a bandeja de alimentação devendo ser determinada e empregada. Mais de uma corrente de alimentação pode ser fornecida ao sistema, e mais de um produto pode ser extraído.

Tradicionalmente, a maioria das colunas de destilação foi construída a partir de um conjunto de bandejas distintas. Cada bandeja é projetada para possibilitar o contato entre o vapor e o líquido em cada estágio da coluna. Os estágios podem ser numerados de cima para baixo ou de baixo para cima. O componente que sai pelo topo da coluna é chamado de produto de cabeça, overhead, produto de topo, destilado, ou produto destilado. Produto destilado pode ser líquido, vapor ou ocasionalmente ambos, dependendo do tipo de condensador usado. Na maioria das vezes, a vazão de destilado é atribuída o símbolo $\mathrm{D}$, e a composição $\mathrm{X}_{\mathrm{D}}$. $\mathrm{O}$ componente retirado na parte inferior da coluna é chamado de produto final, ou fundo, representado pelo símbolo $\mathrm{B}$, com composição $\mathrm{X}_{\mathrm{B}}$. Em alguns casos, geralmente no refino de petróleo, um ou mais produtos intermediários ou sidedraw podem ser retirados da coluna.

No processo de destilação, o vapor que sai pelo topo da coluna passa por um condensador, onde é parcialmente ou totalmente condensado. O líquido resultante é mantido temporariamente no tanque de refluxo. Uma corrente de líquido é retirada do tanque e é inserida na bandeja superior da coluna como refluxo (R) para promover a separação. A parte acima da bandeja de alimentação na coluna é chamada de seção de retificação. Nesta seção, o 
vapor é enriquecido pelo contato com o refluxo. A parte da coluna abaixo da bandeja de alimentação é chamada de seção de esgotamento. A parte líquida da alimentação serve como o refluxo para esta seção. A pressão de operação da coluna é tipicamente controlada ajustando-se a retirada de calor no condensador. A base da coluna é normalmente usada como reservatório para armazenamento de líquido que é deixado pela bandeja inferior. Um trocador de calor chamado de refervedor é usado para aquecer a mistura líquida armazenada no fundo da coluna. $\mathrm{O}$ vapor resultante é retornado à coluna por meio das bandejas três ou quatro. Em uma coluna normal, os gradientes de temperatura e pressão são de baixo para cima.

A coluna de destilação binária pode ser observada do ponto de vista de controle, como um sistema multivariável (MIMO) $5 \times 5$ (ver Figura 5-1), ou seja, há cinco variáveis que podem ser manipuladas para o controle: vazão de refluxo $\mathrm{R}$, vazão do vapor $\mathrm{V}$ proporcional à troca de calor no refervedor $Q_{B}$, vazão do destilado $D_{L}$, vazão do produto de fundo $B_{L}$ e a vazão do condensador $\mathrm{C}$ responsável pela retirada de calor; e cinco variáveis controladas, as pressões na base, intermediária ou no topo $\mathrm{P}$, o nível do refervedor $\mathrm{L}_{\mathrm{B}}$ e o nível do tanque de refluxo $L_{D}$, e as composições do produto de fundo e destilado $X_{B}$ e $X_{D}$, respectivamente. As perturbações podem ocorrer na vazão de alimentos $\mathrm{F}$ e em sua composição $\mathrm{X}_{\mathrm{F}}$.

Existe um grande número de possibilidades que podem ser usadas como estratégias empregadas no controle de colunas de destilação. Na Tabela 5-1 são listados alguns pares de variáveis PV-MV usados no controle de uma coluna de destilação. 
Tabela 5-1 - Estruturas de controle empregadas nas colunas de destilação.

\begin{tabular}{|c|c|c|c|c|}
\hline \multirow{2}{*}{$\begin{array}{c}\text { Nome da } \\
\text { estrutura }\end{array}$} & \multicolumn{2}{|c|}{ Malha de controle da qualidade da separação } & \multicolumn{2}{c|}{$\begin{array}{c}\text { Malha de controle dos níveis dos } \\
\text { vasos de topo e fundo }\end{array}$} \\
\cline { 2 - 5 } & MV & PV & MV & PV \\
\hline \multirow{2}{*}{ R-V } & R & Qualidade do topo & D & nível do topo \\
\cline { 2 - 5 } & $\mathrm{V}$ & Qualidade da base & B & nível do fundo \\
\hline \multirow{2}{*}{ D-V } & D & Qualidade do topo & R & nível do topo \\
\cline { 2 - 5 } & V & Qualidade da base & B & nível do fundo \\
\hline \multirow{2}{*}{ RR-V } & RR & Qualidade do topo & D & nível do topo \\
\cline { 2 - 5 } & $\mathrm{V}$ & Qualidade da base & B & nível do fundo \\
\hline \multirow{2}{*}{ R-B } & R & Qualidade do topo & D & nível do topo \\
\cline { 2 - 5 } & $\mathrm{B}$ & Qualidade da base & V & nível do fundo \\
\hline \multirow{2}{*}{ RR-BR } & RR & Qualidade do topo & D & nível do topo \\
\cline { 2 - 5 } & BR & Qualidade da base & V & nível do fundo \\
\hline
\end{tabular}

Na prática, as colunas de destilação são controladas de forma hierárquica (Buckley et al., 1985; Luyben, 1992; Wolff \& Skogestad, 1996), ou seja, primeiro são projetados os controladores para o nível e pressão. Normalmente, em malhas de controle com múltiplas entradas e saídas, regulam-se a pressão e os níveis no tanque de refluxo e refervedor, de modo que seja mantido o estoque de materiais e, garantindo assim, uma operação segura da coluna e evitando a ocorrência de drenagens e inundações (Luyben, 1992). Além disso, as dinâmicas das malhas de controle das composições e dos níveis são desacopladas, sendo que os controles de qualidade dos produtos de fundo e do topo são simplificados por meio da redução do modelo da coluna para um sistema MIMO $2 \times 2$ (Skogestad et al. 1990;. Luyben, 1992).

Neste trabalho, será assumido que os fluxos são usados para controlar os níveis $L_{B} \mathrm{e}$ $L_{D}$ no refervedor e do tanque de refluxo, respectivamente, enquanto que a pressão é regulada pelo calor retirado no condensador por meio da vazão $C$ do fluido de resfriamento no condensador. As entradas manipuladas restantes, vazões de vapor do refervedor e do refluxo $V$ e $R$, são usados para regular as composições $X_{D}$ e $X_{L}$. Esta configuração apresenta a vantagem de ser praticamente independente dos ajustes das malhas de controle dos níveis (Skogestad, 1997). Outras configurações de controle considerando os acoplamentos entre as 
malhas dos níveis, resultando num sistema de controle multivariável $4 \times 4$ (Riggs \& Huang, 2002) ou $5 \times 5$ (Lundström et al., 1995), podem ser também utilizadas.

Com o propósito de facilitar o entendimento do presente trabalho, a seguir é apresentado o processo de destilação de etanol para a produção de álcool hidratado.

\subsection{Estudo da Produção do Álcool Hidratado em Destilarias de Etanol}

Após o processo de fermentação, tem-se uma mistura líquida contendo vários componentes, dentre os quais o etanol e a água. Uma vez que a concentração de etanol é bastante baixa, não superior a 10\% em volume, é necessário utilizar uma operação unitária

para concentrá-lo. Uma possibilidade é efetuar a destilação do mosto fermentado. Tal destilação pode ser realizada utilizando-se vários equipamentos operando continuamente ou em batelada.

Álcool hidratado é a denominação dada ao álcool com graduação alcoólica em torno de 93,2 ${ }^{\circ}$ INPM, em geral utilizado como combustível automotivo. No processo de destilação para obtenção do álcool etílico (hidratado) a destilação em estágio simples (destilação flash) não é apropriada. Dessa forma faz-se o uso de sistemas compostos por vários sistemas simples, resultando num equipamento multiestágios, no qual é possível, em princípio, obter componentes com grau de pureza mais elevado. Uma unidade de destilação alcoólica é ilustrada na Figura 5-2 a seguir. 


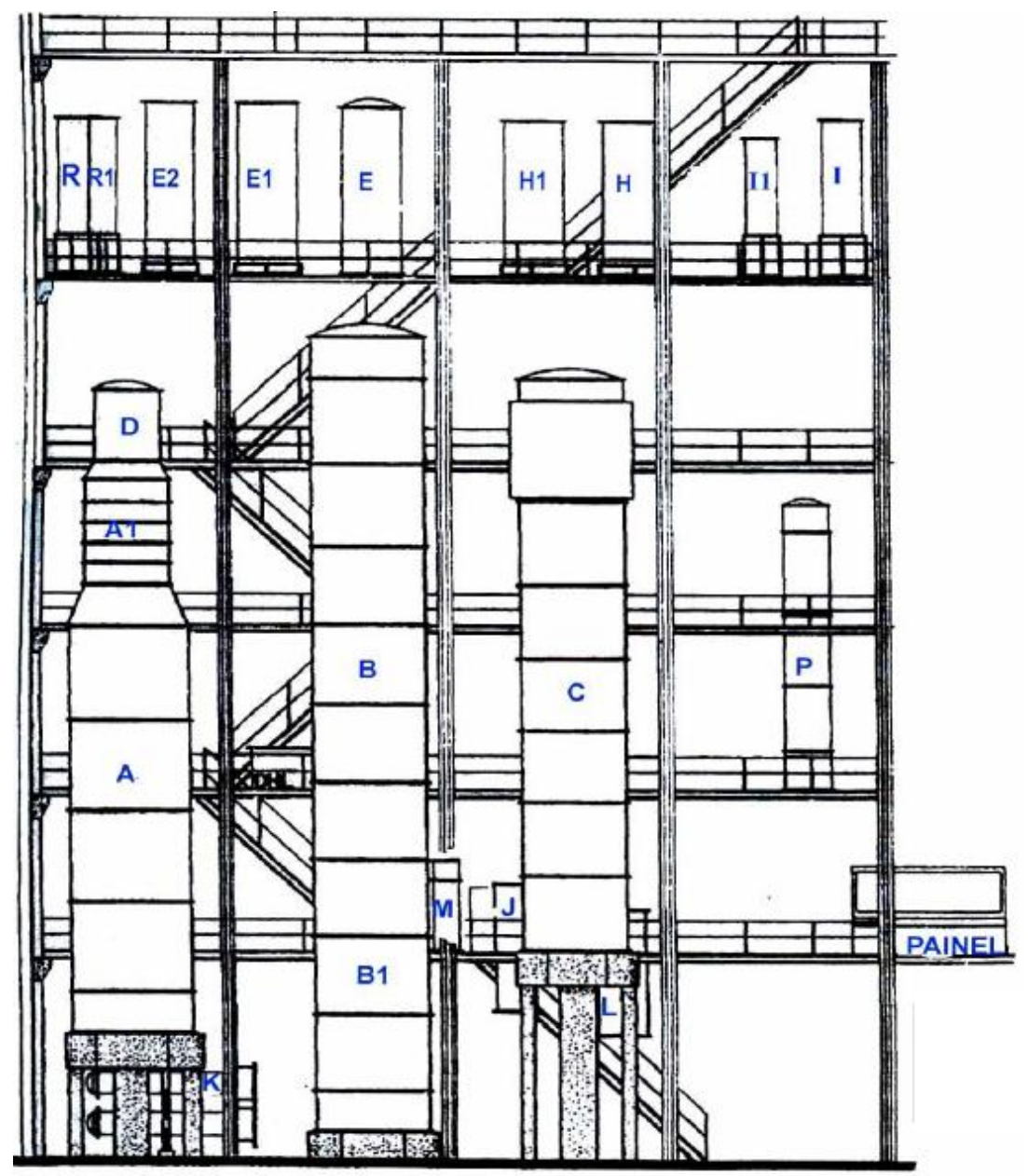

Figura 5-2 - Vista esquemática de uma unidade de destilação alcoólica.

A coluna "A", conhecida como coluna de esgotamento do vinho, possui de 15 a 20 bandejas. Nessa etapa é produzida uma mistura chamada de flegma, com concentração de 35 a $65{ }^{\circ} \mathrm{GL}$ e, como subproduto a vinhaça. A coluna "A1" é composta por 8 bandejas e seu objetivo é elevar o teor alcoólico e a depuração do vinho que consiste na evaporação dos produtos mais voláteis. Sobreposta à coluna "A1" tem-se a coluna “D”, ela é composta por 6 bandejas e é separada da coluna "A1" por uma bandeja cega. A interligação dessas colunas é feita por uma tubulação em forma de "U", tendo como função concentrar o álcool de segunda.

A coluna de retificação se caracteriza por apresentar uma seção de esgotamento (B1) e uma coluna de concentração ou enriquecimento (B). Nesta coluna o flegma é concentrado de 86 a $97{ }^{\circ} \mathrm{GL}$, ocorrendo ainda a separação dos produtos de cauda (óleo fúsel, flegmaça), e de cabeça (álcool hidratado, aldeídos e ésteres). O aquecimento das colunas "A" e "B" é 
realizado pela injeção de vapor (escape ou vegetal) no fundo de cada delas, ou indiretamente através do trocador-evaporador, garantindo dessa forma, a pressão e temperatura necessárias ao longo da coluna.

\subsubsection{Procedimento de Destilação do Álcool Hidratado}

Em regime normal de produção, o inicio do processo consiste no bombeamento do vinho centrifugado oriundo da dorna volante para caixa de vinho no topo da destilaria, ou diretamente para o aquecedor de vinho "E", onde sofre aquecimento com os vapores da coluna retificadora "B". Para separação do álcool dos demais componentes do vinho, empregam-se várias destilações específicas, operações que se baseiam na diferença entre os pontos de ebulição das substâncias.

Em seguida, o vinho pré-aquecido a uma temperatura na faixa de 70 à $75^{\circ} \mathrm{C}$ é levado ao conjunto de recuperadores ou trocador de calor "K", onde é aquecido por meio da vinhaça que é retirada como produto de fundo da coluna "A", alcançando uma temperatura em torno de 90 à $94{ }^{\circ} \mathrm{C}$, e em seguida alimenta a Coluna "A1". A vinhaça, antes de sair da coluna "A", circula através do "K" (aquecedor indireto), vaporizando-se através da troca de calor com o vapor, de modo a manter a coluna aquecida e reduzir o volume de vinhaça.

Na coluna "A1" o vinho é aquecido por meio dos vapores que sobem da calandra, entrando em ebulição, e sofrendo uma epuração onde é retirada a maior parte das impurezas presentes no vinho, principalmente os produtos leves (produtos de cabeça) que sobem para a coluna "D" situada na parte superior da Coluna "A1".

A coluna "D" é aquecida pelos vapores da coluna "A1", que recirculam na coluna, acumulando os produtos de cabeça. Aqui é extraída (máximo de 10\%) uma parte de álcool de segunda, com graduação de 93 a $95^{\circ} \mathrm{GL}$. Os vapores alcoólicos são condensados e tornados através dos condensadores "R" e "R1". 
Da base da coluna "A1", o vinho segue para a coluna "A", aonde vai descendo e diminuindo o teor alcoólico até atingir à base da coluna "A", originando assim a vinhaça. Os vapores da bandeja 16 ou 18 ou 24, dependendo do aparelho, são retirados da coluna "A" e alimentam a coluna "B", onde são concentrados em torno de 96 a 96,3 GL. A corrente de líquido descendente da coluna "B" vai diminuindo seu teor alcoólico até atingir à base da coluna "B1", à temperatura de $\pm 105^{\circ} \mathrm{C}$, recebendo a denominação de flegmaça (praticamente isenta de álcool).

Na coluna "B", os vapores vão se enriquecendo à medida que sobem e as impurezas, principalmente álcoois homólogos superiores, são concentradas em regiões apropriadas e devem ser retiradas para não afetar a qualidade do álcool. Essas impurezas são conduzidas ao decantador de óleo fúsel. Os vapores provenientes da coluna "B" são enviados aos condensadores "E", "E1" e "E2", sendo os dois últimos resfriados com auxílio de água, extraindo-se parte dos vapores condensados na forma de álcool de segunda, rico em impurezas de cabeça. O álcool hidratado de 92,6 a 93,80 ${ }^{\circ}$ INPM que é obtido no topo desta coluna possui melhor qualidade do que o obtido nos condensadores, pois o mesmo sofre um processo de pasteurização. Na base da coluna "B" é retirado o álcool fraco que retorna para a coluna "A". A Figura 5-3 a seguir mostra os equipamentos utilizados nos processos de destilação, retificação e desidratação. 


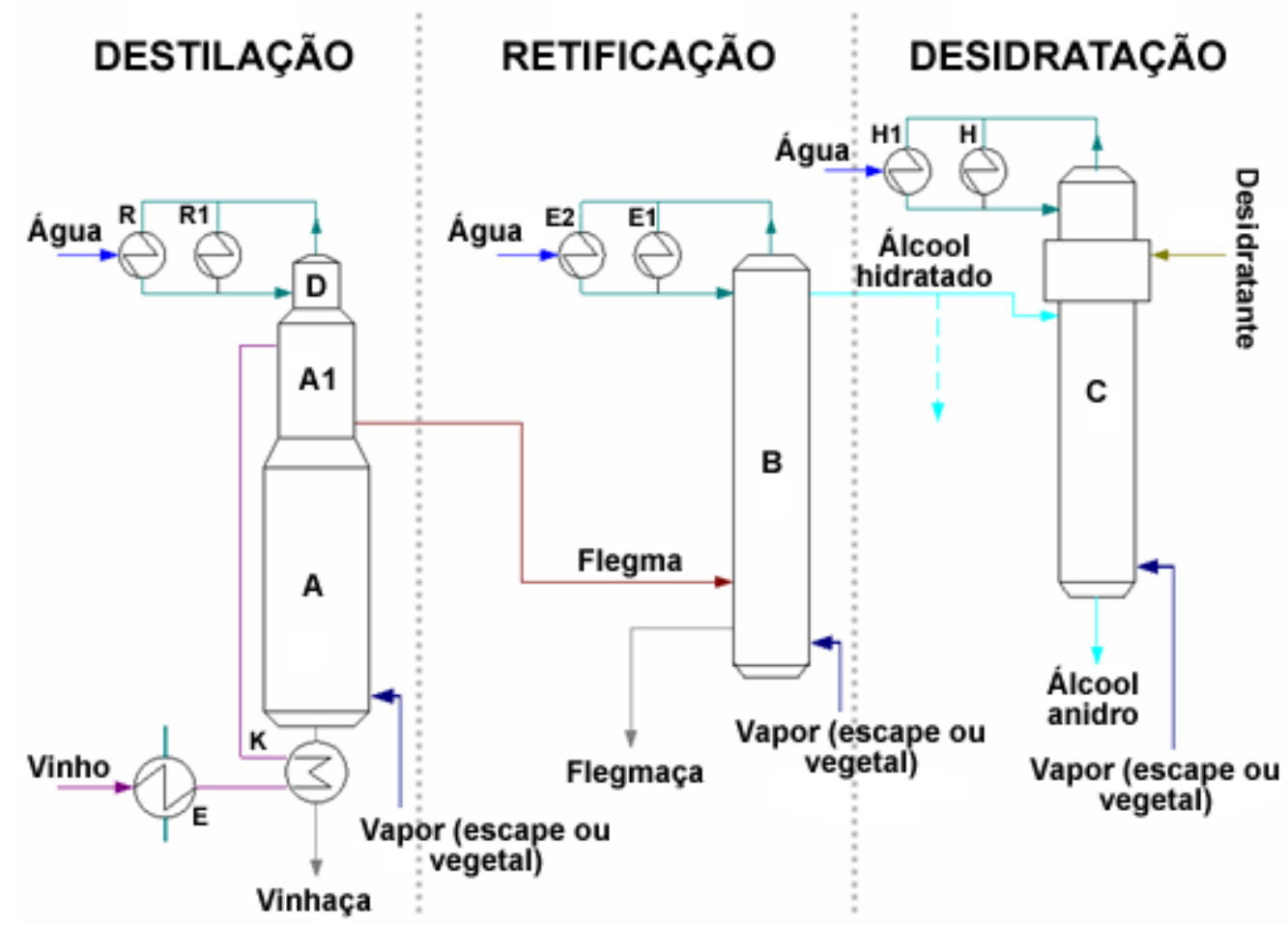

Figura 5-3 - Processo simplificado de destilação de álcool.

\subsubsection{Retirada de Álcool Hidratado da Coluna B}

Algumas destilarias produzem apenas álcool hidratado, devendo seu teor alcoólico estar a um limite mínimo nunca inferior a $92,7^{\circ}$ INPM. Valores inferiores não são aceitos pelos compradores e superiores significam perdas de rentabilidade por parte dos produtores. Deste modo é indispensável o controle dessa variável e mantê-la o mais próximo de 92,7 ${ }^{\circ}$ INPM.

Assim, para garantir a qualidade do produto e o maior rendimento possível, deve-se dispor de instrumentação capaz de medir o teor alcoólico diretamente ou indiretamente. Os instrumentos mais modernos atualmente usados para esse fim são os medidores mássico de efeito Coriollis. Já na medição indireta deve-se estimar o teor alcoólico por meio de um algoritmo de inferência com base em variáveis secundárias que possam ser medidas de forma online. 
Basicamente, o processo de fabricação de álcool hidratado termina na coluna "B", visto que para a produção de álcool anidro devem-se ter outras colunas para obter a desidratação do álcool hidratado. Todavia, diversos são os problemas que podem ocorrer ao longo das colunas "A" e "B" que devem ser observados pelos engenheiros de processo, dentre eles, podem-se destacar as chamadas "perdas de álcool na vinhaça" causadas basicamente por:

- excesso de vinho;

- falta de vapor na coluna "A";

- contrapressão da coluna "B";

- incrustações nas bandejas;

- trocador K furado.

Analisando os itens acima observa-se que as três primeiras causas estão diretamente relacionadas entre si e devem ser controladas. Para as demais, a solução é obtida realizando procedimentos operacionais de manutenção como limpeza, inspeção e de reparos. Diversos são as estratégias de controle existentes para controlar as colunas "A" e "B" com o intuito de sanarmos os problemas existentes.

De forma geral, a coluna em estudo tem a finalidade de separar o etanol (produto de topo) da água (Produto de fundo). Devido às dificuldades em sua medição, em muitos casos a concentração de etanol é controlada indiretamente através do controle das temperaturas de base e de topo, sendo as vazões de vapor e de refluxo as respectivas variáveis manipuladas.

\subsection{Sensores Virtuais Aplicados em Colunas de Destilação}

Nos processos químicos em geral, principalmente no setor petroquímico, existe um grande número de propriedades que devem ser controladas ao longo dos processos produtivos, tornando imprescindível a utilização de técnicas que possam medir ou estimar tais 
propriedades. Temperaturas, vazões e pressões podem ser mensuradas de forma online por meio de sistemas de medição específicos, tais como termoresistências, termopares, medidores de pressão e vazão, etc, também chamadas de variáveis secundárias. Entretanto, existem variáveis que só podem ser quantificadas por meio de métodos e técnicas mais elaboradas, com, por exemplo, análises laboratoriais. Neste grupo encontram-se as composições das correntes de topo e fundo nas colunas de destilação, os índices de fluidez dos reatores poliméricos, etc. Em geral, essas variáveis são responsáveis pela determinação da qualidade do produto fabricado e são chamadas variáveis primárias.

A determinação destas variáveis, que normalmente implica no uso de análises de laboratório, em geral apresentam algumas desvantagens, como o alto custo devido às técnicas empregadas e à utilização de mão-de-obra especializada, além do tempo de análise que conforme a aplicação também pode ser elevado. Outro ponto a ser destacado é a baixa periodicidade dessas análises, em geral, são realizadas com uma frequência de uma a três análises ao dia, o que impossibilita o acompanhamento contínuo dessas variáveis.

Atualmente, uma alternativa viável buscando contornar esse problema é a utilização, em conjunto com as análises laboratoriais, dos sensores virtuais, que se caracterizam pela determinação indireta das variáveis de difícil aquisição. O desenvolvimento de sensores virtuais é um bom exemplo do uso da informação contida no banco de dados dos sistemas de supervisão (histórico) visando a otimização dos processos industriais, uma vez que utiliza esses dados para encontrar uma relação matemática entre as variáveis secundárias medidas continuamente na planta com aquelas variáveis primárias que devem ser estimadas. Portanto, a inferência é basicamente uma correlação de uma propriedade em função de variáveis escolhidas, que são continuamente medidas no processo produtivo.

O projeto de sensores virtuais implica na seleção da estrutura de estimação apropriada e na escolha do algoritmo de estimação adequado capaz de executar a tarefa de inferência. 
Especificamente em colunas de destilação, as variáveis comumente inferidas são a composição de topo e fundo das colunas, uma vez que o controle de tais propriedades depende de análises laboratoriais esparsas ou de analisadores em linha. As variáveis secundárias, neste caso em questão, são temperaturas, vazões, níveis e pressões, que se caracterizam pela fácil aquisição.

O acompanhamento frequente das composições de topo e fundo em uma coluna de destilação costuma ser importante, principalmente porque estas composições, além de serem dependentes de variáveis como refluxo e aquecimento no refervedor, são também afetadas por variações súbitas de composição na carga. Outro ponto importante, associado às análises de laboratório, é o atraso de transporte entre o local de amostragem e a corrente específica que deve ser analisada. Por exemplo, a amostragem de concentração de topo em uma coluna de destilação geralmente é realizada depois do vaso pulmão existente no topo da coluna. Dessa forma, uma análise neste ponto corresponde a uma média entre os valores de composição que ocorreram no intervalo de tempo de acúmulo do vaso de topo, e não necessariamente correspondendo à composição de topo. Já uma inferência de concentração via sensor virtual estima a corrente de topo sem acúmulo do vaso, pois utiliza as variáveis da coluna medidas em um momento específico para realizar o cálculo.

Mejdell et al. (1991a; 1991b; 1993) em seu trabalho destacam que o mais importante não está no número de sensores, mas na relação existente entre as medições de entrada e saída. Portanto, em projeto de sensores virtuais, algumas perguntas que deverão ser respondidas: (a) quantas medições são realmente necessárias? (b) As informações contidas nas medições são sempre significativas ou alteram com o tempo? Na literatura está disponível uma grande variedade de algoritmos caracterizados pelas diferenças estruturais existentes e nas diversas técnicas de ajuste. No entanto, não existe uma clareza a respeito da conexão entre propriedades estruturais e a seleção do algoritmo estimador. Isto implica nas seguintes 
perguntas: qual algoritmo deve ser usado no desenvolvimento do sensor virtual? $\mathrm{O}$ algoritmo selecionado pode comprometer as propriedades estruturais da coluna?

A fim de projetar um sensor virtual robusto para uma coluna de destilação é imprescindível encontrar as respostas para as questões acima, e para isso, entender o comportamento do aparelho de destilação se faz necessário. Isso pode ser obtido por meio da observação de experimentos do funcionamento da coluna, ou por meio do estudo usando um modelo matemático ou abstrato do processo. É importante ressaltar que, sendo o objetivo deste trabalho o projeto de estimadores robustos capazes de realizar o monitoramento online da composição do produto, o modelo a ser adotado deve ser compacto, mas capaz de capturar as principais características da dinâmica da coluna.

Na operação, controle e otimização de sistemas, a inferência de variáveis de processo por meio de RNAs pode ser visto como um problema de identificação, uma vez que a estrutura neural utilizada deve ser capaz de representar de forma eficiente à dinâmica existente entre as variáveis secundárias e primárias do processo em estudo. Como mostrado na Seção 3.7, uma das principais vantagens de se utilizar redes neurais na identificação de sistemas é a sua capacidade de representar, ou aprender, características não lineares desses sistemas.

Dessa forma, a inferência de propriedades em função de variáveis medidas no processo é uma alternativa que proporciona algumas vantagens, tais como boa precisão e baixo tempo de resposta. No setor químico e petroquímico, as RNAs têm sido aplicadas em diversas áreas. Na estimação de propriedades, as RNAs permitem a obtenção de modelos de inferência abrangentes e precisos, podendo ser utilizadas no controle em tempo real, nos arranjos de controle em malha simples, ou em arquiteturas de controle multivariável. 
Atualmente, tem sido cada vez mais frequente o uso de ferramentas matemáticas aliadas à tecnologia da informação pelo setor industrial, principalmente buscando melhorar as especificações dos produtos e um maior controle das emissões de compostos poluentes.

Assim, o uso de sensores virtuais pode ser uma boa alternativa em relação aos sensores tradicionais, nos casos onde as variáveis secundárias possam ser obtidas de forma satisfatória. Nestes casos, diversas aplicações podem ser destacadas, tais como: inferência de variáveis; detecção de falhas; previsão de desempenho; aproximação de funções não lineares; e identificação de padrões de processos (Fortuna et al., 2007). 


\section{Capítulo VI}

\section{Materiais, Métodos e Discussão dos Resultados}

\subsection{Materiais e Métodos}

A metodologia empregada no desenvolvimento desse trabalho possui as seguintes etapas:

- $1^{\mathrm{a}}$ etapa - Escolha e Coleta de dados: $\mathrm{Na}$ fase inicial foram realizadas as medições no processo para levantamento da base de dados contendo as suas variáveis primárias e secundárias. As principais atividades desenvolvidas nesta etapa foram:

a) estudo das principais características planta de produção de etanol utilizada;

b) aquisição de dados, armazenado via supervisório, no banco de dados da planta (histórico).

- $2^{\mathrm{a}}$ etapa - Pré-processamento dos dados: Aqui foi realizado um estudo sobre quais variáveis secundárias têm influência relevante nas variáveis de saída, as quais são importantes na fase de treinamento da RNA. Isto pôde ser feito com o auxílio de técnicas estatísticas de seleção de variáveis. As principais atividades nesta etapa foram as seguintes:

a) detecção de possíveis inconsistências nos dados;

b) análise de sensibilidade das variáveis de entrada;

c) divisão do conjunto de dados de entrada em subconjunto de treinamento, validação e teste. 
- $\quad 3^{\mathrm{a}}$ etapa - Escolha da RNA: Nesta etapa foi definida qual arquitetura de rede a ser utilizada, a quantidade de neurônios e camadas da RNA, as funções de ativação que foram utilizadas para as camadas e o algoritmo de treinamento. Esta escolha foi feita com base no problema em questão, considerando, por exemplo, se o sistema é estático ou dinâmico, linear ou não.

- $4^{\mathrm{a}}$ etapa - Treinamento: Aqui foi realizado o treinamento para que a RNA tivesse capacidade de reproduzir o comportamento do sistema, no qual os parâmetros da rede foram ajustados para que o estímulo nas entradas fornecesse o valor desejado na saída.

- $5^{\mathrm{a}}$ etapa - Teste: Finalmente, foi realizada a verificação do modelo a fim de prever a saída do sistema frente aos dados de entrada utilizados no treinamento, de modo a verificar a capacidade de generalizar para qualquer conjunto de valores reais de entrada do processo. Este procedimento foi realizado para validação do modelo obtido.

- $6^{\mathrm{a}}$ etapa - Estudo comparativo: Nessa etapa foi realizado um estudo comparativo entre os resultados apresentados pelos modelos estimados por meio de RNAs e aqueles obtidos por meio da representação no espaço de estados (Aguirre, 2007).

O diagrama de blocos correspondente ao processo de desenvolvimento do sensor virtual é mostrado na figura a seguir: 


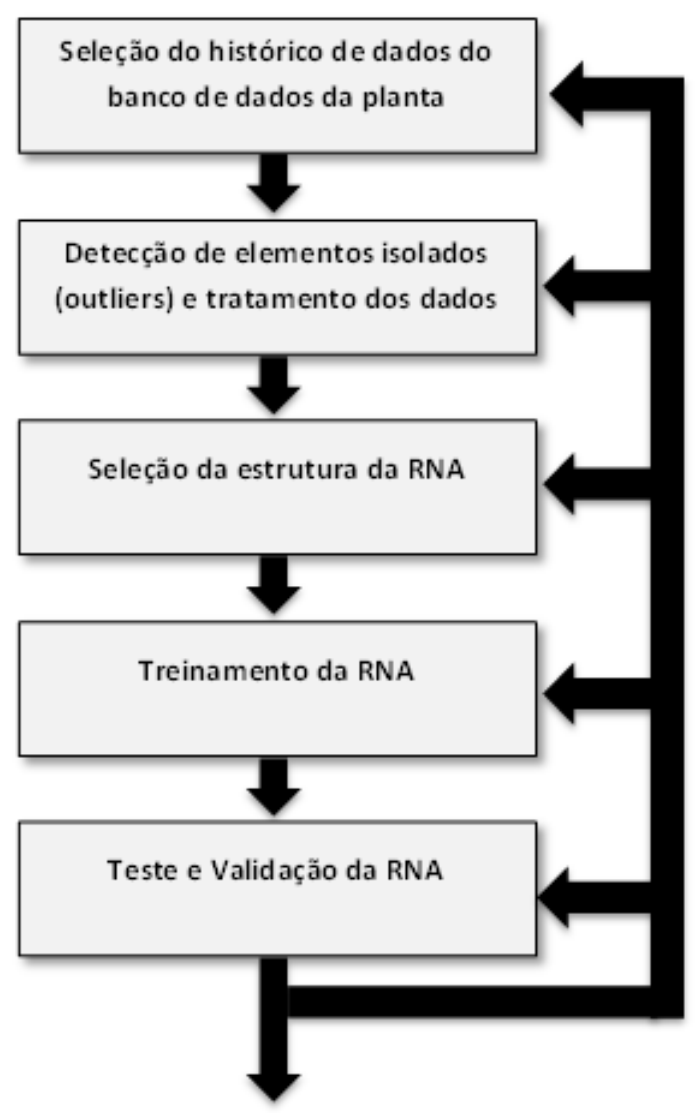

Figura 6-1 - Diagrama de blocos das etapas envolvidas no projeto do sensor virtual ( $1^{\mathrm{a}}$ a $5^{\mathrm{a}}$ etapa).

\subsection{Escolha e Coleta de Dados}

No desenvolvimento do estimador, os primeiros passos consistem na observação e coleta dos dados pertinentes ao problema. Todos os dados disponíveis para a elaboração dessa dissertação foram obtidos de uma coluna de destilação real. Os dados foram obtidos por meio do sistema de controle e aquisição de dados.

O módulo de supervisão e controle é composto por um conjunto de programas empregados na operação, monitoramento de alarmes, armazenamento de dados em histórico e emissão de relatórios, e é interligado a uma rede Ethernet para comunicação com os outros setores da empresa.

Em geral, o software de supervisão possui os seguintes recursos:

- interface gráfica amigável com o operador;

- $\quad$ sinópticos de visualização do processo; 
- telas gráficas;

- telas de histórico das variáveis;

- frontal dos controladores;

- estações automático/manual;

- resumo de alarme;

- sintonia dos PID's;

- disponibilização de dados provenientes do processo via Drive DDE para geração de relatórios e/ou cálculo.

Um estudo mais detalhado da coluna de destilação foi realizado na Seção 5.3. Neste trabalho, as perturbações na coluna foram limitadas às condições operacionais da planta.

\subsubsection{Descrição Básica da Automação da Área de Destilação}

O sucesso ou não do modelo inferencial depende diretamente da etapa de seleção de variáveis, já que esta garante a confiabilidade e a sua validação. O estudo detalhado das malhas de controle servirá como base para a definição das variáveis a serem analisadas na etapa de coleta de dados. As malhas básicas de controles da coluna para a produção de álcool hidratado são as seguintes:

- Controle de pressão das colunas "A" e "B": Esse controle consiste na medição da pressão no interior das colunas "A" e "B", e manipular a vazão de vapor do refervedor;

- Controle de alimentação de vinho para a coluna "A": Esse controle consiste na medição da temperatura da bandeja A18, e manipular a vazão de vinho para a coluna "A"; 
- Controle de nível da calandra da coluna "A": Esse controle consiste na medição do nível da coluna "A", e manipular a vazão de retirada da vinhaça na saída da coluna "A";

- Controle de retirada de álcool hidratado através da temperatura da bandeja B4: Esse controle consiste na medição da temperatura da bandeja B4, e controlar a retirada de álcool hidratado da coluna "B" manipulando a vazão do destilado;

- Controle de retirada de álcool hidratado através do teor alcoólico: Esse controle consiste na medição da temperatura da bandeja B4, da vazão de retirada do álcool hidratado e seu teor alcoólico, a fim de controlar a retirada de álcool hidratado da coluna "B" manipulando a vazão de retirada do destilado;

- Controle de nível do tanque de refluxo da coluna "B": Alguns aparelhos de destilação possuem um tanque acumulador de refluxo dos condensadores E/E1/E2, que entram na coluna "B”. Esse controle consiste na medição e controle da vazão de refluxo para a coluna "B", em cascata com o nível do tanque acumulador;

- Controle de pH do álcool hidratado: Esse controle consiste na medição do pH do álcool hidratado retirado pela coluna "B", a fim de manipular a vazão de soda para a coluna "B", através de uma bomba dosadora com inversor de frequência.

Além das variáveis medidas nas malhas de controle listadas acima, existem outras variáveis auxiliares que são medidas com o objetivo de monitorar e serem utilizadas em alarmes no processo de destilação. Essas variáveis são as seguintes:

- Temperatura dos condensadores (E, E1, E2, R, R1);

- Temperatura do vinho antes do condensador "E" e após o trocador "K";

- Temperatura da Coluna A (pé da coluna A1 e entrada de vinho A18); 
- Temperatura da Coluna B (pé da coluna B1, entrada de flegma B4 e topo da coluna);

- Temperatura da água industrial para os condensadores e da água servida na saída dos condensadores;

- Temperatura do vapor;

- Pressão do vapor;

- Pressão do vinho;

- Vazão de vinho para a coluna "A";

- Vazão de vapor para a coluna “A”;

- Vazão de vapor para a coluna "B".

\subsubsection{Definição de Variáveis e Aquisição de Dados}

Na identificação do comportamento dinâmico de sistemas, o primeiro passo a ser dado é a obtenção das amostras experimentais do processo que servirão para o treinamento supervisionado da rede neural de inferência.

Neste trabalho, o modelo de identificação foi definido como sendo um sistema Multiple-Input and Single-Output (MISO), onde o teor alcoólico a ser estimado deve estar correlacionado, direta ou indiretamente, com um conjunto de variáveis secundárias obtidas do processo de forma online. Dessa forma, os dados coletados devem ser representativos, cobrindo-se amplamente o domínio do problema; não devendo cobrir apenas as operações normais ou rotineiras, mas também as exceções e as condições limites do domínio do problema.

Segundo Aguirre (2007), três aspectos são fundamentais na identificação de sistemas: (a) onde excitar a planta; (b) que tipo de sinais serem usados a fim de obter dados representativos da dinâmica do sistema e (c) como amostrá-los. Ao se buscar um modelo 
matemático que relacione dinamicamente duas variáveis de um sistema, parte-se do pressuposto de que há uma correlação significativa entre estas variáveis que justifique o modelo. Com isso, intuitivamente, a função de correlação cruzada apresenta-se como uma ferramenta capaz de determinar se há uma correlação significativa entre duas variáveis candidatas a compor um modelo.

Em geral, nem todas as variáveis disponíveis para aquisição em um processo são igualmente úteis para o desenvolvimento de um modelo baseado em RNAs. A presença de variáveis irrelevantes pode representar uma fonte de perturbação e ruído, e pode conduzir a um sistema com deficiência na sua representação (Aguirre, 2007; Zamprogna et al., 2005).

Em processos industriais reais, mais especificamente em destilarias, convém destacar que algumas medições podem não estar disponíveis ou apresentarem a qualidade desejada, diversos são os motivos para que isso ocorra, por exemplo, a manutenção dos instrumentos de medição. Neste caso, apenas os medidores que garantam uma boa qualidade na medição devem ser efetivamente utilizados.

Após o estudo do processo e sobre o estado das variáveis medidas, a lista de possíveis variáveis disponíveis no processo para serem utilizadas no desenvolvimento do sensor virtual proposto é mostrada na Tabela 6-1 a seguir. 
Tabela 6-1 - Lista de variáveis secundárias medidas de forma online do processo.

\begin{tabular}{|c|c|c|c|c|c|c|c|}
\hline Variável & ID & $\begin{array}{c}\text { Valor } \\
\text { Operacional }\end{array}$ & Unidade & Local de Medição & Tipo & Característica & Tipo de medidor \\
\hline Vazão de vapor do refervedor & VR & 8531,89 & $\mathrm{Kg} / \mathrm{h}$ & Coluna A & Entrada & Relação indireta & $\begin{array}{c}\text { Transmissor de pressão } \\
\text { Rosemount série } 3051 \mathrm{~S} \\
\text { Placa de orifício }\end{array}$ \\
\hline Vazão de alimentação & $\mathrm{F}$ & 6712,58 & $\mathrm{~m}^{3} / \mathrm{h}$ & Coluna A & Entrada & Relação indireta & $\begin{array}{c}\text { Transmissor de pressão } \\
\text { Rosemount série } 3051 \mathrm{~S} \\
\text { Placa de orifício }\end{array}$ \\
\hline $\begin{array}{l}\text { Vazão de retirada do produto do } \\
\text { topo }\end{array}$ & $\mathrm{DL}$ & 2786,35 & $\mathrm{~m}^{3} / \mathrm{h}$ & Coluna B & Entrada & Relação direta & $\begin{array}{c}\text { Placa de orifício }+ \\
\text { Transmissor de pressão } \\
\text { Rosemount série } 3051 \mathrm{~S}\end{array}$ \\
\hline Razão do Refluxo & RR & 0,37 & & Coluna B & Entrada & Relação direta & estimada \\
\hline Pressão no fundo & PB & 0,47 & bar & Coluna B & Entrada & Relação indireta & $\begin{array}{l}\text { Transmissor de pressão } \\
\text { Rosemount série } 3051 \mathrm{~S} \\
\end{array}$ \\
\hline Pressão no meio & $\mathrm{PM}$ & 0,39 & bar & ---- & Entrada & Relação indireta & $\begin{array}{l}\text { Transmissor de pressão } \\
\text { Rosemount série } 3051 \mathrm{~S}\end{array}$ \\
\hline Pressão no topo & PT & 0,3 & bar & Coluna B & Entrada & Relação indireta & $\begin{array}{l}\text { Transmissor de pressão } \\
\text { Rosemount série } 3051 \mathrm{~S}\end{array}$ \\
\hline Pressão do condensador E & $\mathrm{PC}$ & 0,36 & bar & Coluna B & Entrada & Relação indireta & $\begin{array}{l}\text { Transmissor de pressão } \\
\text { Rosemount série } 3051 \mathrm{~S}\end{array}$ \\
\hline Temperatura no fundo (A18) & TB & 91 & ${ }^{\circ} \mathrm{C}$ & Coluna B & Entrada & Relação direta & Pt 100 \\
\hline Nível do tanque de refluxo & LR & 1,2 & $\mathrm{~m}$ & Coluna B & Entrada & Relação indireta & $\begin{array}{l}\text { Transmissor de pressão } \\
\text { Rosemount série } 3051 \mathrm{~S}\end{array}$ \\
\hline Concentração do produto do topo & $\mathrm{XD}$ & 93,2 & ${ }^{\circ} \mathrm{INPM}$ & Coluna B & Saída & ----- & Micro Motion (Emerson) \\
\hline
\end{tabular}




\subsubsection{Escolha da Taxa de Amostragem}

Segundo Aguirre (2007), em sistemas que apresentam características não lineares, o sinal de excitação deve variar em amplitude e frequência, de modo a excitar todas as suas dinâmicas.

Portanto, na aquisição de dados para identificação de sistemas, a amostragem deve ocorrer de forma suficientemente rápida, garantindo-se que as frequências de interesse estejam bem representadas em todo conjunto de dados, ou seja, algumas interações não lineares só aparecerão e serão reproduzidas se a taxa de amostragem for suficientemente rápida.

Por outro lado, ocorrendo uma super-amostragem, onde o sinal amostrado é mais rápido do que o necessário, frequentemente ocorrem problemas numéricos durante a estimação de parâmetros do modelo (Aguirre, 1993; Billings et al., 1978).

Entretanto, na prática uma, super-amostragem pode também provocar problemas na seleção de estrutura, assim como uma sub-amostragem pode provocar o efeito de dados adjacentes não serem correlacionados, impossibilitando assim a identificação.

A definição da taxa de amostragem em identificação de sistemas está associada a dois problemas de ordem prática. Primeiramente, se a taxa de amostragem $T_{S}$ é muito pequena, $y(k) \cong y\left(k-T_{S}\right)$, os dados são altamente correlacionados, levando-se a problemas de mal condicionamento numérico nas demais etapas de identificação. Esse problema recebe o nome de redundância. No outro extremo, se $T_{S}$ é muito grande, os dados podem não apresentar correlação nenhuma.

Especificamente em identificação de sistemas não lineares, as funções de correlação são largamente empregadas. Essa técnica é empírica e se baseia nas noções de redundância e irrelevância para indicarem a taxa de amostragem a ser utilizada. Os resultados embora sejam 
satisfatórios, são apenas indicadores, dentro de uma faixa de confiança, das taxas de amostragens possíveis de serem utilizadas.

Todavia, na prática, a frequência de amostragem é normalmente definida entre 5 a 10 vezes a maior do que a maior componente de frequência contida nos dados, e não apenas 2 vezes maior (frequência de Nyquist) como determinado pelo teorema de Shannon.

Neste trabalho é utilizado o procedimento prático proposto por Aguirre (2007). Esse método tem apresentado boas indicações em casos práticos. O método consiste em realizar uma amostragem dos sinais de entrada e a saída do sistema e analisar suas autocovariâncias.

Por definição, autocorrelação é a correlação existente entre dois valores da mesma variável nos instantes $x_{k}$ e $x_{k}+\tau$, onde $k$ é chamado de atraso (lag). A autocorrelação possui a finalidade de medir a intensidade com que um valor observado no tempo $t$ é influenciado por aquele observado no tempo $t-\tau$. Já a autocovariância é a medida de dependência entre duas observações separadas por $\tau$ intervalos de tempo.

Para avaliar os efeitos causados pela sobre-amostragem são utilizadas as funções de autocovariância linear e não linear aplicadas a um par entrada/saída, conforme mostrado nas Equações (6-1) e (6-2) a seguir (Zanata, 2005).

Linear:

$$
\operatorname{Cov}_{x, y}(\tau)=\frac{1}{N} \sum_{k=1}^{N}[x(k)-\bar{x}] .[y(k-\tau)-\bar{y}]
$$

Não Linear:

$$
\operatorname{Cov}_{x, y}^{*}(\tau)=\frac{1}{N} \sum_{k=1}^{N}\left[x^{2}(k)-\bar{x}^{2}\right] \cdot\left[y^{2}(k-\tau)-\bar{y}^{2}\right]
$$

onde: $x$ e y são os vetores de entrada e de saída, respectivamente;

$\bar{x} e \bar{y}$ são os valores médios dos respectivos vetores;

$\tau$ corresponde ao número de atrasos em análise;

$N$ é a quantidade de elementos dos vetores entrada e de saída. 
O sinal de entrada usado para avaliar a sobre-amostragem é mostrado na Figura 6-2 a seguir. O tempo de amostragem utilizado foi de 15 segundos. Na Figura 6-2 (a) e (b) são apresentadas a composição e a temperatura no fundo da coluna "B" (bandeja A18) e a composição do destilado. Os gráficos das demais entradas são mostrados no ANEXO (A).

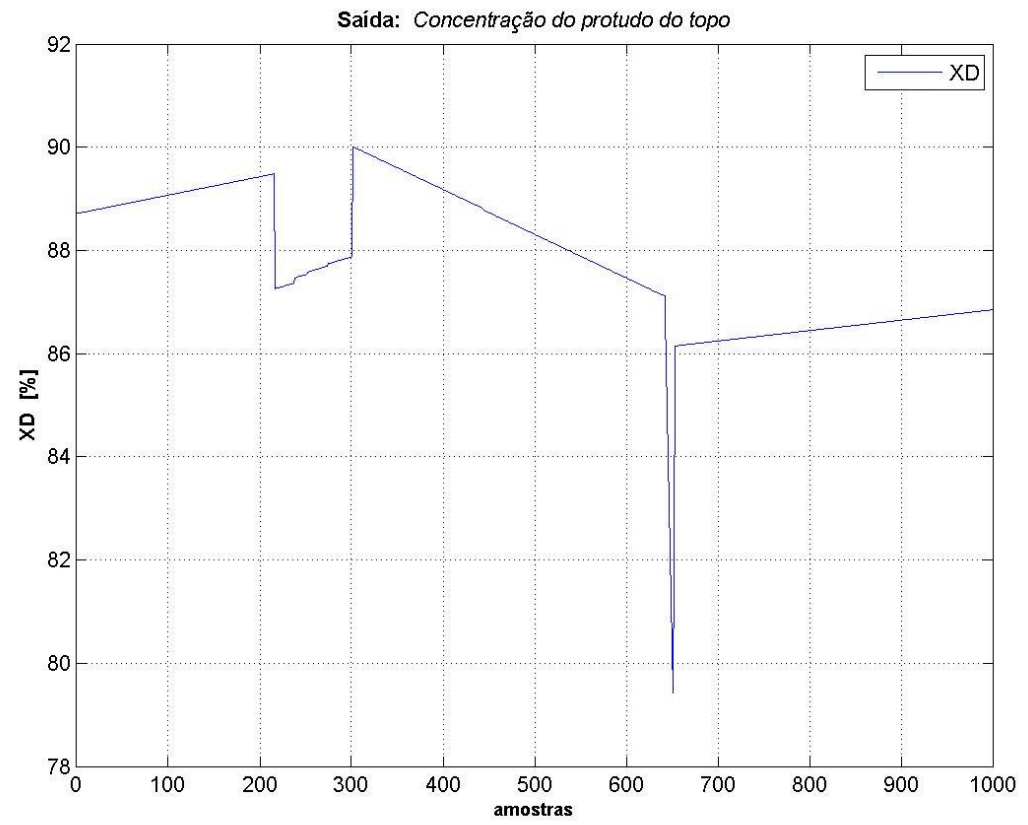

(a)

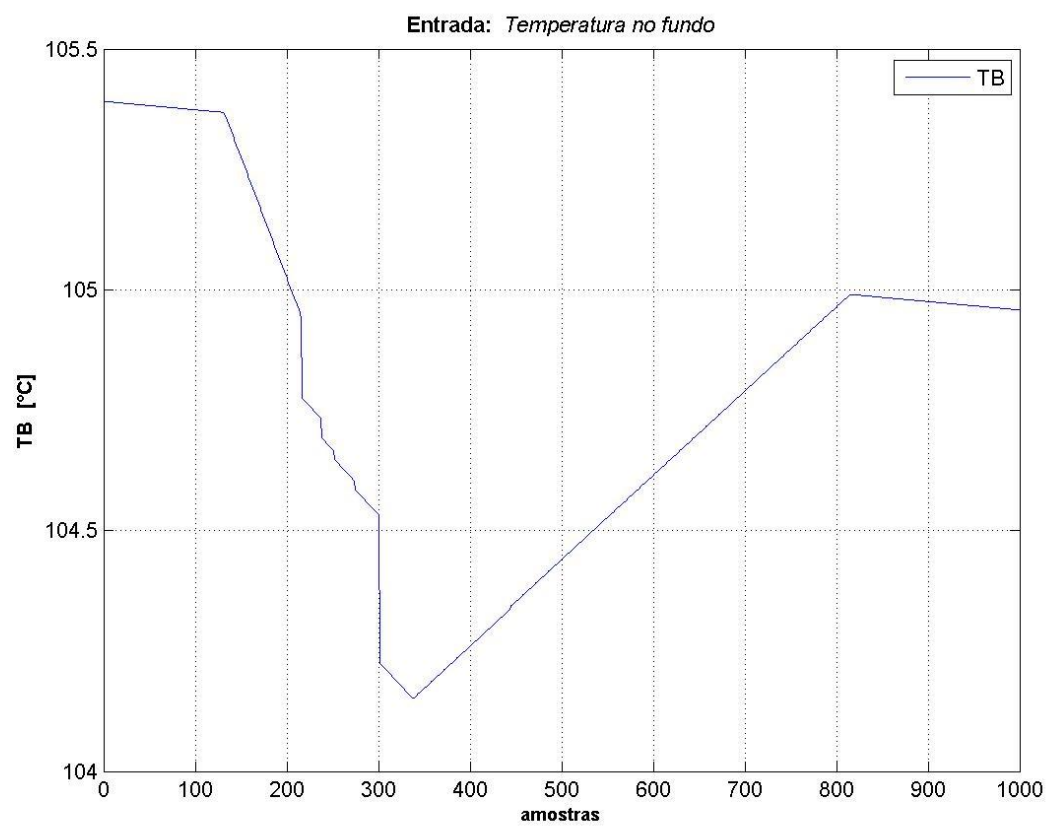

(b)

Figura 6-2 - Dados de entrada (a) e saída (b) aquisitados para a determinação do tempo de amostragem. 
Para a definição do período de amostragem as autocovariâncias (linear e não linear) entre a temperatura (entrada) e a composição (saída), obtidas por meio das Equações (6-1) e (6-2), são mostradas na Figura 6-3 abaixo.

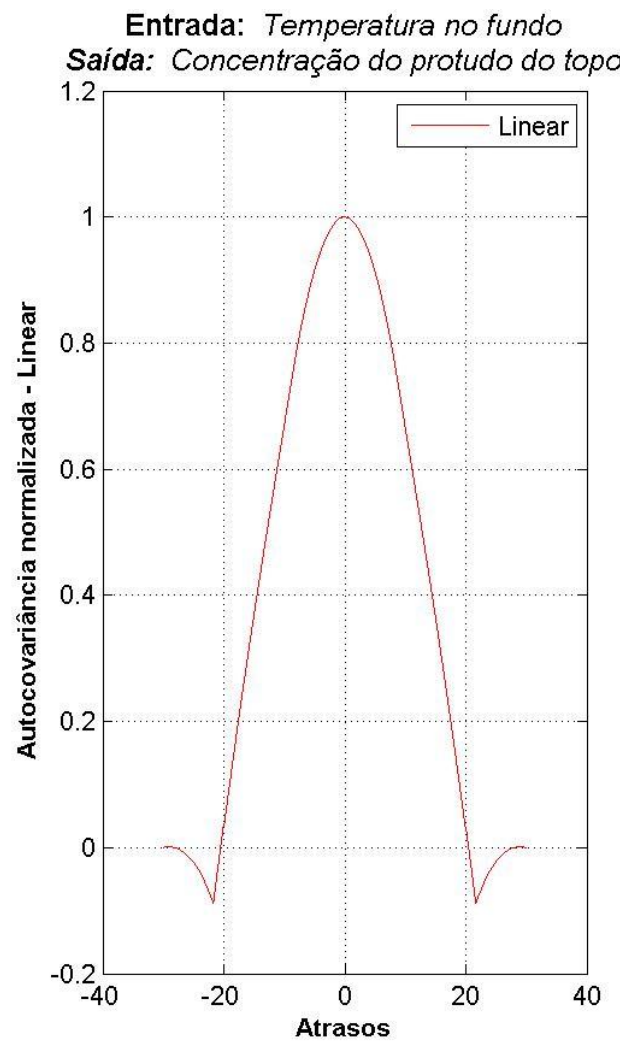

(a)

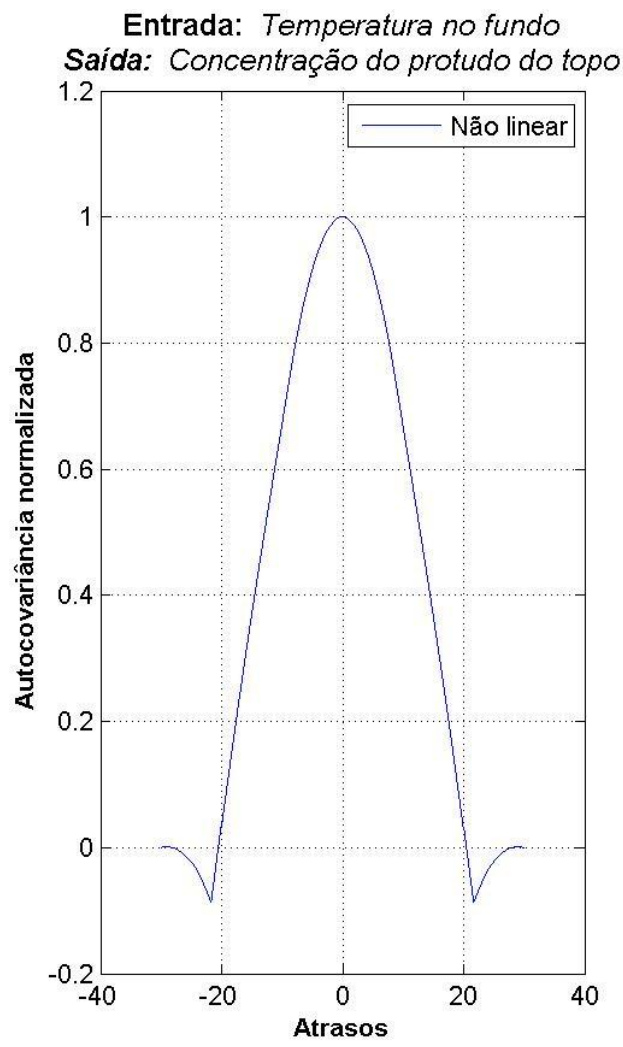

(b)

Figura 6-3 - (a) Autocovariância linear. (b) Autocovariância não-linear.

De acordo com Aguirre (2007) é necessário que o período de amostragem do sinal respeite a seguinte relação:

$$
\frac{\tau_{m}}{20} \leq T_{s} \leq \frac{\tau_{m}}{10}
$$

Portanto, se o sinal com amostragem estiver dentro da faixa estabelecida, dada pela equação (6-3), o sinal poderá ser utilizado. Se o sinal estiver violando o limite superior de (6-3), faz-se necessário decimar os sinais até que estes se encontrem dentro da faixa. Caso o sinal viole a restrição inferior, será então necessário repetir o teste usando uma taxa de amostragem maior na aquisição dos dados. Os limites inferiores e superiores da equação (6-3) podem ser relaxados para 5 e 25 respectivamente (Aguirre, 2007). 
Verifica-se nos gráficos da Figura 6-3 acima que o primeiro mínimo entre as duas autocovariâncias ocorre para o atraso $\tau_{m}=21,2$ amostras. Portanto, $T_{s}$ deve ser definido entre 1,06 a 2,12 do período de amostragem inicial que foi de 15 segundos, ou seja, observase que a faixa viável para o período de amostragem está entre 16 e 32 segundos. Nessa dissertação é adotado o período de amostragem igual a 30 segundos ou uma Taxa de amostragem igual a $4\left[\frac{\text { amostras }}{\min }\right]$. Com isso, procurou-se analisar componentes com constante de tempo mínima de 2,5 minutos. Os demais gráficos de autocovariância linear e não linear estão disponíveis para análise no ANEXO (A). A tabela a seguir mostra o valor correspondente ao $1^{\circ}$ mínimo e o intervalo viável do período de amostragem para as variáveis de entrada.

Tabela 6-2 - Valores correspondentes do $1^{\circ}$ mínimo, $\tau_{m}$ e a faixa viável de valores para o período de amostragem.

\begin{tabular}{|c|c|c|c|c|c|c|c|c|}
\hline Entrada & Saída & $\begin{array}{l}1^{\circ} \text { Min } \\
\text { linear }\end{array}$ & $\begin{array}{c}1^{\circ} \text { Min } \\
\text { não Linear }\end{array}$ & $\tau_{m}$ & $\frac{\tau_{m}}{20}$ & $\frac{\tau_{m}}{10}$ & $\begin{array}{c}T_{S} \\
\text { mínimo }\end{array}$ & $\begin{array}{c}T_{S} \\
\text { máximo }\end{array}$ \\
\hline VR & \multirow{10}{*}{ XD } & 21,30 & 21,30 & 21,30 & 1,07 & 2,13 & 15,98 & 31,95 \\
\hline$F$ & & 21,20 & 21,20 & 21,20 & 1,06 & 2,12 & 15,90 & 31,80 \\
\hline $\mathrm{DL}$ & & 21,20 & 21,20 & 21,20 & 1,06 & 2,12 & 15,90 & 31,80 \\
\hline $\mathrm{RR}$ & & 30,00 & 30,00 & 30,00 & 1,50 & 3,00 & 22,50 & 45,00 \\
\hline PB & & 21,10 & 21,10 & 21,10 & 1,06 & 2,11 & 15,83 & 31,65 \\
\hline PM & & 21,20 & 21,20 & 21,20 & 1,06 & 2,12 & 15,90 & 31,80 \\
\hline $\mathrm{PT}$ & & 21,20 & 21,20 & 21,20 & 1,06 & 2,12 & 15,90 & 31,80 \\
\hline $\mathrm{PC}$ & & 21,10 & 21,10 & 21,10 & 1,06 & 2,11 & 15,83 & 31,65 \\
\hline TB & & 21,20 & 21,20 & 21,20 & 1,06 & 2,12 & 15,90 & 31,80 \\
\hline LR & & 30,00 & 30,00 & 30,00 & 1,50 & 3,00 & 22,50 & 45,00 \\
\hline
\end{tabular}

\subsubsection{Determinação da Ordem do Modelo}

Para obter a ordem do modelo existem alguns métodos como, por exemplo, o Akaike's Information Criterion (AIC), Minimum Description Length (MDL) e Error Reduction Ratio (ERR) (Aguirre, 1993). Neste trabalho foi empregado o método False Nearest Neighbor (FNN) (Rhodes \& Morari, 1998). A escolha desse algoritmo ocorreu devido à sua independência da estrutura do modelo a ser identificado, que neste caso é 
definida pela própria rede neural. Outro fato importante na escolha desse algoritmo é sua aplicabilidade tanto em sistemas lineares quanto sistemas não lineares.

Segundo Rhodes et al. (1998), o método FNN consiste na avaliação da geometria dos dados de entrada e saída coletados do sistema. Havendo informação suficiente no vetor de regressão capaz de prever a futura saída, então para quaisquer dois vetores de regressão, que estão próximos no espaço de regressão, as saídas correspondentes também estarão próximas.

Dado o ponto, $\quad z_{l, m}(k)=[y(k-\tau), \cdots y(k-l \tau), u(k-\tau), \cdots, u(k-m \tau)], \quad$ o objetivo é encontrar o ponto $z_{l, m}(j)$ no conjuntos de dados onde a distância euclidiana é minimizada, ou seja:

$$
\mathrm{D}=\min \left(\left\|z_{m, l}^{k}-z_{m . l}^{j}\right\|_{2}\right)
$$

Para isso utiliza-se o critério dado pela Eq. (6-5) a seguir, para determinar se o vizinho é verdadeiro ou falso:

$$
\frac{|y(k)-y(j)|}{\left\|z_{m, l}^{k}-z_{m . l}^{j}\right\|_{2}} \leq \mathrm{R}
$$

sendo $\|.\|_{2}$ a distância euclidiana e R um limiar previamente definido, com valores entre 10 e 30. Se a expressão for verdadeira, este é um vizinho verdadeiro, caso contrário, foi identificado um falso vizinho. Rhodes et al. (1998) mostram que, para valores de R neste intervalo, o número de falsos vizinhos se mantém quase constante.

$\mathrm{O}$ algoritmo $\mathrm{FNN}$, foi desenvolvido com objetivo de determinar o menor número $k$ de atrasos possíveis de serem utilizados, com a finalidade de determinar a saída $y$ de um sistema diretamente de um conjunto de dados que representa a dinâmica do sistema.

Analisando os gráficos da Figura 6-4 a seguir observa-se que para acréscimos no valor de R, a partir de 4, não se veem grandes diferenças na porcentagem de falsos vizinhos, conforme esperado. Os gráficos analisados indicam uma ordem global igual a 4, ou seja, a 
dinâmica do sistema pode ser modelada utilizando-se os regressores $y(k-1), y(k-2)$, $y(k-3), u(k-1), u(k-2), u(k-3)$ e u(k-4). Os demais gráficos obtidos pelo algoritmo FNN estão disponíveis para análise no ANEXO (A).
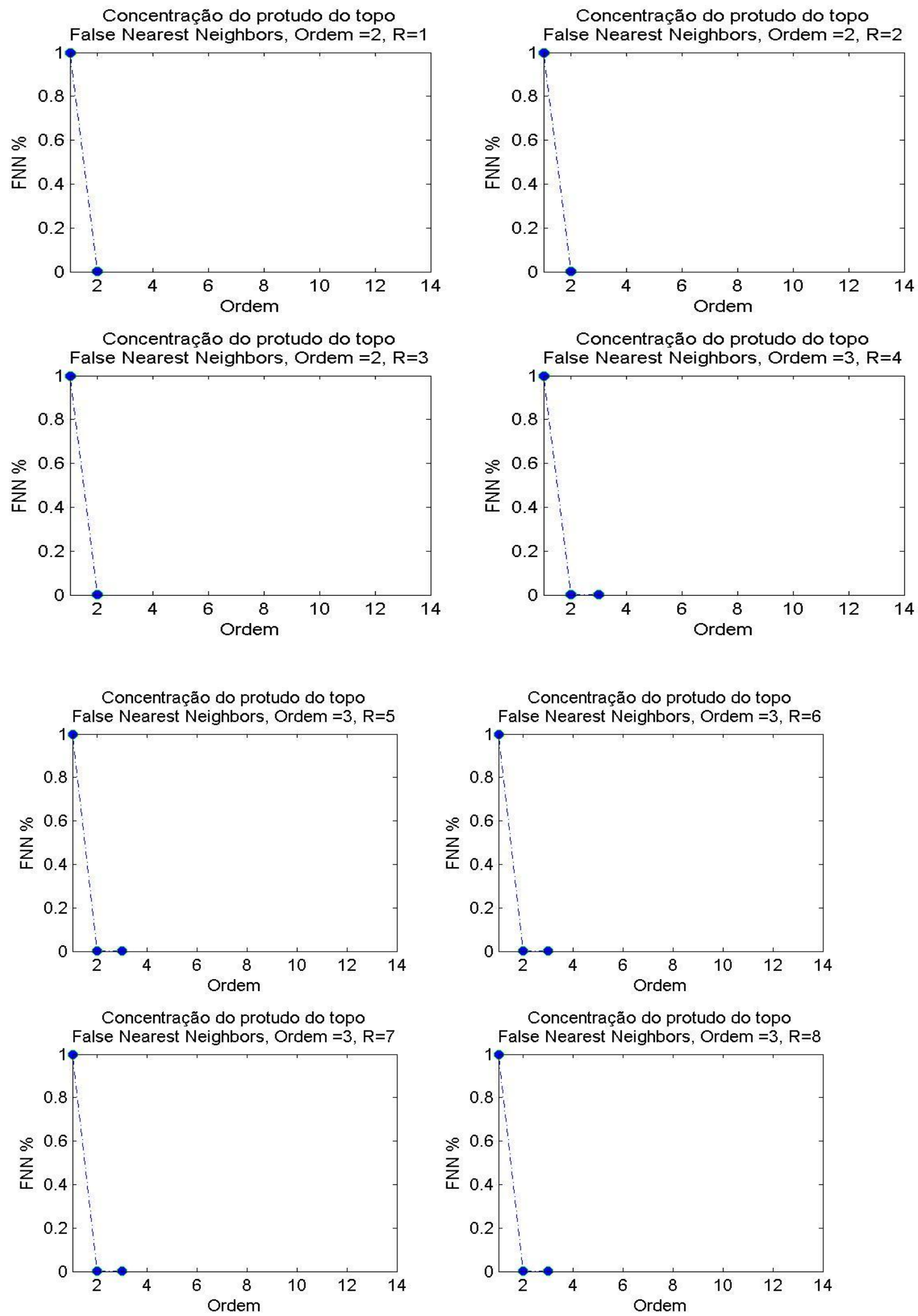

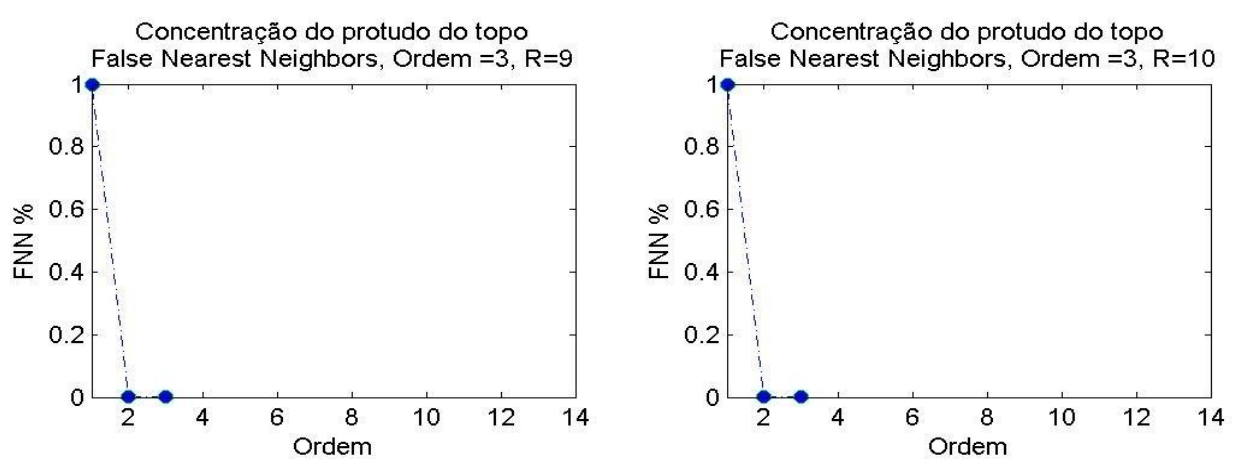

Figura 6-4- Resultado do algoritmo FNN (percentual de falsos vizinhos x ordem).

Na tabela a seguir são apresentados resultados obtidos através do algoritmo FNN.

Tabela 6-3 - Aplicação do algoritmo FNN nas entradas e saída para obter a ordem do modelo.

\begin{tabular}{|c|c|c|c|c|c|c|c|c|c|c|c|}
\hline & \multicolumn{10}{|c|}{ Entradas } & Saída \\
\hline R & VR & F & DL & RR & PB & PM & PT & PC & TB & LR & XD \\
\hline 1 & 3 & 3 & 3 & 2 & 2 & 2 & 2 & 3 & 2 & 4 & 2 \\
\hline 2 & 3 & 4 & 4 & 2 & 2 & 2 & 2 & 3 & 2 & 4 & 2 \\
\hline 3 & 3 & 4 & 4 & 2 & 2 & 3 & 3 & 3 & 3 & 4 & 2 \\
\hline 4 & 3 & 4 & 4 & 2 & 2 & 3 & 3 & 3 & 3 & 4 & 3 \\
\hline 5 & 4 & 4 & 4 & 3 & 3 & 3 & 3 & 3 & 3 & 4 & 3 \\
\hline 6 & 4 & 4 & 4 & 3 & 3 & 3 & 3 & 3 & 3 & 4 & 3 \\
\hline 7 & 5 & 4 & 4 & 3 & 3 & 3 & 3 & 3 & 3 & 4 & 3 \\
\hline 8 & 5 & 4 & 4 & 3 & 3 & 3 & 3 & 4 & 3 & 4 & 3 \\
\hline 9 & 5 & 4 & 4 & 3 & 3 & 3 & 4 & 4 & 3 & 4 & 3 \\
\hline 10 & 5 & 4 & 4 & 3 & 3 & 3 & 4 & 4 & 3 & 4 & 3 \\
\hline
\end{tabular}

\subsubsection{Seleção das Entradas e Saída}

Ao se buscar um modelo de inferência capaz de relacionar dinamicamente, duas ou mais entradas e uma única saída, parte-se do pressuposto de que existe correlação entre as variáveis de entrada e de saída que justifique o modelo, além da não existência de correlação entre todas as entradas.

Um dos problemas envolvendo o projeto de um sistema de inferência é a seleção das variáveis secundárias a serem utilizadas. Uma prática comum consiste em adotar várias medições de temperatura nos pratos das colunas de destilação buscando representar ou estimar a composição dos produtos dessas colunas (Zhang, 2001; Mejdell, \& Skogestad; 
1991a e 1991b), além de outras variáveis, tais como a vazão de refluxo, a pressão no vaso de condensado e a temperatura do refervedor.

No entanto, é importante destacar que em processos industriais reais, mais especificamente unidades de destilação, as medidas de temperatura em todos os estágios geralmente não estão disponíveis. Neste caso, apenas temperaturas que são efetivamente medidas na unidade podem ser utilizadas na base de dados.

Em regime, a alimentação da coluna é composta por uma mistura de água e etanol nos estados líquido e vapor, e em equilíbrio térmico. Na grande maioria dos trabalhos as temperaturas são consideradas as mais importantes variáveis na inferência da composição do destilado nas colunas de destilação. Mejdell e Skogestad (1991a) garantem que para misturas binárias à pressão constante, as temperaturas na base e no topo da coluna são excelentes indicadores das composições. No entanto, devido às variações que podem ocorrer na pressão ao longo do processo, alterações indesejáveis podem ocorrer também das composições dos componentes nos pratos.

As vazões de líquido e de vapor descrevem toda movimentação interna da coluna provocando alterações nas temperaturas, pressões e composições na mesma. As medições das vazões no interior da coluna são medições difíceis de serem obtidas. Porém, podem ser medidas na alimentação e nos extremos da coluna (condensador e refervedor) para serem utilizadas na inferência da composição. Todavia, poucos trabalhos faz referência do uso dessas vazões no projeto de sensores virtuais, sendo que apenas Zamprogna (2001) relata o uso dessas variáveis com um aumento na precisão da estimação.

De qualquer forma, no projeto de um sensor virtual capaz de fazer a inferência da composição do destilando numa coluna de destilação por meio de RNA, deve-se dispor de um conjunto de dados suficientemente grande. Neste trabalho foram disponibilizados os dados relativos às 12 variáveis que podem ser vistas na 
Tabela 6-4 a seguir. Como o objetivo final é a obtenção de um estimador para a composição no topo da coluna "B" de um aparelho de destilação, torna-se então claro que tal variável deve ser escolhida como saída do modelo.

Tabela 6-4 - Tabela com informações básicas sobre as variáveis secundárias e primária do processo.

\begin{tabular}{|l|c|c|c|c|c|c|c|c|c|c|}
\hline Número de variáveis: & 12 & & \\
Número de entradas: & 11 \\
Número de saídas: & 1 \\
\hline \multicolumn{7}{|l|}{ Entradas } \\
\hline VR & F & DL & RR & PB & PM & PT & PC & TB & LR & XD \\
\hline ton $/ \mathrm{h}$ & $\mathrm{m}^{3} / \mathrm{h}$ & $\mathrm{m}^{3} / \mathrm{h}$ & --- & bar & bar & bar & bar & ${ }^{\circ} \mathrm{C}$ & $\mathrm{m}$ & ${ }^{\circ}$ INPM \\
\hline
\end{tabular}

O próximo passo é verificar se as demais variáveis podem ser utilizadas como entrada do sistema de inferência sem que haja redundância entre tais variáveis. Portanto, calcularamse as funções de correlação cruzada entre cada uma das variáveis candidatas e a saída (ver Tabela 6-5).

Tabela 6-5 - Matriz correlação Cruzada.

\begin{tabular}{|c|c|c|c|c|c|c|c|c|c|c|c|}
\hline & VR & F & DL & RR & PB & PM & PT & PC & TB & LR & XD \\
\hline VR & 1,0000 & 0,7317 & $-0,6415$ & $-0,6900$ & 0,9127 & 0,9201 & 0,8215 & $-0,6283$ & 0,7845 & $-0,6026$ & $-0,3901$ \\
\hline F & 0,7317 & 1,0000 & $-0,6674$ & $-0,8809$ & 0,6446 & 0,5806 & 0,4688 & $-0,6341$ & 0,8556 & $-0,9314$ & $-0,4215$ \\
\hline DL & $-0,6415$ & $-0,6674$ & 1,0000 & 0,6074 & $-0,6286$ & 0,6011 & $-0,6331$ & 0,7401 & $-0,7187$ & 0,5908 & 0,4281 \\
\hline RR & $-0,6900$ & $-0,8809$ & 0,6074 & 1,0000 & $-0,5774$ & $-0,5201$ & $-0,5187$ & 0,5635 & $-0,7461$ & 0,8131 & 0,3583 \\
\hline PB & 0,9127 & 0,6446 & $-0,6286$ & $-0,5774$ & 1,0000 & 0,9266 & 0,7872 & $-0,6113$ & 0,7548 & $-0,6009$ & $-0,3898$ \\
\hline PM & 0,9201 & 0,5806 & 0,6011 & $-0,5201$ & 0,9266 & 1,0000 & 0,8271 & $-0,5750$ & 0,6523 & $-0,5275$ & 0,4084 \\
\hline PT & 0,8215 & 0,4688 & $-0,6331$ & $-0,5187$ & 0,7872 & 0,8271 & 1,0000 & $-0,5460$ & 0,5745 & $-0,4620$ & $-0,3549$ \\
\hline PC & $-0,6283$ & $-0,6341$ & 0,7401 & 0,5635 & $-0,6113$ & $-0,5750$ & $-0,5460$ & 1,0000 & $-0,7023$ & 0,6166 & $-0,4154$ \\
\hline TB & 0,7845 & 0,8556 & $-0,7187$ & $-0,7461$ & 0,7548 & 0,6523 & 0,5745 & $-0,7023$ & 1,0000 & $-0,8154$ & 0,4742 \\
\hline LR & $-0,6026$ & $-0,9314$ & 0,5908 & 0,8131 & $-0,6009$ & $-0,5275$ & $-0,4620$ & 0,6166 & $-0,8154$ & 1,0000 & 0,3411 \\
\hline XD & $-0,3901$ & $-0,4215$ & 0,4281 & 0,3583 & $-0,3898$ & 0,4084 & $-0,3549$ & $-0,4154$ & 0,4742 & 0,3411 & 1,0000 \\
\hline
\end{tabular}

O coeficiente de correlação varia de -1 a 1 . O sinal indica direção positiva ou negativa do relacionamento e seu valor sugere a força da relação entre as variáveis. Uma correlação perfeita (-1 ou 1) indica que o escore de uma variável pode ser determinado exatamente ao se saber o escore da outra. No outro oposto, uma correlação de valor zero indica que não há relação linear entre as variáveis. Para Cohen (1988) o valor situado entre 0,10 e 0,39 indica 
uma fraca dependência entre as variáveis, valor situado entre 0,40 e 0,69 indica dependência moderada e valor entre 0,70 e 1 pode ser interpretado como dependência forte.

De posse dos resultados, verificou-se então que todas as variáveis apresentaram correlação com a saída. Entretanto, as variáveis DL, TB e LR apresentaram uma correlação mais significativa e, dessa forma, foram pré-selecionadas.

Analisando os resultados da Tabela 6-5 anterior, verifica-se que todas as variáveis estão correlacionadas moderadamente com a saída. Entretanto, as variáveis F, DL, PM, TB e PC apresentaram correlação mais significativa, conforme ilustrado também nos gráficos das Figuras 6-5 a 6-9, sendo que então foram também pré-selecionadas.

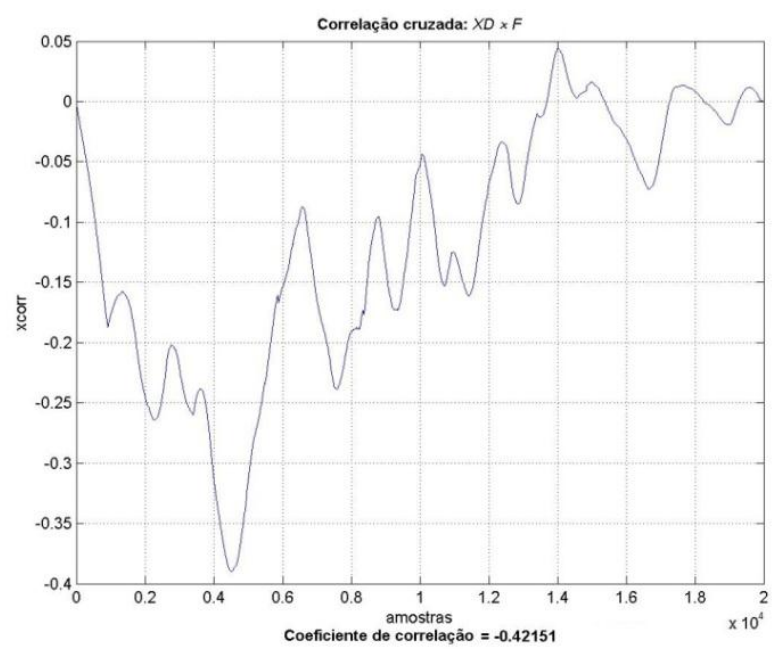

Figura 6-5 - Funções de correlação cruzada entre a variável candidata F com a saída XD.

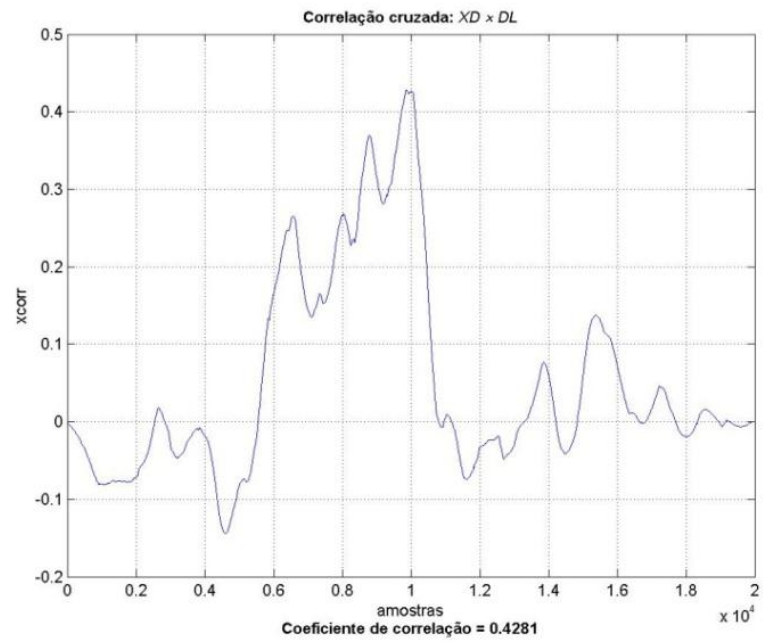

Figura 6-6 - Funções de correlação cruzada entre a variável candidata DL com a saída XD. 


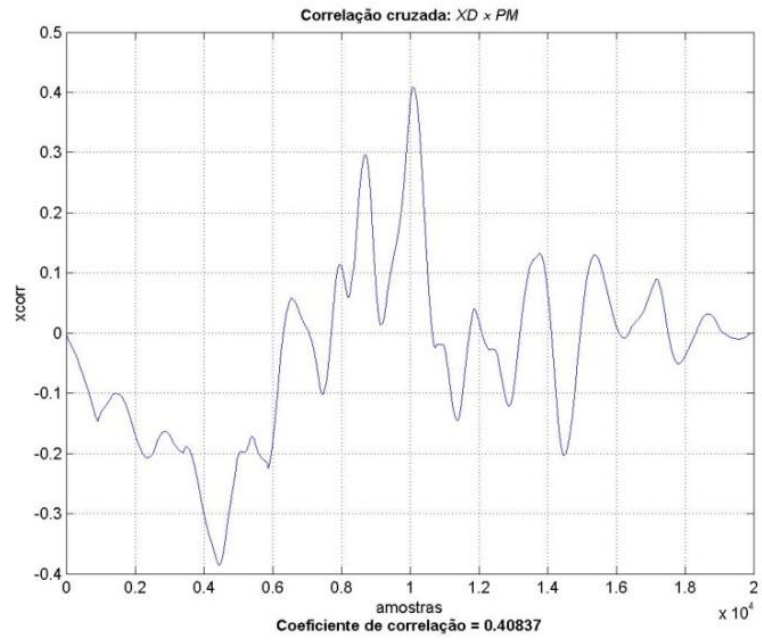

Figura 6-7 - Funções de correlação cruzada entre a variável candidata PM com a saída XD.

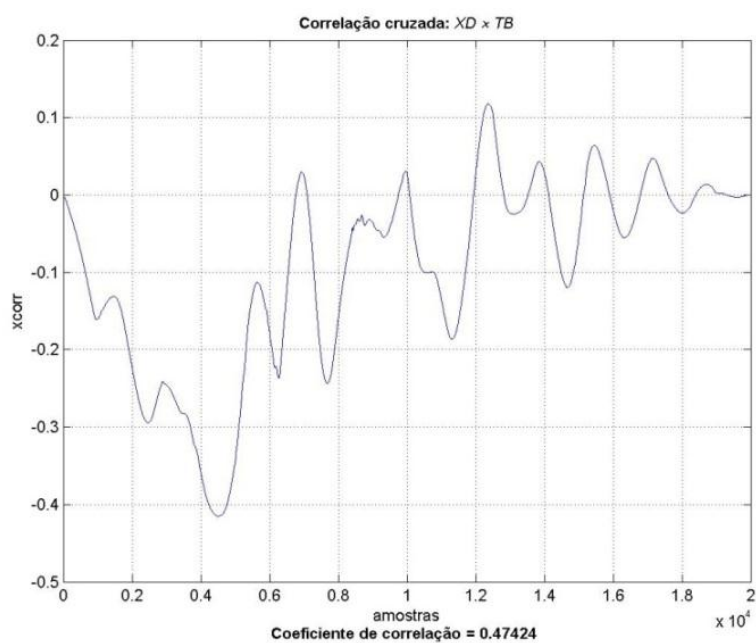

Figura 6-8 - Funções de correlação cruzada entre a variável candidata TB com a saída XD.

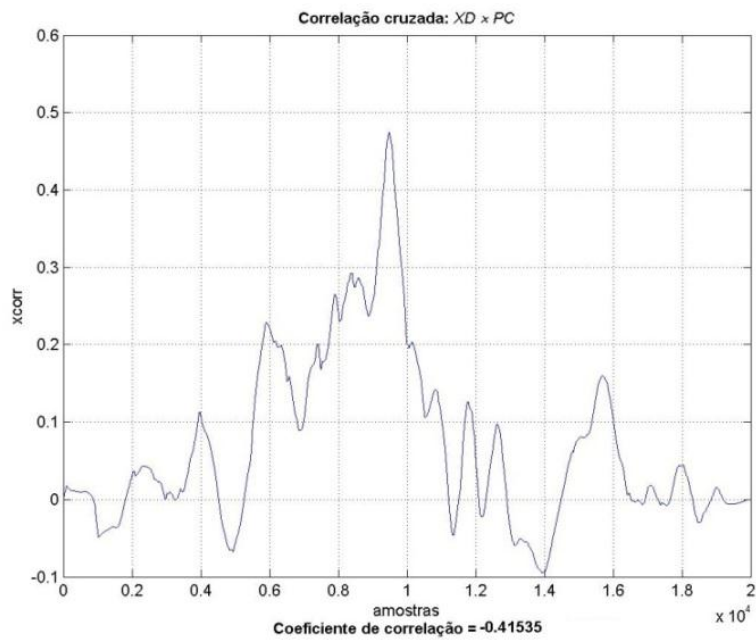

Figura 6-9 - Funções de correlação cruzada entre a variável candidata PC com a saída XD. 
A seguir, por meio da Tabela 6-5 e das Figuras 6-10 a 6-19 mostradas a seguir, verificou-se se há existência de possíveis correlações entre as entradas pré-selecionadas a serem usadas com entrada no sensor virtual. O restante dos gráficos das funções de correlação cruzada entre as demais entradas estão disponíveis para análise no anexo (A).

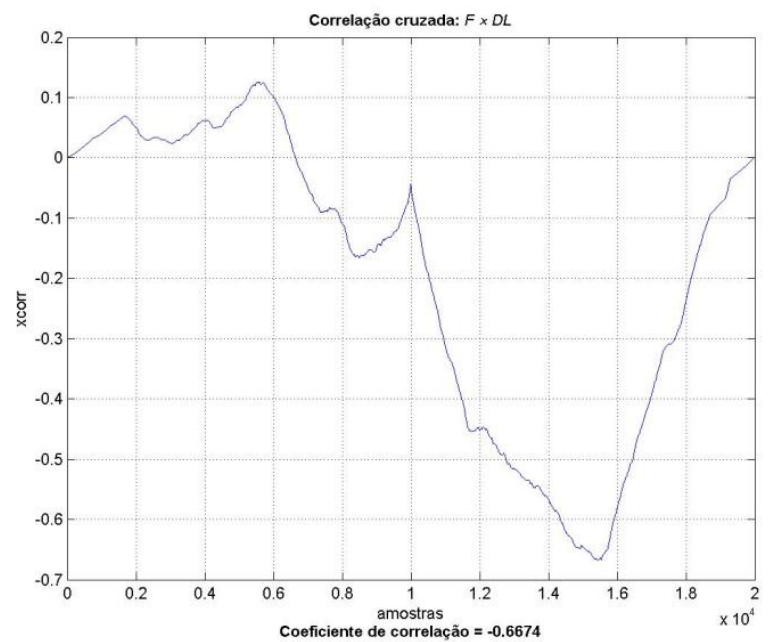

Figura 6-10 - Função correlação cruzada entre as entradas candidatas F e DL.

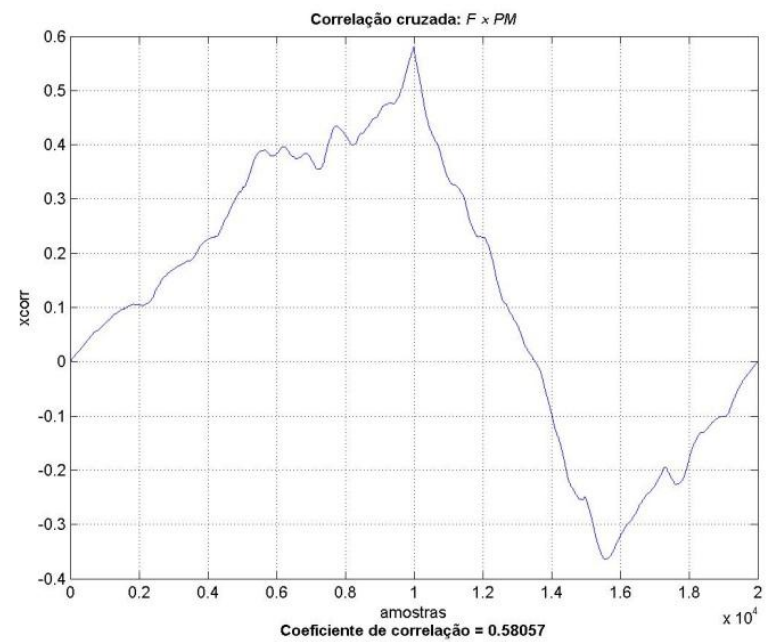

Figura 6-11 - Função correlação cruzada entre as entradas candidatas F e PM. 


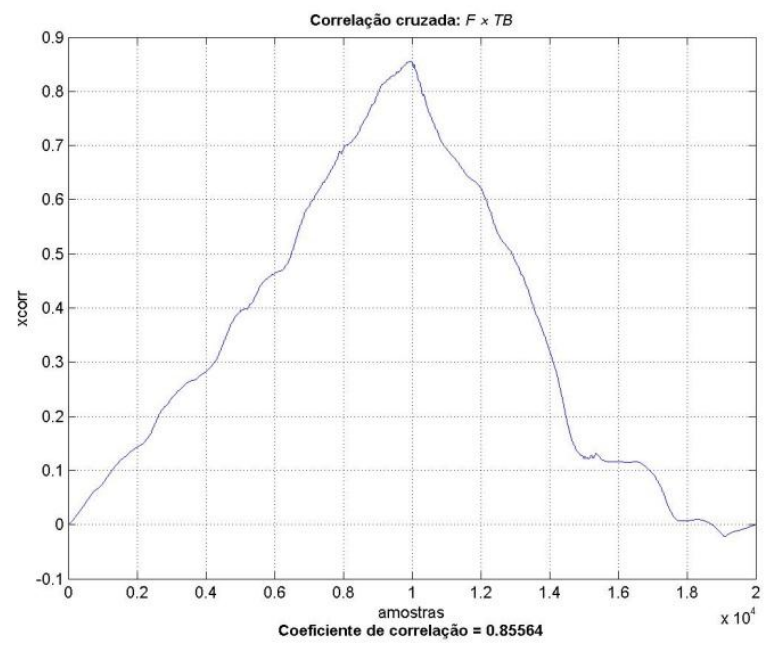

Figura 6-12 - Função correlação cruzada entre as entradas candidatas F e TB.

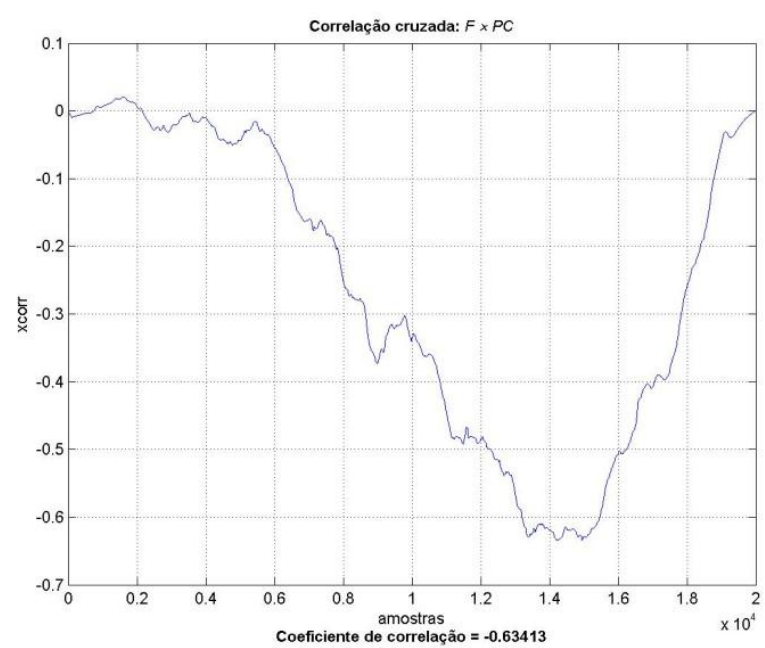

Figura 6-13 - Função correlação cruzada entre as entradas candidatas F e PC.

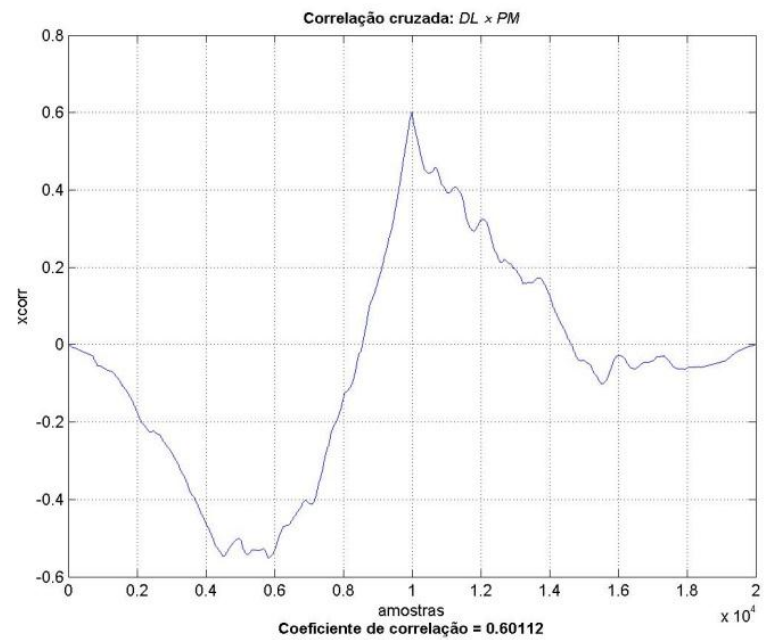

Figura 6-14 - Função correlação cruzada entre as entradas candidatas DL e PM. 


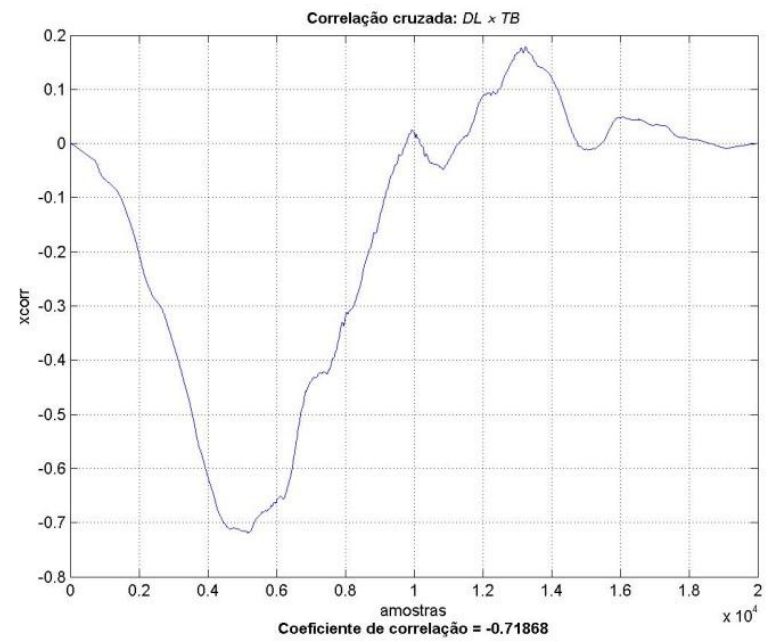

Figura 6-15 - Função correlação cruzada entre as entradas candidatas DL e TB.

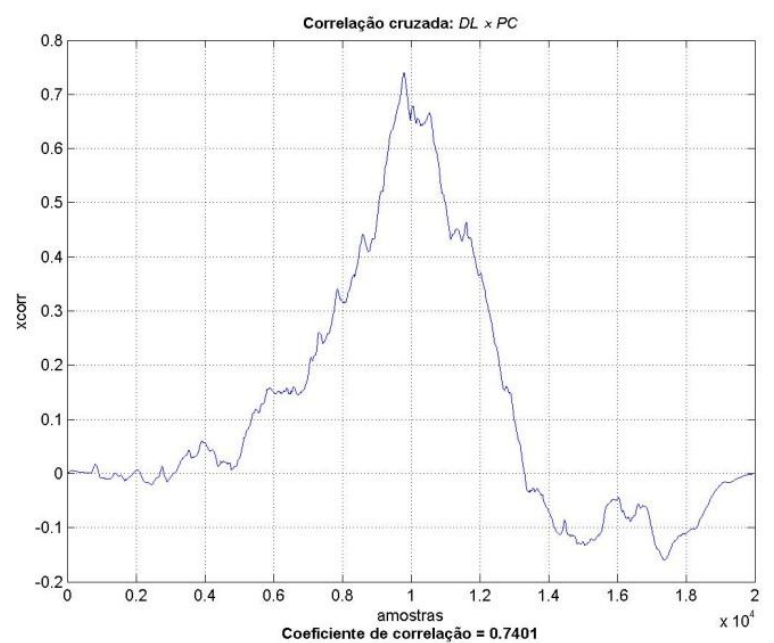

Figura 6-16 - Função correlação cruzada entre as entradas candidatas DL e PC.

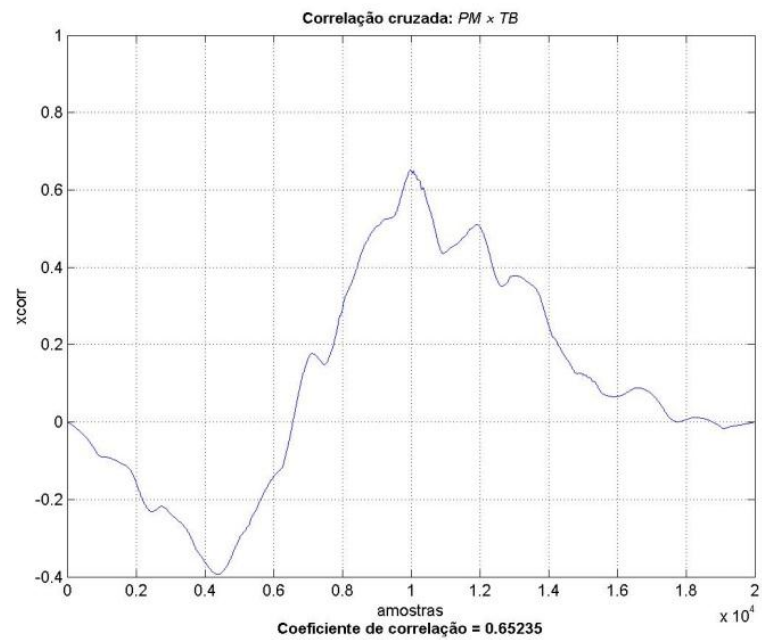

Figura 6-17 - Função correlação cruzada entre as entradas candidatas PM e TB. 


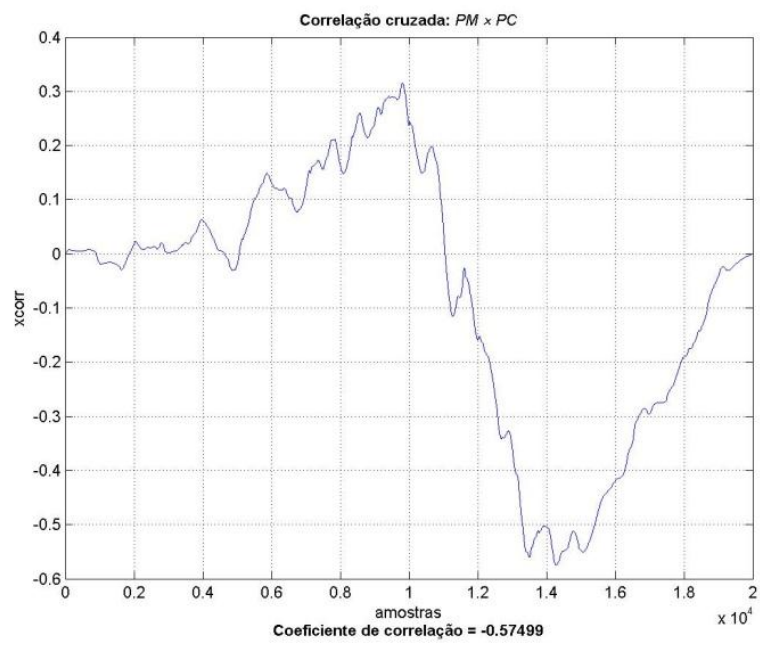

Figura 6-18 - Função correlação cruzada entre as entradas candidatas PM e PC.

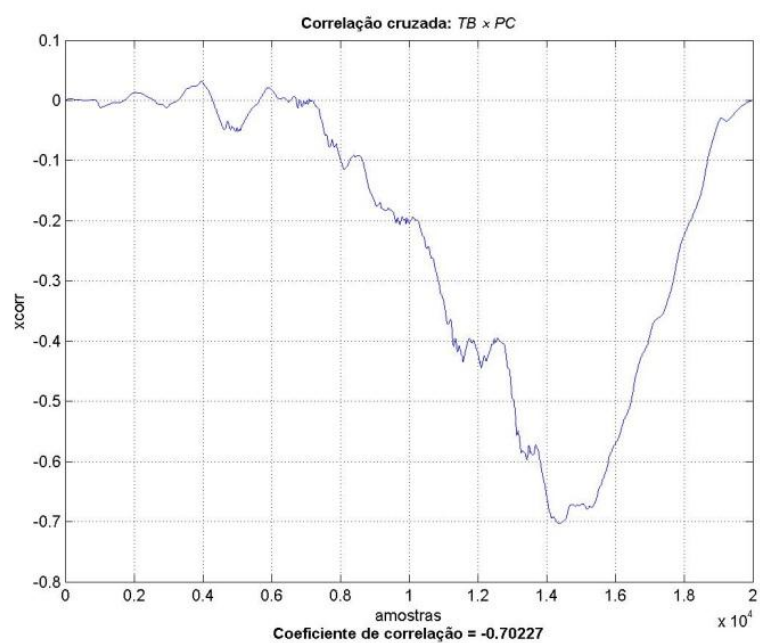

Figura 6-19 - Função correlação cruzada entre as entradas candidatas TB e PC.

Analisando o resultado da covariância cruzada entre as variáveis candidatas, definiuse a vazão de alimentação de vinho (VF), temperatura na bandeja A18 (TB) e vazão de saída do destilado (DL) como possíveis variáveis de entrada e como saída da rede a composição do etanol (XD) em ${ }^{\circ}$ INPM, conforme listado na Tabela 6-6 seguinte. Os gráficos das aquisições de todas as variáveis utilizadas nessa etapa estão disponíveis no anexo (A).

Tabela 6-6 - Lista de variáveis candidatas selecionadas.

\begin{tabular}{|l|c|c|c|c|}
\hline \multicolumn{1}{|c|}{ Variável } & ID & Valor Operacional & Unidade & Tipo \\
\hline Vazão de alimentação & F & 6712,58 & $\mathrm{~m}^{3} / \mathrm{h}$ & Entrada \\
\hline Vazão de retirada do produto do topo & DL & 2786,35 & $\mathrm{~m}^{3} / \mathrm{h}$ & Entrada \\
\hline Temperatura no fundo (A18) & TB & 91 & ${ }^{\circ} \mathrm{C}$ & Entrada \\
\hline Concentração do produto do topo & XD & 93,2 & ${ }^{\circ}$ INPM & Saída \\
\hline
\end{tabular}




\subsection{Pré-Processamento de Dados}

Nesta etapa é realizada uma análise criteriosa sobre os dados coletados buscando minimizar ambiguidades e possíveis erros associados à etapa de aquisição de dados. Normalmente, os dados coletados são divididos em duas categorias: dados de treinamento, que serão utilizados para o treinamento da rede e dados de teste, os quais serão utilizados para verificar seu desempenho sob condições reais de utilização. Além dessa divisão, pode-se usar também uma subdivisão do conjunto de treinamento, criando um conjunto de validação, utilizado para verificar a eficiência da rede quanto à sua capacidade de generalização durante o treinamento, podendo então ser empregado como critério de parada do treinamento.

Depois de determinados os conjuntos de treinamento, teste e validação, foi realizada a remoção de picos indesejáveis buscando, dessa forma, a redução de seus efeitos, visto que, em ambientes industriais os picos são induzidos nos sensores e sistema de aquisição de dados. Portanto, nessa etapa são definidos os conjuntos de dados que serão utilizados no projeto da rede.

Na prática, nem todas as entradas e saídas apresentam a mesma ordem de grandeza. Os valores numéricos obtidos estão relacionados às grandezas físicas que, em geral, não têm as mesmas dimensões. Para contornar esse problema realizou-se a normalização das entradas e saídas por meio da função mapminmax existente no toolbox do matlab, que ajusta o conjunto de dados no intervalo $[-1,1]$ levando em conta os valores máximo e mínimo de cada variável medida. A padronização dos dados faz com que os valores apresentados à rede não se afastem dos limites dinâmicos da função de ativação, além de aproximar a faixa de variação dos dados de entrada com a dos pesos iniciais, o que contribui para a convergência do algoritmo de treinamento (Zhang et al., 1998). Outro processamento realizado nessa etapa é a remoção do valor médio do conjunto de dados. 
Nesse trabalho foram usados dados reais coletados de uma coluna de destilação pertencente a uma destilaria de etanol. Esses dados foram coletados por meio de um sistema de supervisão e, no total, foram aquisitadas 54 horas e 10 minutos de dados do processo operando em condições normais. Foram analisadas 11 variáveis do processo mais a base de tempo, conforme pode ser visto na Tabela 6-7 a seguir.

Tabela 6-7 - Informações básicas sobre os dados aquisitados.

Conjunto de dados para definição do período de amostragem:

\begin{tabular}{|l|c|c|c|}
\hline Período de aquisição & $21 / 10 / 2011$ (12h30min) até 21/10/2011 (16h40min) \\
\hline Total de amostras aquisitadas & 1000 & $4 \mathrm{~h} 10 \mathrm{~min}$ \\
\hline Taxa de amostragem & 4 & \multicolumn{2}{c|}{ amostras/min } \\
\hline Período de amostragem & $\begin{array}{c}\text { Segundos } \\
\text { Minutos }\end{array}$ \\
\hline Conjunto de dados para treinamento, teste e validação da RNA: \\
\hline Período de aquisição $07 / 11 / 2011(12 \mathrm{~h} 30 \mathrm{~min})$ até $11 / 11 / 2011$ (16h30min) \\
\hline Total de amostras aquisitadas & 12000 & $100 \mathrm{~h}$ \\
\hline Quantidade de amostras usadas no treinamento da RNA & 10000 & $83 \mathrm{~h} 20 \mathrm{~min}$ \\
\hline Conjunto de treinamento & $70 \%$ & 7000 & $58 \mathrm{~h} 20 \mathrm{~min}$ \\
\hline Conjunto de teste $15 \%$ & 1500 & $12 \mathrm{~h} 30 \mathrm{~min}$ \\
\hline Conjunto de validação & $15 \%$ & 1500 & $12 \mathrm{~h} 30 \mathrm{~min}$ \\
\hline Taxa de amostragem & 2 & amostras/min \\
\hline Período de amostragem & 30 & Segundos \\
\hline
\end{tabular}

Os dados aquisitados contendo cerca de 13000 pontos foram divididos em 2 conjuntos. O primeiro para a definição do período de amostragem, contendo 1000 pontos coletados numa taxa de 4 amostras por minuto, totalizando-se então em 4 horas de 10 minutos de aquisição. Um segundo agrupamento de dados usado no treinamento, teste e validação da RNA foi composto de 12000 pontos, coletados numa taxa de 2 amostras por minuto, totalizando-se em 83 horas e 20 minutos de aquisição. Após o pré-processamento da rede foram utilizados 7000 pontos para o treinamento, 1500 para a etapa de teste e 1500 na validação do modelo. 
Os dados foram divididos em blocos contínuos devido à caraterística do problema de identificação, onde as redes usadas dependem dos estados anteriores. Os gráficos das aquisições das variáveis disponíveis encontram-se no Anexo (A).

\subsection{Escolha da RNA}

Identificar um sistema dinâmico significa determinar um modelo por meio de um conjunto de dados medidos desse sistema. As redes neurais recorrentes têm sido usadas com êxito na realização deste trabalho. Um sistema dinâmico é aquele cuja saída atual pode ser determinada com base em suas entradas e saídas passadas, ou seja, são sistemas com memória.

Assim, um modelo linear de um sistema dinâmico, em sua forma discreta, pode ser descrito da seguinte forma:

$$
\begin{gathered}
y(k)=a_{1} y(k-1)+a_{2} y(k-2)+\cdots+a_{j} y(k-j)+b_{1} u(k-1) \\
+b_{2} u(k-2)+b_{i} y(k-i)+e(k)
\end{gathered}
$$

O erro de modelagem pode ser descrito por:

$$
e(k)=y(k)-\hat{y}(k)
$$

Sendo a saída estimada dada por:

$$
\begin{gathered}
\widehat{y}(k)=a_{1} y(k-1)+a_{2} y(k-1)+\cdots+a_{j} y(k-j)+b_{1} u(k-1) \\
+b_{2} u(k-2)+b_{i} y(k-i)
\end{gathered}
$$

De forma bem simplificada, este modelo pode ser identificado por meio de uma RNA, com $i+j$ entradas, sendo $j$ delas realimentadas da saída constituída de um único neurônio com função de ativação linear.

Em identificação de sistemas, as RNAs têm um importante papel na modelagem caixa-preta (identificação estrutural) e caixa cinza de sistemas dinâmicos não lineares 
(Sjöberg, 1994; Narendra \& Parthsarathy, 1990). As RNAs podem ser aplicadas, com diferentes regressores, em modelos dinâmicos caixa-preta não lineares, tais como:

- TDNN: usa apenas as medidas passadas do vetor $u(k-i)$ na entrada de uma rede estática;

- NNFIR (Network Non-linear Finite Impulse Response model): usa apenas as medidas passadas do vetor $u(k-i)$, atrasadas internamente, como regressores numa rede estática;

- NNARX (Network Non-linear AutoRegressive model structure eXogenous inputs): emprega o vetor das entradas $u(k-i)$ e das saídas $y(k-j)$ passadas como regressores (modelo série-paralelo);

- NNOE (Network Non-linear Output Error model): utiliza o vetor das entradas passadas $u(k-i)$ e das saídas previstas passadas $\hat{y}_{u}(k-j \mid \theta)$, como entradas da RNA. Este modelo é denominado modelo paralelo;

- NNARMAX (Network Non-linear AutoRegressive Moving Average model structure with eXogenous inputs): esta rede utiliza os vetores $e(k-i), u(k-i) \mathrm{e}$ $y(t-j)$

- NNBJ (Network Non-linear Box-Jenkins model structure): utilizam os quatro tipos de regressores mencionados nos itens anteriores;

- modelos não lineares, representados no espaço de estados: utiliza os componentes passados "virtualmente" das saídas.

Por definição, as redes neurais recorrentes são redes com realimentação de uma ou mais saídas, globais ou intermediárias. O caso de realimentação de uma saída intermediária pode ocorrer em redes com uma ou mais camadas escondidas, onde a saída de um neurônio da camada escondida é realimentada na rede. 
Durante a definição de qual tipo de modelo usar, linear ou não linear, é importante levar em consideração que, ao contrário do que se possa parecer, a principal motivação para se usar modelos não lineares não é melhorar sua precisão. Existem razões mais fortes para, em uma determinada aplicação, se faça a opção por modelos não lineares, com por exemplo, o fato de que os modelos não lineares são capaz de produzir determinado comportamento dinâmicos que os modelos lineares não conseguem representar (Aguirre, 2007).

As redes neurais dinâmicas são topologias projetadas para incluir relações temporais de forma explícita no mapeamento entrada-saída. Em particular, a rede TDNN introduz atraso no tempo nas entradas da rede (Waibel et al., 1989). Neste caso, a linha de atraso do filtro linear é chamada de memória de curto prazo.

Na topologia de rede TDNN substituem-se os sinais de entrada de uma MLP por uma linha de atraso. Cada conexão é representada por um filtro de impulso de resposta com duração finita, conhecida como FIR (Finite Duration Impulse Response) (Braga et al., 2000).

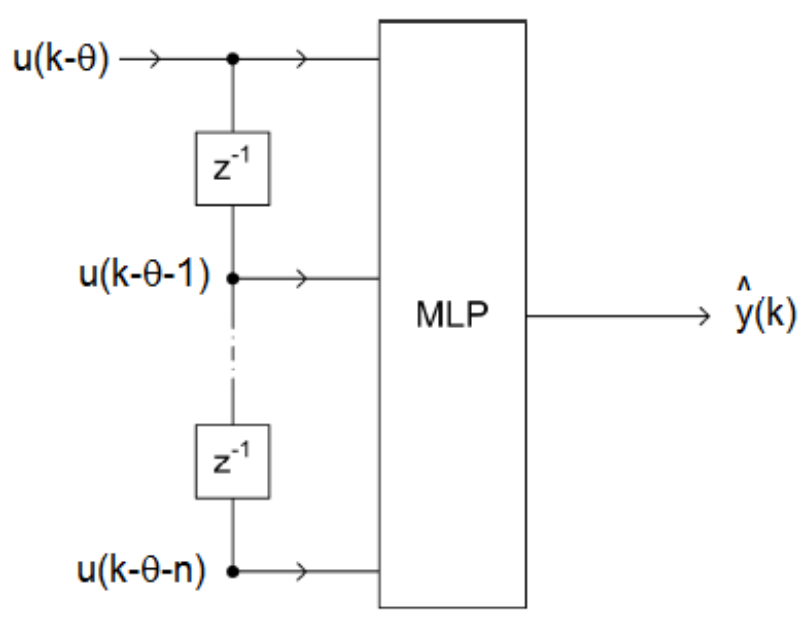

Figura 6-20 - Esquema TDNN para identificação de sistemas.

A Equação (6-9) descreve matematicamente a saída de um modelo não linear FIR.

$$
\hat{y}(t)=f[y(t-\theta), u(t-\theta-1), \ldots, u(t-\theta-n)]
$$

onde $f($.) é uma função não linear mapeada pela rede TDNN por meio da entrada $u$ e pela saída $\hat{y}$ da planta. 
As redes neurais recorrentes são outra técnica capaz de lidar com variações temporais. Há dois tipos de redes recorrentes: aquelas em que o padrão de entrada é fixo e a saída caminha, dinamicamente, para um estado estável, e aquelas em que tanto a entrada quanto a saída variam com o tempo; estas últimas são mais gerais e são utilizadas com mais frequência. A Figura 6-21 (a) e Figura 6-21 (b) apresentam o diagrama de uma rede NNARX, onde $\hat{y}$ é a saída estimada, $\theta$ o atraso de transporte, $m$ a ordem da saída, $n$ a ordem da entrada, $y$ a saída e $u$ a entrada da planta.

Pode-se notar a aplicação de regressores nesse modelo, fazendo que a saída presente da rede neural esteja relacionada com valores passados da entrada e saída do sistema a ser identificado. A utilização de regressores é de fundamental importância, uma vez que a estrutura é projetada com o intuito de identificar a dinâmica existente em um sistema físico.

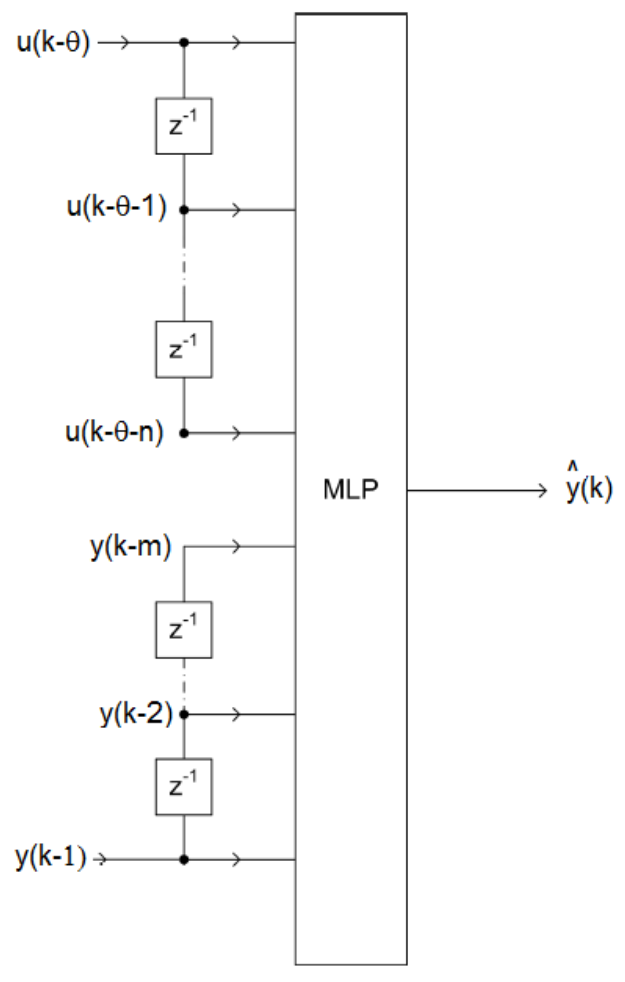

(a)

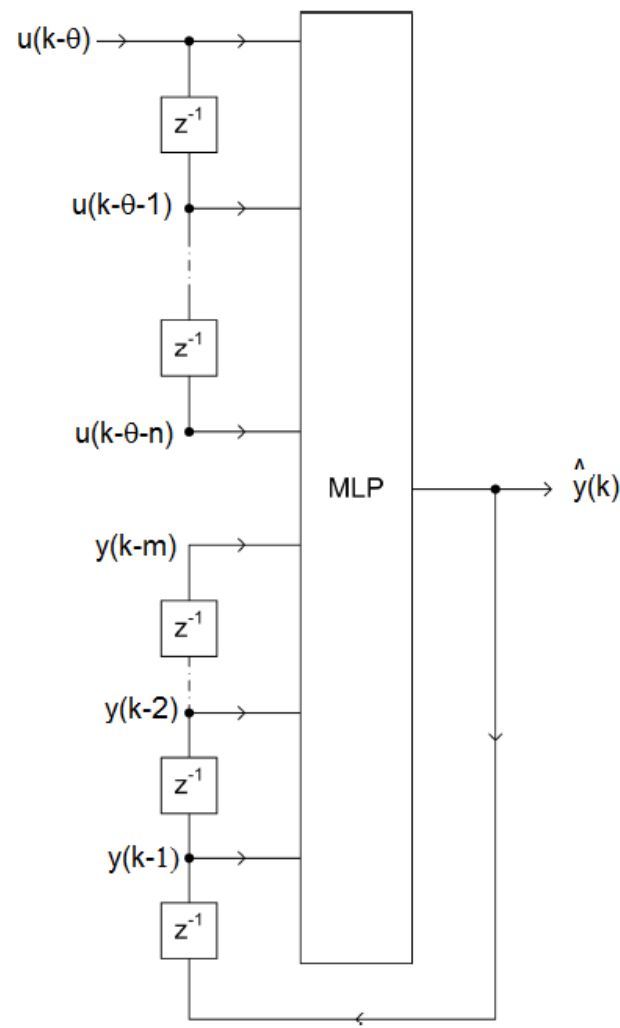

(b)

Figura 6-21 - Esquema NNARX para Identificação de sistemas: (a) modelo série-paralelo e (b) modelo paralelo. 
A expressão matemática que descreve o modelo não linear pode ser descrita como representado em (6-10).

$$
\hat{y}(k)=f[y(k-1), \ldots, y(k-n), u(k-\theta), \ldots, u(k-\theta-m)]
$$

onde $f($. ) é uma função não linear mapeada pela rede neural por meio da entrada $u$ e pela saída $\hat{y}$ da planta.

A rede TDNN representa um compromisso entre simplicidade da estrutura da rede e poder de processamento. O ponto positivo é que ela pode ser treinada com o algoritmo backpropagation, desde que o sinal desejado esteja disponível a cada instante. Por outro lado, como dificuldade de projeto, além daquelas apresentadas pela MLP, nas redes TDNN existe também a escolha do tamanho da linha de atraso.

Por outro lado, nas redes NNARX a estimativa gerada é sempre estável, uma vez que representa relações puramente algébricas entre a estimativa e as medições passadas das entradas e saídas do processo, não existindo a realimentação da saída estimada. Dessa forma, ela é a estrutura preferida quando o sistema a ser modelado é determinístico ou apresentar baixo nível de ruído (Haykin, 2001).

Existem diversas estruturas de modelagem, cada uma com suas vantagens e desvantagens. Neste trabalho, as redes usadas como base para o sistema de inferência proposto foram a rede TDNN e a NNARX.

\subsection{Treinamento}

Um grande problema enfrentado na aplicação de RNA é o elevado tempo de treinamento da rede. Inúmeros fatores podem contribuir para esse tempo elevado de treinamento: número de neurônios insuficientes e/ou de camadas subdimensionadas, conjunto de treinamento e quantidade de entradas muito grande, ineficiência do algoritmo de treinamento utilizado, etc. 
Dessa forma, a partir das arquiteturas NNARX e TDNN definidas na Seção 6.4 e utilizando a divisão dos dados aquisitados, em conjunto de treinamento, teste e validação, é realizado o treinamento da rede neural por meio da toolbox de redes neurais do software MATrix LABoratory (MATLAB ${ }^{\circledR}$ versão R2010b), da MathWorks, Inc, USA. Esse programa é uma ferramenta de alto desempenho amplamente utilizado na comunidade acadêmica que integra análise numérica, cálculo com matrizes e construção de gráficos.

Ao final de cada etapa de treinamento, a rede é então submetida a testes de validação para avaliar sua capacidade de generalização. A Tabela 6-8 a seguir mostra o número de neurônios usados na camada de entrada, na camada oculta com base no número de entradas e nos atrasos.

Tabela 6-8 - Definição dos atrasos e número de neurônios utilizados no treinamento.

\begin{tabular}{|c|c|c|c|c|c|c|c|c|c|c|c|}
\hline \multirow{2}{*}{ Entradas } & \multirow{2}{*}{ Ordem } & \multirow{2}{*}{ Atrasos } & \multicolumn{2}{|c|}{$\mathrm{N}^{\circ}$ de entradas } & \multirow{2}{*}{\multicolumn{7}{|c|}{$\mathrm{N}^{\mathrm{o}}$ de neurônios na camada oculta }} \\
\hline & & & TDNN & NNARX & & & & & & & \\
\hline \multirow{6}{*}{$\begin{array}{c}\text { F } \\
\text { DL } \\
\text { TB }\end{array}$} & 2 & 2 & 3 & 6 & 15 & 20 & 30 & 45 & 60 & 75 & 100 \\
\hline & 4 & 4 & 5 & 10 & 15 & 20 & 30 & 45 & 60 & 75 & 100 \\
\hline & 6 & 6 & 7 & 14 & 15 & 20 & 30 & 45 & 60 & 75 & 100 \\
\hline & 8 & 8 & 9 & 18 & 15 & 20 & 30 & 45 & 60 & 75 & 100 \\
\hline & 10 & 10 & 11 & 22 & 15 & 20 & 30 & 45 & 60 & 75 & 100 \\
\hline & 12 & 12 & 13 & 26 & 15 & 20 & 30 & 45 & 60 & 75 & 100 \\
\hline \multirow{6}{*}{$\begin{array}{c}\mathrm{F} \times \mathrm{DL} \\
\mathrm{F} \times \mathrm{TB} \\
\mathrm{DL} \times \mathrm{TB}\end{array}$} & 2 & 2 & 6 & 9 & 15 & 20 & 30 & 45 & 60 & 75 & 100 \\
\hline & 4 & 4 & 10 & 15 & 15 & 20 & 30 & 45 & 60 & 75 & 100 \\
\hline & 6 & 6 & 14 & 21 & 15 & 20 & 30 & 45 & 60 & 75 & 100 \\
\hline & 8 & 8 & 18 & 27 & 15 & 20 & 30 & 45 & 60 & 75 & 100 \\
\hline & 10 & 10 & 22 & 33 & 15 & 20 & 30 & 45 & 60 & 75 & 100 \\
\hline & 12 & 12 & 26 & 39 & 15 & 20 & 30 & 45 & 60 & 75 & 100 \\
\hline \multirow{6}{*}{$\mathrm{F} \times \mathrm{DL} \times \mathrm{TB}$} & 2 & 2 & 9 & 12 & 15 & 20 & 30 & 45 & 60 & 75 & 100 \\
\hline & 4 & 4 & 15 & 20 & 15 & 20 & 30 & 45 & 60 & 75 & 100 \\
\hline & 6 & 6 & 21 & 28 & 15 & 20 & 30 & 45 & 60 & 75 & 100 \\
\hline & 8 & 8 & 27 & 36 & 15 & 20 & 30 & 45 & 60 & 75 & 100 \\
\hline & 10 & 10 & 33 & 44 & 15 & 20 & 30 & 45 & 60 & 75 & 100 \\
\hline & 12 & 12 & 39 & 52 & 15 & 20 & 30 & 45 & 60 & 75 & 100 \\
\hline
\end{tabular}

As redes utilizadas possuem uma camada de entrada composta por $\mathbf{N}$ neurônios, uma camada oculta contendo $\mathbf{M}$ neurônios e uma saída.

$\mathrm{O}$ algoritmo levenberg-marquardt foi selecionado para o treinamento das redes TDNN e NNARX, pois este algoritmo é uma variação do algoritmo backpropagation padrão 
que utiliza a derivada segunda como forma de otimização do mesmo. Segundo Silva et al. (2010), este algoritmo é capaz de conduzir o treinamento de redes PMC de forma mais rápida que algoritmos tradicionais.

\subsection{Validação do Estimador Neural}

Nesta etapa, um segundo conjunto de dados é utilizado pela rede para testar se os valores gerados por ela estão compatíveis com os valores experimentais. Esse conjunto é composto por 3000 amostras, divididas em 2 subgrupos (teste e validação). Como no treinamento foi utilizado $70 \%$ da base de dados, na validação é usado $15 \%$ da base de dados e no teste $15 \%$. O conjunto de treinamento foi usado para determinar os coeficientes do modelo, o conjunto de validação para especificar a melhor estrutura do modelo e o conjunto de teste para determinar o desempenho do modelo.

Para quantificar o desempenho de estimação das redes TDNN e NNARX, as medidas utilizadas foram o menor percentual do MSE (Mean Squared Error) e o menor MAE (Mean Absolute Error). Esses índices indica a qualidade de aproximação entre o sinal real e o estimado.

Segundo Zanata (2005), a medida de erro MAE é a média aritmética do valor do módulo do erro obtido entre o valor estimado pelo sensor virtual (estimador neural) e o valor esperado, fornecido pelo medidor. Este erro apresenta a magnitude da dispersão dos erros com pesos equivalentes e pode ser calculado por meio da seguinte equação:

$$
M A E=\frac{\sum_{i=1}^{N}|y(i)-\hat{y}(i)|}{N}
$$

A medida de erro MSE é a média dos quadrados das diferenças entre o valor estimado pelo sensor e o valor esperado, fornecido pelo medidor, conforme a expressão (6-12). Este valor é utilizado como medida do desempenho da rede durante o seu treinamento. Esta função 
pondera com maior peso (quadrático) os pontos em que o erro apresentado pela rede for maior.

$$
M S E=\frac{\sum_{i=1}^{N}[y(i)-\hat{y}(i)]^{2}}{N}
$$

A partir dos resultados encontrados, concluiu-se que a estrutura NNARX é a que apresentou melhor desempenho. Os resultados obtidos para algumas das redes treinadas serão expostos a seguir.

\subsection{Resultados e Discussão}

Após coletar, processar e analisar os dados, o próximo passo foi realizar diversos treinamentos com diferentes topologias de redes neurais TDNN e NNARX. A diferença entre elas está no número de entradas, de regressores, e neurônios da camada oculta, conforme visto na Tabela 6-8 anterior, sendo realizadas 588 simulações no total. A seguir serão apresentados os resultados das RNAs que obtiveram os melhores desempenhos na estimação da composição. Nas Tabelas 6-9 e 6-10 são listados os melhores casos para cada topologia de rede que apresentaram o menor erro médio quadrático obtido nas simulações, onde serão mostrados os gráficos de erro, treinamento e validação da RNA.

A decisão sobre os melhores modelos foi tomada em favor da topologia que, usando o conjunto de validação, apresentou a maior capacidade preditiva, com menor número de neurônios na camada escondida e menor número de entradas. 
Tabela 6-9 - Os 15 melhores resultados da simulação para a rede TDNN.

\begin{tabular}{|c|c|c|c|c|c|c|c|c|c|c|c|c|c|}
\hline \multirow{3}{*}{$\begin{array}{c}\text { Simulação } \\
56\end{array}$} & \multirow{3}{*}{$\begin{array}{c}\text { Neurônios } \\
45 \\
\end{array}$} & \multirow{3}{*}{$\begin{array}{c}\begin{array}{c}\text { Ordem } \\
\text { (regressores) }\end{array} \\
2\end{array}$} & \multicolumn{3}{|c|}{ Entrada } & \multicolumn{4}{|c|}{ MSE } & \multicolumn{4}{|c|}{ MAE } \\
\hline & & & \multirow[t]{2}{*}{$\mathrm{F}$} & \multirow{2}{*}{$\begin{array}{c}\text { DL } \\
*\end{array}$} & \multirow[t]{2}{*}{$\mathrm{TB}$} & \multicolumn{2}{|c|}{ Validação } & \multicolumn{2}{|c|}{ Teste } & \multicolumn{2}{|c|}{ Validação } & \multicolumn{2}{|c|}{ Teste } \\
\hline & & & & & & 0,4708 & $47,08 \%$ & 0,3533 & $35,33 \%$ & 0,5950 & $59,50 \%$ & 0,4915 & $49,15 \%$ \\
\hline 26 & 20 & 6 & & $*$ & & 0,4737 & $47,37 \%$ & 0,4331 & $43,31 \%$ & 0,5949 & $59,49 \%$ & 0,5269 & $52,69 \%$ \\
\hline 107 & 75 & 12 & & $*$ & & 0,4967 & $49,67 \%$ & 0,3812 & $38,12 \%$ & 0,5617 & $56,17 \%$ & 0,4989 & $49,89 \%$ \\
\hline 189 & 45 & 6 & & $*$ & * & 0,5239 & $52,39 \%$ & 1,0255 & $102,55 \%$ & 0,5814 & $58,14 \%$ & 0,8380 & $83,80 \%$ \\
\hline 38 & 30 & 2 & & $*$ & & 0,5282 & $52,82 \%$ & 0,4891 & $48,91 \%$ & 0,6269 & $62,69 \%$ & 0,5542 & $55,42 \%$ \\
\hline 101 & 75 & 8 & & $*$ & & 0,5294 & $52,94 \%$ & 0,3689 & $36,89 \%$ & 0,6241 & $62,41 \%$ & 0,5216 & $52,16 \%$ \\
\hline 113 & 100 & 4 & & $*$ & & 0,5312 & $53,12 \%$ & 0,3995 & $39,95 \%$ & 0,6149 & $61,49 \%$ & 0,5122 & $51,22 \%$ \\
\hline 80 & 60 & 6 & & $*$ & & 0,5326 & $53,26 \%$ & 0,5607 & $56,07 \%$ & 0,6161 & $61,61 \%$ & 0,6033 & $60,33 \%$ \\
\hline 77 & 60 & 4 & & $*$ & & 0,5671 & $56,71 \%$ & 0,5270 & $52,70 \%$ & 0,6211 & $62,11 \%$ & 0,5791 & $57,91 \%$ \\
\hline 104 & 75 & 10 & & $*$ & & 0,5671 & $56,71 \%$ & 0,4116 & $41,16 \%$ & 0,6393 & $63,93 \%$ & 0,5082 & $50,82 \%$ \\
\hline 11 & 15 & 8 & & $*$ & & 0,5684 & $56,84 \%$ & 0,6089 & $60,89 \%$ & 0,6316 & $63,16 \%$ & 0,6325 & $63,25 \%$ \\
\hline 201 & 60 & 2 & & $*$ & $*$ & 0,5692 & $56,92 \%$ & 0,5840 & $58,40 \%$ & 0,6501 & $65,01 \%$ & 0,6260 & $62,60 \%$ \\
\hline 219 & 75 & 2 & & $*$ & $*$ & 0,5701 & $57,01 \%$ & 0,5509 & $55,09 \%$ & 0,6332 & $63,32 \%$ & 0,6057 & $60,57 \%$ \\
\hline 32 & 20 & 10 & & $*$ & & 0,5792 & $57,92 \%$ & 0,5133 & $51,33 \%$ & 0,6192 & $61,92 \%$ & 0,5708 & $57,08 \%$ \\
\hline 14 & 15 & 10 & & $*$ & & 0,5799 & $57,99 \%$ & 0,4000 & $40,00 \%$ & 0,6374 & $63,74 \%$ & 0,5099 & $50,99 \%$ \\
\hline
\end{tabular}


Tabela 6-10 - Os 15 melhores resultados da simulação para a rede NNARX.

\begin{tabular}{|c|c|c|c|c|c|c|c|c|c|c|c|c|c|}
\hline \multirow{3}{*}{$\begin{array}{c}\text { Simulação } \\
8\end{array}$} & \multirow{3}{*}{$\begin{array}{c}\text { Neurônios } \\
15 \\
\end{array}$} & \multirow{3}{*}{$\begin{array}{c}\begin{array}{c}\text { Ordem } \\
\text { (regressores) }\end{array} \\
6 \\
\end{array}$} & \multicolumn{3}{|c|}{ Entrada } & \multicolumn{4}{|c|}{ MSE } & \multicolumn{4}{|c|}{ MAE } \\
\hline & & & \multirow[t]{2}{*}{$\mathrm{F}$} & \multirow{2}{*}{$\frac{\mathrm{DL}}{*}$} & \multirow[t]{2}{*}{$\mathrm{TB}$} & \multicolumn{2}{|c|}{ Validação } & \multicolumn{2}{|c|}{ Teste } & \multicolumn{2}{|c|}{ Validação } & \multicolumn{2}{|c|}{ Teste } \\
\hline & & & & & & 0,000013 & $0,001 \%$ & 0,000933 & $0,093 \%$ & 0,001519 & $0,152 \%$ & 0,003269 & $0,327 \%$ \\
\hline 17 & 15 & 12 & & $*$ & & 0,000014 & $0,001 \%$ & 0,000982 & $0,098 \%$ & 0,001733 & $0,173 \%$ & 0,002656 & $0,266 \%$ \\
\hline 14 & 15 & 10 & & $*$ & & 0,000015 & $0,001 \%$ & 0,000984 & $0,098 \%$ & 0,001890 & $0,189 \%$ & 0,003083 & $0,308 \%$ \\
\hline 5 & 15 & 4 & & $*$ & & 0,000015 & $0,001 \%$ & 0,000933 & $0,093 \%$ & 0,001836 & $0,184 \%$ & 0,002960 & $0,296 \%$ \\
\hline 7 & 15 & 6 & $*$ & & & 0,000022 & $0,002 \%$ & 0,000867 & $0,087 \%$ & 0,002318 & $0,232 \%$ & 0,002414 & $0,241 \%$ \\
\hline 29 & 20 & 8 & & $*$ & & 0,000023 & $0,002 \%$ & 0,001004 & $0,100 \%$ & 0,002736 & $0,274 \%$ & 0,003211 & $0,321 \%$ \\
\hline 11 & 15 & 8 & & $*$ & & 0,000023 & $0,002 \%$ & 0,000900 & $0,090 \%$ & 0,002483 & $0,248 \%$ & 0,002515 & $0,251 \%$ \\
\hline 20 & 20 & 2 & & $*$ & & 0,000024 & $0,002 \%$ & 0,000928 & $0,093 \%$ & 0,002957 & $0,296 \%$ & 0,004897 & $0,490 \%$ \\
\hline 32 & 20 & 10 & & * & & 0,000026 & $0,003 \%$ & 0,000916 & $0,092 \%$ & 0,002368 & $0,237 \%$ & 0,005531 & $0,553 \%$ \\
\hline 26 & 20 & 6 & & $*$ & & 0,000031 & $0,003 \%$ & 0,001002 & $0,100 \%$ & 0,003019 & $0,302 \%$ & 0,003252 & $0,325 \%$ \\
\hline 53 & 30 & 12 & & $*$ & & 0,000035 & $0,003 \%$ & 0,000932 & $0,093 \%$ & 0,002740 & $0,274 \%$ & 0,003035 & $0,304 \%$ \\
\hline 2 & 15 & 2 & & $*$ & & 0,000035 & $0,004 \%$ & 0,000938 & $0,094 \%$ & 0,003795 & $0,380 \%$ & 0,004455 & $0,445 \%$ \\
\hline 138 & 15 & 8 & & $*$ & $*$ & 0,000036 & $0,004 \%$ & 0,000882 & $0,088 \%$ & 0,002655 & $0,265 \%$ & 0,002538 & $0,254 \%$ \\
\hline 127 & 15 & 2 & $*$ & $*$ & & 0,000039 & $0,004 \%$ & 0,000864 & $0,086 \%$ & 0,001858 & $0,186 \%$ & 0,003359 & $0,336 \%$ \\
\hline 23 & 20 & 4 & & $*$ & & 0,000043 & $0,004 \%$ & 0,001590 & $0,159 \%$ & 0,003388 & $0,339 \%$ & 0,005458 & $0,546 \%$ \\
\hline
\end{tabular}




\subsubsection{Desempenho das Redes TDNN}

Ao analisar a Tabela 6-9, comprova-se que a RNA TDNN não apresentou um desempenho satisfatório em nenhuma das simulações. Esse fato pode ser comprovado através do gráfico mostrado na Figura 6-22, que representa o melhor resultado alcançado pela rede TDNN, quando simulada com 45 neurônios na camada oculta, 2 atrasos (regressores) e a vazão de retirada do destilado como entrada.

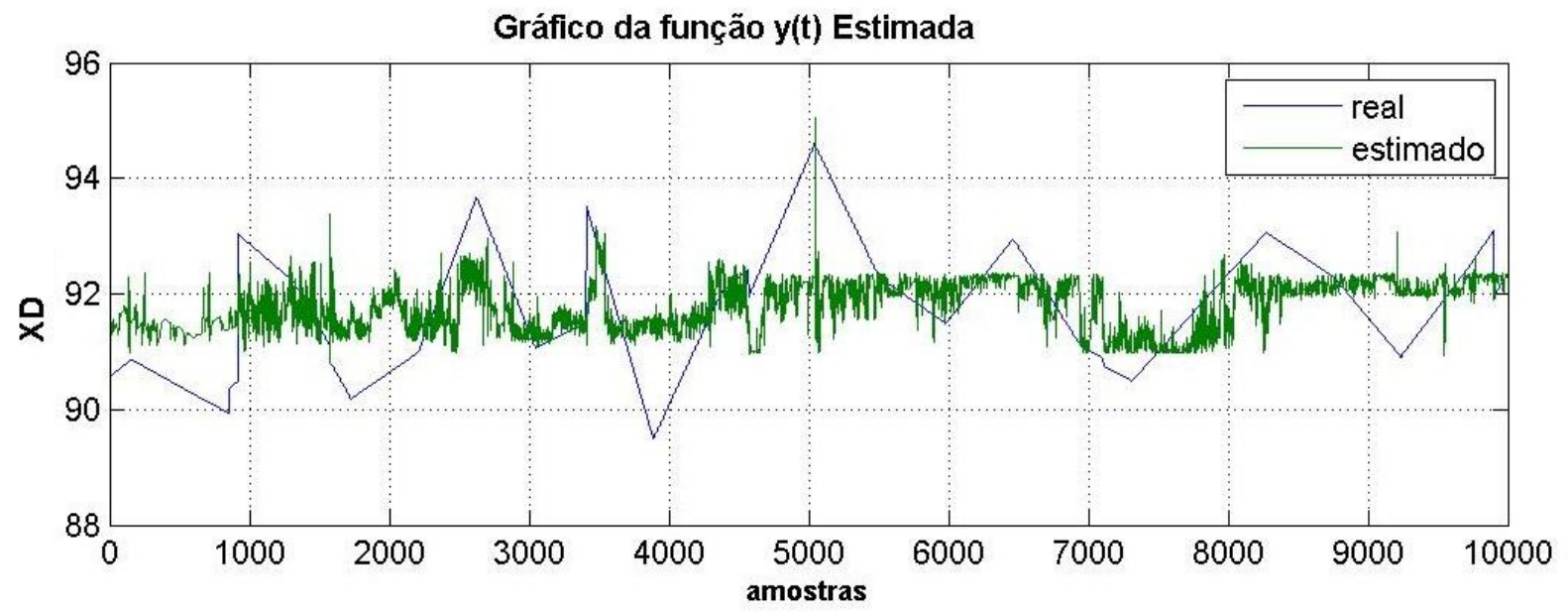

Figura 6-22 - Gráfico da saída (XD em ${ }^{\circ}$ INPM) real e estimada para a rede TDNN de melhor desempenho, sendo a entrada a vazão de retirada do destilado DL $\mathrm{em} \mathrm{m}^{3} / \mathrm{h}$.

Outros gráficos que comprovam o fraco desempenho da rede TDNN proposta também são mostrados nas Figuras 6-23 a 6-28 seguintes. 


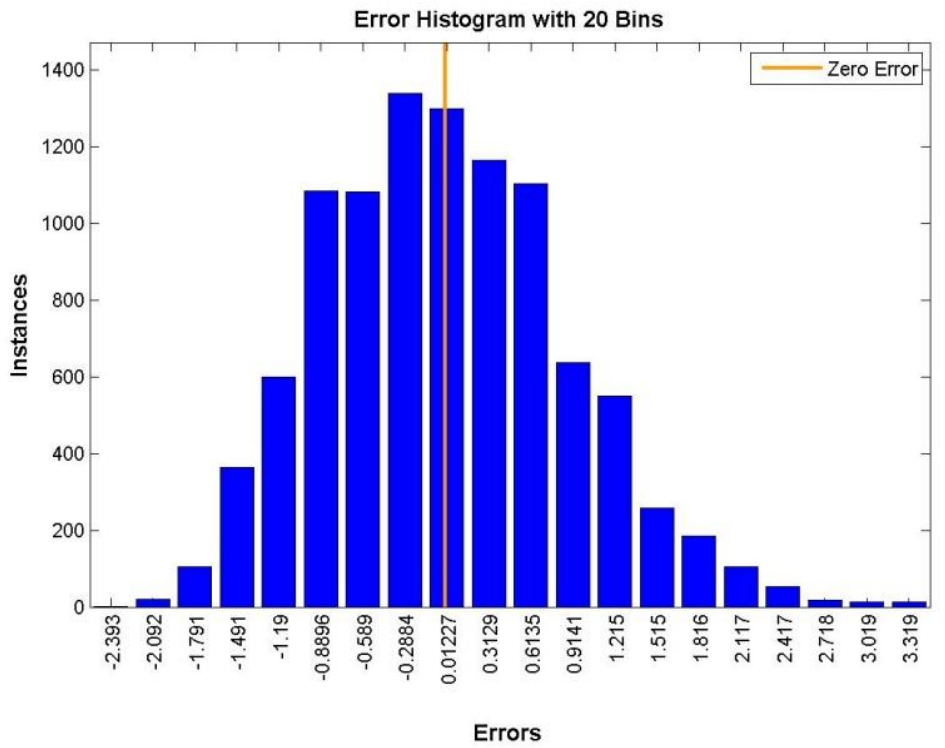

Figura 6-23 - Histograma do erro MSE para a rede TDNN de melhor desempenho.

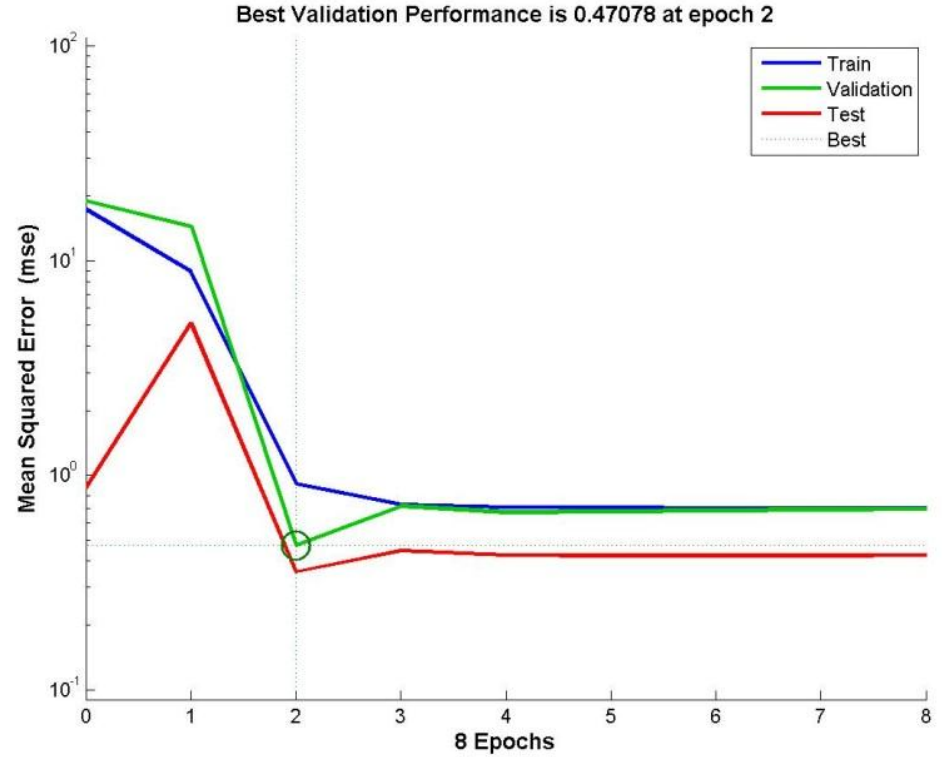

Figura 6-24 - Gráfico da performance (treinamento, validação e teste) para a rede TDNN de melhor desempenho. 


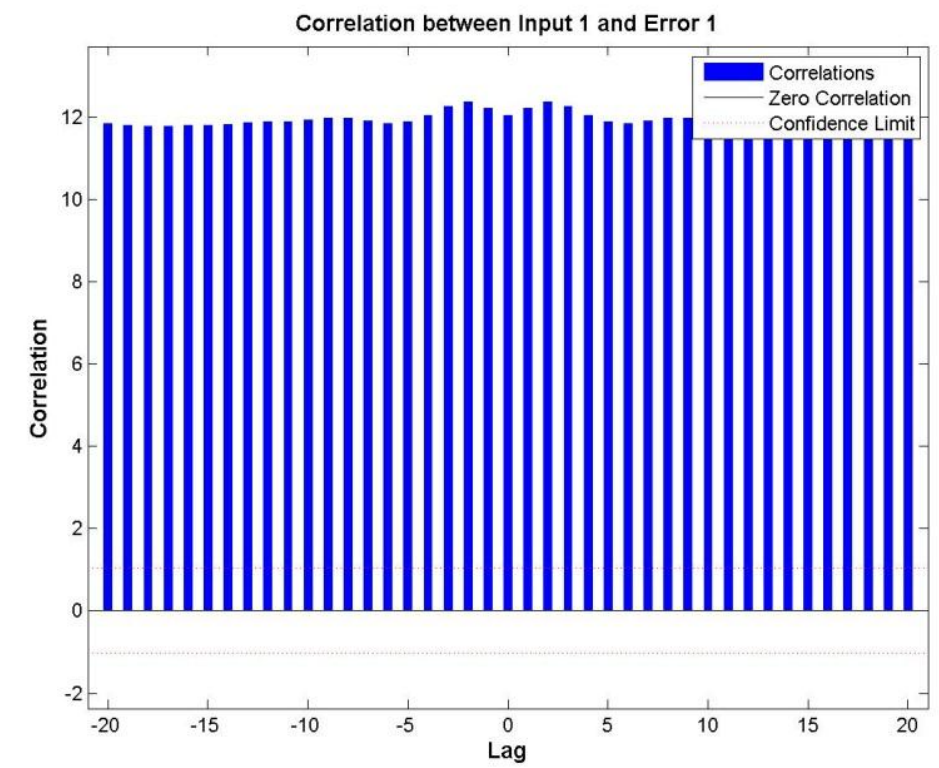

Figura 6-25 - Gráfico da correlação entre entrada DL e o erro para a rede TDNN de melhor desempenho.

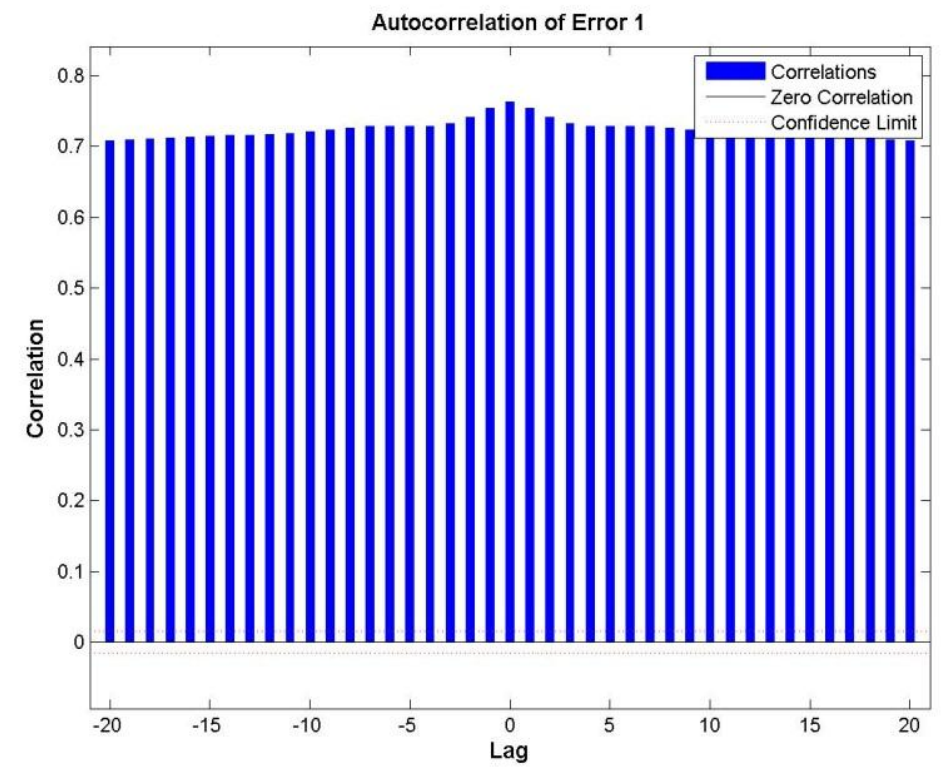

Figura 6-26 - Gráfico da autocorrelação do erro para a rede TDNN de melhor desempenho. 


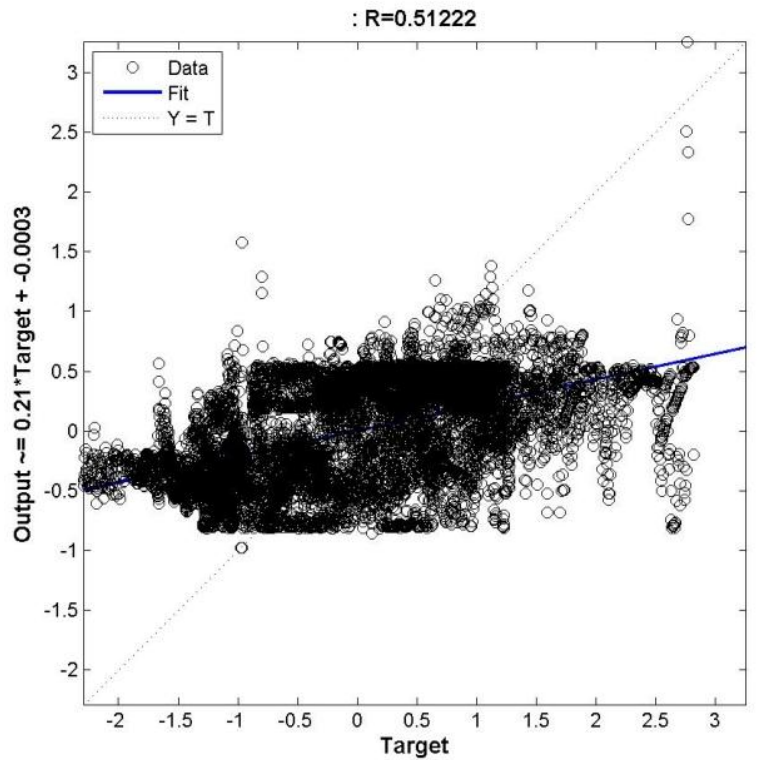

Figura 6-27 - Gráfico da regressão linear entre a saída estimada e a real para a rede TDNN de melhor desempenho.

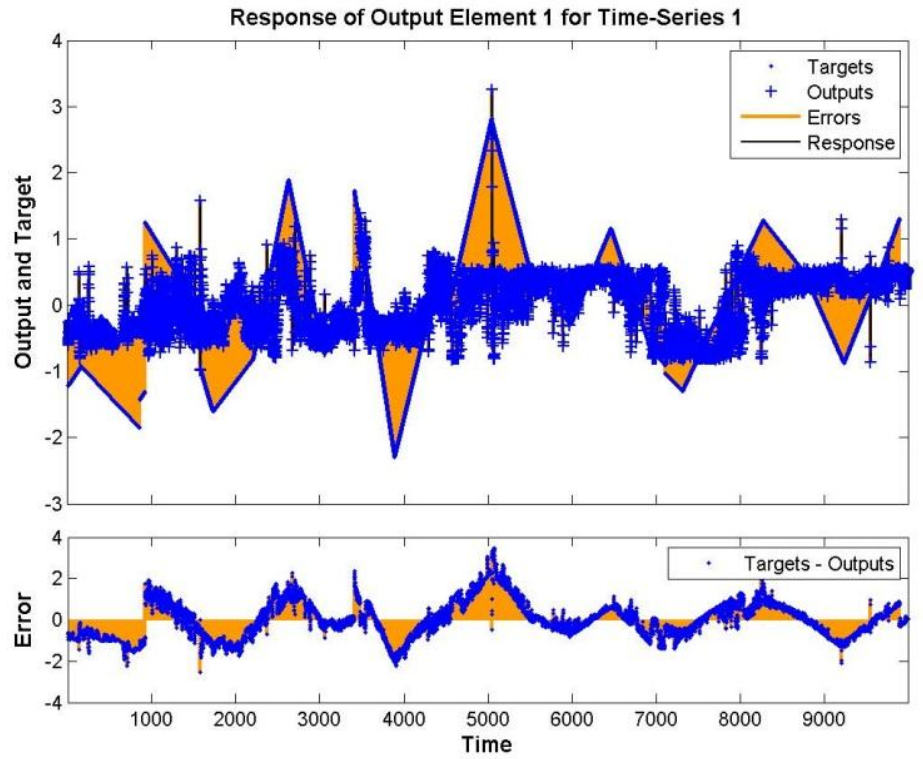

Figura 6-28 - Gráfico da resposta e do erro, obtidos durante o treinamento, para a rede TDNN de melhor desempenho.

Com base nos gráficos das Figuras 6-22 a 6-28 acima é possível perceber que as redes TDNN apresentam certa dificuldade em realizar mapeamentos dinâmicos e, portanto, foram descartadas. Nesse caso, esse fato pode ter sido causado pela moderada correlação entre as variáveis de entrada e a saída. 


\subsubsection{Desempenho das Redes NNARX}

Por meio da Tabela 6-10, como pode ser observado, o melhor índice de desempenho (menores valores de MSE) para o conjunto de validação foram os modelos de rede NNARX, composto de 15 neurônios na camada escondida, apenas a vazão de retirada do destilado (DL) como variável secundária de entrada com 6 ou 12 regressores. Entretanto, os resultados obtidos no presente trabalho mostram que a diferença entre as demais simulações listadas na Tabela 6-10 não tiveram diferenças significativas, ficando muito próximas da melhor simulação.

Observando ainda a Tabela 6-10, percebe-se que os melhores resultados foram alcançados logo nas primeiras simulações para as situações onde o número de neurônios da camada oculta é menor. Segundo Silva et al. (2010), quanto menor o número de neurônios na camada oculta, mais generalista é a RNA, isto é, a rede consegue gerar estimativas de maneira precisa e coerente por meio de padrões que não foram utilizados na fase de treinamento.

Dessa forma, comprova-se que com menos neurônios na camada oculta, melhor é o desempenho do estimador neural simulado. Vale destacar também que para as topologias possuidoras de melhor desempenho, composta por 15 neurônios na camada escondida e com 6 ou 12 regressores, observa-se na Tabela 6-8 que o número de neurônios da camada oculta, para o primeiro caso, é ligeiramente superior que o total de entradas da rede (14), e o dobro para o segundo caso (26). Para uma melhor apreciação, os gráficos seguintes ilustram os resultados obtidos na simulação dessa rede. 


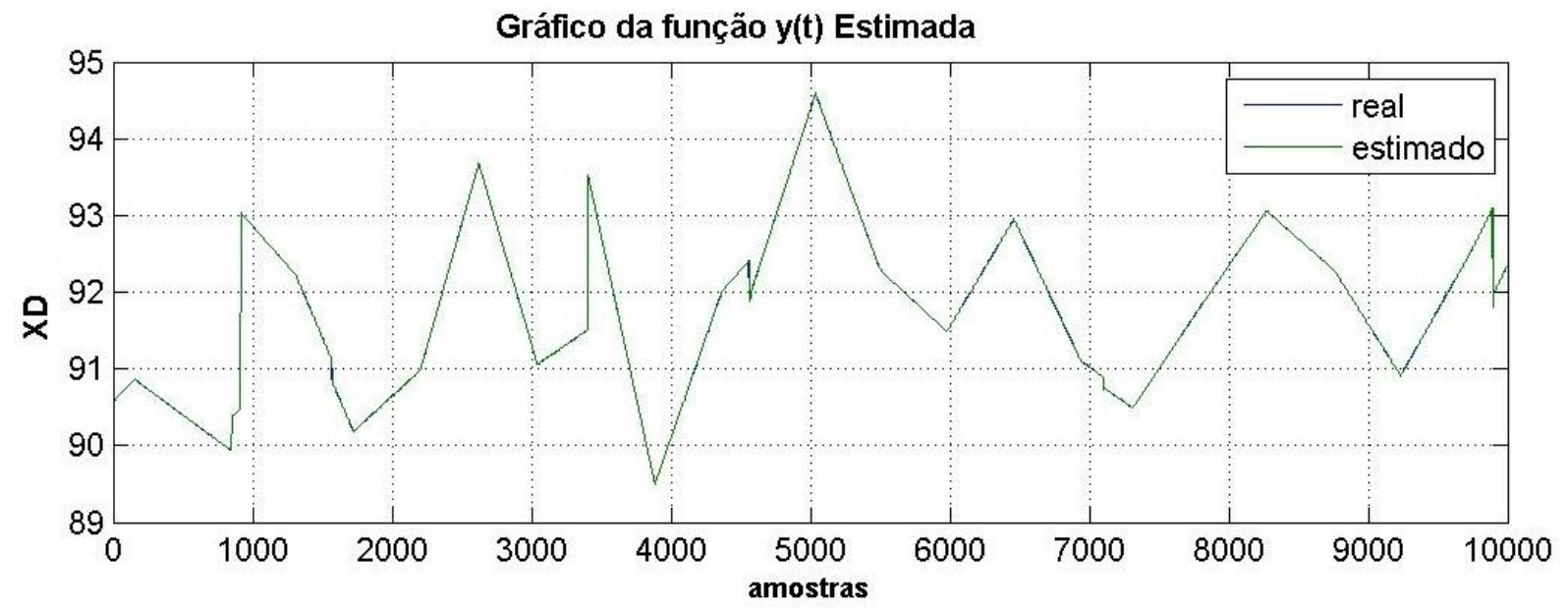

Figura 6-29 - Gráfico da saída (XD em ${ }^{\circ}$ INPM) real e estimada para a rede NNARX (15 neurônios e 6 regressores) de melhor desempenho, sendo a entrada a vazão de retirada do destilado DL $\mathrm{em} \mathrm{m}^{3} / \mathrm{h}$.

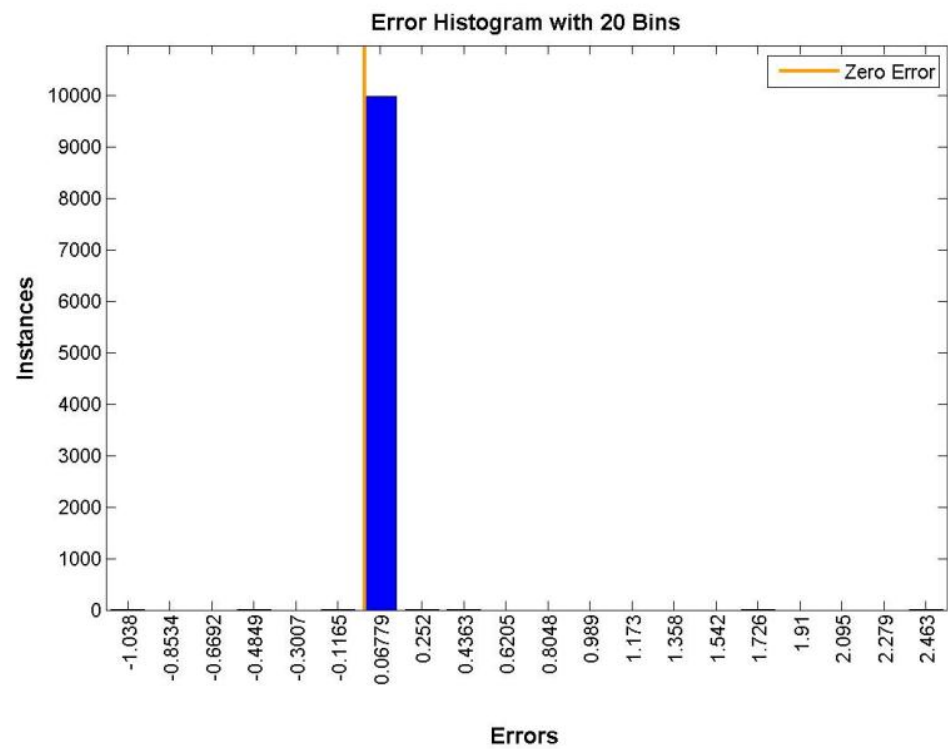

Figura 6-30 - Histograma do erro MSE para a rede NNARX (15 neurônios e 6 regressores) de melhor desempenho. 


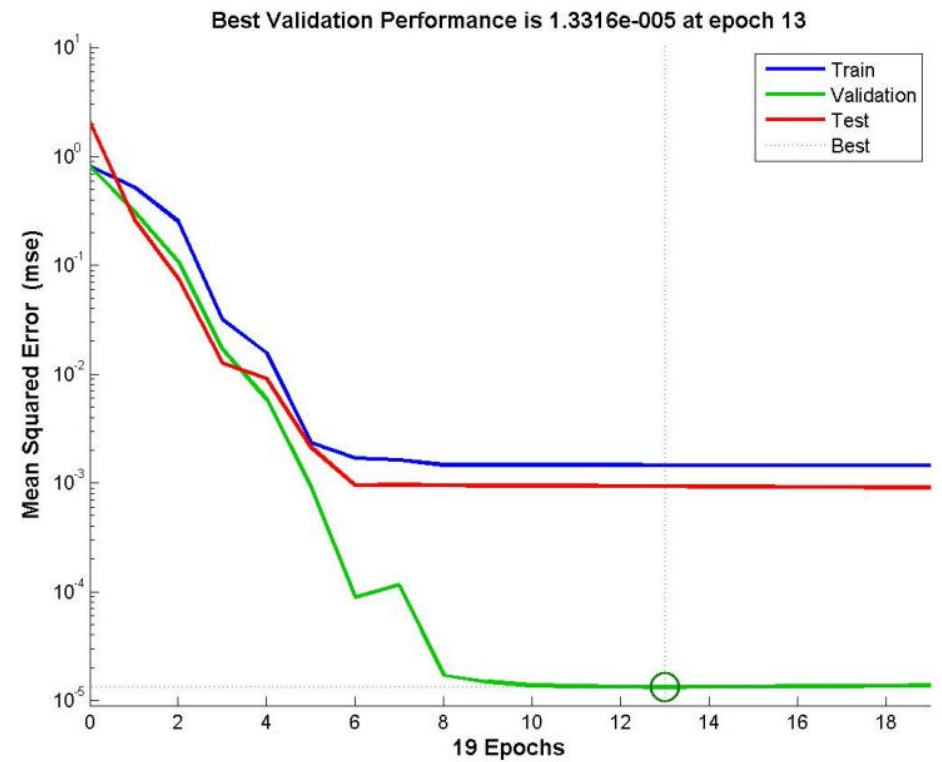

Figura 6-31 - Gráfico da performance (treinamento, validação e teste) para a rede NNARX (15 neurônios e 6 regressores) de melhor desempenho.

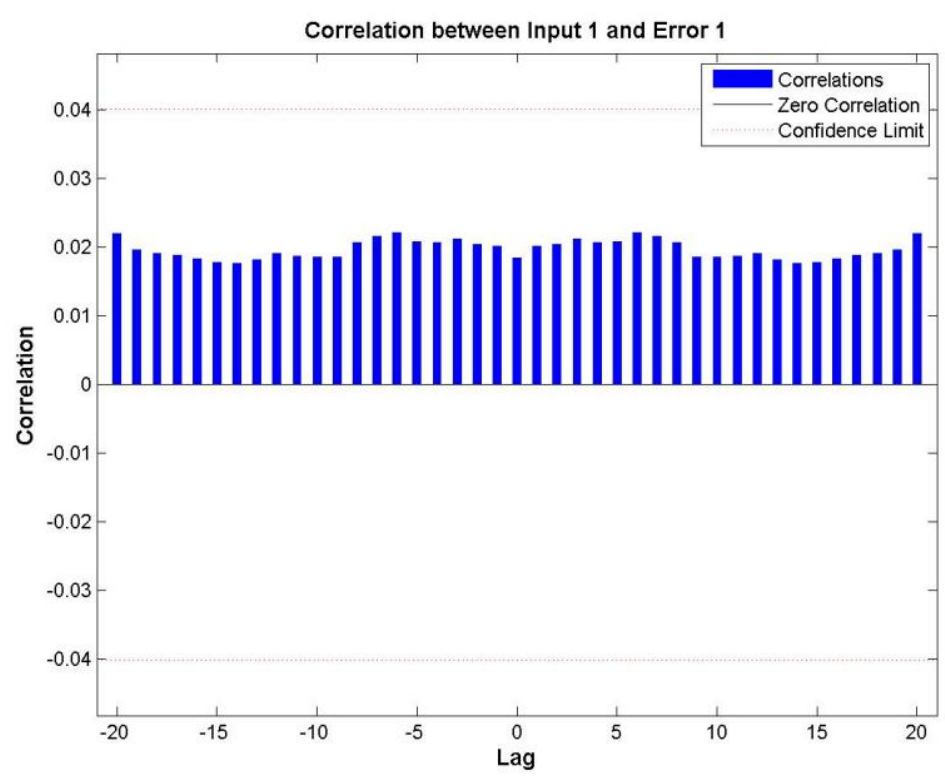

Figura 6-32 - Gráfico da correlação entre entrada DL e o erro para a rede NNARX (15 neurônios e 6 regressores) de melhor desempenho. 


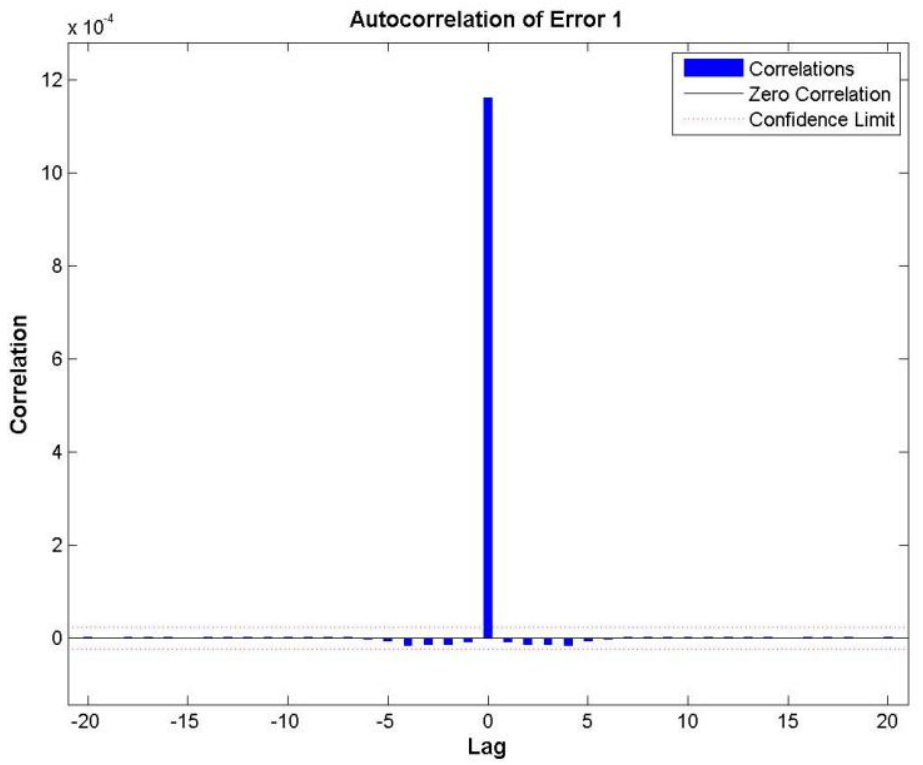

Figura 6-33 - Gráfico da autocorrelação do erro para a rede NNARX (15 neurônios e 6 regressores) de melhor desempenho.

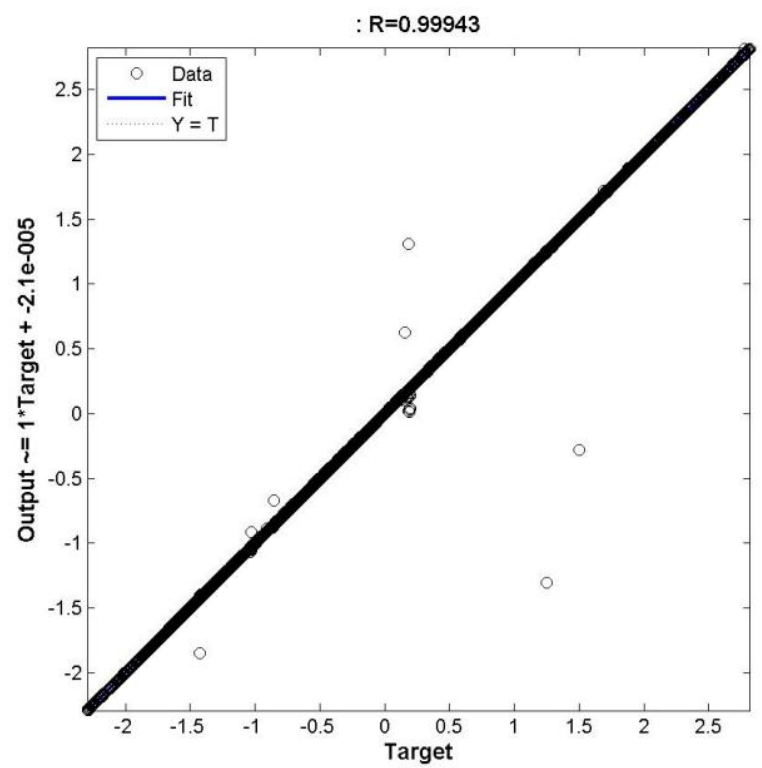

Figura 6-34 - Gráfico da regressão linear entre a saída estimada e a real para a rede NNARX (15 neurônios e 6 regressores) de melhor desempenho. 


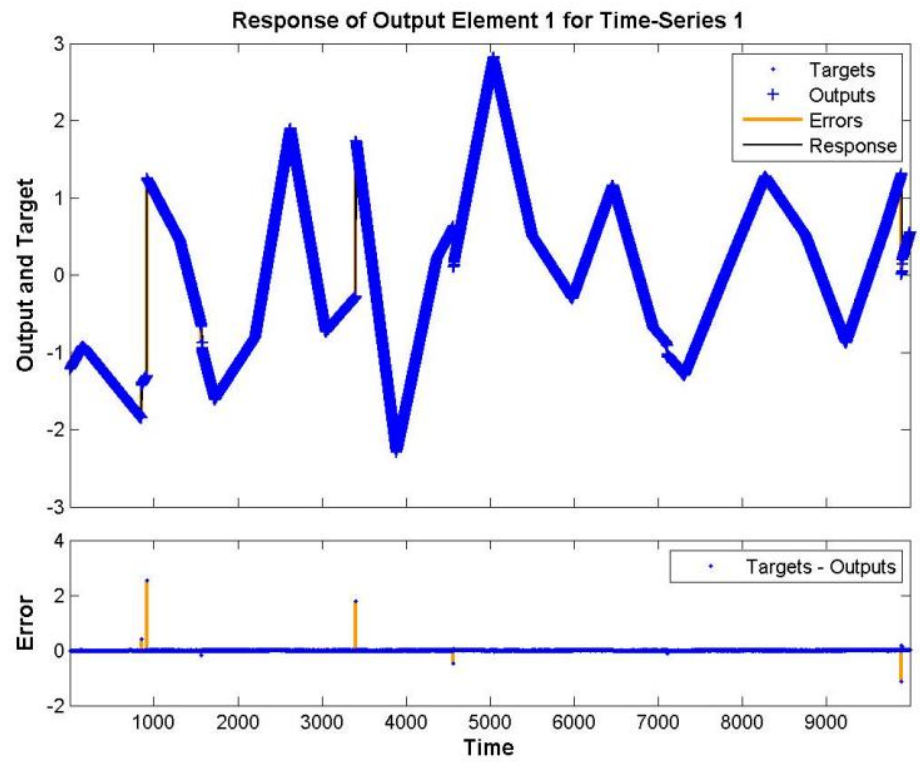

Figura 6-35 - Gráfico da resposta e do erro, obtidos durante o treinamento, para a rede NNARX (15 neurônios e 6 regressores) de melhor desempenho.

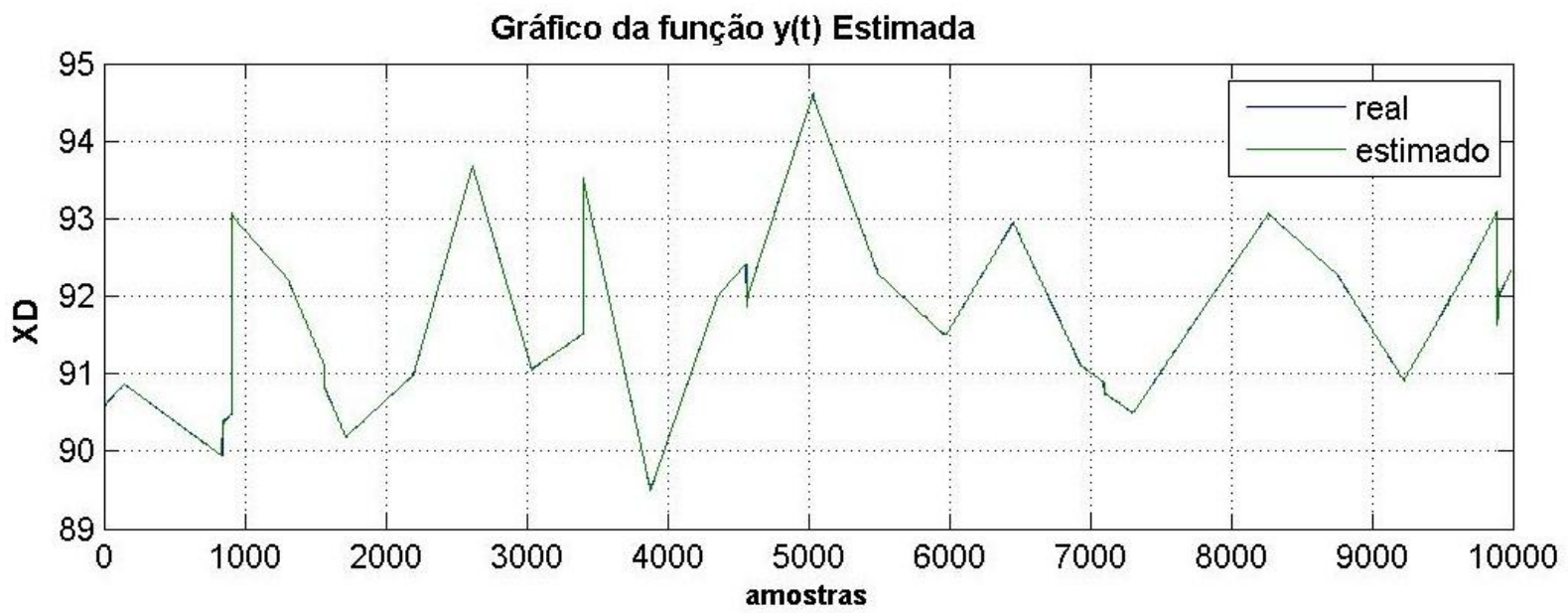

Figura 6-36 - Gráfico da saída (XD em ${ }^{\circ}$ INPM) real e estimada para a rede NNARX (15 neurônios e 12 regressores) com $2^{\circ}$ melhor desempenho, sendo a entrada a vazão de retirada do destilado DL $\mathrm{em} \mathrm{m}^{3} / \mathrm{h}$. 


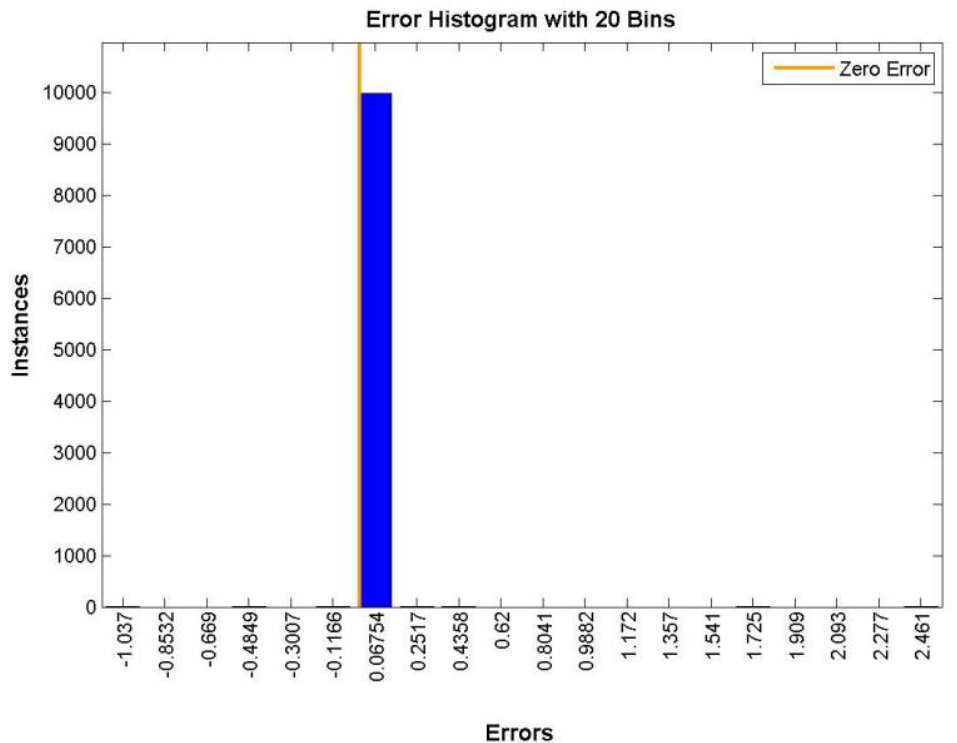

Figura 6-37 - Histograma do erro MSE para a rede NNARX (15 neurônios e 12 regressores) com $2^{\circ}$ melhor desempenho.

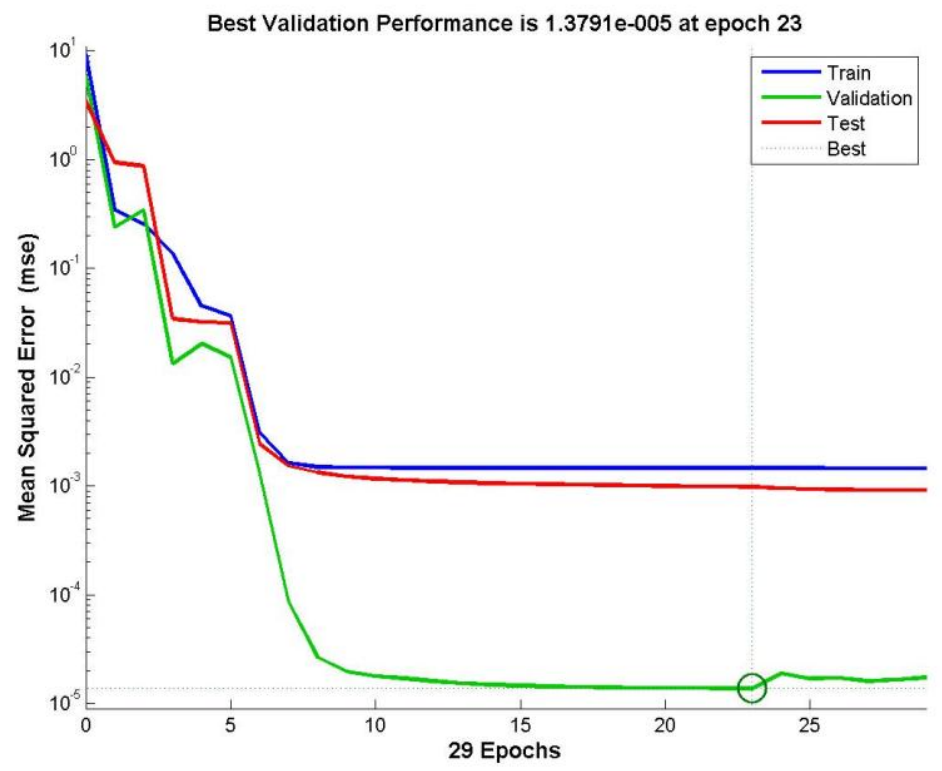

Figura 6-38 - Gráfico da performance (treinamento, validação e teste) para a rede NNARX (15 neurônios e 12 regressores) com $2^{\circ}$ melhor desempenho. 


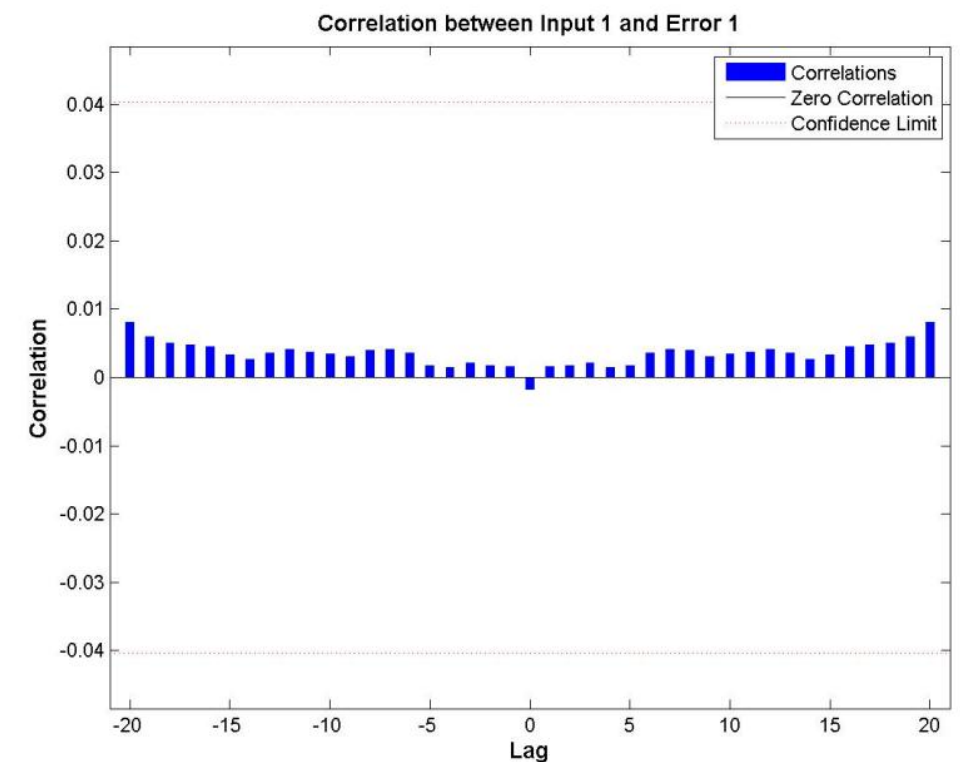

Figura 6-39 - Gráfico da correlação entre entrada DL e o erro para a rede NNARX (15 neurônios e 12 regressores) com $2^{\circ}$ melhor desempenho.

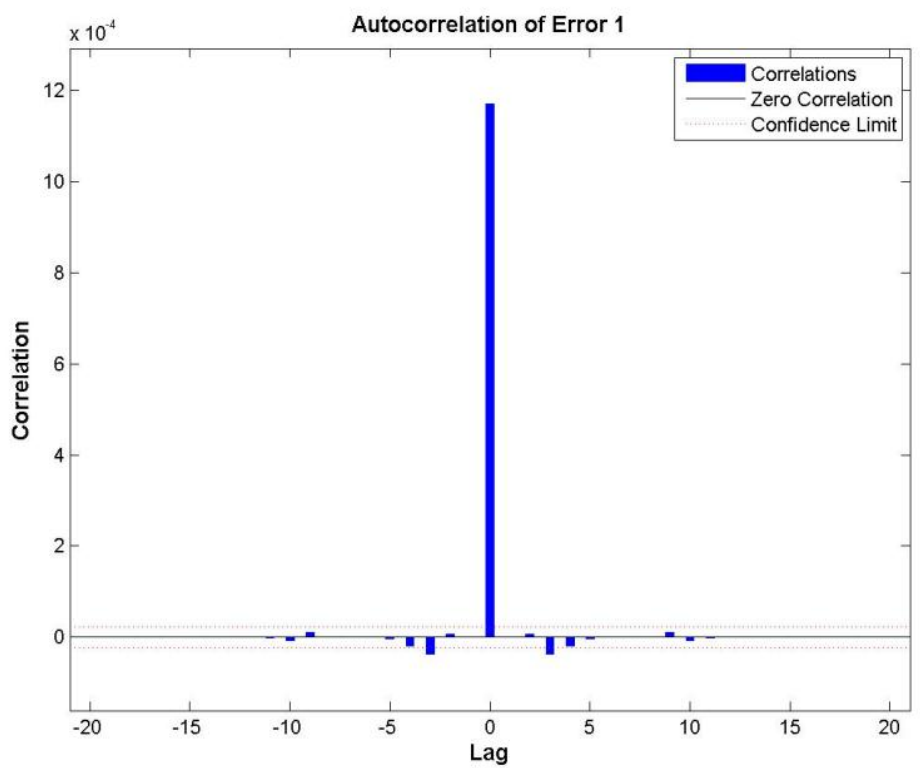

Figura 6-40 - Gráfico da autocorrelação do erro para a rede NNARX (15 neurônios e 12 regressores) com $2^{\circ}$ melhor desempenho. 


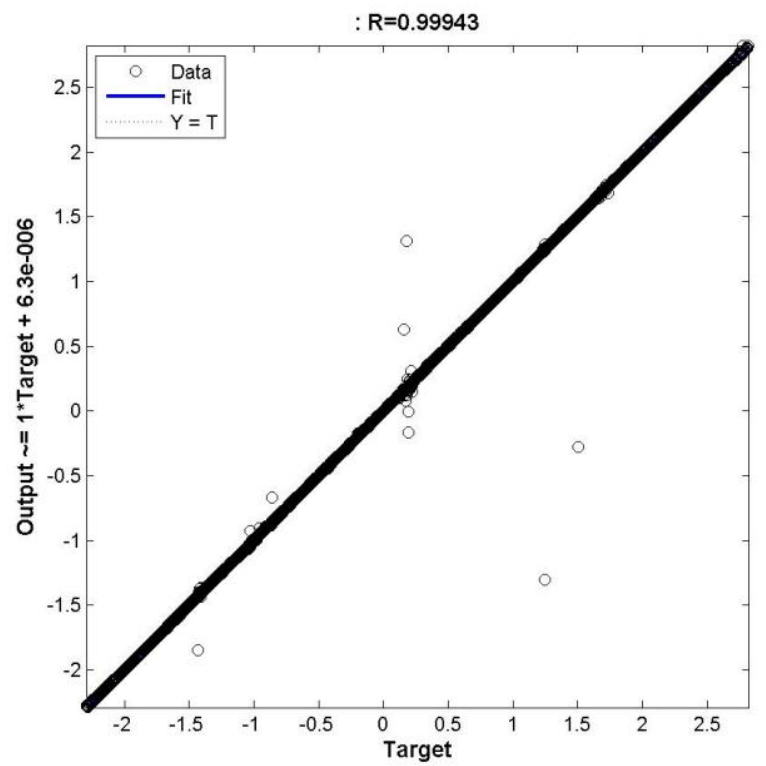

Figura 6-41 - Gráfico da regressão linear entre a saída estimada e a real para a rede NNARX (15 neurônios e 12 regressores) com $2^{\circ}$ melhor desempenho.

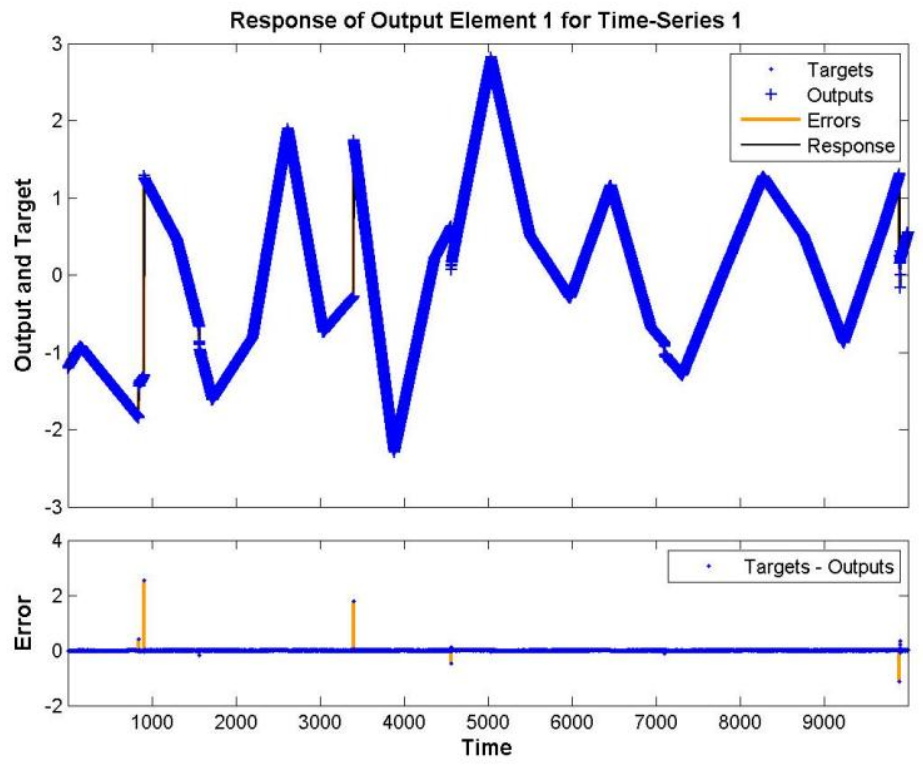

Figura 6-42 - Gráfico da resposta e do erro, obtidos durante o treinamento, para a rede NNARX (15 neurônios e 12 regressores) com $2^{\circ}$ melhor desempenho.

Ao analisar os gráficos anteriores, observa-se que as duas redes possuem erros MSE semelhantes, aproximadamente 0,000013. Observando os histogramas de erro, nota-se que também são praticamente iguais.

Observando as Tabelas 6-9 e 6-10 anteriores, para as redes TDNN e NNARX simuladas, percebe-se a predominância da vazão de retirada do destilado no topo da coluna 
(XD) em apresentar os melhores resultados. Para essa rede TDNN, a combinação das entradas não foi suficiente para melhorar o desempenho do estimador neural, ao passo que para a rede NNARX diminuiu seu desempenho. Isso comprova o resultado obtido na Seção 6.2.5, onde verificou-se que as variáveis selecionadas apresentavam um coeficiente de correlação com a saída muito próximo, além da correlação existente entre elas.

Entretanto, quando as variáveis de entrada são analisadas individualmente, o resultando obtido é muito semelhante; dessa forma, pode-se empregar qualquer uma delas. Assim, outros fatores devem ser levados em consideração na escolha da variável de entrada, como por exemplo, ruídos de medição, periodicidade da manutenção desses medidores, atraso de transporte, tempo de resposta, etc.

Os gráficos mostrados nas Figuras 6-43 a 6-49 a seguir são resultados da simulação da rede NNARX quando sua entrada foi definida com a vazão de alimentação da coluna "A".

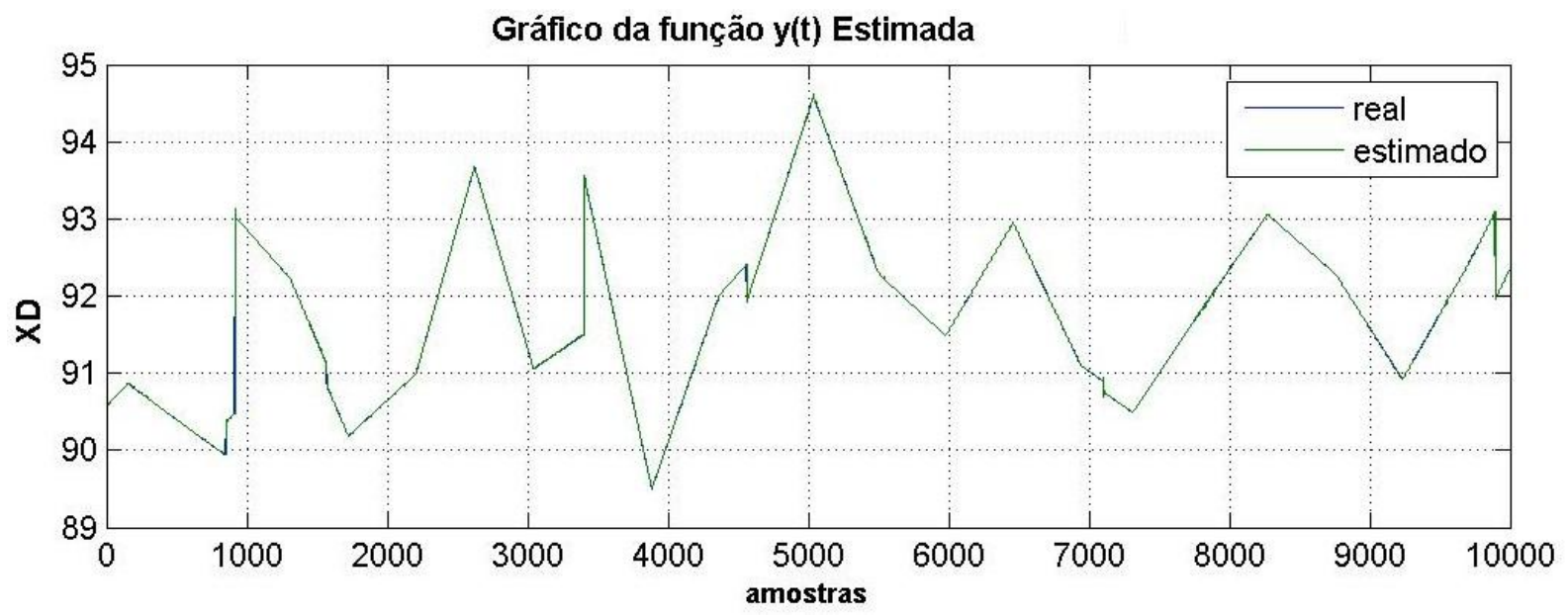

Figura 6-43 - Gráfico da saída (XD em ${ }^{\circ}$ INPM) real e estimada para a rede NNARX (15 neurônios e 6 regressores), sendo a entrada a vazão de alimentação da coluna "A" em m3/h. 


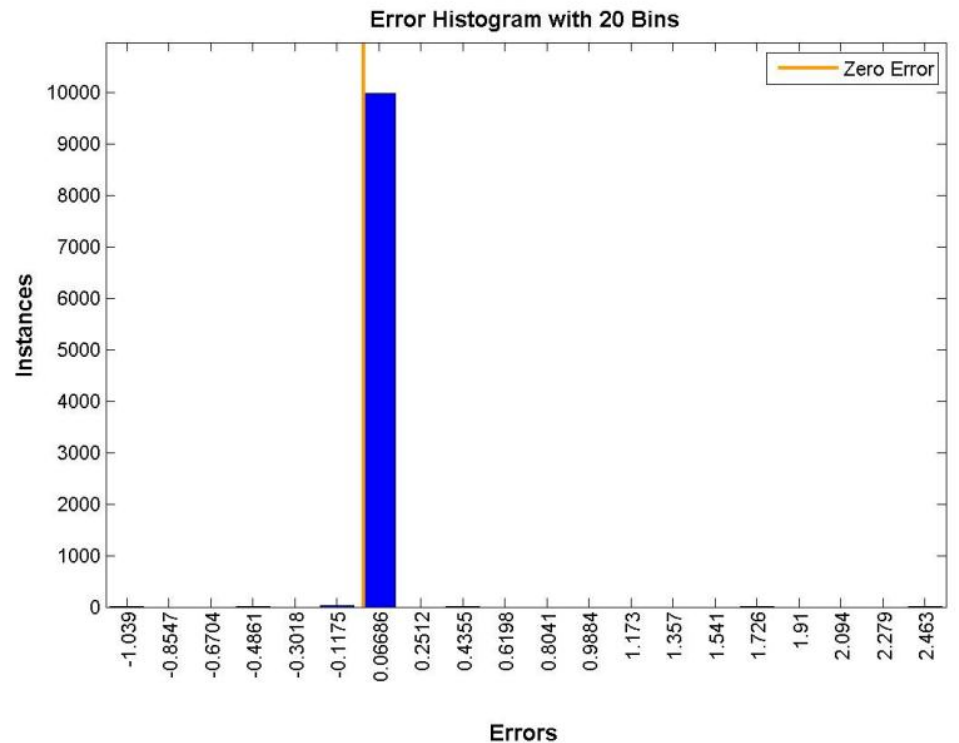

Figura 6-44 - Histograma do erro MSE para a rede NNARX (15 neurônios e 6 regressores).

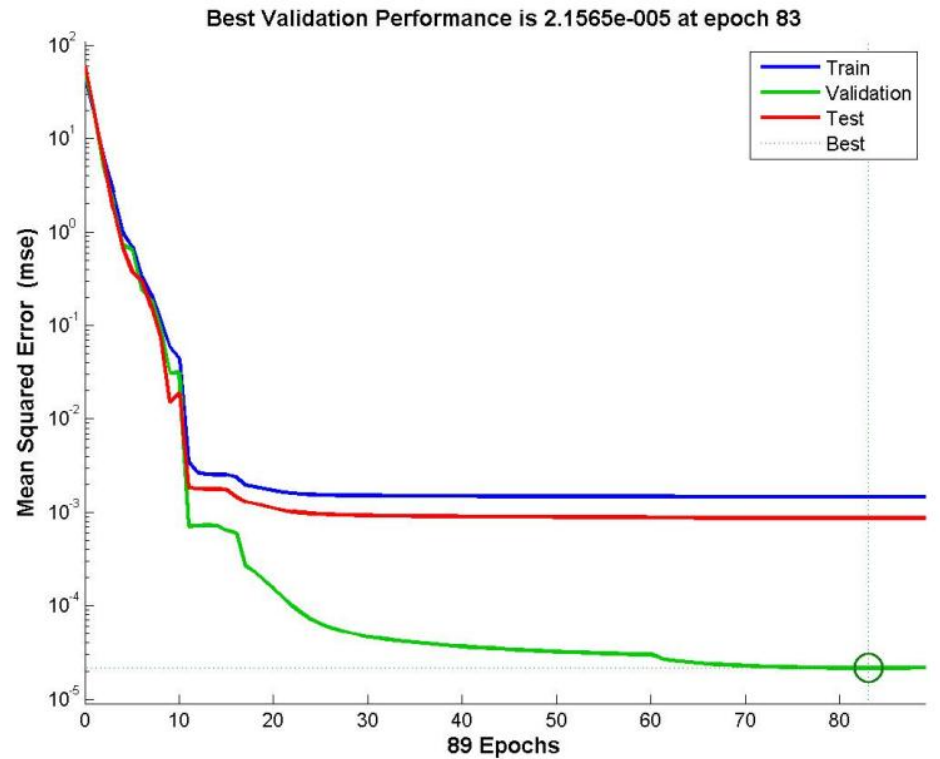

Figura 6-45 - Gráfico da performance (treinamento, validação e teste) para a rede NNARX (15 neurônios e 6 regressores). 


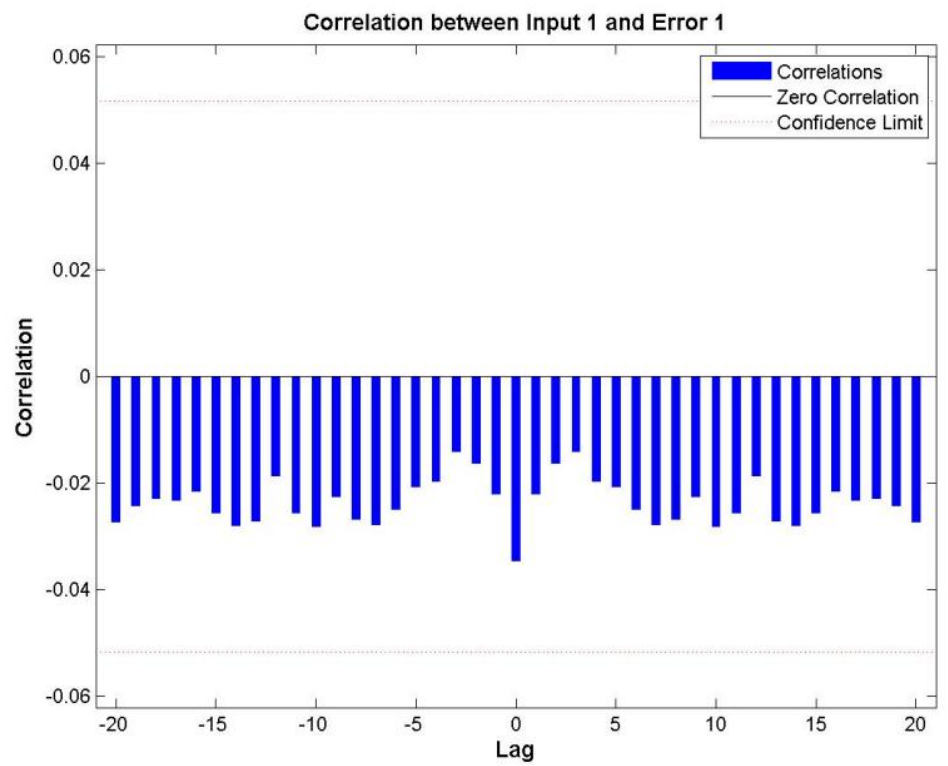

Figura 6-46 - Gráfico da correlação entre entrada DL e o erro para a rede NNARX (15 neurônios e 6 regressores).

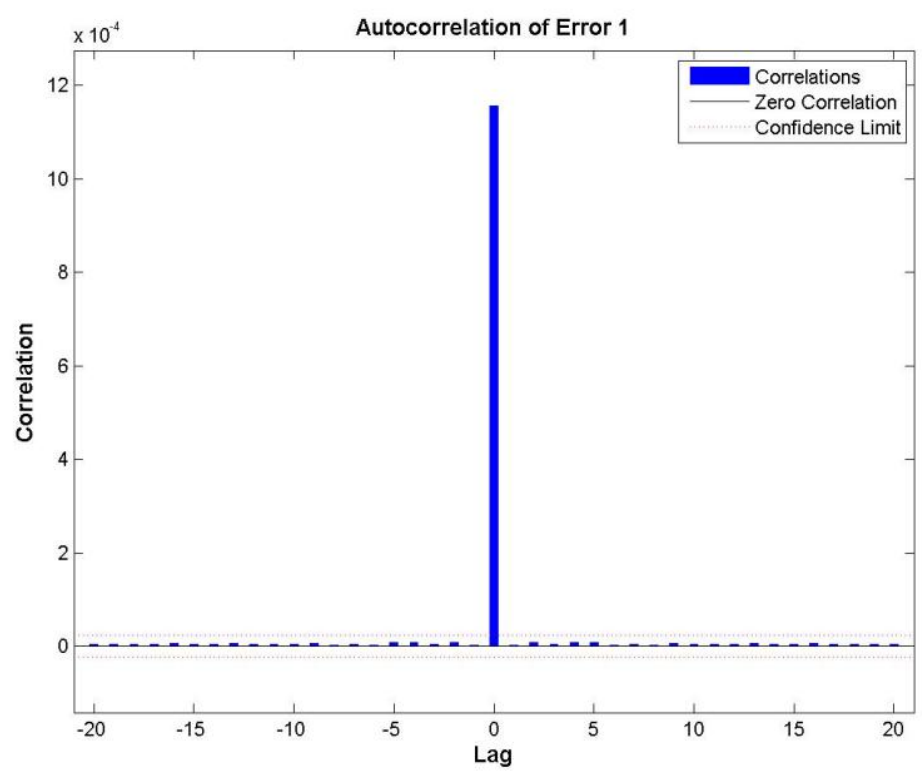

Figura 6-47 - Gráfico da autocorrelação do erro para a rede NNARX (15 neurônios e 6 regressores). 


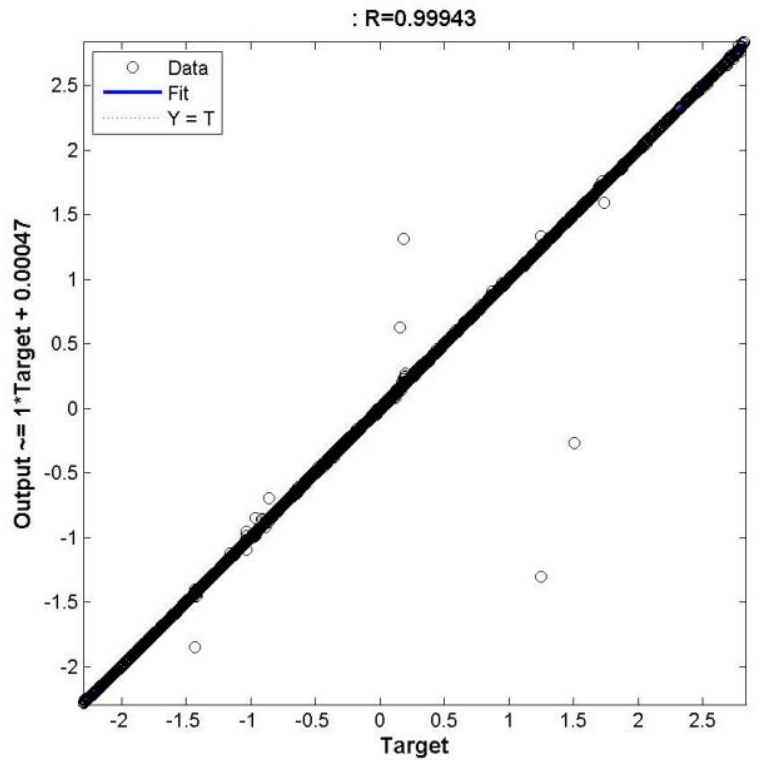

Figura 6-48 - Gráfico da regressão linear entre a saída estimada e a real para a rede NNARX (15 neurônios e 6 regressores).

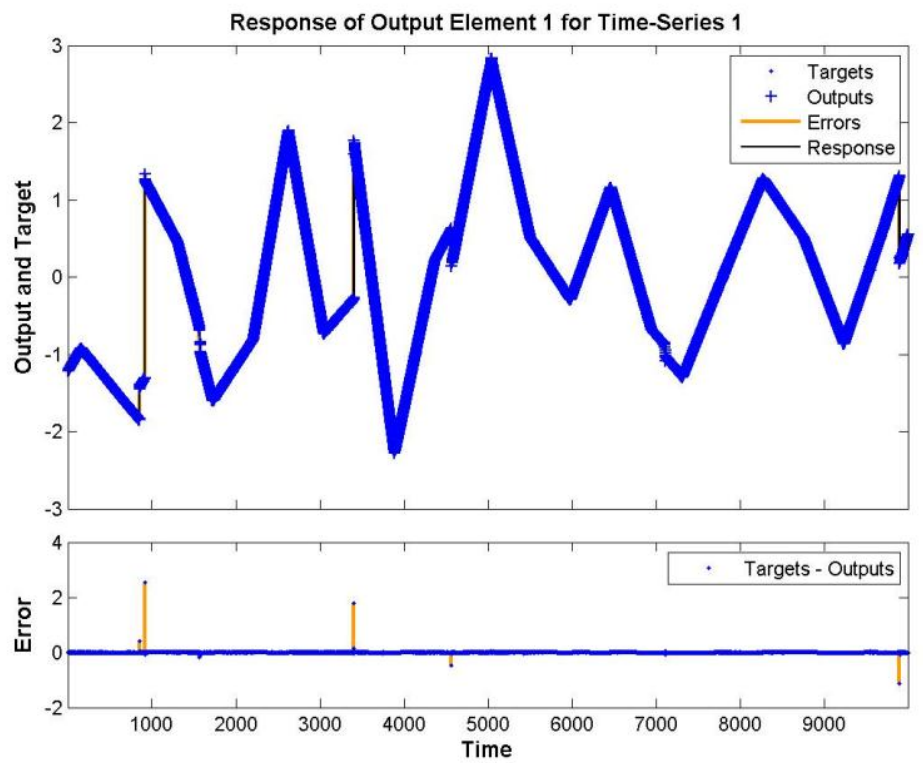

Figura 6-49 - Gráfico da resposta e do erro, obtidos durante o treinamento, para a rede NNARX (15 neurônios e 6 regressores).

Os gráficos mostrados nas Figuras 6-50 a 6-56 a seguir foram obtidos da simulação da rede NNARX tendo como entrada a temperatura na bandeja B4 da coluna "B". 


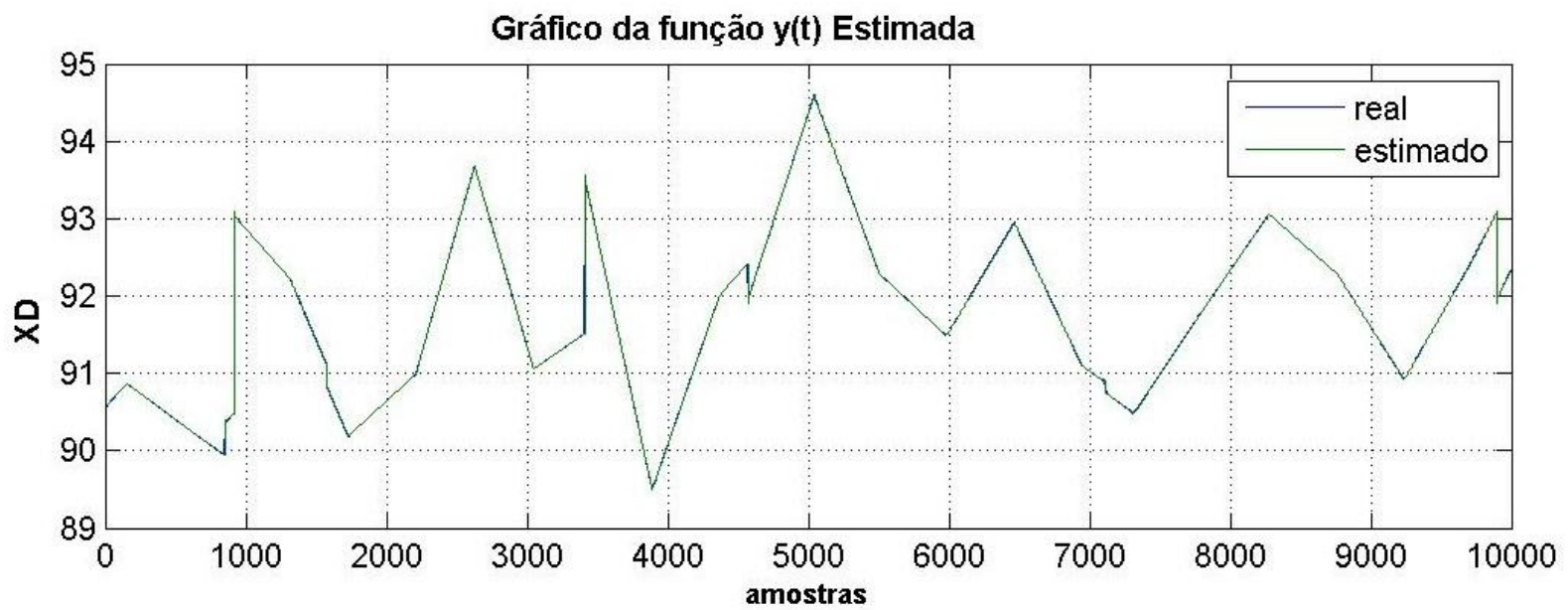

Figura 6-50 - Gráfico da saída (XD em ${ }^{\circ}$ INPM) real e estimada para a rede NNARX (15 neurônios e 2 regressores), sendo a entrada a temperatura na bandeja $B 4$ da coluna " $B$ ".

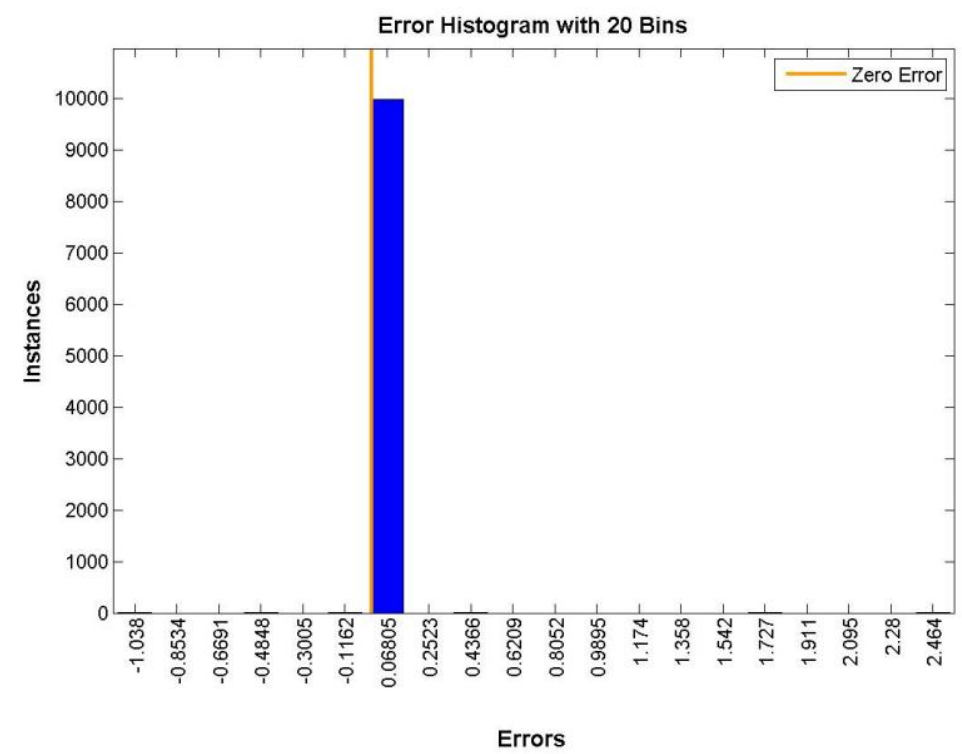

Figura 6-51 - Histograma do erro MSE para a rede NNARX (15 neurônios e 2 regressores). 


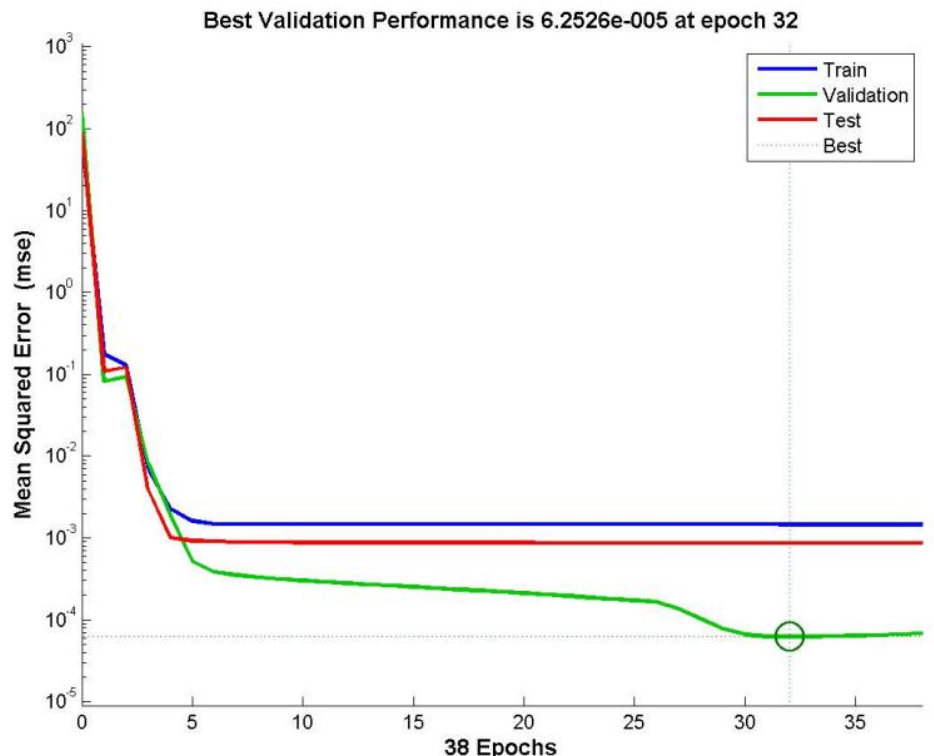

Figura 6-52 - Gráfico da performance (treinamento, validação e teste) para a rede NNARX (15 neurônios e 2 regressores).

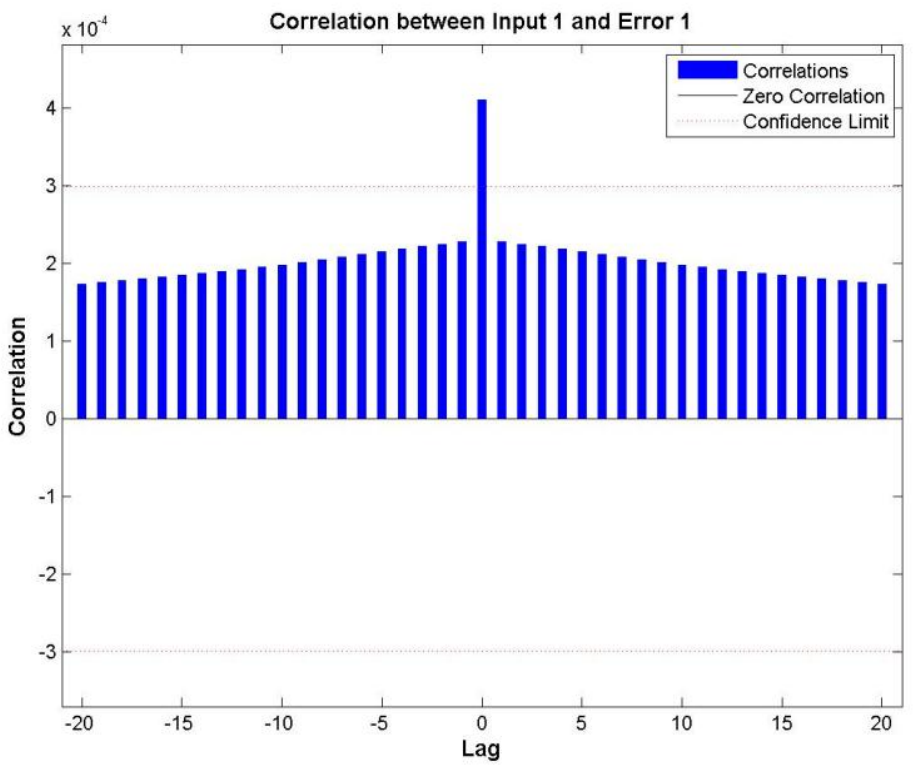

Figura 6-53 - Gráfico da correlação entre entrada DL e o erro para a rede NNARX (15 neurônios e 2 regressores). 


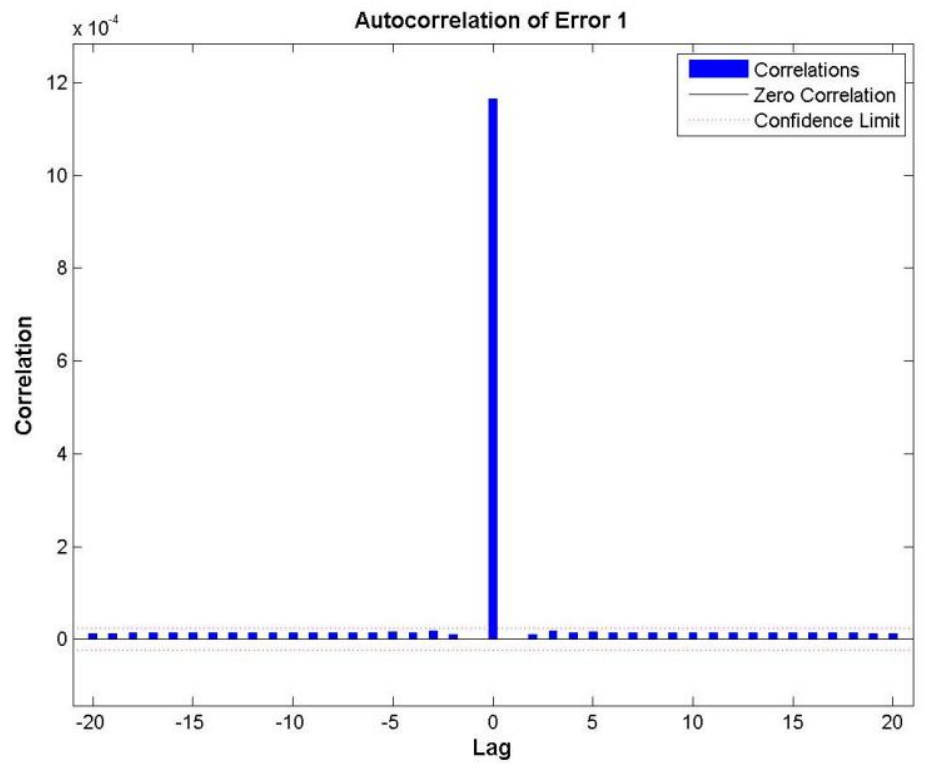

Figura 6-54 - Gráfico da autocorrelação do erro para a rede NNARX (15 neurônios e 2 regressores).

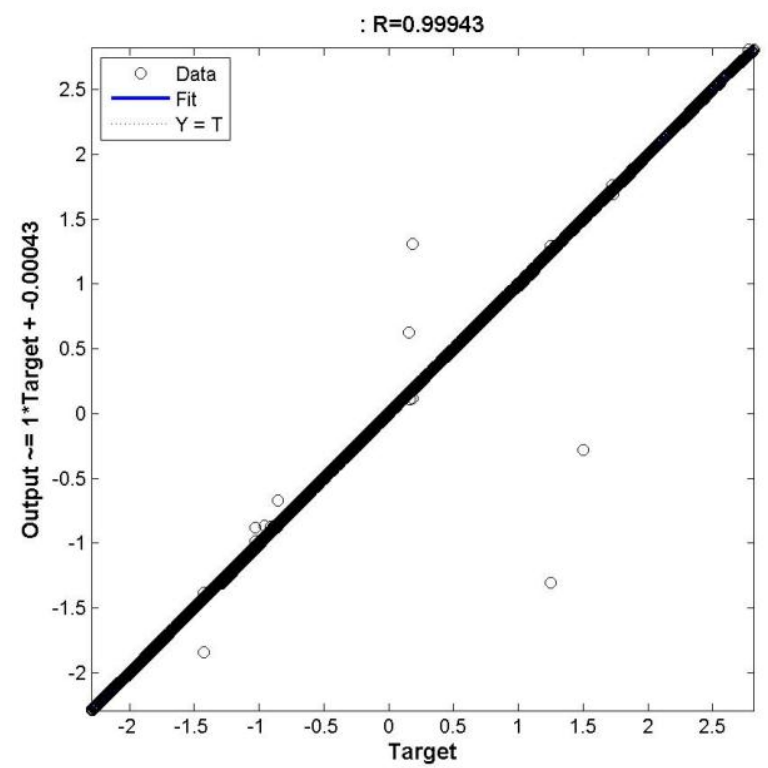

Figura 6-55 - Gráfico da regressão linear entre a saída estimada e a real para a rede NNARX (15 neurônios e 2 regressores). 


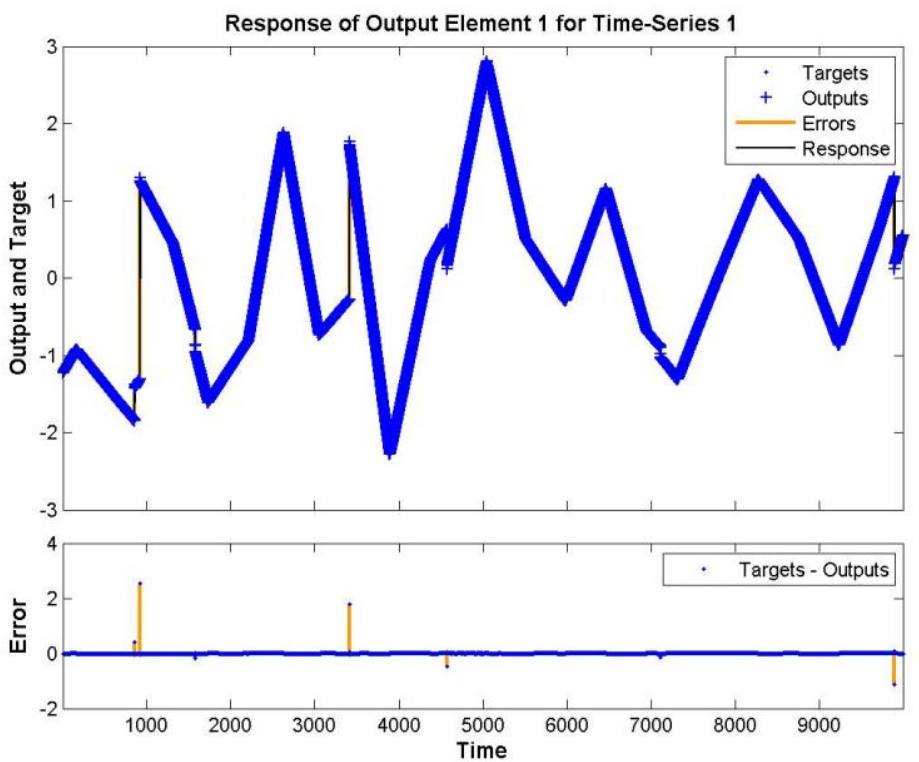

Figura 6-56 - Gráfico da resposta e do erro, obtidos durante o treinamento, para a rede NNARX (15 neurônios e 2 regressores).

Os resultados apresentados neste trabalho foram considerados satisfatórios. Depois de uma revisão dos materiais e métodos usados, acredita-se que estes possam ser realmente aplicados no projeto de sensores virtuais reais.

\subsubsection{Comparação entre a Rede NNARX e a Representação no Espaço de Estados}

Após a realização desse trabalho, concluiu-se que as 3 topologias de rede mostradas na Seção 6.7.2, sendo cada uma possuindo apenas uma entrada, apresentaram um bom desempenho na estimação da saída. Esta seção visa promover uma comparação entre estes modelos e o modelo de espaço de estado, de forma a justificar a sua implementação.

A Tabela 6-11 mostra os 5 modelos de espaço de estado que apresentaram o melhor desempenho com base no menor erro médio para o sistema proposto. Na busca do melhor modelo, utilizaram-se os sinais de entrada individualmente ou a combinação deles, variandose a ordem do modelo de 1 até 12 . O objetivo foi encontrar o melhor modelo para ser comparado com aqueles obtidos pela rede NNARX da Seção 6.7.2, avaliando-se o 
comportamento dos estimadores em torno do ponto de operação onde foram excitados e identificados.

Tabela 6-11 - Modelos de espaços de estados com melhor desempenho.

\begin{tabular}{|c|c|c|c|c|c|}
\hline \multicolumn{4}{|c|}{ Entradas } & \multirow{2}{*}{ Erro Médio } & \multirow{2}{*}{ Índice FPE } \\
\hline $\mathrm{F}$ & DL & TB & Ordem do Modelo & & \\
\hline \multirow[t]{2}{*}{$*$} & $*$ & & 12 & 0,000003 & 0,0016 \\
\hline & & $*$ & 12 & 0,000010 & 0,0028 \\
\hline * & & $*$ & 12 & 0,000026 & 0,0021 \\
\hline$*$ & & $*$ & 11 & 0,000026 & 0,0020 \\
\hline$*$ & & $*$ & 9 & 0,000027 & 0,0021 \\
\hline
\end{tabular}

Nessa dissertação o modelo de espaço de estados foi obtido usando o algoritmo N4SID (Van Overschee et al., 1994). Esse algoritmo é baseado no método de identificação em subespaço de estados e o resultado obtido é um modelo paramétrico que tem a seguinte estrutura:

$$
\begin{aligned}
& x(t+T s)=A x(t)+B u(t)+K e(t) \\
& y(t)=C x(t)+D u(t)+e(t)
\end{aligned}
$$

onde $y(t)$ é um vetor que representa as saídas do sistema no instante $t ; u(t)$ também é um vetor que representa as entradas do sistemas no instante $t ; x(t)$ é o vetor dos estados do sistema e $e(t)$ representa as perturbações do sistema. O objetivo é estimar as matrizes de estado $A, B, C, D$ e $K$ usando a ordem do modelo e os dados de entrada e saída do sistema.

As matrizes de estado estimadas para os modelos de espaço de estado listados na Tabela 6-11, são mostrados nas Tabela 6-12 a 6-16 seguintes. 
Tabela 6-12 - Matrizes de estado estimadas para as entradas F e DL e ordem do sistema $=12$.

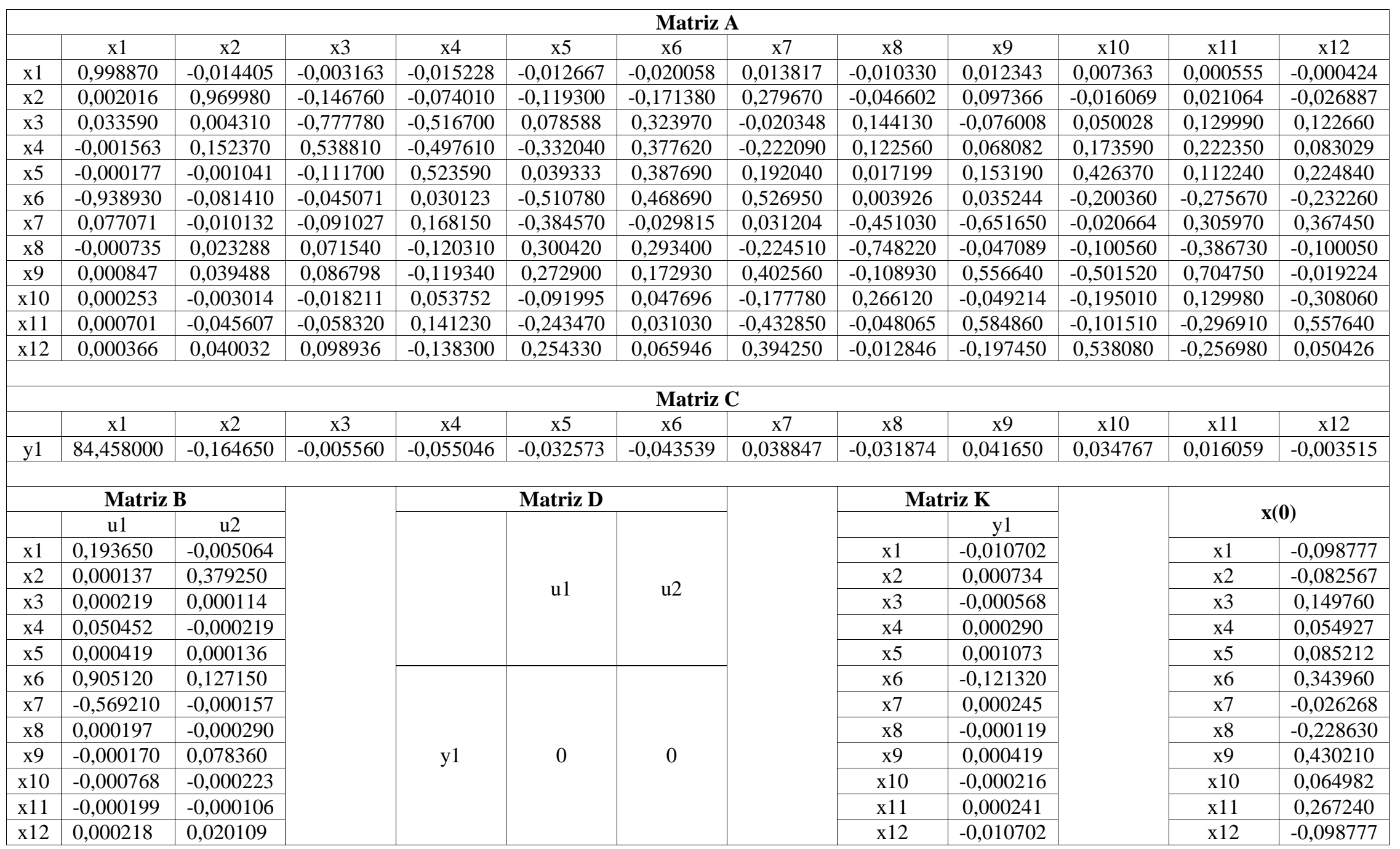


Tabela 6-13 - Matrizes de estado estimadas para a entrada TB e ordem do sistema = 12.

\begin{tabular}{|c|c|c|c|c|c|c|c|c|c|c|c|c|}
\hline \multicolumn{13}{|c|}{ Matriz A } \\
\hline & $\mathrm{x} 1$ & $\mathrm{x} 2$ & $\mathrm{x} 3$ & $\mathrm{x} 4$ & $x 5$ & x6 & $\mathrm{x} 7$ & $\mathrm{x} 8$ & $\mathrm{x} 9$ & $\mathrm{x} 10$ & $\mathrm{x} 11$ & $\mathrm{x} 12$ \\
\hline $\mathrm{x} 1$ & 0,999450 & $-0,027107$ & $-0,003290$ & $-0,001639$ & $-0,013845$ & $-0,016437$ & 0,004762 & $-0,004582$ & $-0,006429$ & $-0,005695$ & $-0,000641$ & $-0,004461$ \\
\hline $\mathrm{x} 2$ & 0,000639 & 0,694030 & $-0,201620$ & $-0,013896$ & $-0,474730$ & $-0,390600$ & 0,169580 & $-0,106550$ & $-0,176100$ & $-0,107850$ & $-0,039901$ & $-0,093260$ \\
\hline $\mathrm{x} 3$ & $-0,002518$ & 0,073503 & 1,015000 & 0,012958 & $-0,258300$ & $-0,049907$ & $-0,050309$ & $-0,155930$ & $-0,031953$ & $-0,075784$ & 0,023511 & $-0,302070$ \\
\hline $\mathrm{x} 4$ & 0,000224 & $-0,036426$ & $-0,045274$ & 0,667590 & 0,432330 & $-0,432790$ & $-0,231110$ & $-0,227060$ & $-0,077109$ & $-0,300170$ & 0,123960 & $-0,356140$ \\
\hline $\mathrm{x} 5$ & 0,000356 & $-0,052573$ & $-0,133660$ & $-0,064742$ & $-0,132490$ & $-0,207780$ & $-0,176490$ & $-0,105310$ & $-0,131740$ & 0,837300 & $-0,227740$ & $-0,306160$ \\
\hline x6 & $-0,000900$ & $-0,039977$ & 0,046460 & 0,570350 & $-0,376470$ & 0,280770 & $-0,341030$ & 0,278420 & 0,188090 & 0,161510 & 0,021126 & 0,077824 \\
\hline $\mathrm{x} 7$ & $-0,001016$ & $-0,014412$ & 0,022957 & 0,089737 & 0,082636 & 0,460440 & 0,242550 & $-0,433320$ & $-0,594290$ & $-0,003389$ & $-0,208430$ & $-0,528410$ \\
\hline $\mathrm{x} 8$ & $-0,000365$ & $-0,015180$ & 0,031363 & 0,236400 & $-0,004894$ & 0,112000 & 0,738240 & $-0,238330$ & 0,499950 & 0,351670 & 0,172370 & 0,220110 \\
\hline $\mathrm{x} 9$ & 0,000459 & $-0,013078$ & 0,019541 & 0,159780 & 0,010280 & 0,109130 & 0,256690 & 0,286410 & $-0,380300$ & 0,246120 & 0,571440 & 0,601730 \\
\hline $\mathrm{x} 10$ & 0,000686 & 0,032166 & $-0,039883$ & $-0,253900$ & $-0,177450$ & 0,096660 & $-0,305200$ & $-0,347530$ & $-0,281620$ & 0,171000 & 0,255140 & 0,462200 \\
\hline $\mathrm{x} 11$ & $-0,000221$ & $-0,007306$ & 0,015626 & 0,118150 & $-0,015216$ & 0,144540 & 0,353260 & 0,401910 & $-0,105200$ & 0,146160 & $-0,634890$ & 1,283000 \\
\hline $\mathrm{x} 12$ & 0,000350 & 0,000675 & $-0,007043$ & $-0,030725$ & $-0,028182$ & 0,037401 & 0,009843 & 0,011941 & 0,006781 & $-0,001027$ & $-0,273660$ & 0,028658 \\
\hline \multicolumn{13}{|c|}{ Matriz C } \\
\hline & $\mathrm{x} 1$ & $\mathrm{x} 2$ & $\mathrm{x} 3$ & $\mathrm{x} 4$ & $\mathrm{x} 5$ & $\mathrm{x} 6$ & $\mathrm{x} 7$ & $\mathrm{x} 8$ & $\mathrm{x} 9$ & $\mathrm{x} 10$ & $\mathrm{x} 11$ & $\mathrm{x} 12$ \\
\hline $\mathrm{y} 1$ & $-94,5750$ & 0,310780 & $-0,089886$ & $-0,012500$ & 0,125550 & 0,049014 & $-0,025110$ & 0,010286 & 0,020565 & 0,022885 & 0,001844 & 0,001591 \\
\hline \multicolumn{3}{|c|}{ Matriz B } & & \multicolumn{3}{|c|}{ Matriz D } & & \multicolumn{2}{|c|}{ Matriz K } & & \multirow{2}{*}{\multicolumn{2}{|c|}{$\mathbf{x}(\mathbf{0})$}} \\
\hline & \multicolumn{2}{|c|}{$\mathrm{u} 1$} & & & \multicolumn{2}{|c|}{$\mathrm{u} 1$} & & & $\mathrm{y} 1$ & & & \\
\hline $\mathrm{x} 1$ & \multicolumn{2}{|c|}{$-0,029662$} & & \multirow{12}{*}{$\mathrm{y} 1$} & \multirow{12}{*}{\multicolumn{2}{|c|}{0}} & & $\mathrm{x} 1$ & $-0,011623$ & & $\mathrm{x} 1$ & 0,013030 \\
\hline $\mathrm{x} 2$ & \multicolumn{2}{|c|}{$-0,651470$} & & & & & & $\mathrm{x} 2$ & 0,014544 & & $\mathrm{x} 2$ & $-0,173080$ \\
\hline $\mathrm{x} 3$ & \multicolumn{2}{|c|}{$-0,084772$} & & & & & & $\mathrm{x} 3$ & $-0,011793$ & & $\mathrm{x} 3$ & $-0,504110$ \\
\hline $\mathrm{x} 4$ & \multicolumn{2}{|c|}{$-1,062500$} & & & & & & $\mathrm{x} 4$ & 0,000267 & & $\mathrm{x} 4$ & 2,493000 \\
\hline $\mathrm{x} 5$ & \multicolumn{2}{|c|}{$-1,302800$} & & & & & & $\mathrm{x} 5$ & $-0,002838$ & & $\mathrm{x} 5$ & $-0,218000$ \\
\hline x6 & \multirow{2}{*}{\multicolumn{2}{|c|}{$\begin{array}{l}0,134240 \\
0,401310\end{array}$}} & & & & & & $\mathrm{x} 6$ & $-0,002242$ & & $\mathrm{x} 6$ & 1,798400 \\
\hline $\mathrm{x} 7$ & & & & & & & & $\mathrm{x} 7$ & 0,000538 & & $\mathrm{x} 7$ & 0,653500 \\
\hline $\mathrm{x} 8$ & \multicolumn{2}{|c|}{$-1,223700$} & & & & & & $\mathrm{x} 8$ & $-0,000053$ & & $\mathrm{x} 8$ & 1,762100 \\
\hline $\mathrm{x} 9$ & \multicolumn{2}{|c|}{1,140600} & & & & & & $\mathrm{x} 9$ & $-0,000150$ & & $\mathrm{x} 9$ & $-0,329430$ \\
\hline $\mathrm{x} 10$ & \multicolumn{2}{|c|}{$-0,676570$} & & & & & & $\mathrm{x} 10$ & $-0,000030$ & & $\mathrm{x} 10$ & $-0,923150$ \\
\hline $\mathrm{x} 11$ & \multirow{2}{*}{\multicolumn{2}{|c|}{$\begin{array}{r}-0,821250 \\
0,514790\end{array}$}} & & & & & & $\mathrm{x} 11$ & 0,000049 & & $\mathrm{x} 11$ & 0,748350 \\
\hline $\mathrm{x} 12$ & & & & & & & & $\mathrm{x} 12$ & $-0,000022$ & & $\mathrm{x} 12$ & $-0,886450$ \\
\hline
\end{tabular}


Tabela 6-14 - Matrizes de estado estimadas para as entradas F e TB e ordem do sistema = 12 .

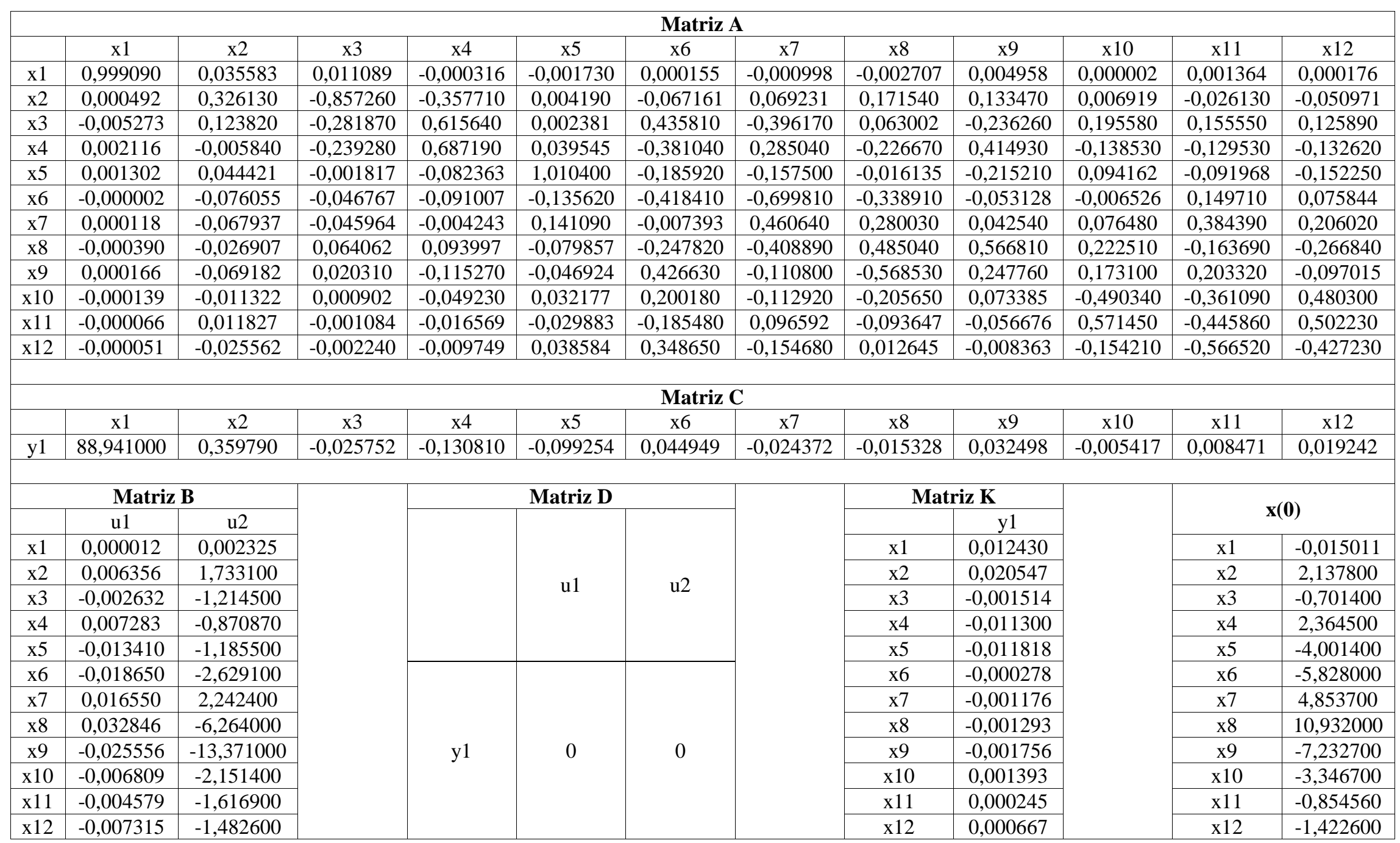


Tabela 6-15 - Matrizes de estado estimadas para as entradas F e TB e ordem do sistema $=11$.

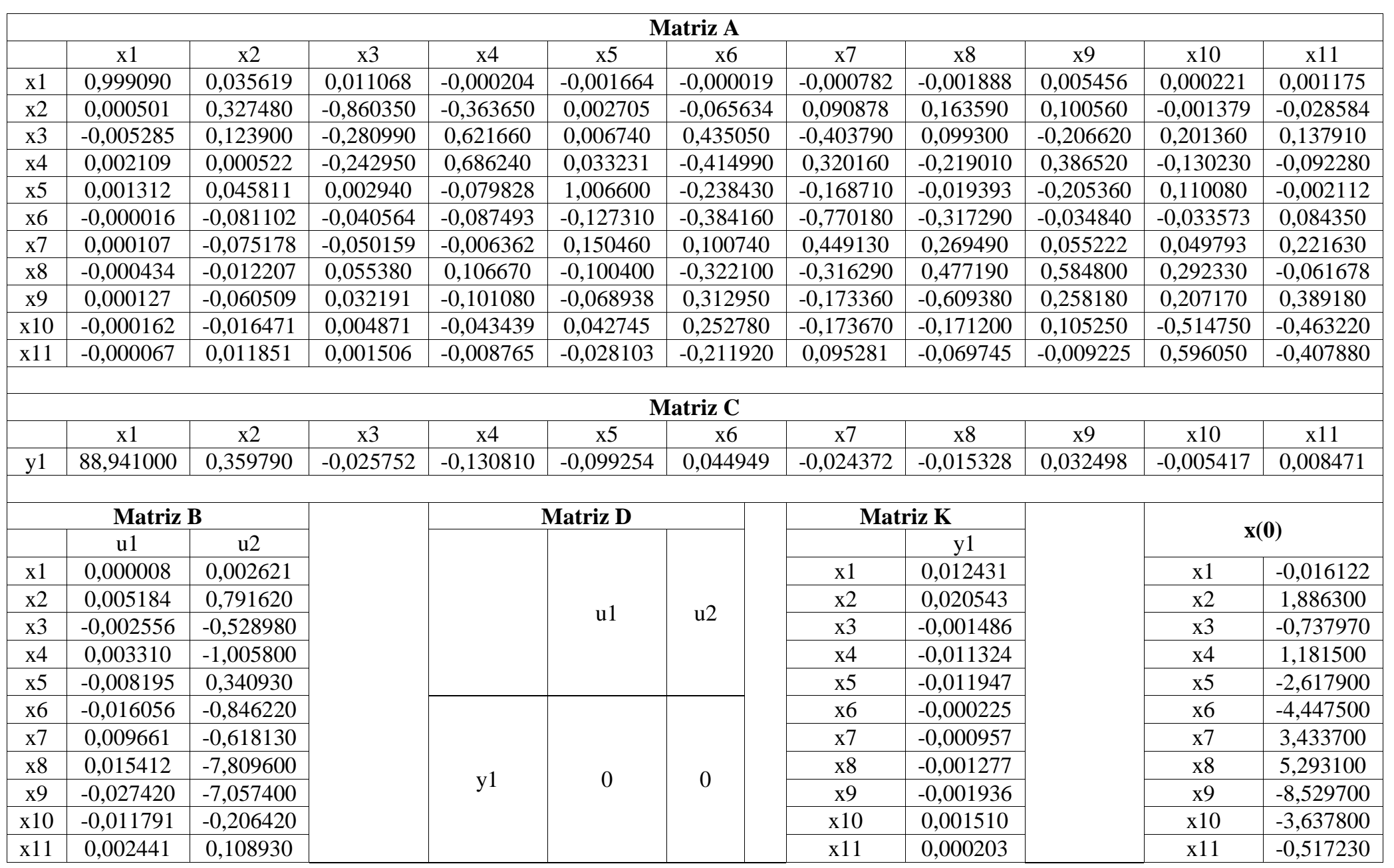


Tabela 6-16 - Matrizes de estado estimadas para as entradas F e TB e ordem do sistema = 9.

\begin{tabular}{|c|c|c|c|c|c|c|c|c|c|}
\hline \multicolumn{10}{|c|}{ Matriz A } \\
\hline & $\mathrm{x} 1$ & $\mathrm{x} 2$ & $\mathrm{x} 3$ & $\mathrm{x} 4$ & $\times 5$ & $\mathrm{x} 6$ & $\mathrm{x} 7$ & $\mathrm{x} 8$ & $\times 9$ \\
\hline $\mathrm{x} 1$ & 0,999090 & 0,035709 & 0,011002 & $-0,000229$ & $-0,001572$ & $-0,000533$ & $-0,000217$ & $-0,000572$ & 0,005025 \\
\hline$x 2$ & 0,000505 & 0,327550 & $-0,859510$ & $-0,368480$ & $-0,003896$ & $-0,059868$ & 0,075359 & 0,119590 & 0,060589 \\
\hline $\mathrm{x} 3$ & $-0,005311$ & 0,126400 & $-0,283090$ & 0,623090 & 0,018705 & 0,416790 & $-0,380150$ & 0,174450 & $-0,164190$ \\
\hline $\mathrm{x} 4$ & 0,002136 & 0,002200 & $-0,245560$ & 0,677660 & 0,025489 & $-0,405970$ & 0,325350 & $-0,246960$ & 0,295120 \\
\hline$x 5$ & 0,001281 & 0,047048 & $-0,000954$ & $-0,084369$ & 1,013800 & $-0,199760$ & $-0,164250$ & $-0,008572$ & $-0,200340$ \\
\hline $\mathrm{x} 6$ & $-0,000047$ & $-0,077877$ & $-0,046527$ & $-0,092968$ & $-0,125620$ & $-0,364930$ & $-0,738150$ & $-0,316190$ & $-0,045213$ \\
\hline $\mathrm{x} 7$ & 0,000114 & $-0,078718$ & $-0,042351$ & 0,002639 & 0,149980 & 0,041565 & 0,435230 & 0,271420 & 0,130410 \\
\hline $\mathrm{x} 8$ & $-0,000398$ & $-0,019919$ & 0,055841 & 0,091430 & $-0,079521$ & $-0,252850$ & $-0,352940$ & 0,503040 & 0,558270 \\
\hline $\mathrm{x} 9$ & 0,000081 & $-0,065552$ & 0,024503 & $-0,114170$ & $-0,055480$ & 0,397650 & $-0,133880$ & $-0,650880$ & 0,309710 \\
\hline \multicolumn{10}{|c|}{ Matriz C } \\
\hline & $\mathrm{x} 1$ & $\mathrm{x} 2$ & $\mathrm{x} 3$ & $\mathrm{x} 4$ & $\mathrm{x} 5$ & $\mathrm{x} 6$ & $\mathrm{x} 7$ & $\mathrm{x} 8$ & $\mathrm{x} 9$ \\
\hline $\mathrm{y} 1$ & 88,941000 & 0,359790 & $-0,025752$ & $-0,130810$ & $-0,099254$ & 0,044949 & $-0,024372$ & $-0,015328$ & 0,032498 \\
\hline \multicolumn{3}{|c|}{ Matriz B } & \multicolumn{3}{|c|}{ Matriz D } & \multicolumn{2}{|c|}{ Matriz K } & \multirow{2}{*}{\multicolumn{2}{|c|}{$\mathbf{x}(\mathbf{0})$}} \\
\hline & $\mathrm{u} 1$ & $\mathrm{u} 2$ & \multirow{10}{*}{ y1 } & \multirow{5}{*}{$\mathrm{u} 1$} & \multirow{5}{*}{$\mathrm{u} 2$} & & $\mathrm{y} 1$ & & \\
\hline $\mathrm{x} 1$ & 0,000000 & 0,002043 & & & & $\mathrm{x} 1$ & 0,012430 & $\mathrm{x} 1$ & $-0,018254$ \\
\hline$x 2$ & 0,007251 & $-0,343520$ & & & & $\mathrm{x} 2$ & 0,020509 & $\mathrm{x} 2$ & 2,339900 \\
\hline$x 3$ & $-0,003616$ & 0,340550 & & & & $x 3$ & $-0,001321$ & $\mathrm{x} 3$ & $-1,016300$ \\
\hline$x 4$ & $-0,000683$ & $-1,620900$ & & & & $\mathrm{x} 4$ & $-0,011480$ & $\mathrm{x} 4$ & 0,069587 \\
\hline$x 5$ & $-0,005918$ & 3,838100 & & \multirow{5}{*}{0} & \multirow{5}{*}{0} & $\mathrm{x} 5$ & $-0,011704$ & $\mathrm{x} 5$ & $-2,062500$ \\
\hline $\mathrm{x} 6$ & $-0,014970$ & 4,789000 & & & & $\mathrm{x} 6$ & 0,000002 & $\mathrm{x} 6$ & $-4,398200$ \\
\hline $\mathrm{x} 7$ & 0,006981 & $-5,345900$ & & & & $\mathrm{x} 7$ & $-0,001047$ & $\mathrm{x} 7$ & 2,619100 \\
\hline $\mathrm{x} 8$ & $-0,014159$ & $-13,621000$ & & & & $\mathrm{x} 8$ & $-0,001268$ & $\mathrm{x} 8$ & $-2,509100$ \\
\hline $\mathrm{x} 9$ & $-0,050866$ & 2,268000 & & & & $\mathrm{x} 9$ & $-0,001409$ & $\mathrm{x} 9$ & $-14,923000$ \\
\hline
\end{tabular}


Nas Figuras-57 a 6-61 seguintes é mostrado o desempenho dos modelos de estados.

Comparam-se, na sequência esses gráficos com aqueles das Figuras 6-9, 6-36, 6-43 e 6-50.
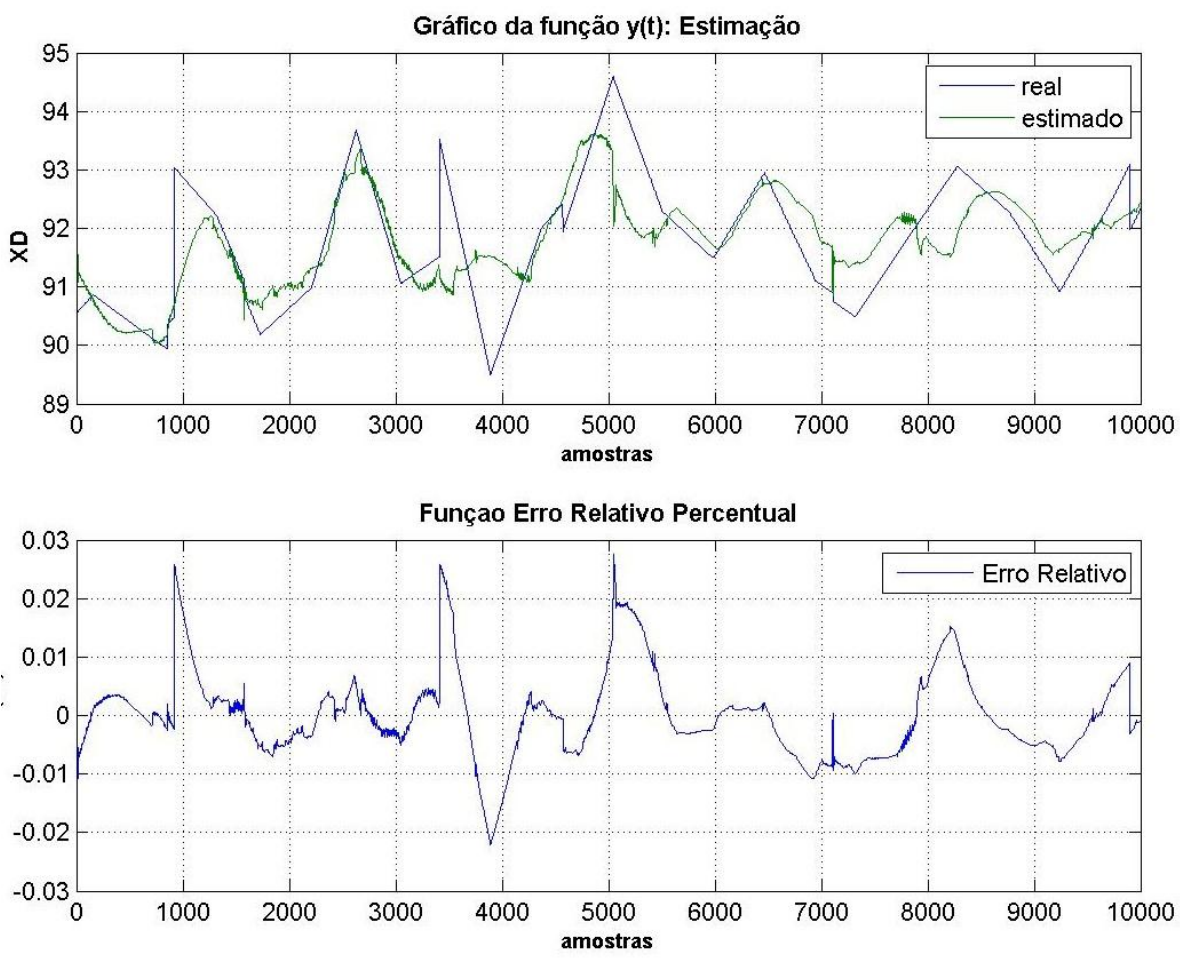

Figura 6-57 - Gráficos que mostram o desempenho do modelo de espaço de estado para as entradas F e DL e ordem do sistema $=12$.
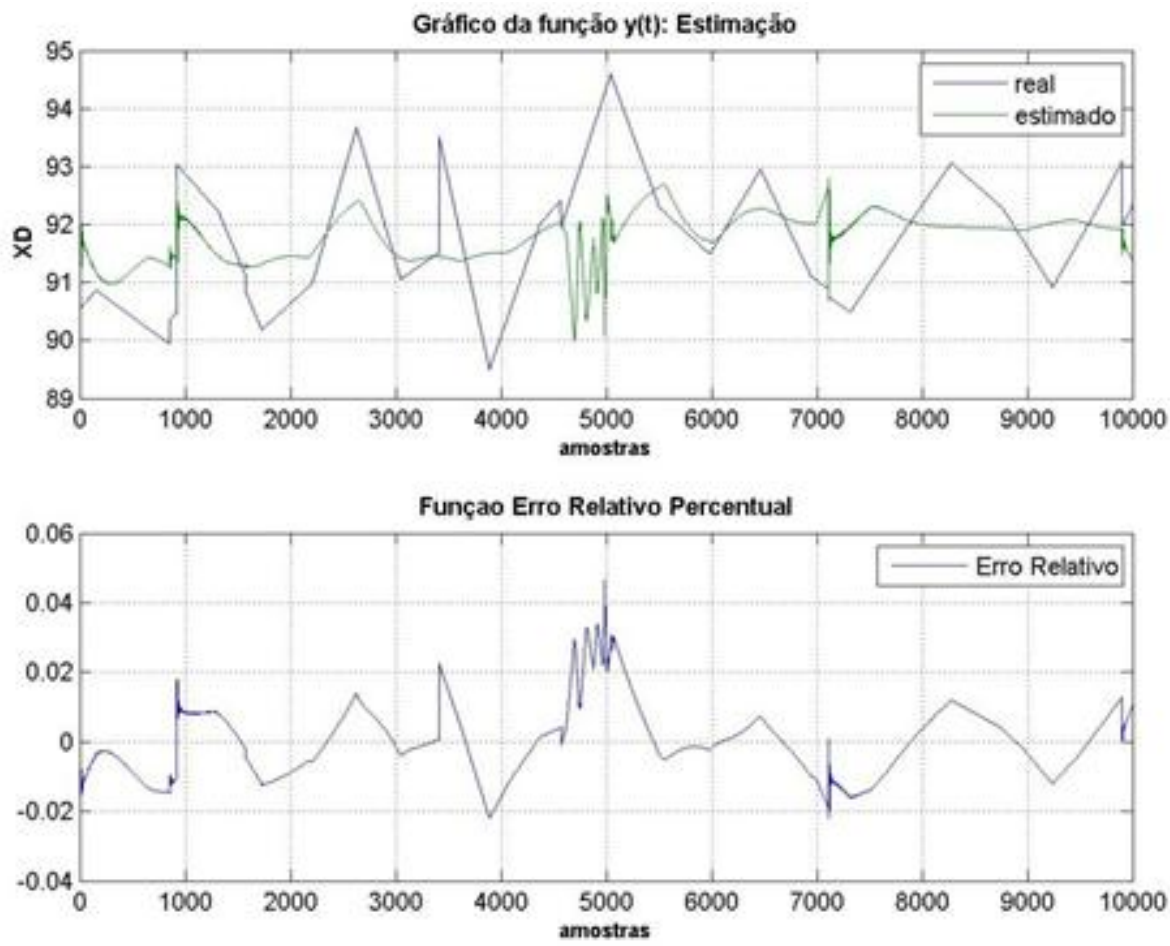

Figura 6-58 - Gráficos que mostram o desempenho do modelo de espaço de estado para a entrada TB e ordem do sistema $=12$. 

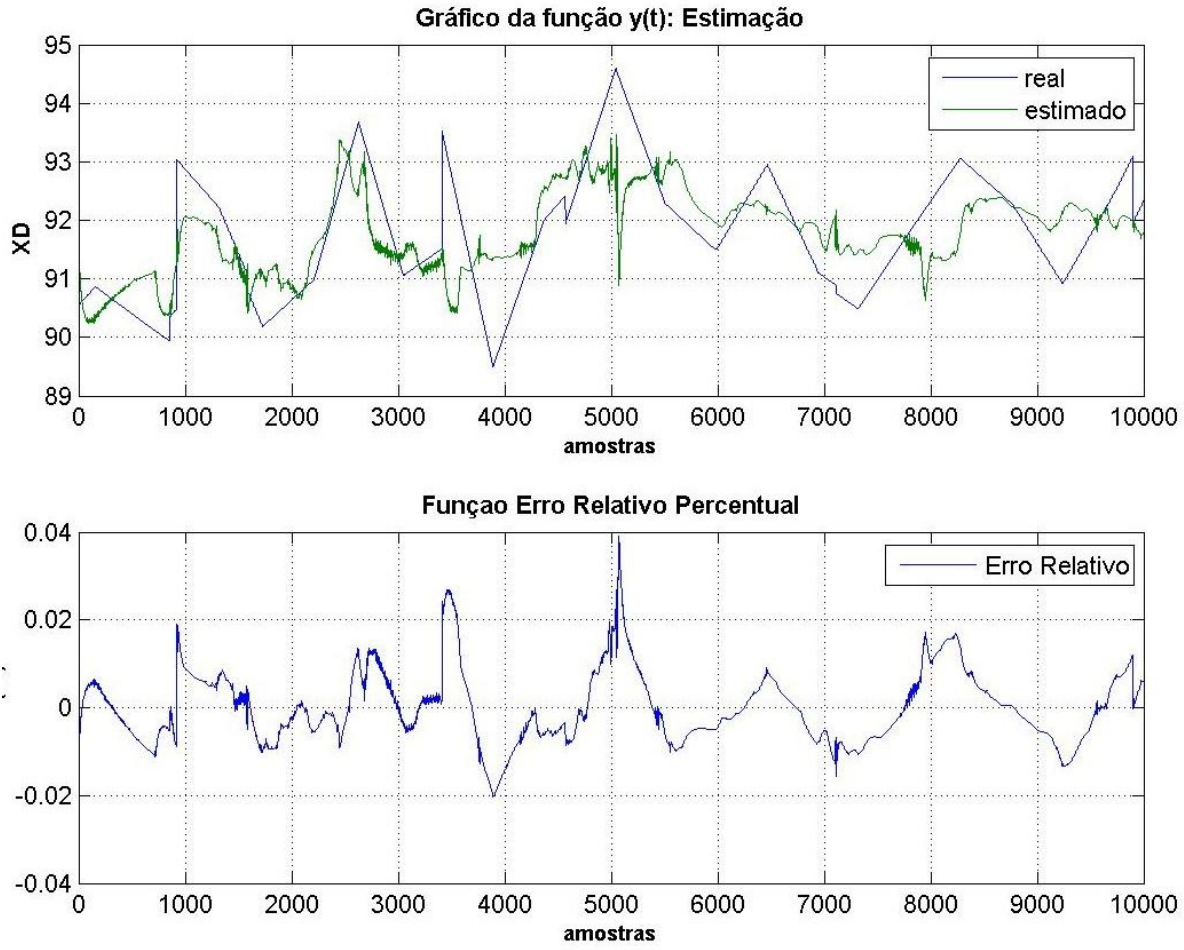

Figura 6-59 - Gráficos que mostram o desempenho do modelo de espaço de estado para as entradas F e TB e ordem do sistema $=12$.
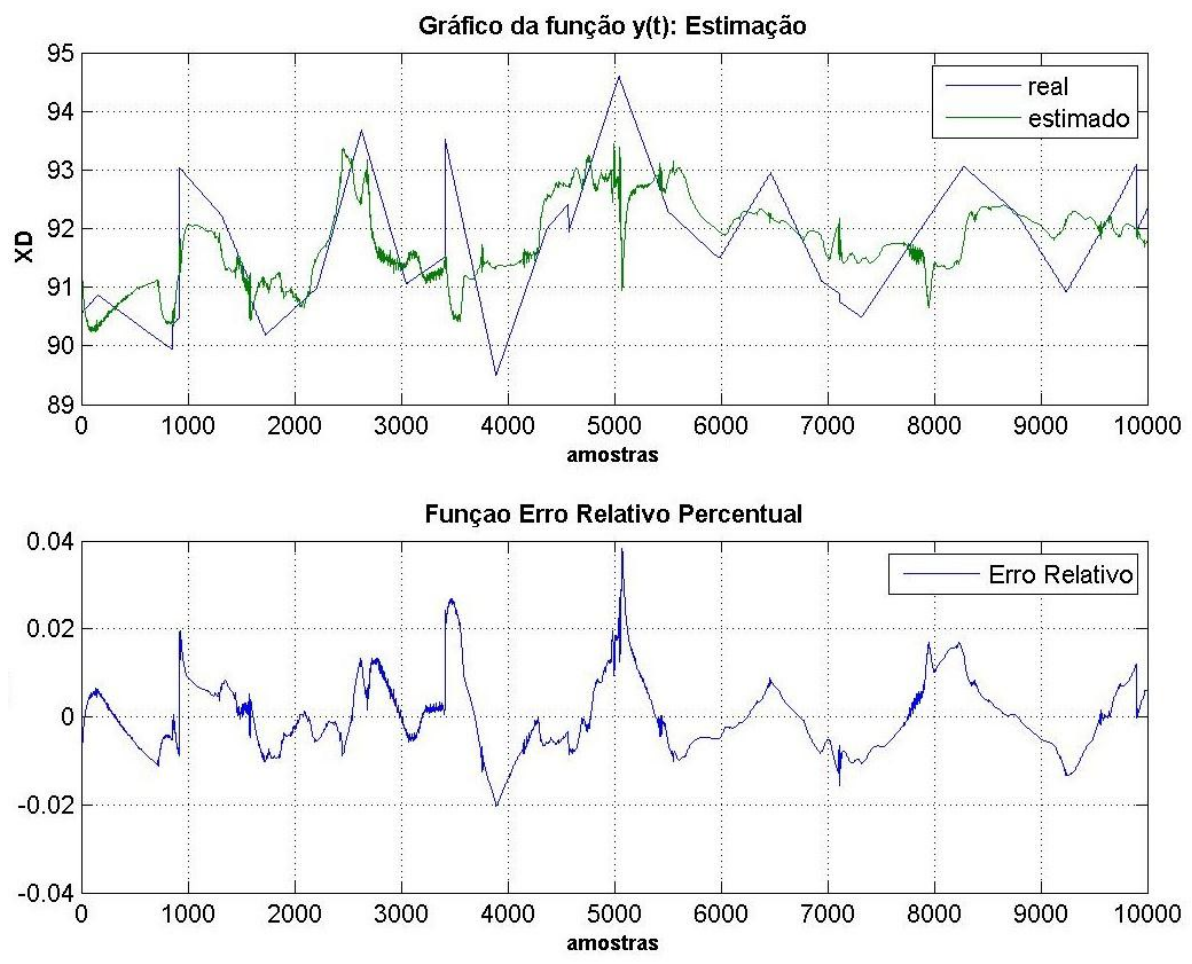

Figura 6-60 - Gráficos que mostram o desempenho do modelo de espaço de estado para as entradas F e TB e ordem do sistema $=11$. 

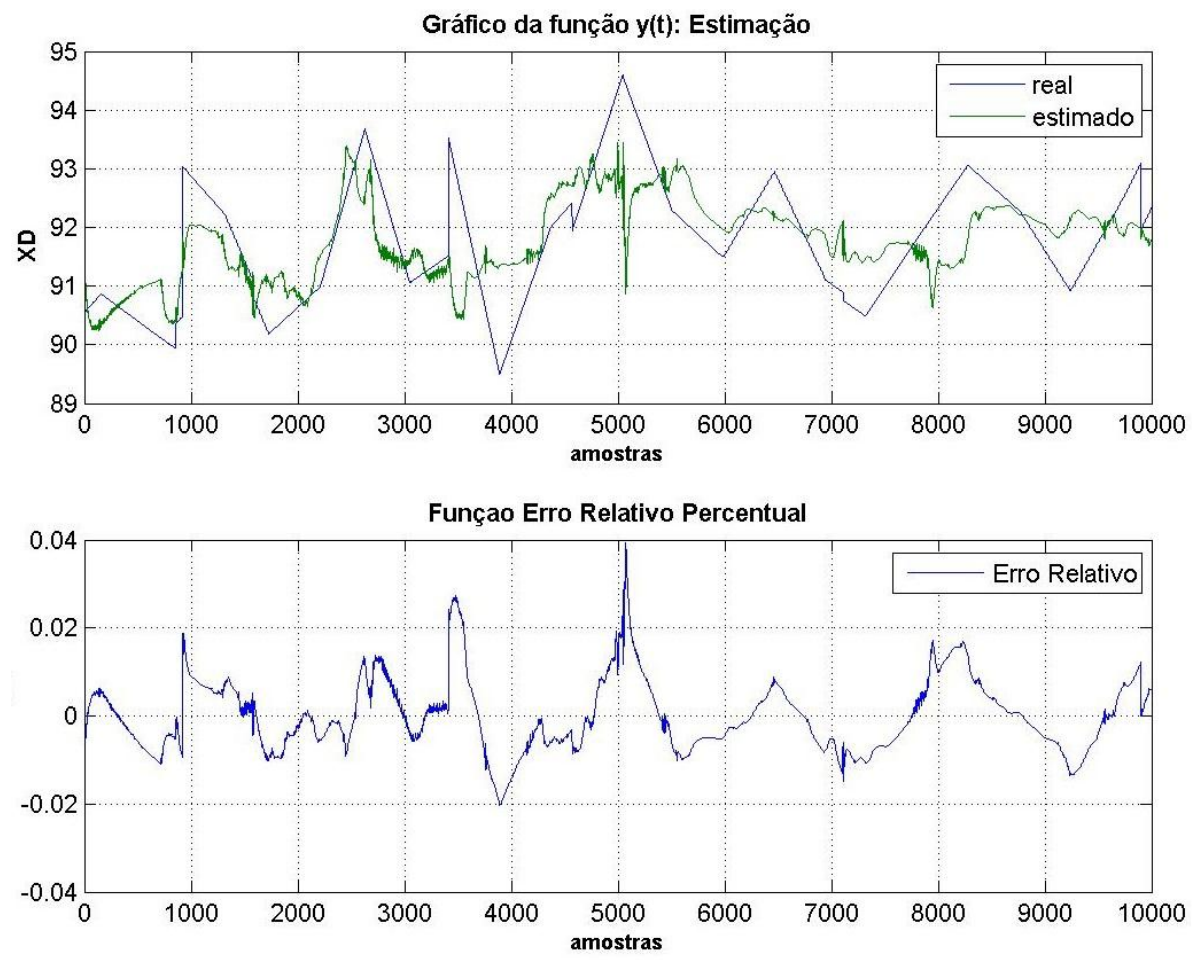

Figura 6-61 - Gráficos que mostram o desempenho do modelo de espaço de estado para as entradas F e TB e ordem do sistema $=9$.

Os gráficos das Figuras 6-57 a 6-61 comprovam que os modelos lineares se mostraram de pouca valia quando comparados aos modelos obtidos pelas RNAs. Como já era esperado, o uso dos modelos lineares fica restrito a uma faixa estreita em torno do ponto onde foram linearizados, sendo um fator limitante para utilização como sensores virtuais estimados numa faixa de operação. 



\section{Capítulo VII}

\section{Conclusões Gerais e Trabalhos Futuros}

\subsection{Conclusões Gerais}

Neste trabalho duas abordagens foram consideradas para o desenvolvimento de um sensor virtual capaz de estimar a composição do produto destilado numa coluna binária de destilação de etanol. A primeira abordagem emprega uma rede neural TDNN, sendo que a segunda baseia-se na modelagem ARX implementada por meio de uma rede recorrente NNARX.

De acordo com os resultados obtidos, a rede TDNN não apresentou bons resultados, mostrando-se incapaz de estimar a composição utilizando o conjunto de dados coletados. Entretanto, com base nos resultados obtidos pela rede NNARX, pode-se verificar sua capacidade de generalização quando usada como estimador neural não linear.

Entretanto, notou-se a grande importância das etapas de escolha, coleta e préprocessamento dos dados, visto que estas são fatores determinantes para um alto ou baixo grau de generalização das RNAs, influenciando-se diretamente nos resultados obtidos. A escolha das variáveis de entrada foi feita verificando sua correlação com a saída. Com isso, buscou-se maximizar a eficiência da identificação do modelo.

Numa primeira análise, escolheram-se então como variáveis de entrada a vazão de alimentação da coluna "A", a vazão de retirada do produto destilado no topo da coluna "B" e a temperatura na bandeja B4 da coluna "B", sendo que a composição do produto destilado foi a saída a ser estimada.

No treinamento das redes, utilizou-se o método de Levenberg-Marquardt para diminuir o tempo de treinamento e possíveis erros de convergência da rede. Devido ao grande 
número de simulações realizadas, pode-se constatar que esse objetivo foi claramente atingido. Pode ser observado que o número de neurônios da camada oculta, o número de entradas, e o método de otimização afetam de forma considerável o desempenho computacional em termos de tempo de processamento.

O sensor virtual implementado por meio da rede NNRAX mostrou-se de grande valia e confiabilidade, podendo ser utilizado tanto na medição da variável frente a inviabilidade de aquisição de um sensor físico como também na intervenção durante uma falha ou manutenção desse sensor.

\subsection{Trabalhos Futuros}

Com o intuito de ampliar esses estudos sugere-se como futuros trabalhos, o estudo mais aprimorado sobre o desenvolvimento de modelos de inferência não lineares baseados em RNA, como forma de ampliar a faixa de operação do sensor virtual. A partir deste trabalho inicial propõe-se estudar outras variáveis críticas nos processos de fabricação de açúcar e álcool que também possam ser inferidas através de outras variáveis de acesso fácil acesso.

Enfim, devido a grande aplicabilidade dos sensores virtuais a nível industrial, surgem boas perspectivas de pesquisa em outras áreas, podendo se tornar uma alternativa aos sistemas já existentes. 


\section{Referência Bibliográfica}

Aguirre, L. A.; (1993). Quantitative measure of modal dominance for continuous systems.

Proceedings of the 32nd IEEE Conference on Decision and Control, San Antonio, Texas, USA, pp. 2405-2410.

Aguirre, L.A.; (2007). Introdução a Identificação de Sistemas - Técnicas Lineares e Não lineares Aplicadas a Sistemas Reais. $3^{\text {a }}$ ed., Editora UFMG, Belo Horizonte-MG.

Baffi, G.; Martin, E.B.; Morris, A.J.; (2000). Non-linear dynamic projection to latent structures modelling. Chemometrics and Intelligent Laboratory Systems, 52(1), 5-22.

Baratti, R.; Bertucco, A.; Da Rold, A.; Morbidelli M.; (1995) Development of a Composition Estimator for Binary Distillation Columns. Application to a Pilot Plant, Chem. Engng. Sci., 50, pp. 1541-1550.

Barto, A. G.; (1989). Connectionist Learning for Control: An Overview, (89-89). University of Massachusetts Amherst.

Baruch, I.S.; Flores, J.M.; Thomas, F.; Gortcheva, E.; (2001). A multimodel recurrent neural network for systems identification and control. Neural Networks, 2001. Proceedings. IJCNN '01. International Joint Conference on, vol. 2, nº, pp. 1291-1296.

Bauer, M.H.; Stichlmair, J. (1998). Design and Economic Optimization of Azeotropic Distillation Processes Using Mixed-Integer Nonlinear Programming, Comput. Chem. Eng., 22, 9, 1271-1286, 0098-1354. 
Benne, M.; (2000). Artificial neural networks for modelling and predictive control of an industrial evaporation process. Journal of Food Engineering, 46(4), pp. 227-234.

Bhat, N.; McAvoy, T.J.; (1990). Use of neural nets for dynamic modeling and control of chemical process systems. Computers \& Chemical Engineering, vol.14, Issues 4-5, pp. $573-582$.

Billings, S.A.; Fakhouri, S.Y.; (1978). Identification of a class of nonlinear systems using correlation analysis. Electrical Engineers, Proceedings of the Institution of , vol.125, no.7, pp.691-697.

Braga, A. P., Ludermir, T. B., Carvalho, A. C. P. L. F.; (2000). Redes Neurais Artificiais Teoria e Aplicações, LTC.

Brosilow, C.B.; Babu, J.; (1978). Inferential control of processes: Part I. Steady state analysis and design, AIChE Journal, Vol. 24, Issue 3, American Institute of Chemical Engineers, pp. 485-492.

Brouwer, R. K.; (2000). A Fuzzy Recurrent Artificial Neural Network (FRANN). for Pattern Classification. presented at International Journal of Uncertainty, Fuzziness and Knowledge-Based Systems, pp. 525-538.

Buckley, P. S.; Luyben, W. L.; Shunta, F. S.; (1985). Design of Distillation Control Systems. Instrument Society of America, Research Triangle Park, USA.

Campos, M.; Teixeira, H.; (2006). Controles típicos de equipamentos e processos industriais. São Paulo: Edgard Blücher.

Casali, A., Gonzalez; G., Torres, F.; Vallebouna, G.; Castelli, L.; Gimenez, P. (1998). Particle size distribution soft-sensor for a grinding circuit. Powder Technology, 99, 15-21. 
Chen S, Billings SA, (1989). Representations of non-linear system: the NARMAX model. International Journal of Control 49:1012-1032

Chen, S.; Billings, S.A.; (1992a). Neural Networks for Nonlinear Dynamic System Modeling and Identification. Znt. J. Control, vol. 56, nº.2, 1992, pp. 319-346.

Chen, S.; Billings; S.A. Grant, P.M.; (1992b) Recursive Hybrid Algorithm for nonlinear system identification using radial basis function networks. Int.J.Contr.vol 55.no.5, pp.1051-1070.

Chua, L.O.; Yang, L.; (1988). Cellular neural networks: theory. Circuits and Systems, IEEE Transactions on, vol. $35, \mathrm{n}^{\circ} .10,1988$, pp. $1257-1272$.

Cohen, J.; (1988). Statistical power analysis for the behavioral sciences. Hillsdale, NJ, Erlbaum.

Dimopoulos, K.P.; Kambhampati, C.; (1999). Multiple Interconnected Hopfield Networks for Intelligent Global Linearising Control. Neural Networks, IJCNN '99, International Joint Conference on, vol.3, Washington-DC, pp. 2135-2140.

Doebelin, E.O.; (1980). System modeling and response - Theorical and experimental approaches. New York: John Wiley \& Sons, Inc. Wiley.

Ferneda, E.; (2006). Redes neurais e sua aplicação em sistemas de recuperação de informação. Ci. Inf. [online]. vol.35, n.1, pp. 25-30. ISSN 0100-1965.

Fogel, D.; Michalewicz, Z.; (1997). Handbook of evolutinary computation. New York: Oxford University Press. 
Fortuna,L.; Graziani,S.; Rizzo, A.; Xibilia, M. G. (2007); Softsensors for monitoring and control of industrial processes. London, UK:Springer.

Goodman, N.; (1954/1983). Fact, Fiction, and Forecast, 1st/4th ed., Cambridge, MA: Harvard University Press.

Gorji, A.A.; Menhaj, M.B.; (2008). Identification of nonlinear state space models using an MLP network trained by the EM algorithm. Neural Networks. IJCNN 2008, (IEEE World Congress on Computational Intelligence). IEEE International Joint Conference on, vol., no., pp.53-60, 1-8.

Haykin, S.; (2001). Redes neurais: princípios e prática. trad. Paulo Martins Engel, 2.ed., Porto Alegre: Bookman.

Hebb; D.O.; (1949). The organization of behavior: A neuropsychological theory. John Wiley and Sons, Inc., New York.

Hinton, G.E.; Salakhutdinov, R.; (2006). Reducing the dimensionality of data with neural networks. Science, 31 (5786), pp. 504-507.

Hinton, G.E.; (2007). Boltzmann machine. Scholarpedia, 2(5):1668.

Hopfield, J.J; Tank, D.W.; (1986). Computing with neural circuits: a model. Science, vol.233, $n^{\circ} .4764$, pp. 625-633.

Hornik, K.; Stinchcombe, M.; White, H.; (1989). Multilayer feedforward networks are universal approximators. Neural Networks, vol.2, Issue 5, pp. 359-366. 
Isik, C.; Cakmakci, A.M.; (1993). Identification of a nonlinear multivariable dynamic process using feed-forward networks. Neural Networks, 1993, IEEE International Conference on , vol. 1, pp.564-567.

Iyoda, E.; (2000). Inteligência Computacional no Projeto Automático de Redes Neurais Híbridas e Redes Neurofuzzy Heterogêneas. Dissertação de Mestrado, FEEC:UnicampSP.

Jang, J.S.R.; Sun, C.T.; (1993). Functional Equivalence between Radial Basis Function Networks and Fuzzy Inference Systems. IEEE Trans. on Neural Networks, vol.4, 1993, pp. 156-159.

Jin-Tsong Jengt and Tsu-Tain Lee (1999). An Approximate Equivalence Neural Network to Conventional Neural Network for the Worst-case Identification and Control of Nonlinear System.

Joseph, Babu \& Brosilow, Coleman B.; (1978). Inferential control of processes: Part I. Steady state analysis and design, AIChE Journal, Vol. 24, Issue 3, American Institute of Chemical Engineers, pp. 485-492.

Juang, J.; (1994). Applied System Identification. Prentice Hall.

Juditsky A, Hjalmarsson H, Benveniste A, Delyon B, Ljung L, Sjöberg J, Zhang Q, (1995). Nonlinear black-box models in system identification: mathematical foundations. Automatica 31: pp.1725-1750.

Klamkin, M.P.; (1987). Mathematical modeling: Classroom notes in applied mathematics. SIAM, Philadelphia, U.S.A. 
Klir, G.J.; Folger, T.A.; (1988). Fuzzy Sets, Uncertainty, and Information. State University of New York, Binghamton, Prentice Hall International.

Kresta, J.V.; Marlin, T.E.; MacGregor, J.F.; (1994). Development of Inferential Process Models using PLS, Computers and Chemical Engineering 18 (7), pp. 597-611.

Kuschewski, J.G.; Hui, S.; Zak, S.H.; (1993). Application of feedforward neural networks to dynamical system identification and control. Control Systems Technology, IEEE Transactions on, vol. 1, no.1, pp. 37-49.

Leondes, C.T.; (1998). control and dynamic systems, (Cornelius T. Leondes, Ed.),. Academic Press.

Lima, C.A.M.; (2000). Emprego de Teoria de Agentes no Desenvolvimento de Dispositivos Neurocomputacionais Híbridos e Aplicação ao Controle e Identificação de Sistemas, Dinâmicos. Dissertação de Mestrado, FEEC:Unicamp-SP.

Lin, Y; Cunningham III, G.A.; (1995). A New Approach to Fuzzy-Neural System Modeling. Fuzzy Systems, IEEE Transactions on, vol.3, nº 2, pp. 190-198.

Ljung, L.; Söderström, T.; (1987). Theory and Practice of Recursive Identification. MIT PRESS.

Ljung, L.; (1999). System Identification: Theory for user. $2^{a}$ ed., Prentice Hall.

L. Ljung.; (2001). Estimating linear time invariant models of non-linear time-varying systems. European Journal of Control, 7(2-3):203-219, Sept 2001. Semi-plenary presentation at the European Control Conference. 
Lo, J.T.; Bassu, D.; (2001). Adaptive vs. accommodative neural networks for adaptive system identification. Neural Networks, 2001. Proceedings. IJCNN '01. International Joint Conference on, vol. 2, nº., pp. 1279-1284.

Lundström, P.; Skogestad, S.; (1995). Opportunities and difficulties with 5 x 5 distillation control. Journal of Process Control, 5(4), pp. 249-261.

Luyben, William L.; (1987). Derivation of transfer functions for highly nonlinear distillation columns. Industrial \& Engineering Chemistry Research, vol. 26, nº.12, pp. 2490-2495.

Luyben, W. L.; (1992). Diagonal Controller Tuning En: W. L. Luyben (Ed.), Practical Distillation Control, Van Nostrand Reinhold, NY, pp. 229-247.

Mashor, M.Y.; (2004) Perforrnance comparison between HMLP, MLP and RBF networks with application to on-line system identification. IEEE Conference on Cybernetics and Intelligent Systems, vol. 1, pp. 643-648.

McAvoy, T.J.; Arkun Y.; ZAFIRIOU, E.; (1989). Workshop Proceedings on Model Based Process Control. Pergamon Press, Oxford, IFAC.

McCulloch, W.S. \& Pitts, W.; (1943). A logical calculus of the ideas immanent in nervous activity. Bulletin of Mathematical Biophysics, 5(4), pp.115-133.

Meireles, M. R. G.; Almeida, P. E. M.; Simões, M.G.; (2003). A Comprehensive Review for Industrial Applicability of Artificial Neural Networks. IEEE Transactions on Industrial Electronics, 50(3), pp. 585-601.

Mejdell, T.; Skogestad, S.; (1991). Composition Estimator in a Pilot-Plant Distillation Column Using Multiple Temperatures. Industrial \& Engineering Chemistry Research, 30, pp. $2555-2564$. 
Mejdell, T.; Skogestad, S.; (1991). Estimation of Distillation Compositions from Multiple Temperature Measurements Using Partial-Least-Squares Regression. Industrial \& Engineering Chemistry Research, 30, pp. 2543-2555.

Mejdell, T.; Skogestad, S.; (1993). Output estimation using multiple secondary measurements: High-Purity Distillation. A.I.Ch.E.J., 39(10), pp. 1641-1653.

Moura, L.G.; (2003) Modelagem Empírica de Colunas de Destilação utilizando Redes Neurais de Wavelets para Otimização e Controle de Processos. Dissertação, (Mestrado em Engenharia Química). Departamento de Engenharia Química da Universidade Federal de Santa Catarina - UFSC, Florianópolis.

Narendra, K.S.; Parthasarathy K.; (1990). Identification and control of dynamical systems using neural networks. IEEE Transactions on Neural Networks 1(1):4-27.

Narendra, K.S.; Balakrishnan, J.; Ciliz, M.K.; (1995). Adaptive and Learning using Multiple Models. Switching and Tuning. IEEE Control Systems Magazine, pp. 37-50.

Narendra, K. S.; Mukhopadhyay, S.; (1997). Adaptive Control Using Neural Networks and Approximate Models, IEEE Transactions on Neural Networks, pp. 475-485, vol. 8, no. 3.

Narendra, K.S.; Parthasarathy K.; (2003). Back propagation and dynamical systems. Part II: identification, Centre Syst. Sci., CT, tch, rep. 8902.

Nechyba, M.C.; Yangsheng Xu; (1994). Neural network approach to control system identification with variable activation functions. Intelligent Control, 1994., Proceedings of the 1994 IEEE International Symposium on, vol. , nº, pp. 358-363.

Nerrand, O. et al., (1993). Neural Networks and Nonlinear Adaptive Filtering: Unifying Concepts and New Algorithms. Neural Computation, pp. 165-199. 
Nguyen, D. H.; Widrow, B.; (1990). Neural Networks for Self-Learning Control Systems. IEEE Control Systems Magazine, pp. 18-23.

Park; S.; Han, C.; (2000). A Nonlinear Soft Sensor based on Multivariate Smoothing Procedure for Quality Estimation in Distillation Columns, Computers and Chemical Engineering 24, pp. 871-877.

Patra, J.C. et al.; (1999). Identification of nonlinear dynamic systems using functional link artificial neural networks. IEEE transactions on systems man and cybernetics Part B Cybernetics a publication of the IEEE Systems Man and Cybernetics Society, 29(2), pp. 254-262.

Qin, S.J.; (1997). Neural network for intelligent sensors and control-practical issues and some solutions, in: O. Omidvar, D.L. Elliott (Eds.), Neural Systems for Control, Academic Press, New York, USA.

Qin, S.J. \& McAvoy, T.J.; (1992). Nonlinear PLS modeling using neural networks, Computers \& Chemical Engineering, Vol. 16, Issue 4, Neutral network applications in chemical engineering, April, pp. 379-391.

Rademaker, O.; Rijnsdorp, J. E.; Maarleveld, A.; (1975). Dynamics and control of continuous distillation units. Elsevier Scientific Pub. Co.

Radhakrishnan, V. R.; Mohamed, A. R.; (2000). Neural networks for the identification and control of blast furnace hot metal quality, Journal of Process Control, Volume 10, Issue 6, December, pp. 509-524.

Riggs, J. B.; Huang, H.; (2002). Including levels in MPC to improve distillation control. Ind. Eng. Chem. Res., Vol. 41, pp. 4048-4053. 
Riggs, J.; Enagandula, S.; (2006). Distillation control configuration selection based on product variability prediction. Control Engineering Practice, 14(7), 743-755.

Rhodes, C.; Morari, M.; (1998) Determining the model order of nonlinear input/output systems directly from data. AIChE Journal, v. 44, p. 151-163.

Rosenblatt, F.; (1958). The perceptron: A theory of statistical separability in cognitive systems. Buffalo: Cornell Aeronautical Laboratory, Inc. Rep. No. VG-1196-G-1.

Rosenblatt, F.; (1960). Perceptron Simulation Experiments. Proceedings of the IRE, 48(3), 301-309.

Rosenblatt, F.; (1962). Principles of Neurodynamics: Perceptrons and the Theory of Brain Mechanisms, Washington, DC: Spartan.

Russell, B.; (1948), Human Knowledge: Its Scope and Limits, London: Routledge.

Sadegh, N.; (1993). A perceptron network for functional identification and control of nonlinear systems. Neural Networks, IEEE Transactions on, vol.4, nº6, pp. 982-988.

Sanchez, E.N. Poznyak, A.S. Wen Yu (1999). Dynamic multilayer neural network for nonlinear system identification. Neural Networks, 1999. IJCNN '99. International Joint Conference on, Issue Date: 1999, Volume: 3, On page(s): 2109 - 2113 vol.3, Washington, DC.

Segatto, E. C.; Coury, D. V.; (2006). Redes neurais artificiais recorrentes aplicadas na correção de sinais distorcidos pela saturação de transformadores de corrente. Sba Controle \& Automação [online]. vol.17, n.4, pp. 424-436. ISSN 0103-1759. 
Shinskey, F.G.; (1984). Distillation Control for Productivity and Energy Conservation (p. 353). Mcgraw-Hill (Tx).

Shinskey, F. G.; (1996). Process Control Systems: Application, Design, and Tuning (p. 439). McGraw-Hill Professional.

Silva, I.N.; Spatti, D.H.; Flauzino, R.A.; (2010). Redes Neurais Artificiais Para Engenharia e Ciências Aplicadas - Curso Prático. Artliber editora.

Sjöberg J, Hjalmarsson H, Ljung L, (1994). Neural networks in system identification. 10th IFAC System Identification-Symposium, Cophenagen.

Sjöberg J.; Zhang Q.; Ljung L.; Benveniste A.; Delyon B.; Glorennec P.Y.; Hjalmarsson H.; Juditsky A.; (1995). Nonlinear black-box modeling in system identification: a unified overview. Automatica 31:1691-1724.

Skogestad, S.; Lundström. P.; Jacobsen, E. W.; (1990). Selecting the best distillation control configuration. AIChE J., Vol. 36, No. 5, pp. 753-764.

Skogestad, S.; (1992). Dynamics and Control of Distillation Columns - A Critical Review. Presented at IFAC-symposium DYCORD+'92, Maryland, pp. 27-29.

Skogestad, S.; (1997). Dynamics and control of distillation columns: a critical survey. Modeling, Identification and Control, Vol. 18, No. 3, pp. 177-217.

Srinivasan, B.; Prasad, U. R.; Rao, N.J.; (1994). Backpropagation through adjoints for the identification of nonlinear dynamic systems using recurrent neural models. Neural Networks, IEEE Transactions on, vol.5, nº.2, pp. 213-228. 
Straub, S.; Schroder, D.; (1996). Identification of nonlinear dynamic systems with recurrent neural networks and Kalman filter methods. Circuits and Systems, 1996. ISCAS '96., Connecting the World, 1996 IEEE International Symposium on, vol.3, nº, pp. 341-344.

Sung-Woo Kim; Sun-Gi Hong; Tae-Duck Ohm; Ju-Jang Lee; (1994) "Neural network identification and control of unstable systems using supervisory control while learning," Neural Networks. IEEE World Congress on Computational Intelligence., 1994 IEEE International Conference on , vol.4, no., pp. 2500-2505.

Suykens , Johan A.; Vandewalle, J.; de Moor, Bart L. R.; (1996). Artificial Neural Networks for Modelling and Control of Non-Linear Systems. Kluwer Academic Publishers, Norwell, MA.

Takagi, T.; sugeno, M.; (1985). Fuzzy Identification of Systems and Its Application to Modeling and Control, IEEE Transations on Systems, Man and Cybernetics, vol. 15, $\mathrm{n}^{\mathrm{o}} 1$, pp. 116-132.

Takens, F.; Rand, D.; Young, L.-S.; (1981). Dynamical Systems and Turbulence, Warwick 1980, (D. Rand \& L.-S. Young, Eds.) , (Vol. 898, pp. 366-381). Springer Berlin Heidelberg.

Tham, M.T.; Vagi, F.; Morris, A.J.; Wood, R.K.; (1991). Multivariable and multirate selftuning control: a distillation column case study. Control Theory and Applications, IEE Proceedings D, vol.138, nº 1, pp. 9-24.

Unberhauen, H; Roa, G.P.; (1998). A review of identification in continuos-time systems. Annual Reviews in Control, vol. 22, pp. 145-171. 
Van Overschee, P; De Moor, B; (1994). N4SID: Subspace algorithms for the identification of combined deterministic-stochastic systems, Automatica, Vol. 30, no. 1. pp. 75-93.

Waibel, A.; Hanazawa, T.; Hinton, G.; Shikano, K.; Lang, K.; (1989). Phoneme recognition using time delay neural networks. IEEE Trans. Acoustics, Speech and Signal Processing, Vol. 37, No. 12, pp. 1888-1898.

Werbos, P.; (1974). Beyond Regression: New Tools for Prediction and Analysis in the Behavioral Sciences. PhD thesis, Harvard University, Cambridge, MA.

Widrow, B.; Hoff, M.E. Jr.; (1960). Adaptive switching circuits, in 1960 IRE WESCON Convention Record, Part 4, New York: IRE, pp. 96-104.

Widrow, B.; Lehr, M.A.; (1990). 30 years of adaptive neural networks: perceptron, Madaline, and backpropagation. Proceedings of the IEEE, vol.78, $\mathrm{n}^{\circ}$ 9, pp. 1415-1442.

Wilson, D. J. H.; Irwin, G. W.; Lightbody, G.; (1997). Nonlinear PLS modeling using radial basis function. In American Control Conference, Albuquerque, New Mexico June 4-6.

Wolff, E. A.; Skogestad S.; (1996). Temperature cascade control of distillation columns. Ind. Eng. Chem. Res., Vol. 35, pp. 475-484.

Wolpert, D.H.; (1995a), "The relationship between PAC, the statistical physics framework, the Bayesian framework, and the VC framework," in Wolpert, 117-214.

Wolpert, D.H.; (1996a), "The lack of a priori distinctions between learning algorithms," Neural Computation, 8, 1341-1390.

Wolpert, D.H.; (1996b), "The existence of a priori distinctions between learning algorithms," Neural Computation, 8, 1391-1420. 
Xiaoou Li; Wen Yu; (2002). Dynamic system identification via recurrent multilayer perceptrons, Information Sciences-Informatics and Computer Science: An International Journal, v.147 n.1-4, p.45-63.

Yamada, T.; Yabuta, T.; (1993). Dynamic system identification using neural networks. Systems, Man and Cybernetics, IEEE Transactions on, vol. 23, nº 1, pp. 204-211.

Yang, D.; Lee, K.; (1997). Monitoring of a distillation column using modified extended Kalman filter and a reduced order model. Computers \& Chemical Engineering, 21(97), S565-S570.

Yang, S.-shung; Tseng, C.-shiow; (1996). An Orthogonal Neural Network for Function Approximation - Systems, Man and Cybernetics, Part B, IEEE Transactions on. October, 26(5), 0-5.

Yen-Wei Chen; Narieda, S.; Yamashita, K.; (2003). "Blind nonlinear system identification based on a constrained hybrid genetic algorithm," Instrumentation and Measurement, IEEE Transactions on , vol.52, no.3, pp. 898- 902.

Yong, F.; Chow, T.W.S.; (2000). Orthogonal wavelet neural networks applying to identification of Wiener model. IEEE Transactions on Circuits and Systems I: Fundamental Theory and Applications, 47(4), 591-593.

Zamprogna, E.; Barolo, M.; Seborg, D. E.; (2005). Optimal selection of soft sensor inputs for batch distillation columns using principal component analysis. Journal of Process Control, $15(1), 39-52$.

Zanata, D.R.P.; (2005). Desenvolvimento de sensor virtual empregando redes neurais para medição da composição em uma coluna de destilação. Dissertação de Mestrado em 
Engenharia (Engenharia de Sistemas), Escola Politécnica, Universidade de São Paulo, São Paulo, 229p.

Zhang, Y.-M.; Li, X.R.; (1996). Hybrid training of RBF networks with application to nonlinear systems identification. Decision and Control, 1996, Proceedings of the 35th IEEE, vol.1, nº, 1996, pp. 937-942.

Zhang, J (2001). Inferential feedback control of distillation composition based on PCR and PLS. Proceedings of the American Control Conference 2: 1021-1196. Arlington, VA, EUA.

Zhang, G.P.; et al.; (1998). Forecasting with neural networks: the state of art. International of Forecasting, v.14, p.35-62, Mar.

Zhao, Y.-H.; (2003). A Soft Sensor Based on Nonlinear Principal Component Analysis, 2003 International Conference on Machine Learning and Cybernetics Xian China.

Zhu, Q.M.; (2003). A back propagation algorithm to estimate the parameters of non-linear dynamic rational models, Applied Mathematical Modeling, Volume 27, Issue 3, Pages 169-187. 



\section{ANEXOS}

\section{ANEXO A}

\section{DADOS UTILIZADOS NA DEFINIÇÃO DO TEMPO DE AMOSTRAGEM}
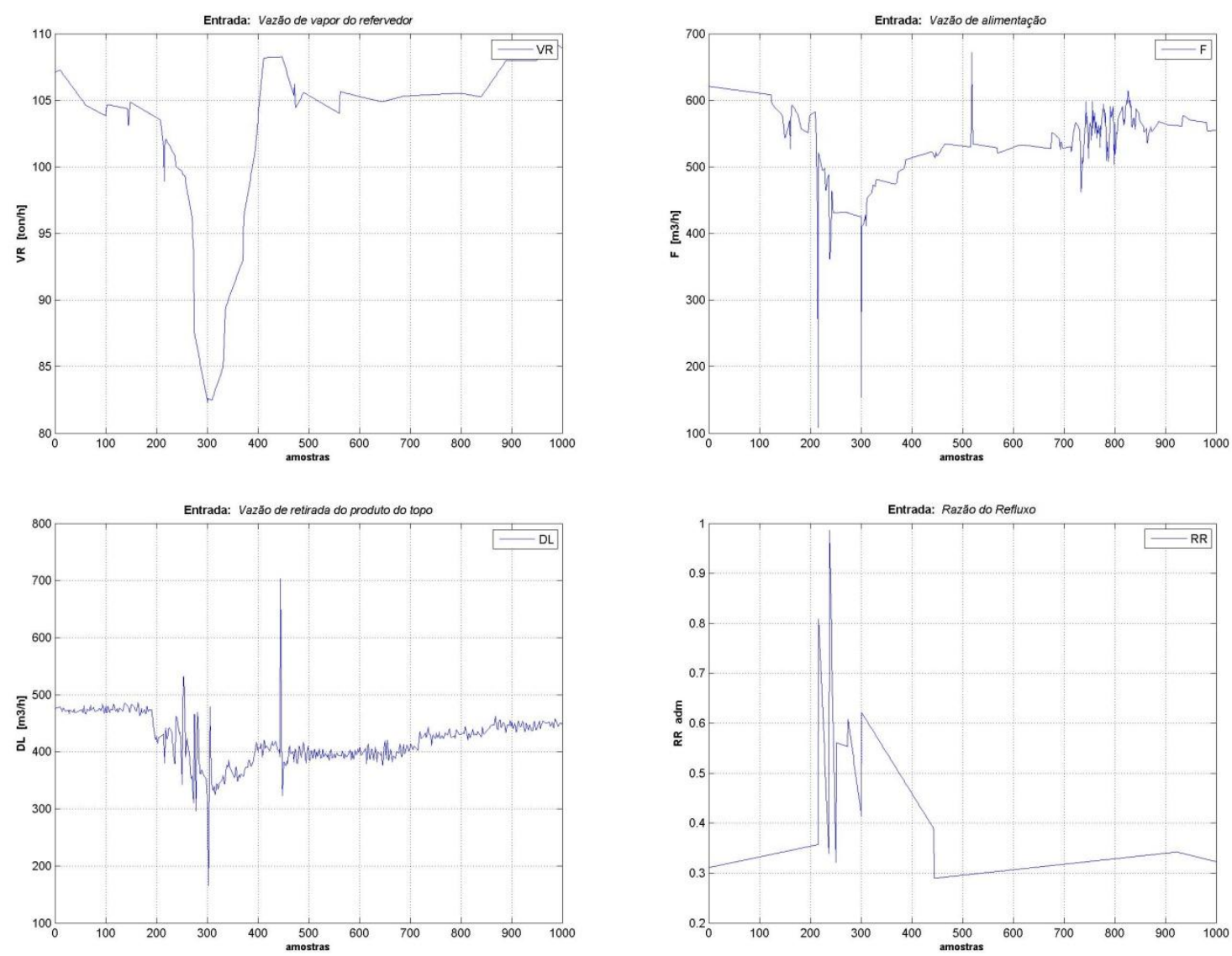

Gráfico das entradas VR, F, DL e RR usadas na avaliação do tempo de amostragem (1000 amostras). 

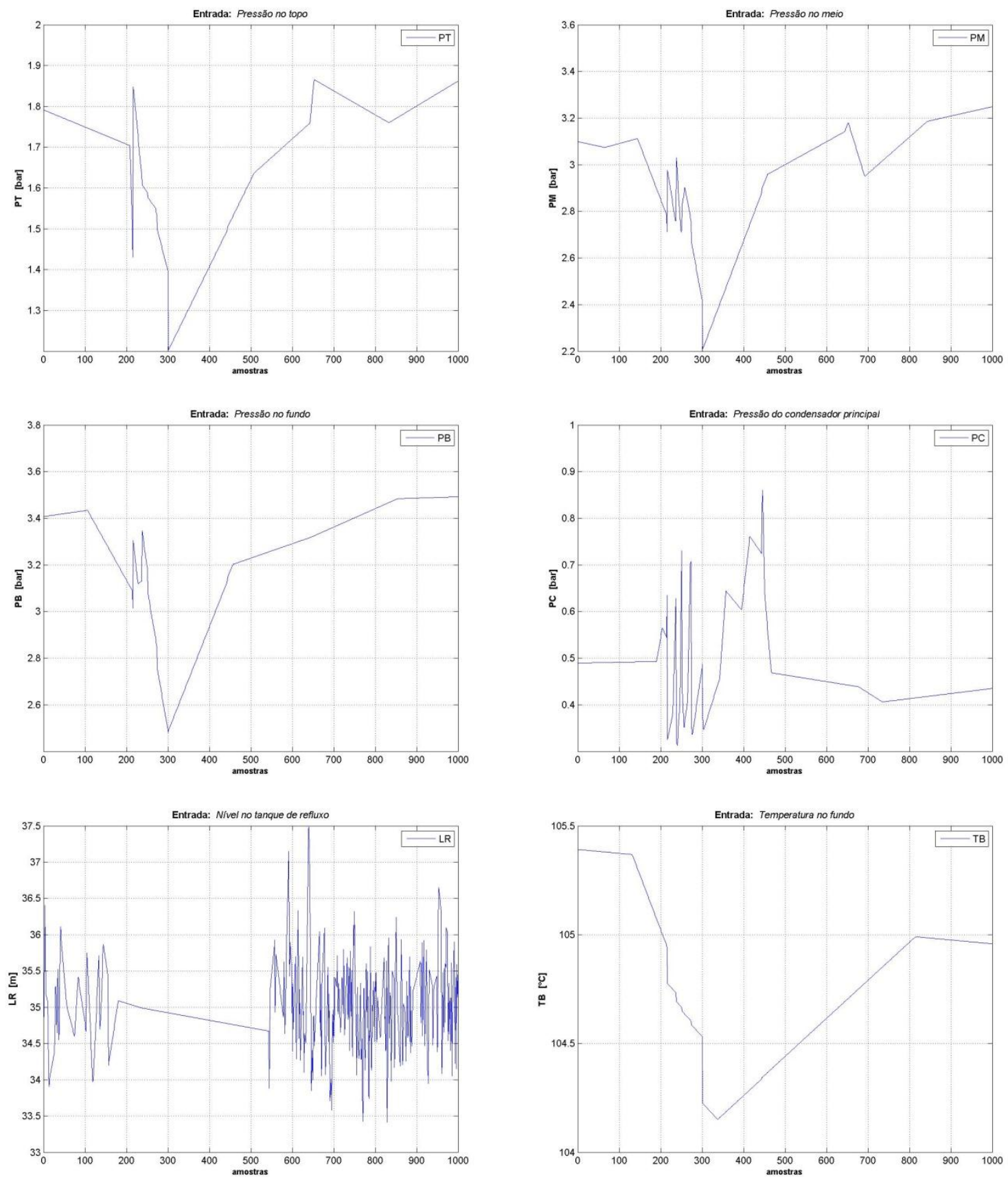

Gráfico das entradas PT, PM, PB, PC, LR e TB usadas na avaliação do tempo de amostragem (1000 amostras). 


\section{AUTOCOVARIÂNCIA DAS ENTRADAS E SAÍDA}
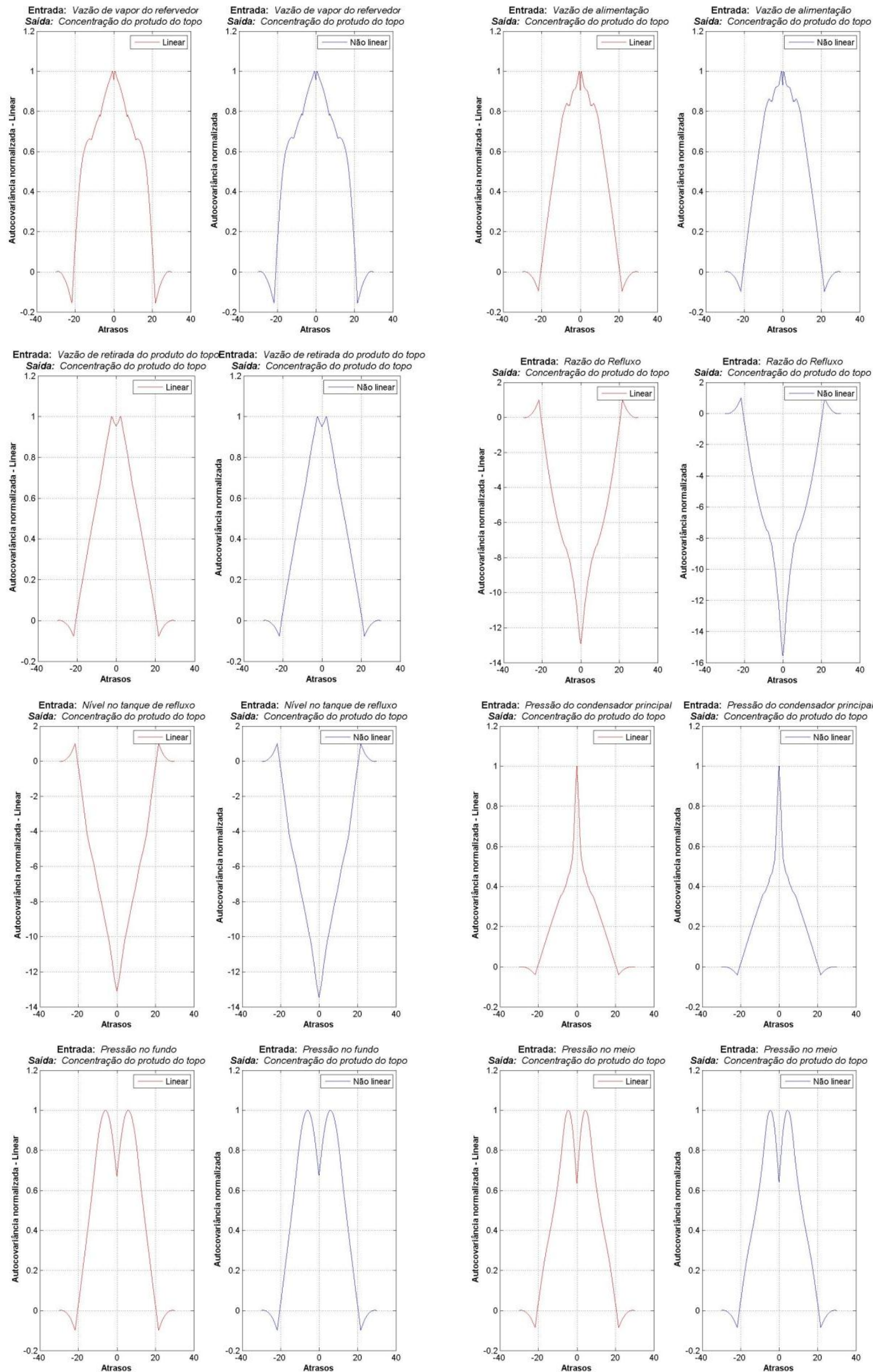

Gráficos da autocovariância linear e não linear das entradas VR, F, DL, RR, LR, PC, PB e PM versus XD. 

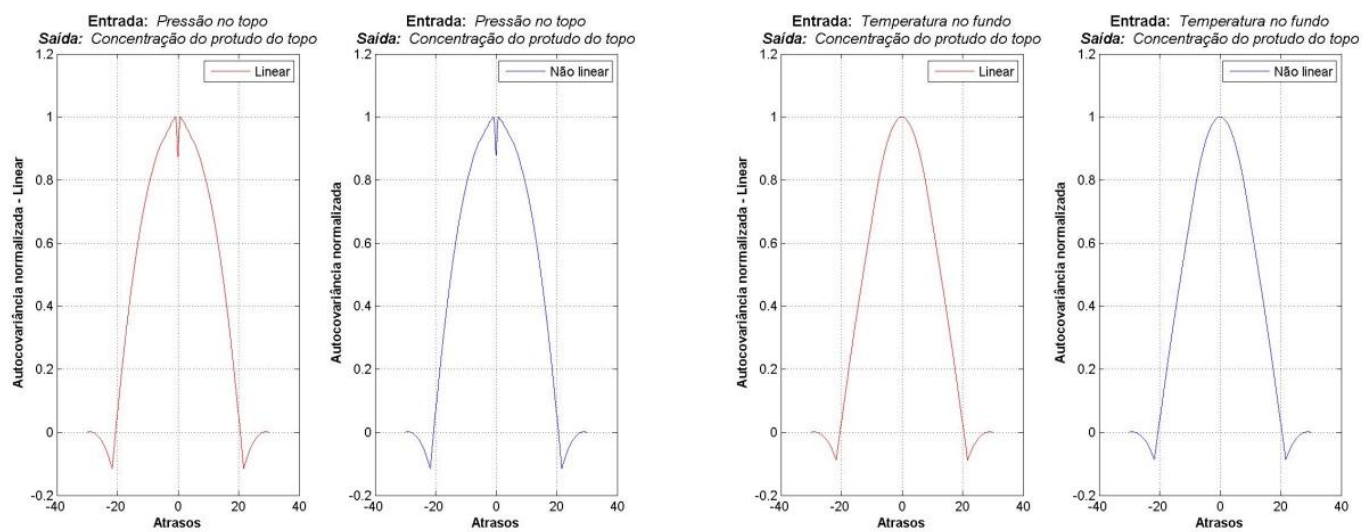

Gráficos da autocovariância linear e não linear das entradas PT e TB versus XD. 


\section{ALGORITMO FNN}
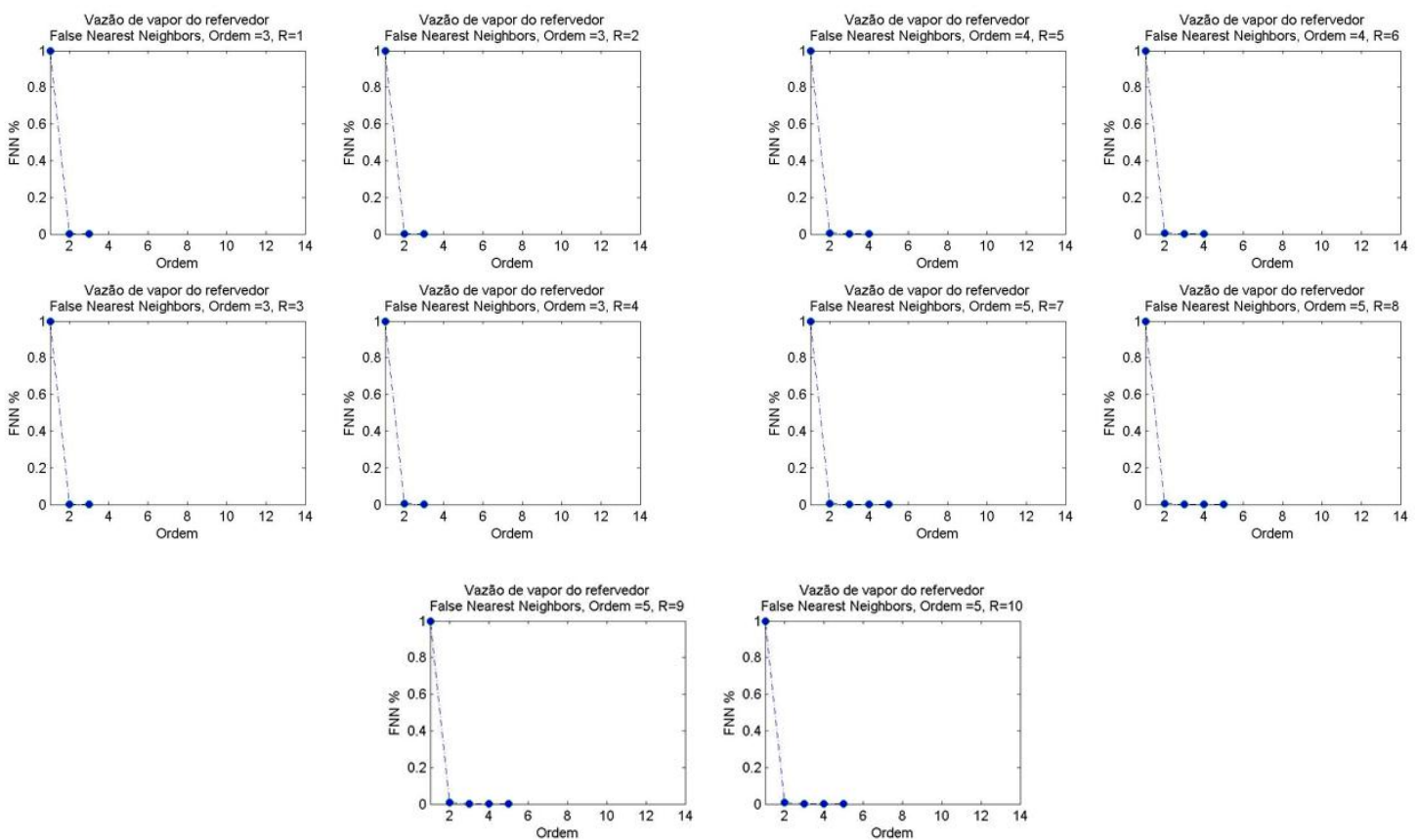

Gráficos resultantes da aplicação do algoritmo FNN na entrada VR para determinar a ordem global da planta.
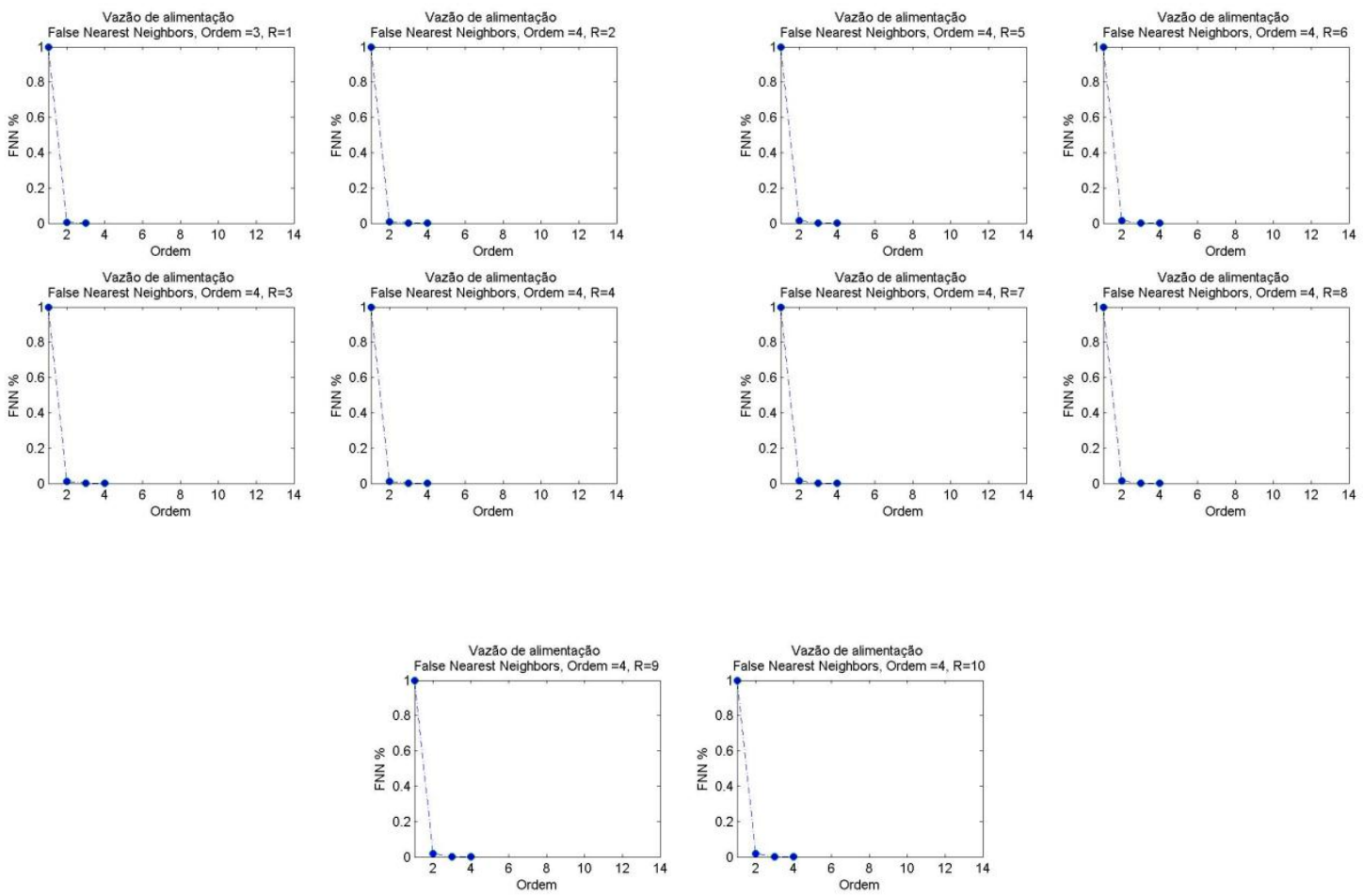

Gráficos resultantes da aplicação do algoritmo FNN na entrada F para determinar a ordem global da planta. 

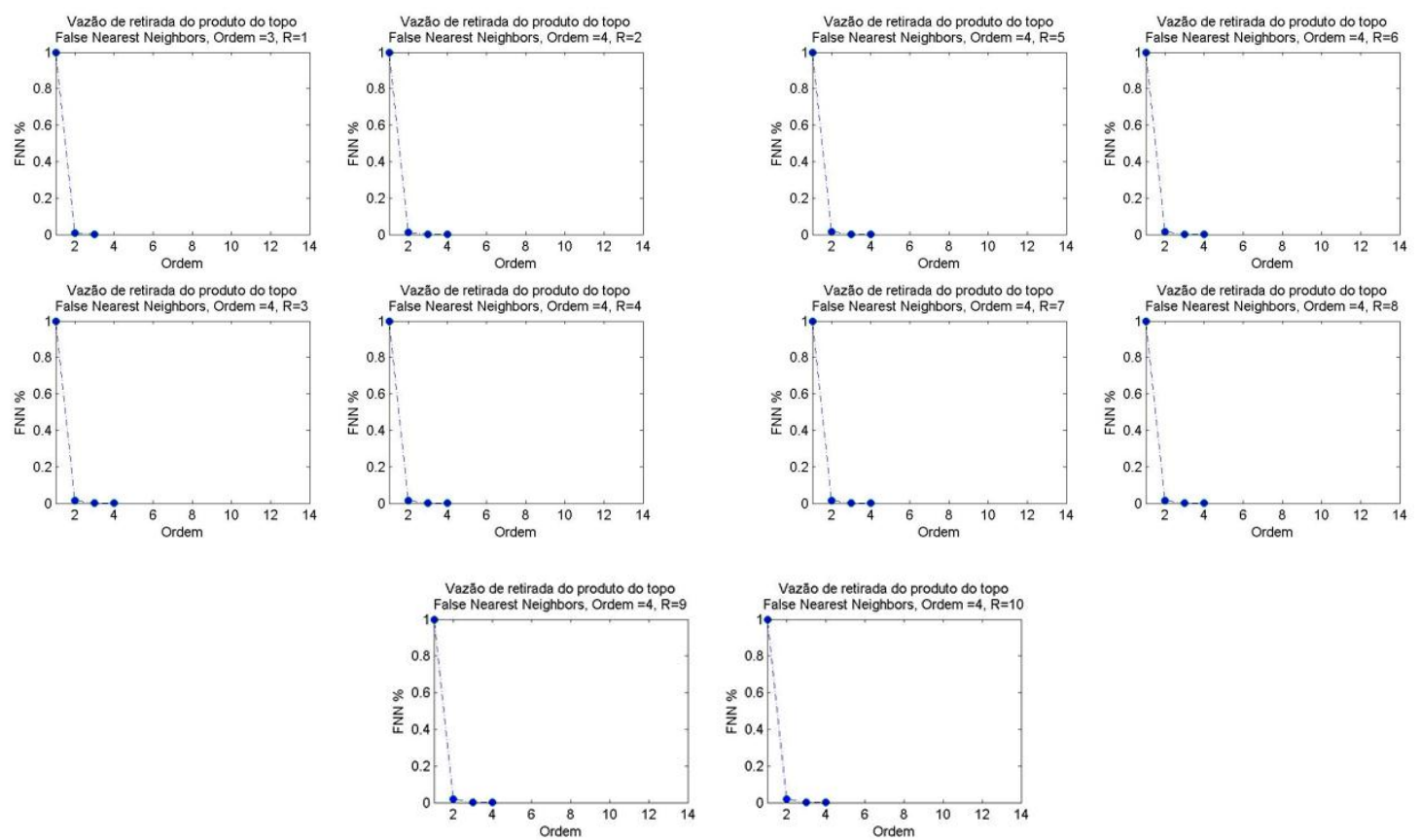

Gráficos resultantes da aplicação do algoritmo FNN nas entradas DL para determinar a ordem global da planta.
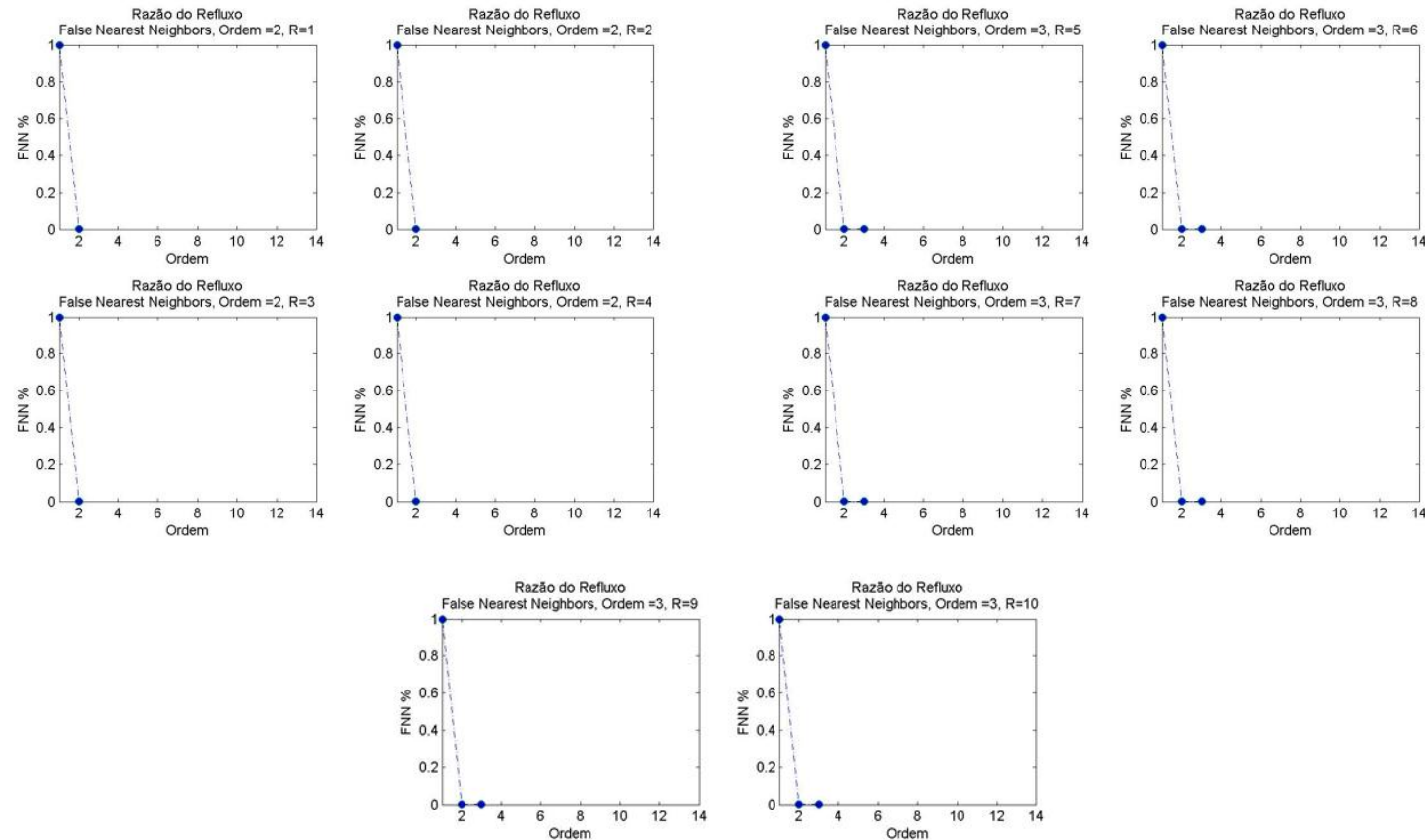

Gráficos resultantes da aplicação do algoritmo FNN nas entradas RR para determinar a ordem global da planta. 

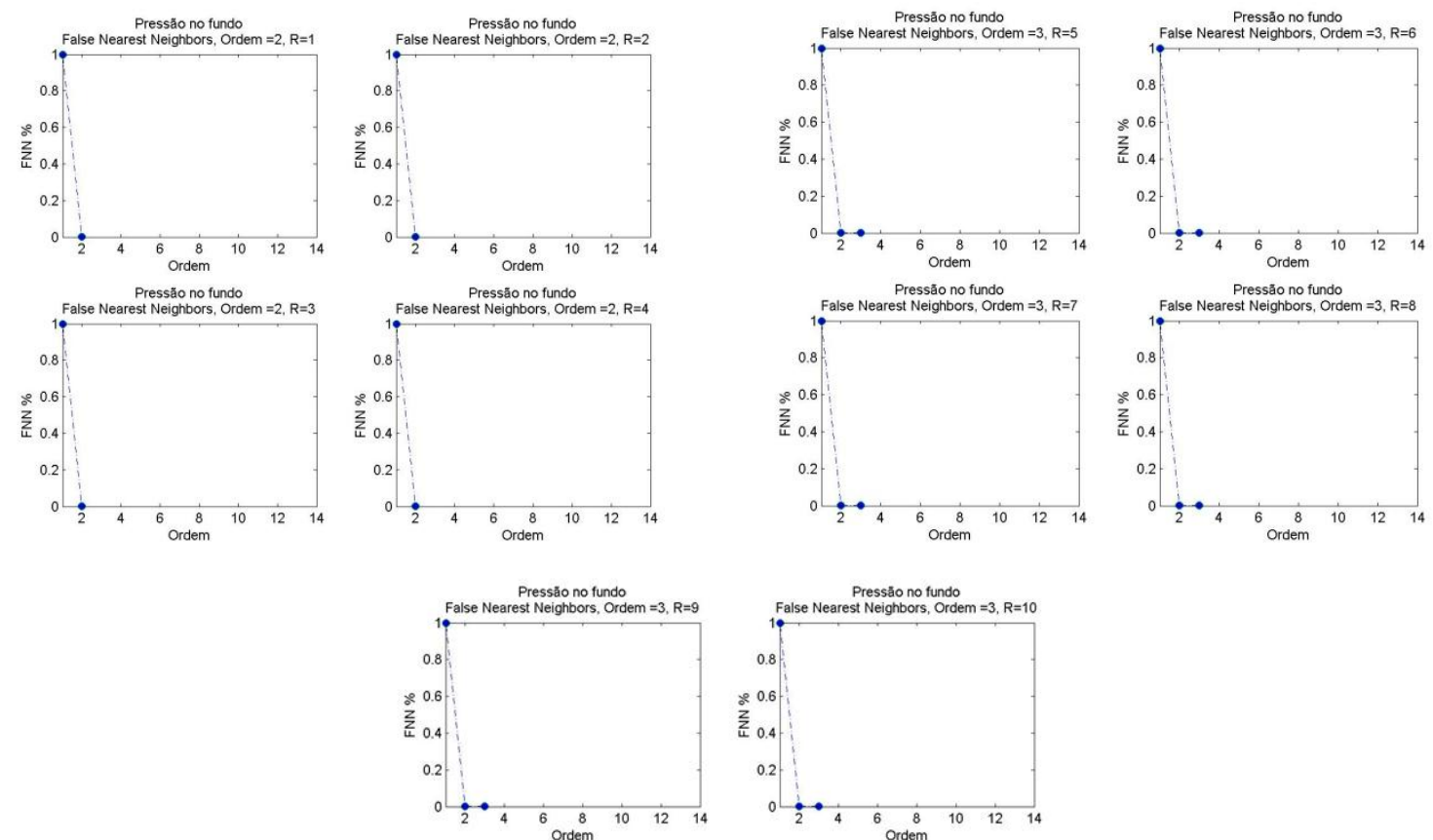

Gráficos resultantes da aplicação do algoritmo FNN nas entradas PB para determinar a ordem global da planta.
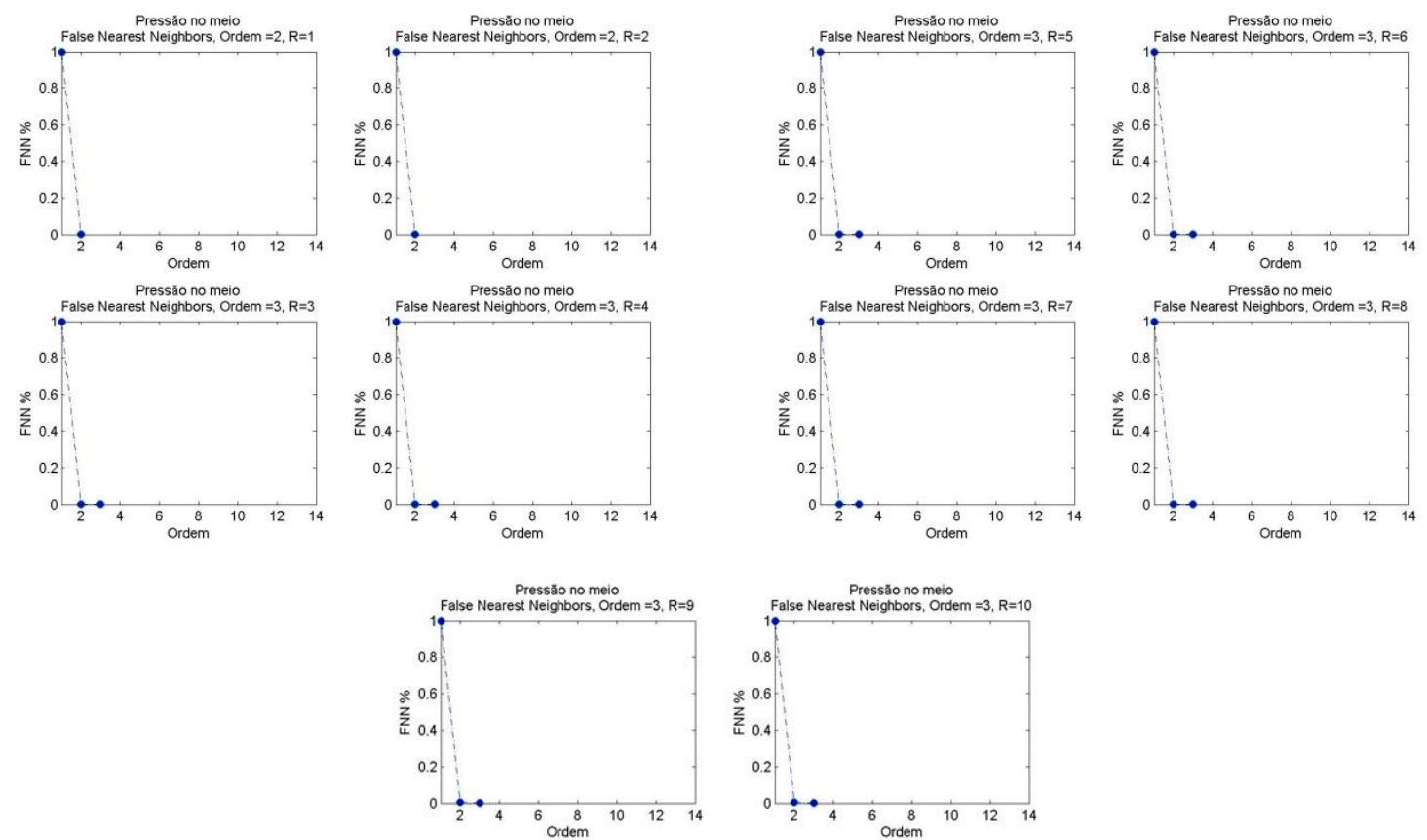

Gráficos resultantes da aplicação do algoritmo FNN nas entradas PM para determinar a ordem global da planta. 

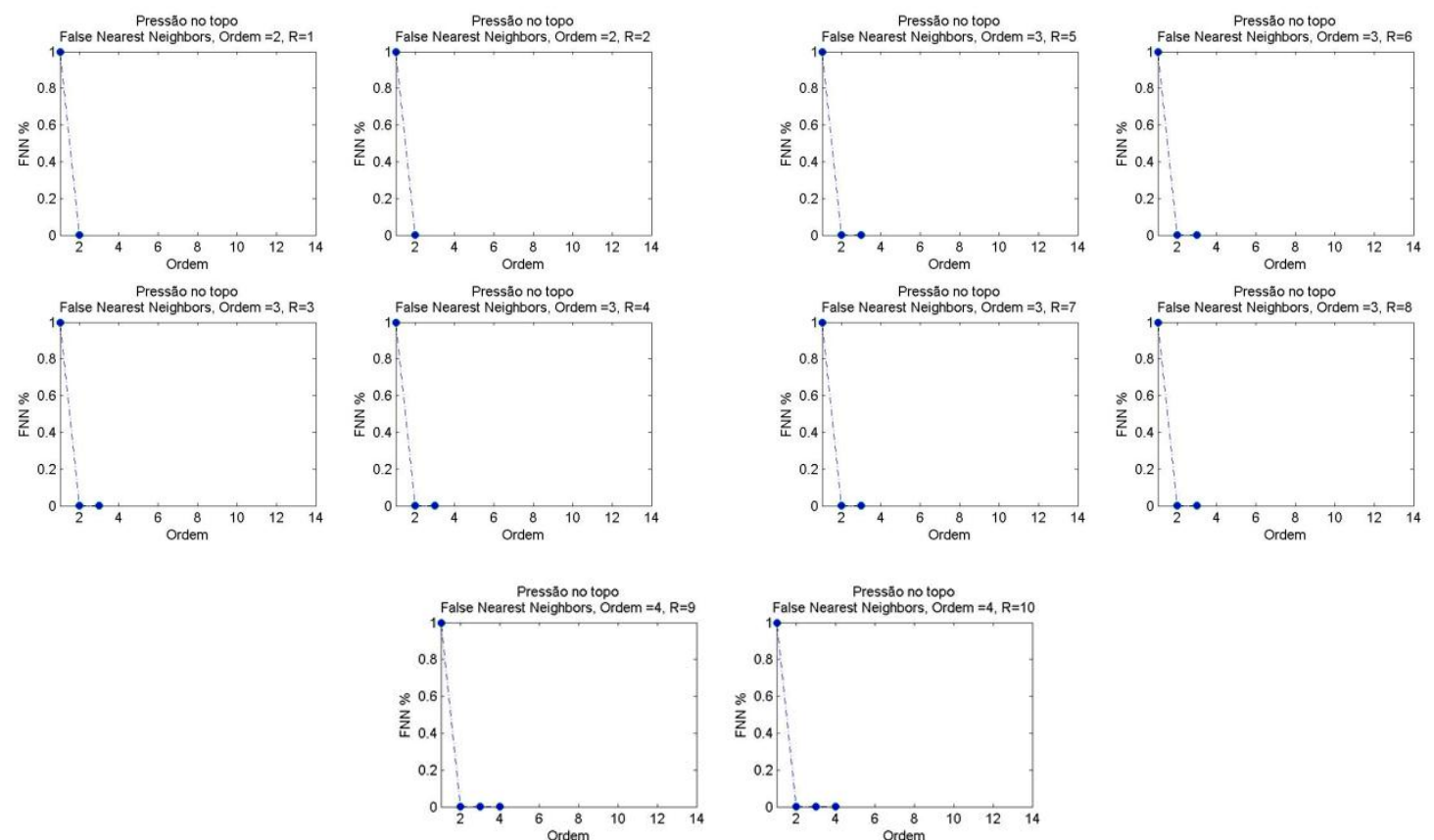

Gráficos resultantes da aplicação do algoritmo FNN nas entradas PT para determinar a ordem global da planta.
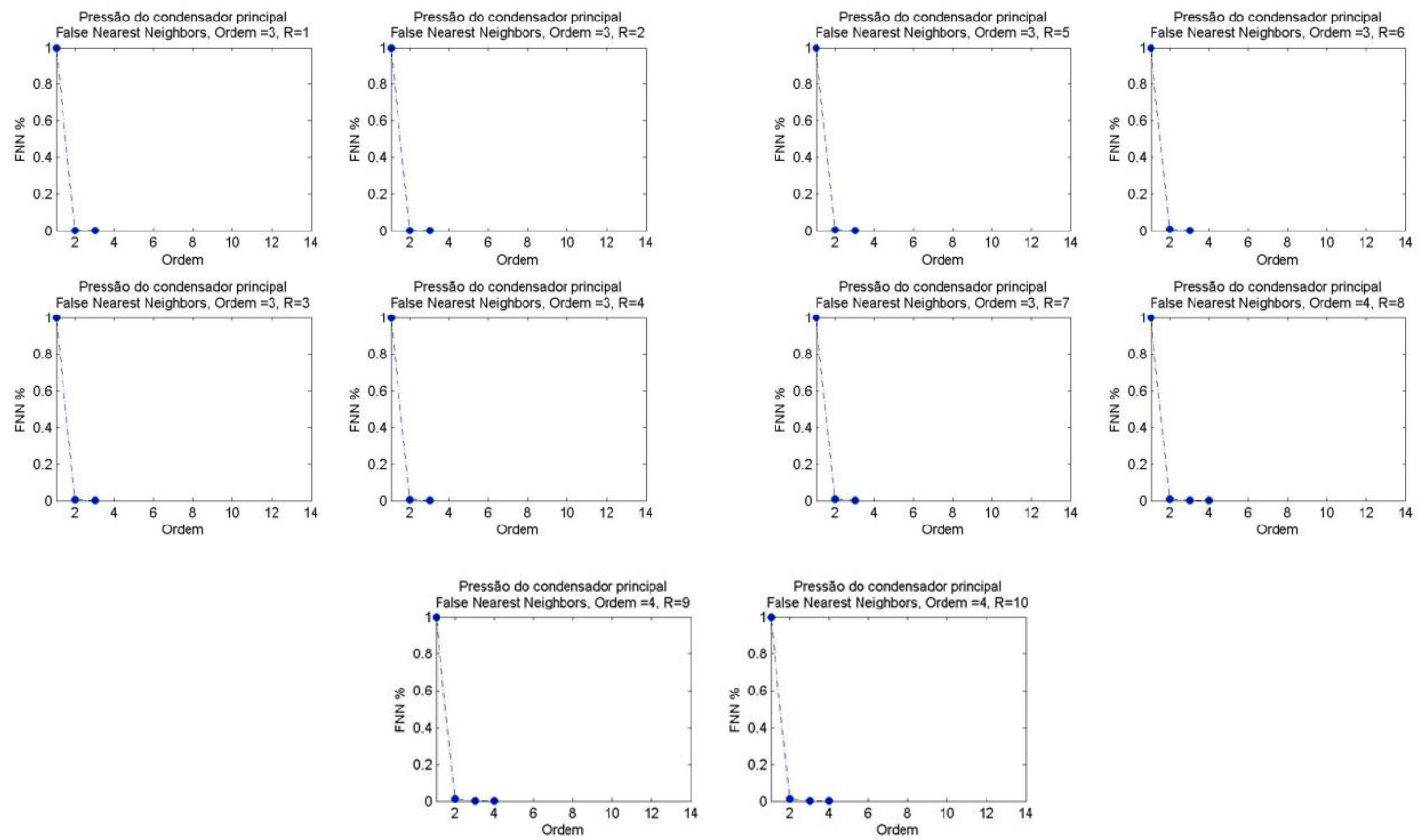

Gráficos resultantes da aplicação do algoritmo FNN nas entradas PC para determinar a ordem global da planta. 

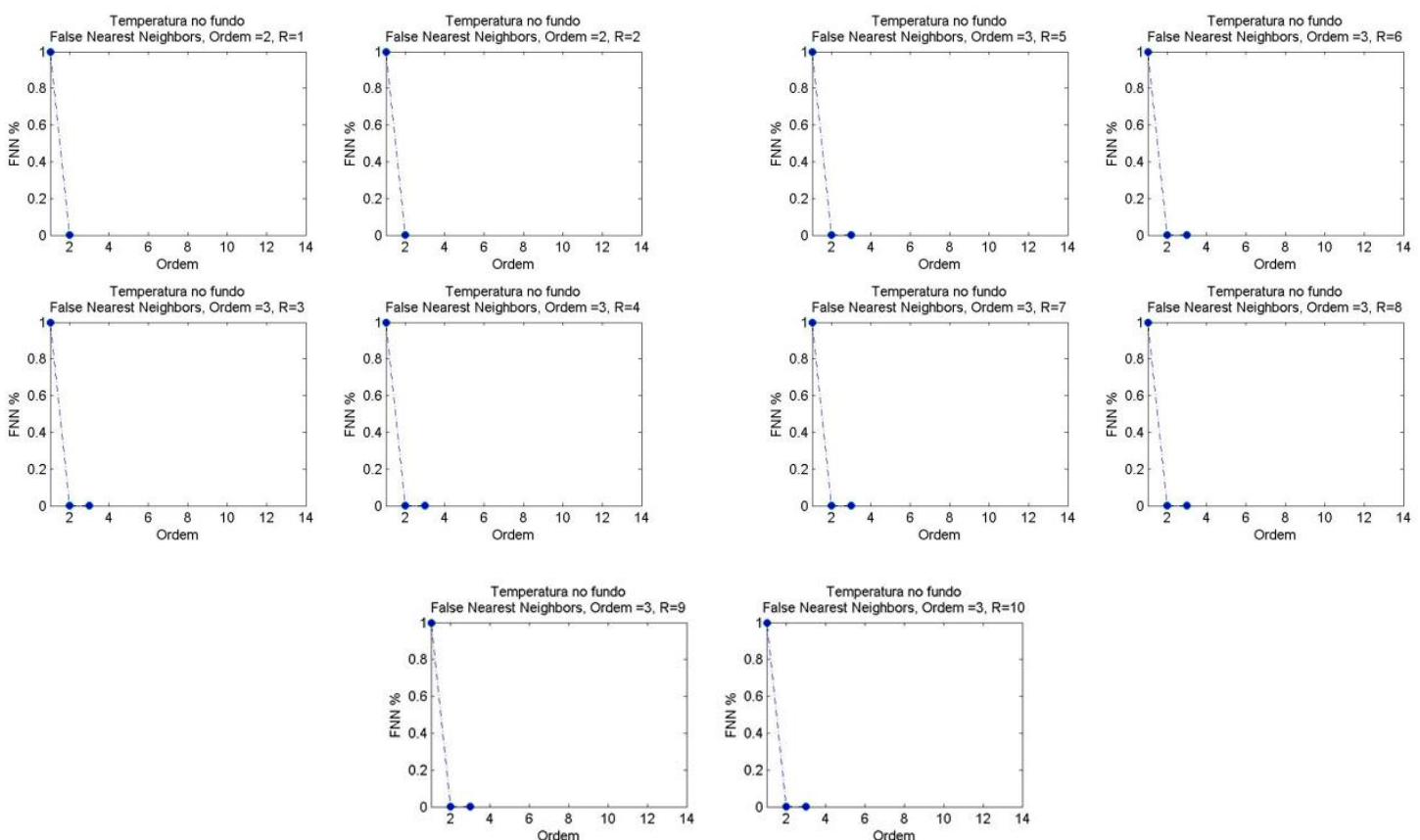

Gráficos resultantes da aplicação do algoritmo FNN nas entradas TB para determinar a ordem global da planta.
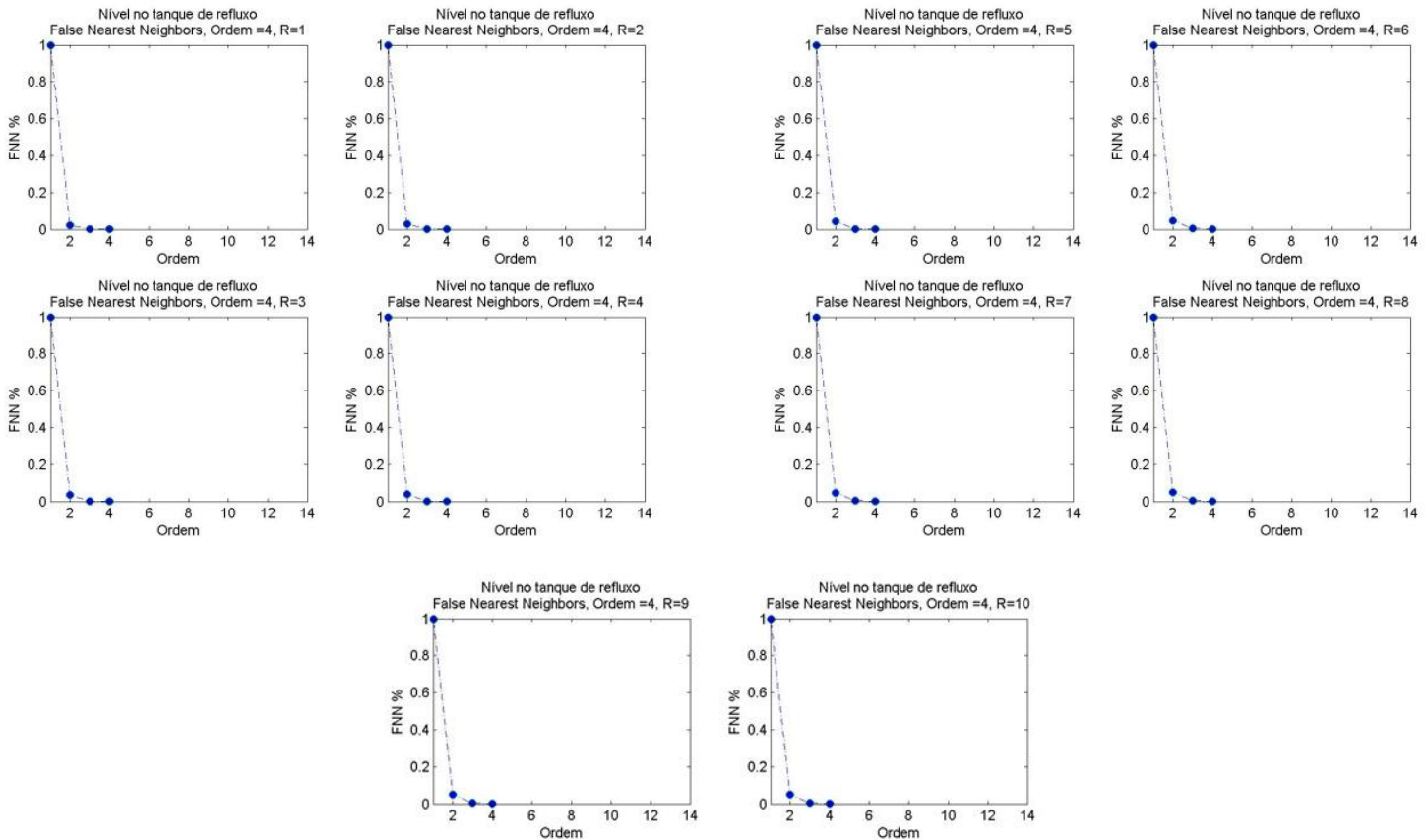

Gráficos resultantes da aplicação do algoritmo FNN nas entradas LR para determinar a ordem global da planta. 


\section{AQUISIÇÕES DE DADOS DAS ENTRADAS E SAÍDAS}

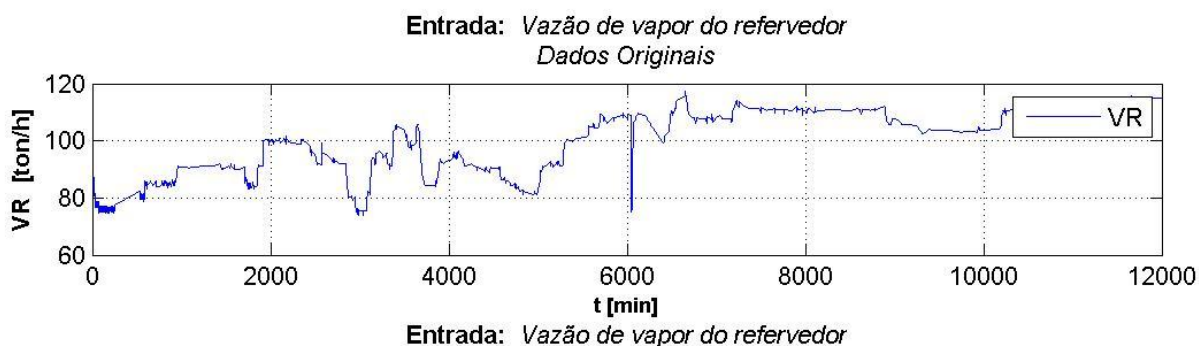

Entrada: Vazão de vapor do refervedor

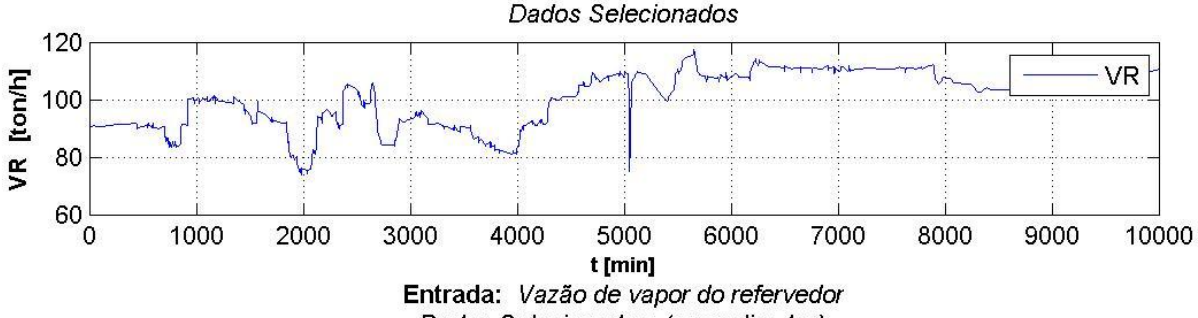
Dados Selecionados: (normalizados)

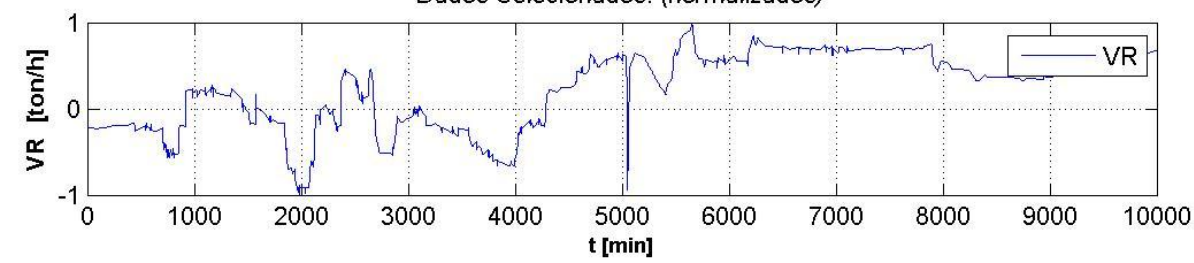

Gráfico da entrada VR: aquisitada, selecionada, normalizada.

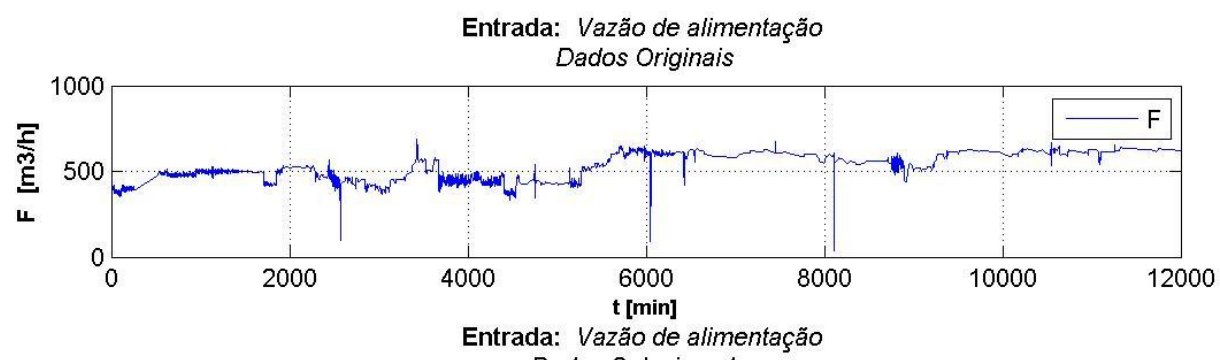
Dados Selecionados

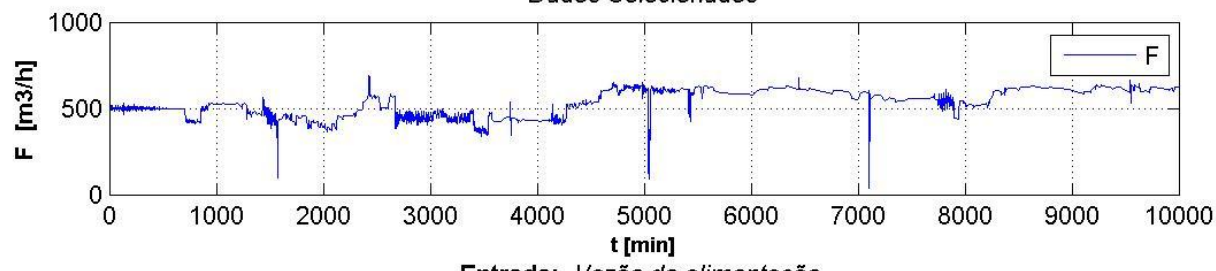

Entrada: Vazão de alimentação

Dados Selecionados: (normalizados)

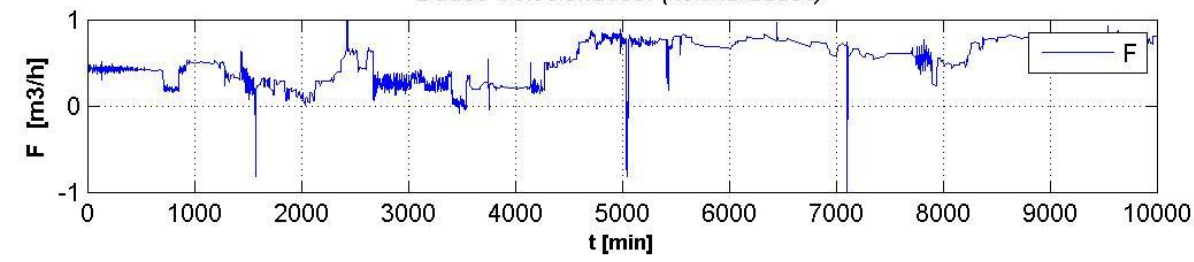

Gráfico da entrada F: aquisitada, selecionada, normalizada. 
Entrada: Vazão de retirada do produto do topo Dados Originais

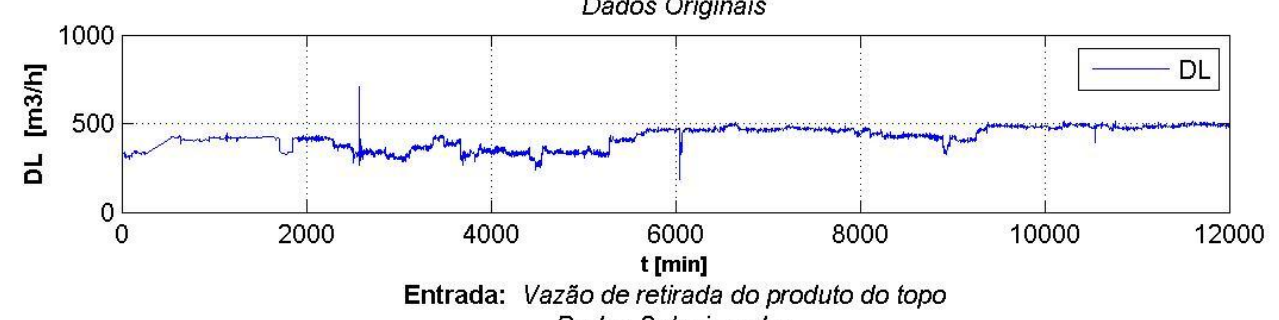
Dados Selecionados

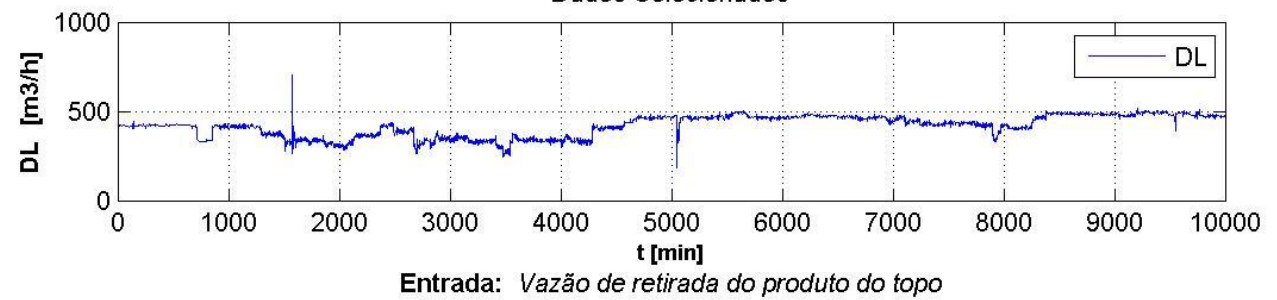

trada: Vazão de retirada do produto do topo

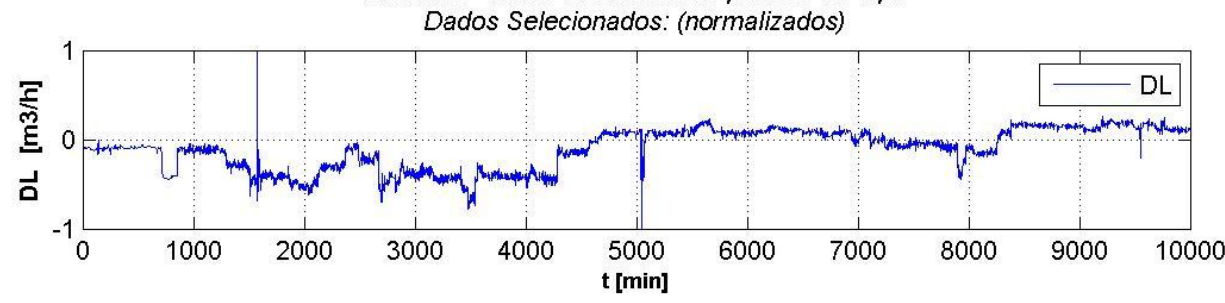

Gráfico da entrada DL: aquisitada, selecionada, normalizada.
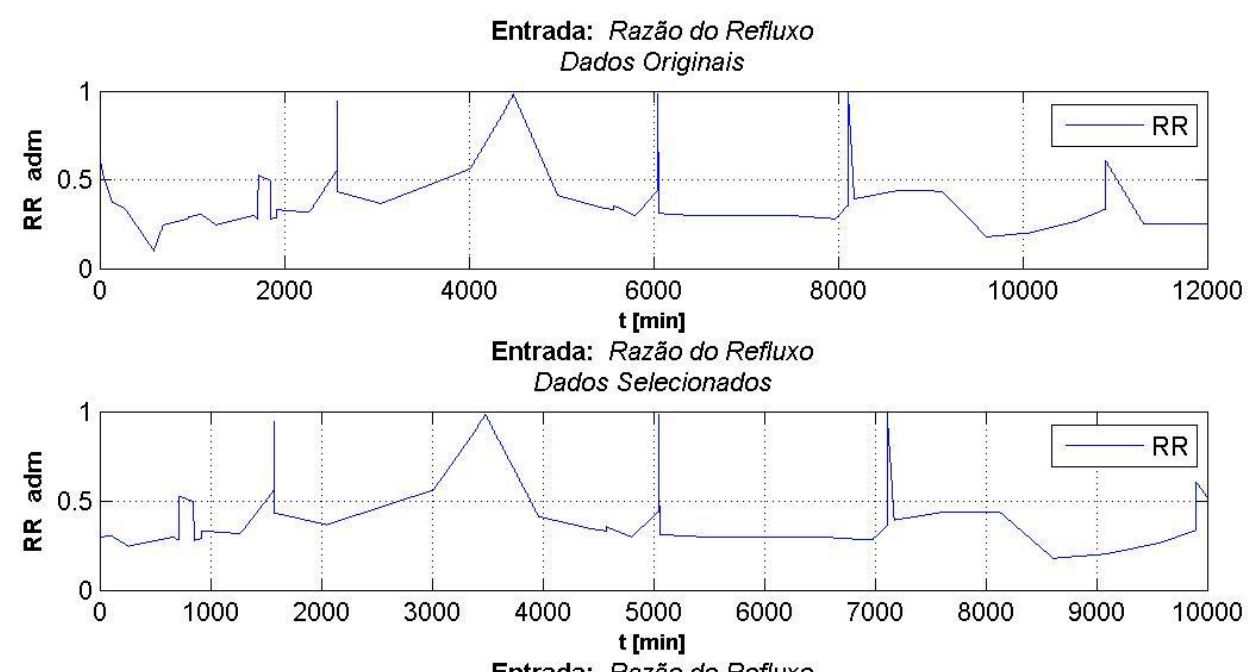

Entrada: Razão do Refluxo

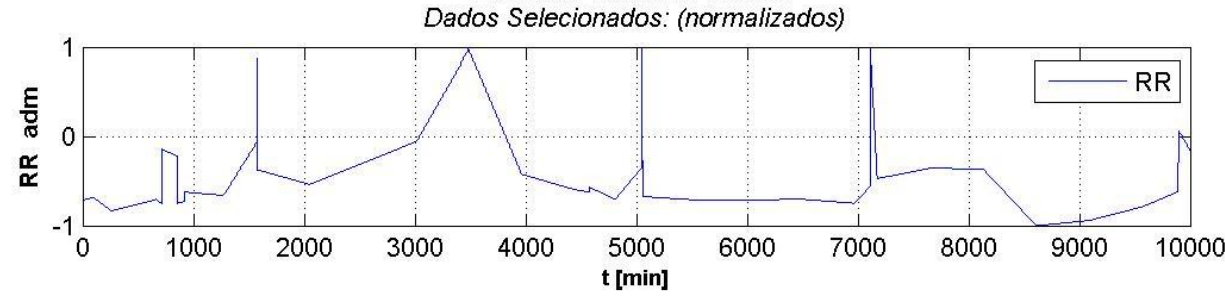

Gráfico da entrada RR: aquisitada, selecionada, normalizada. 

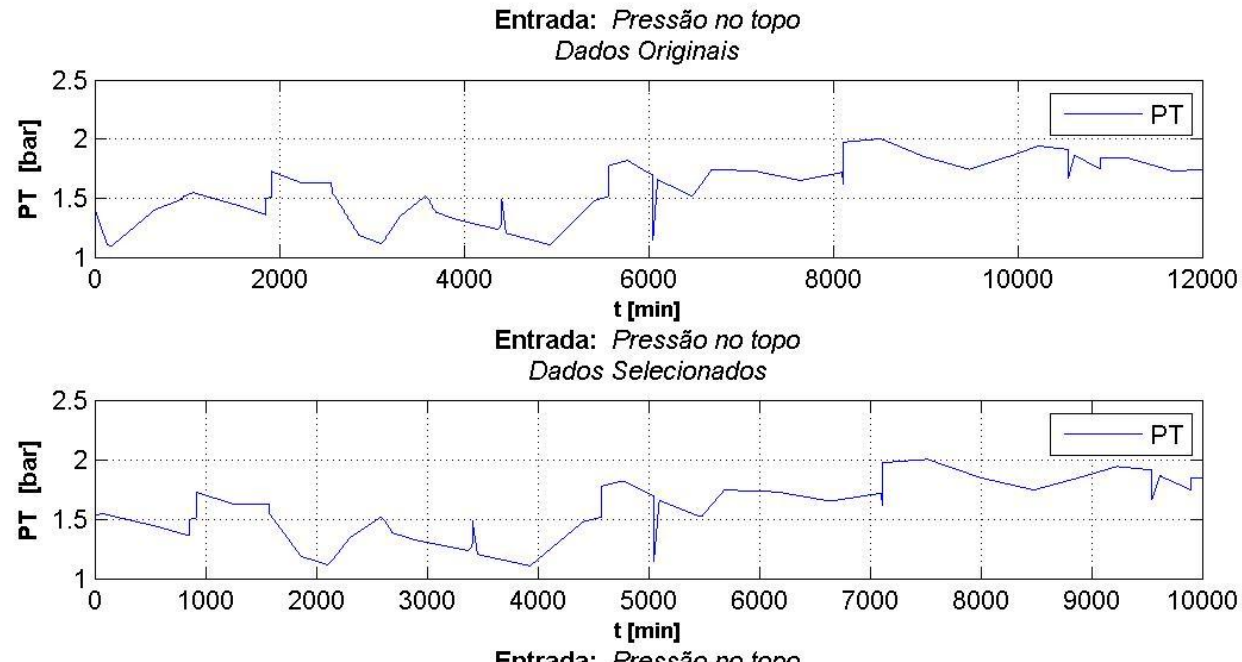

Entrada: Pressão no topo

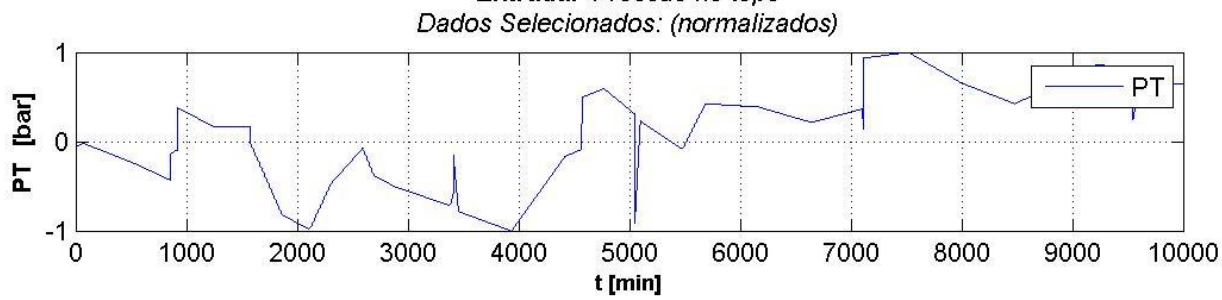

Gráfico da entrada PT: aquisitada, selecionada, normalizada.

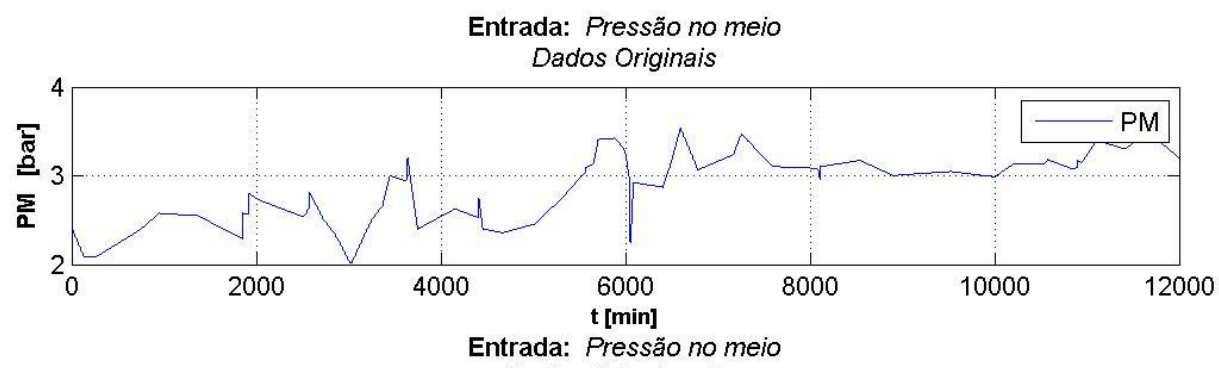

ntrada: Pressão no me

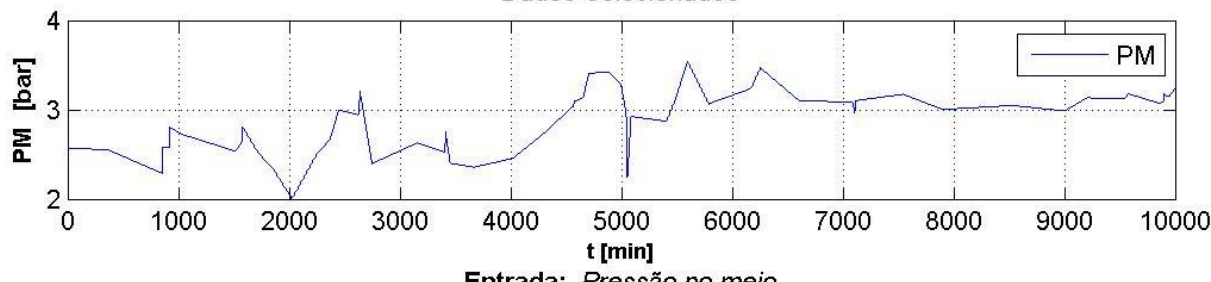

Entrada: Pressão no meio

Dados Selecionados: (normalizados)

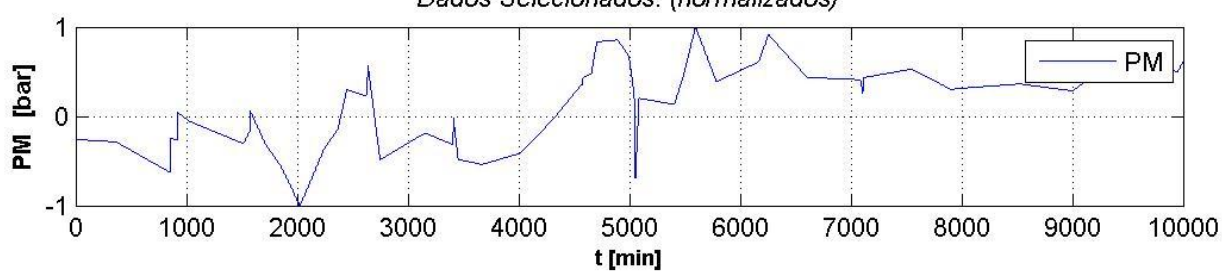

Gráfico da entrada PM: aquisitada, selecionada, normalizada. 
Entrada: Pressão no fundo Dados Originais
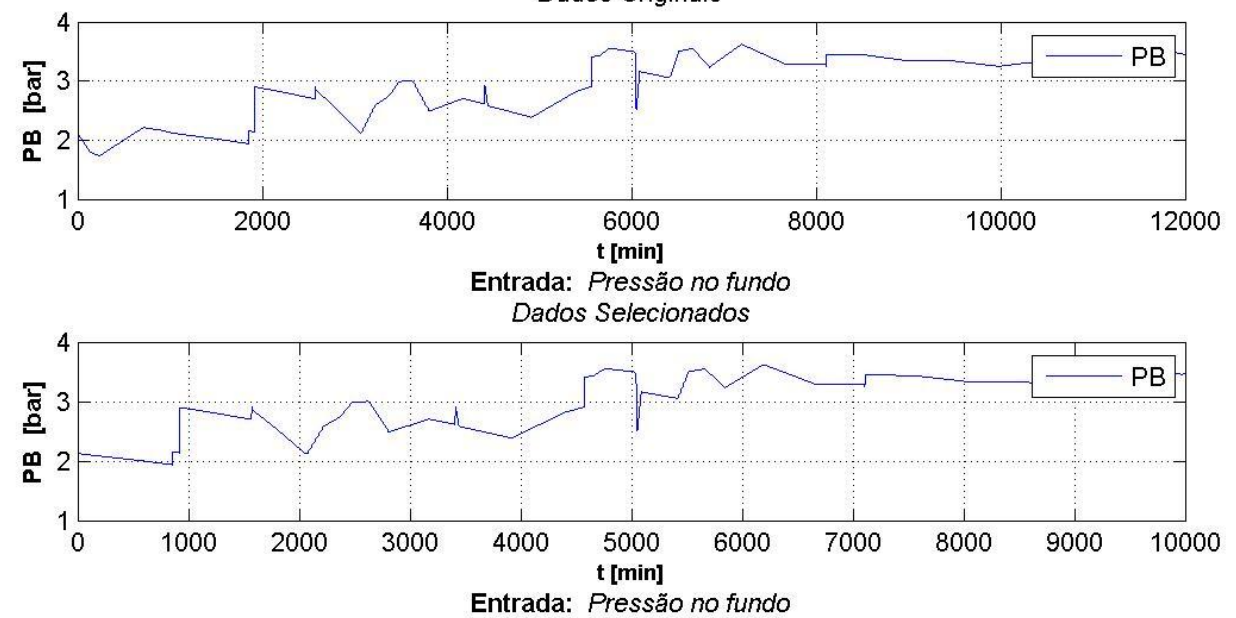

Entrada: Pressão no fundo

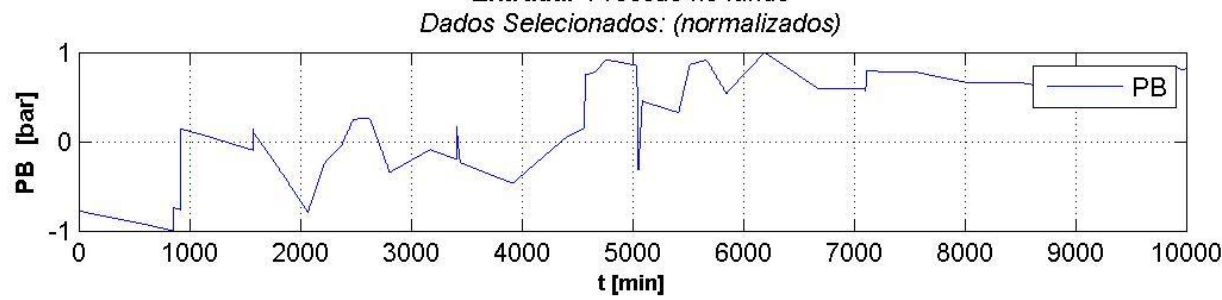

Gráfico da entrada PB: aquisitada, selecionada, normalizada.

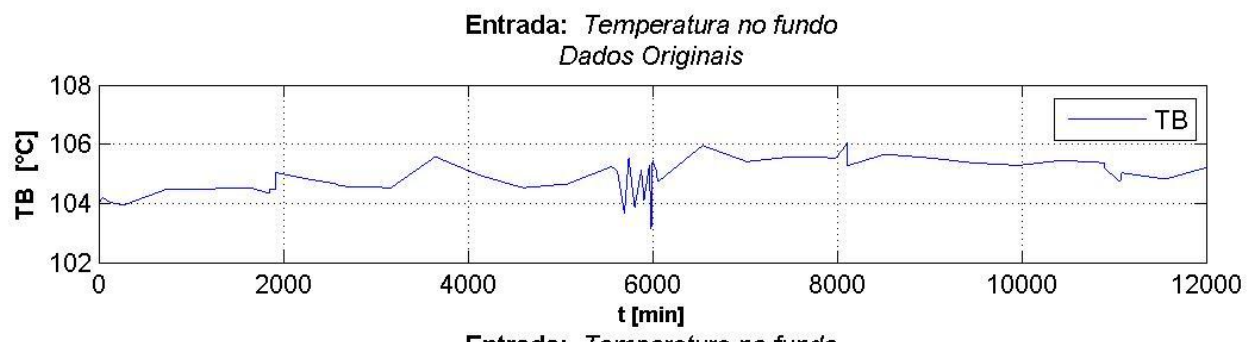

Entrada: Temperatura no fundo Dados Selecionados

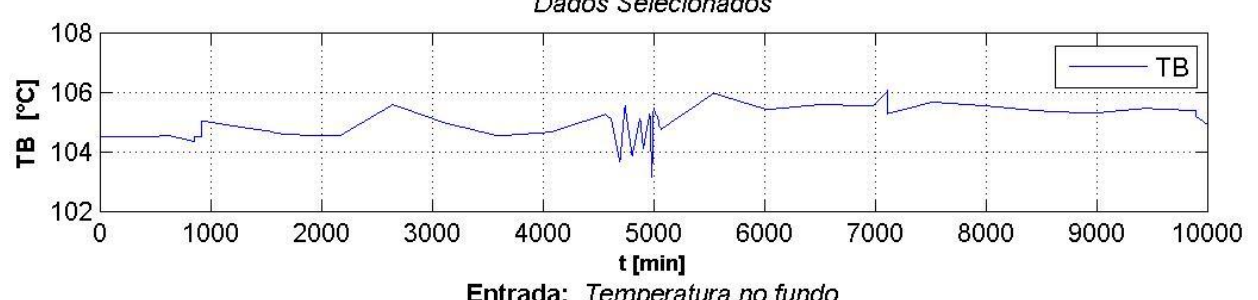

Entrada: Temperatura no fundo

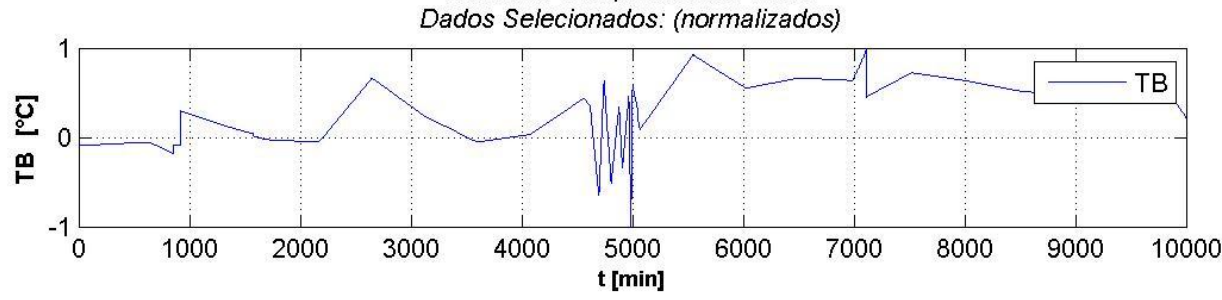

Gráfico da entrada TB: aquisitada, selecionada, normalizada. 
Entrada: Pressão do condensador principal Dados Originais

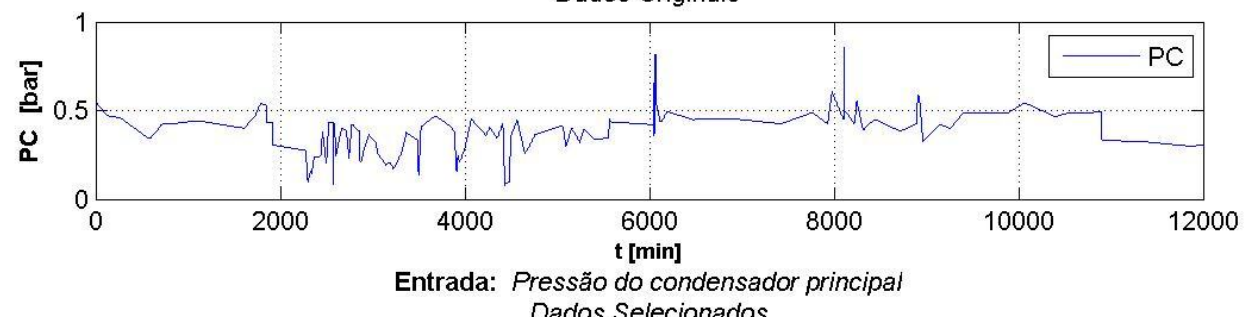
Dados Selecionados

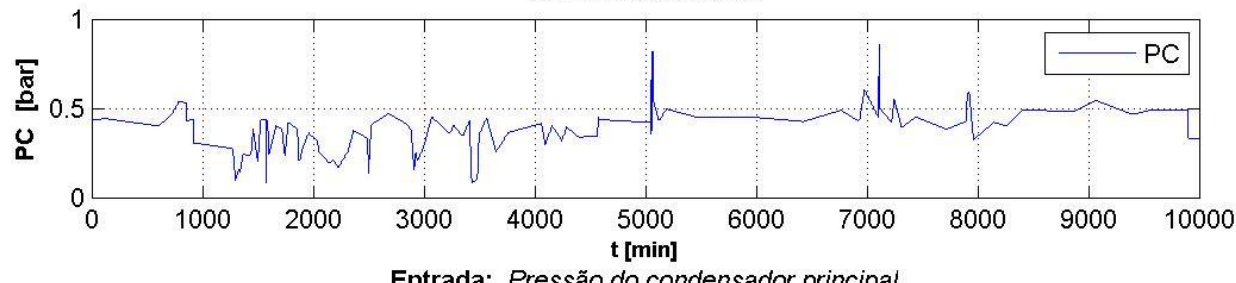

Entrada: Pressão do condensador principa Dados Selecionados: (normalizados)

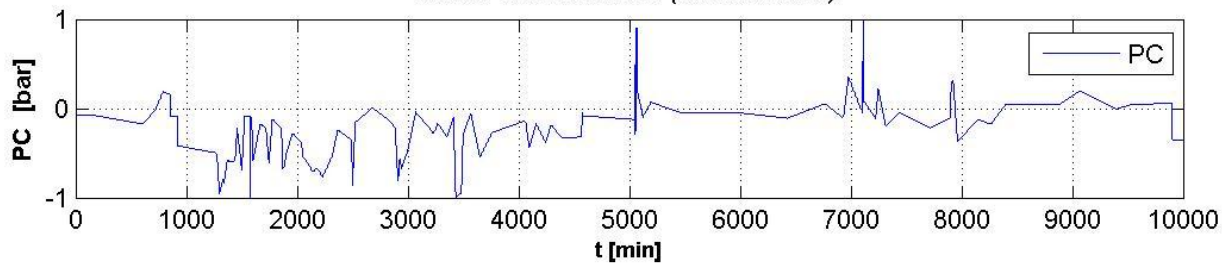

Gráfico da entrada PC: aquisitada, selecionada, normalizada.

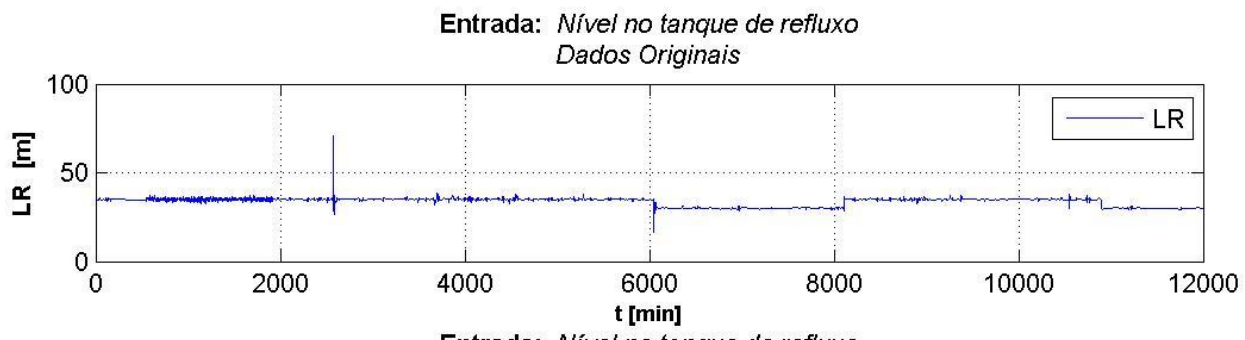

Entrada: Nivel no tanque de refluxo Dados Selecionados

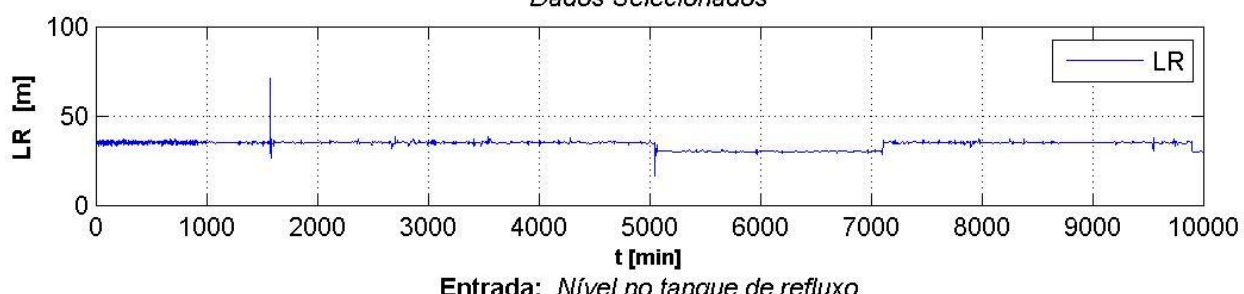

Entrada: Nível no tanque de refluxo

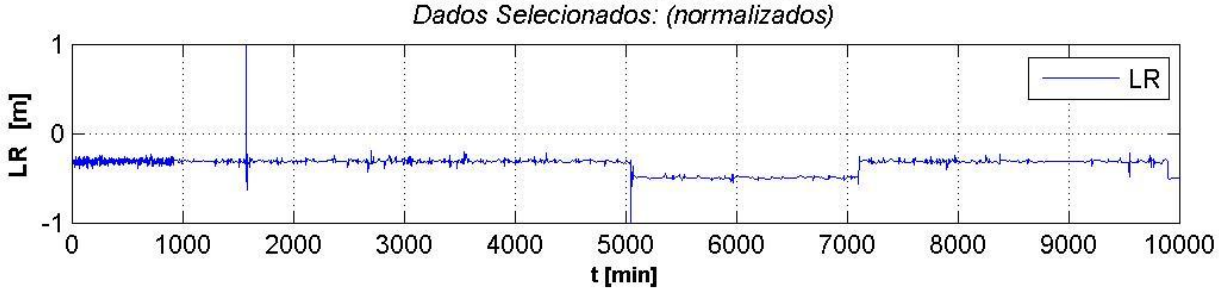

Gráfico da entrada LR: aquisitada, selecionada, normalizada. 
Saída: Concentração do protudo do topo Dados Originais

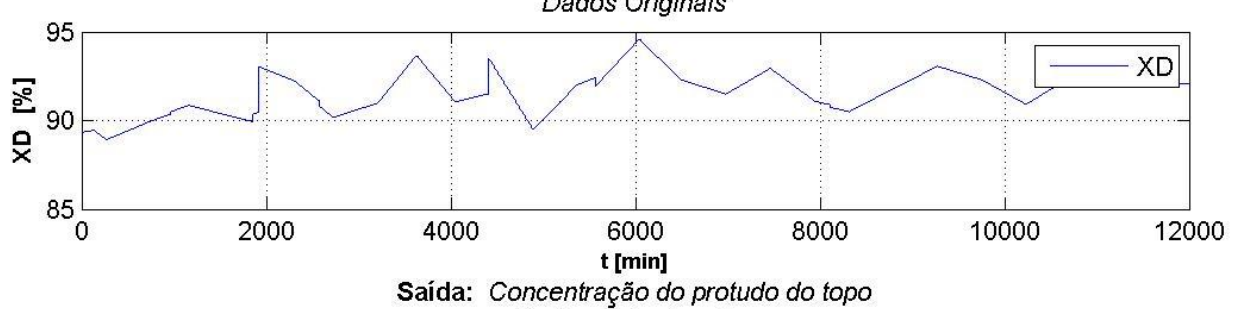

Saída: Concentração do protudo do topo

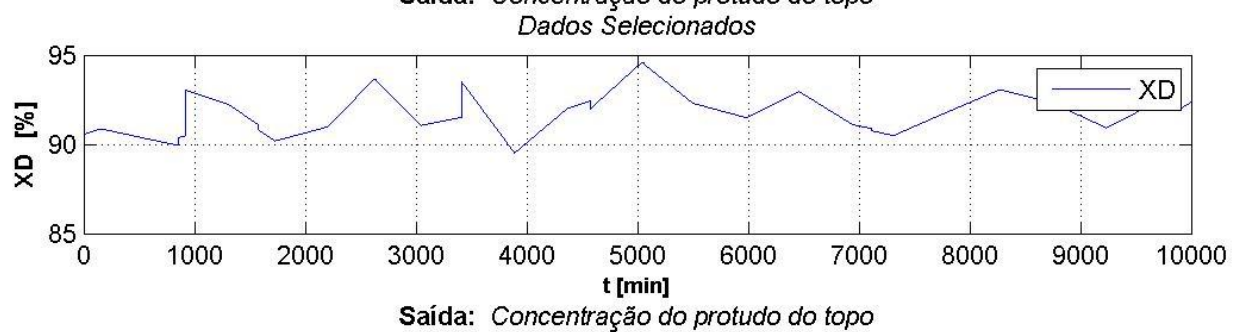

Saída: Concentração do protudo do topo

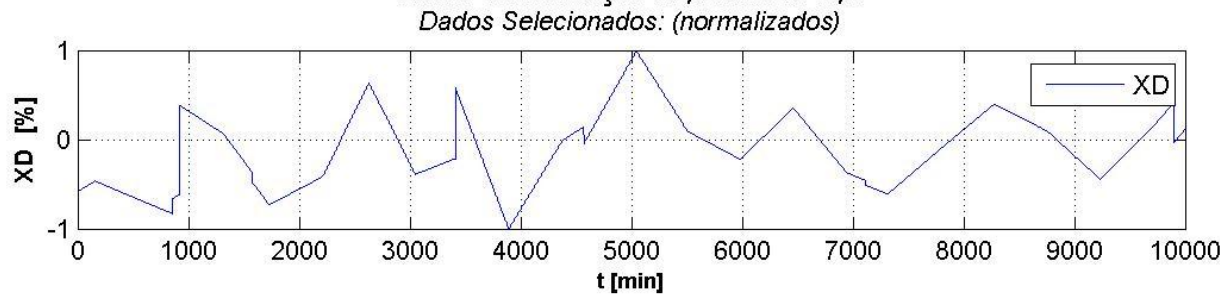

Gráfico da saída XD: aquisitada, normalizada. 
CONJUNTO DE DADOS DE TREINAMENTO, TESTE E VALIDAÇÃO

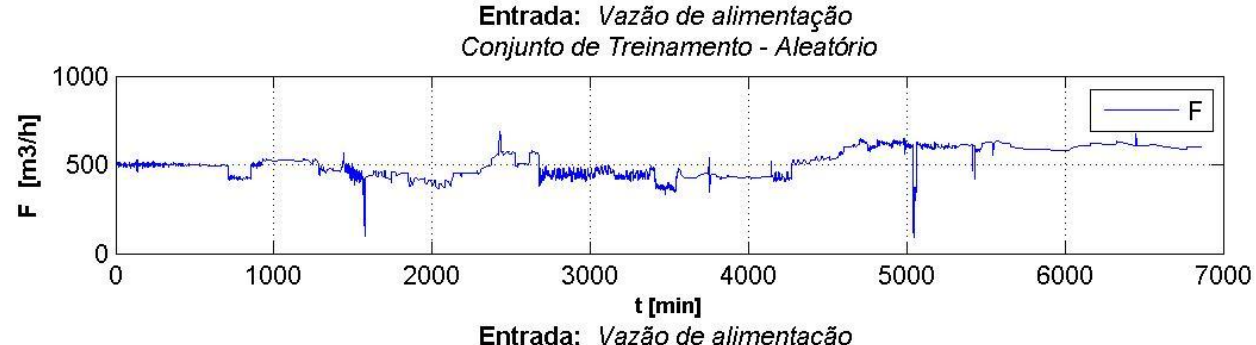

Entrada: Vazão de alimentação

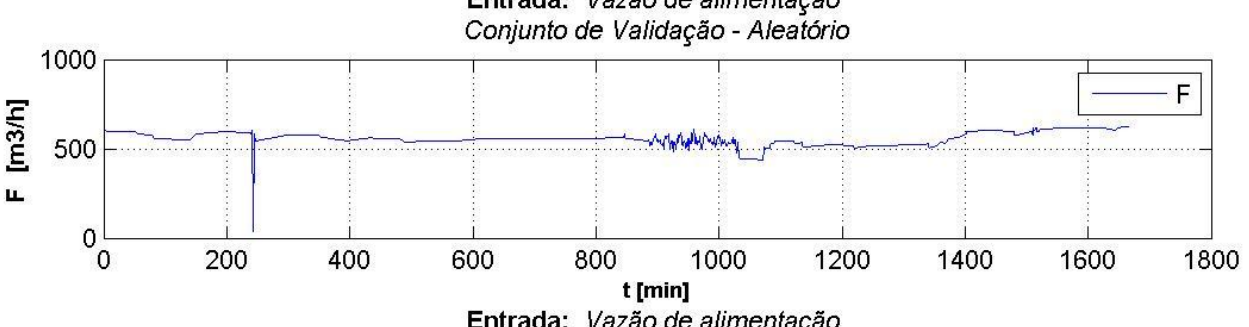

Entrada: Vazão de alimentação

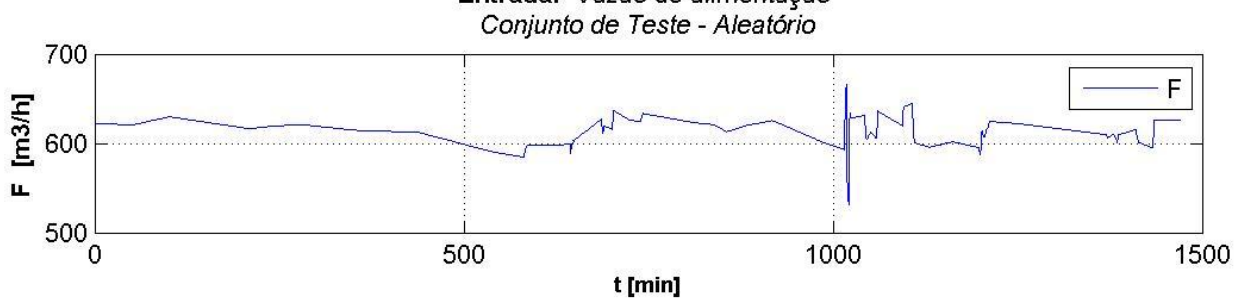

Entrada F: conjunto de treinamento, teste, validação.

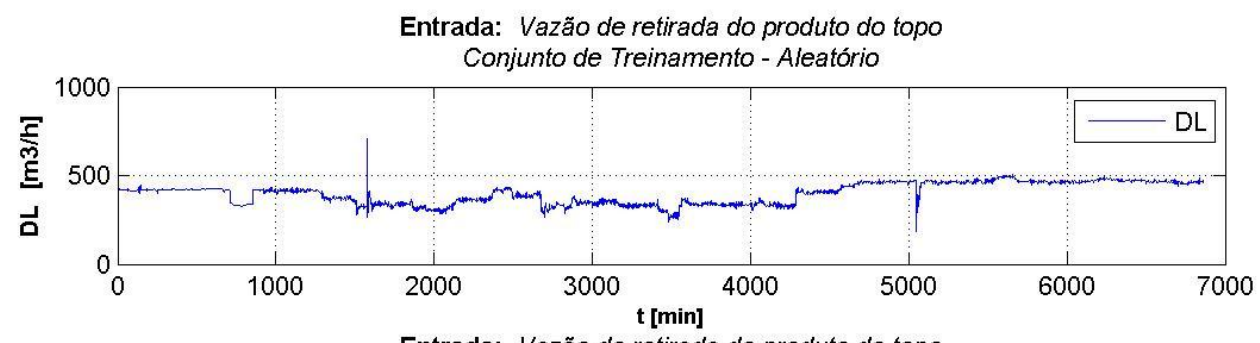

Entrada: Vazão de retirada do produto do topo Conjunto de Validação - Aleatório

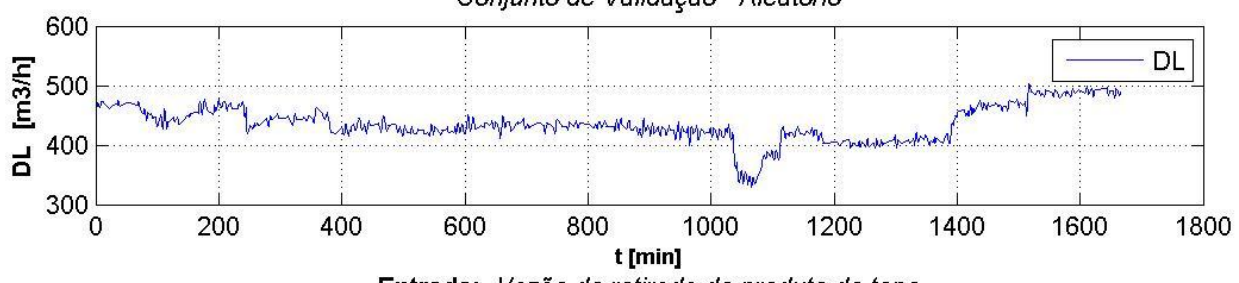

Entrada: Vazão de retirada do produto do topo Conjunto de Teste - Aleatório

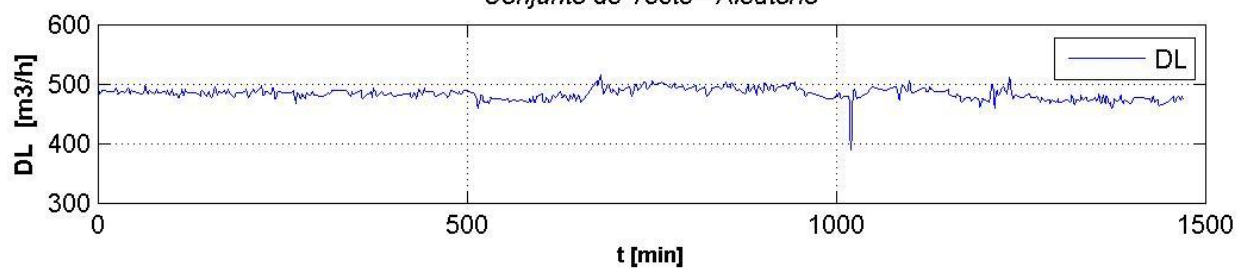

Entrada DL: conjunto de treinamento, teste, validação. 


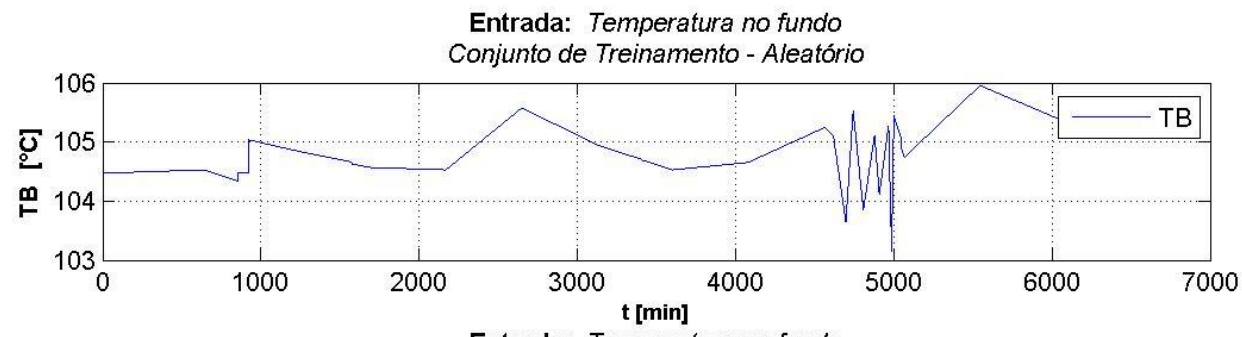

Entrada: Temperatura no fundo

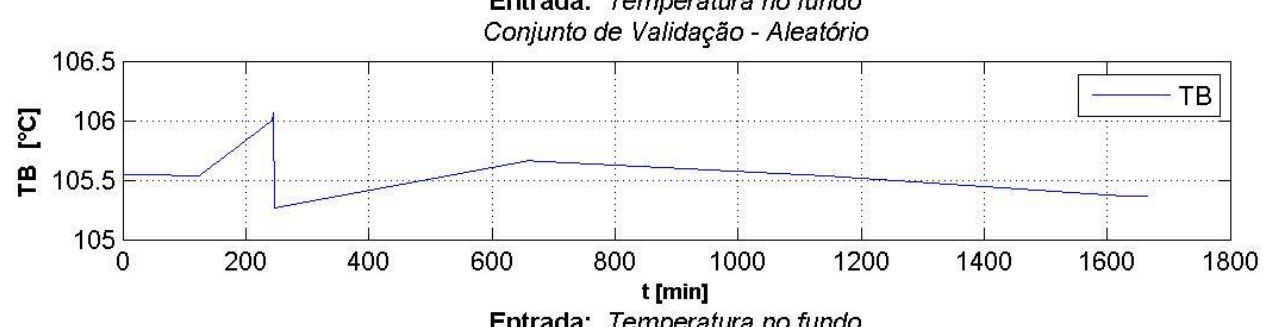

Entrada: Temperatura no fundo

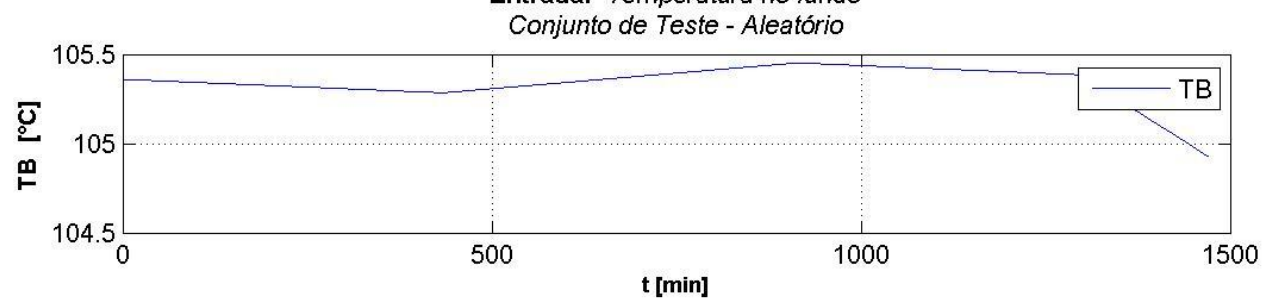

Entrada TB: conjunto de treinamento, teste, validação.

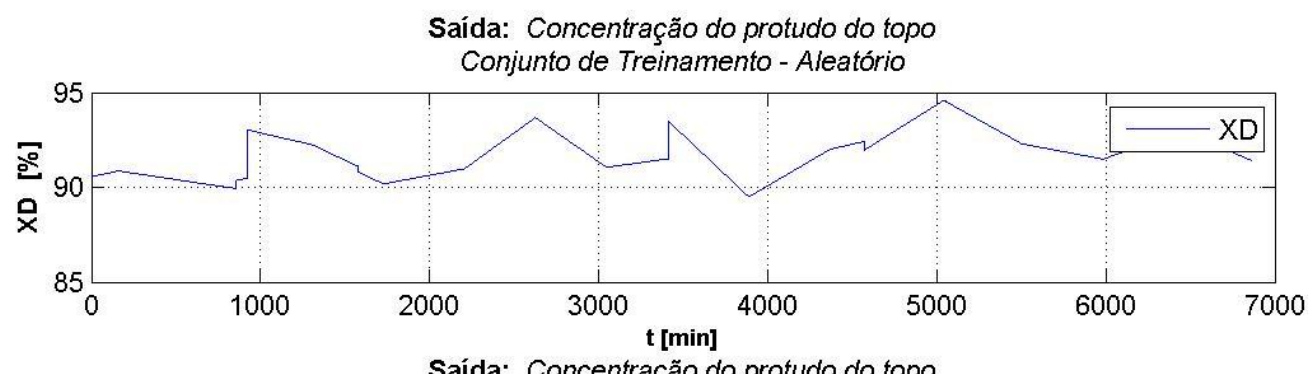

Saída: Concentração do protudo do topo

Conjunto de Validação - Aleatório

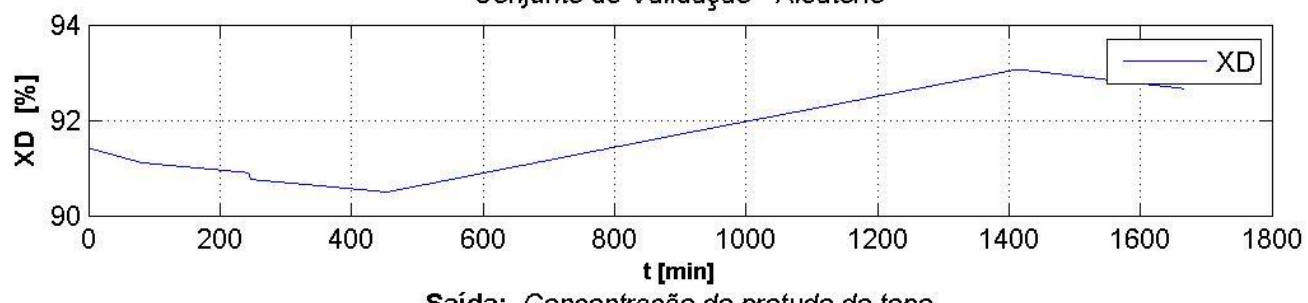

Saída: Concentração do protudo do topo Conjunto de Teste - Aleatório

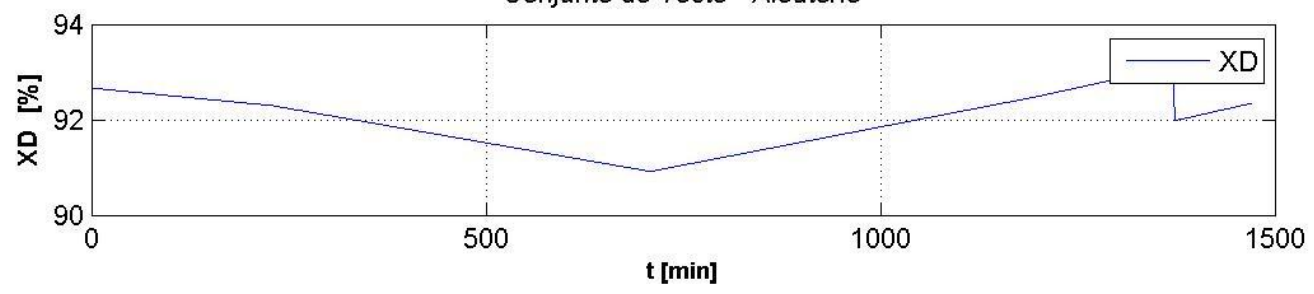

Saída XD: conjunto de treinamento, teste, validação. 
FUNÇÕES DE CORRELAÇÃO CRUZADA
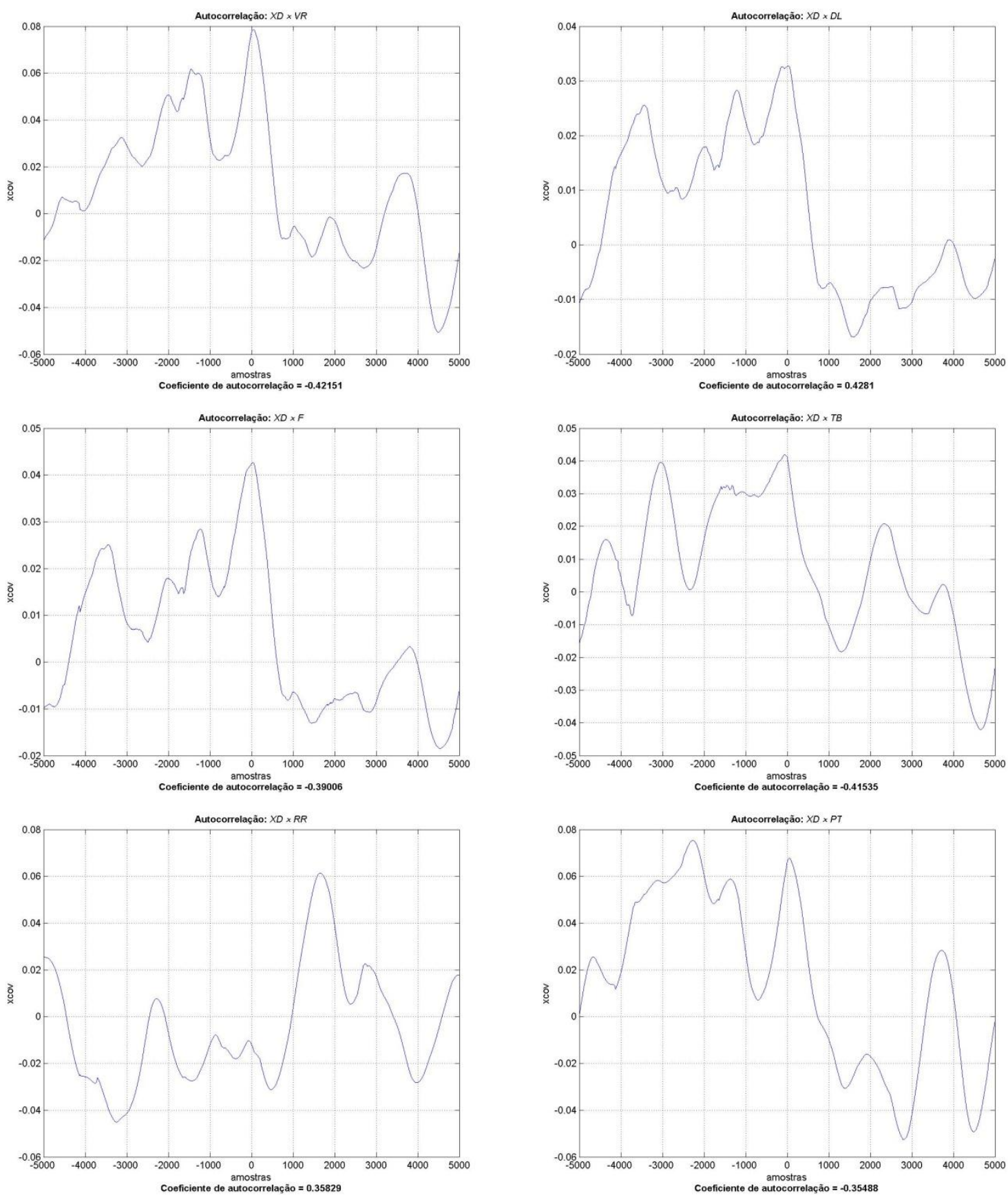

Correlação cruzada entre as entradas VR, DR, F, TB, RR, PT e a saída XD. 
199
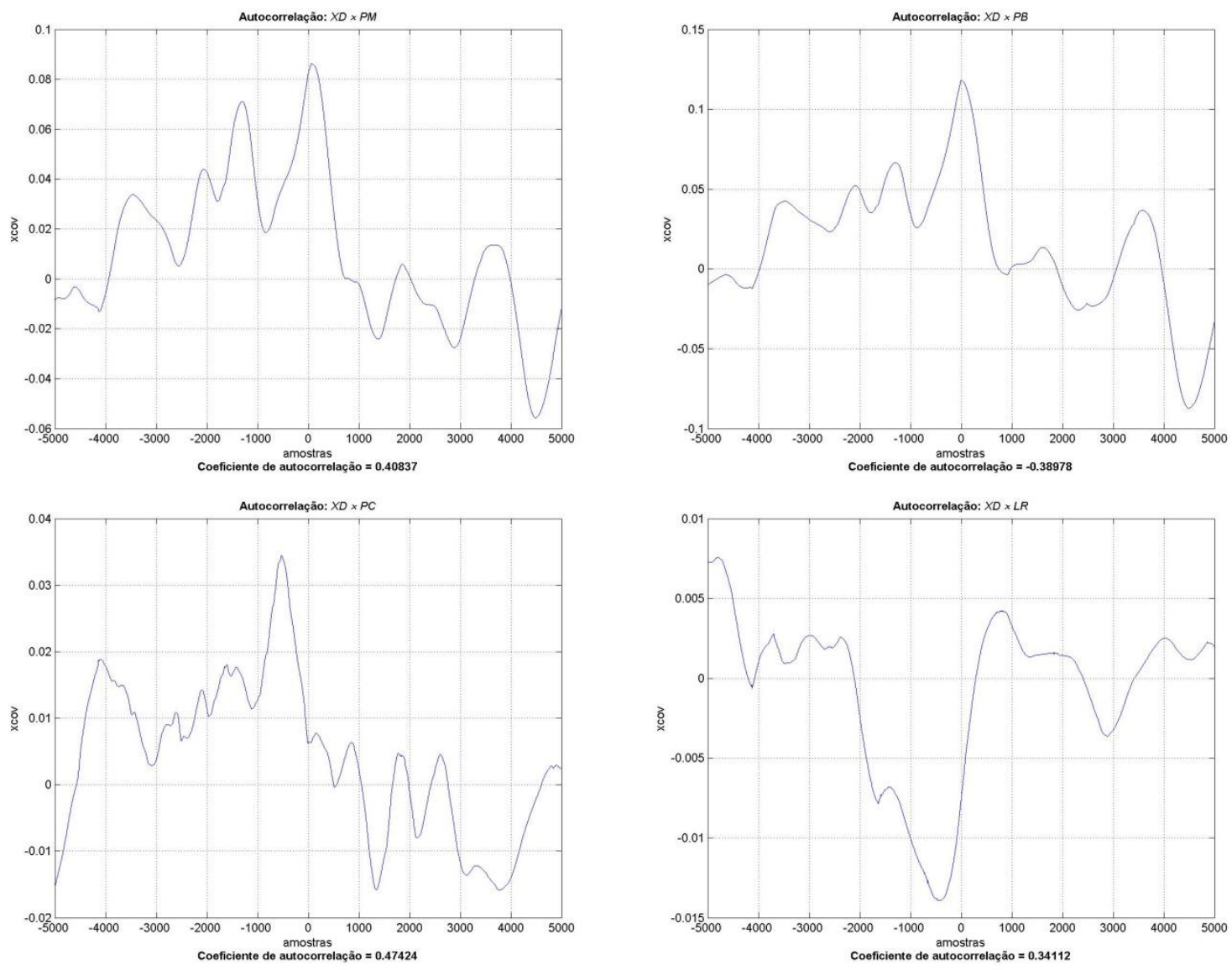

Correlação cruzada entre as entradas PM, PB, PC, LR e a saída XD. 

A figura a seguir mostra a configuração básica da rede TDNN utilizada como estrutura de inferência.

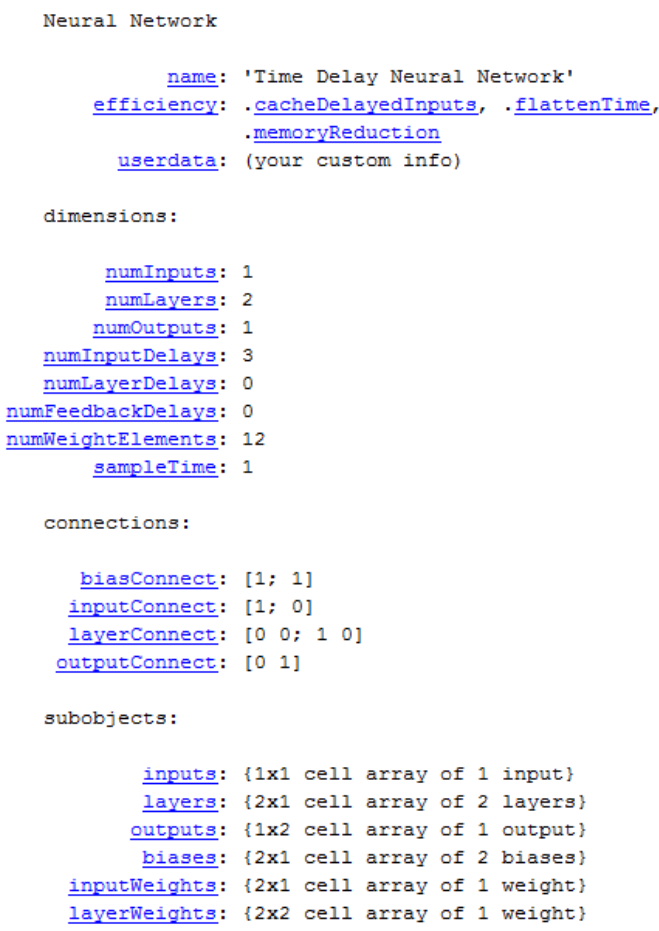

Neural Network

name: 'Time Delay Neural Network'

efficiency: .cacheDelayedInputs, .flattenTime, -memoryReduction

userdata: (your custom info)

dimensions:

numInputs: 1

numLayers: 2

numoutputs: 1

numInputDelays: 3

numLayerDelays: 0

numFeedbackDelays: 0

numWeightElements: 12

sampleTime: 1

connections:

biasConnect: [1; 1$]$

inputConnect: $[1 ; 0]$

layerConnect: $\left[\begin{array}{lll}0 & 0 ; 1 & 0\end{array}\right]$

outputConnect: [ [ 1 1 $]$

subobjects:

inputs: \{1x1 cell array of 1 input\}

layers: $\{2 \times 1$ cell array of 2 layers

outputs: \{1x2 cell array of 1 output

biases: \{2x1 cell array of 2 biases

inputWeights: \{2x1 cell array of 1 weight

layerWeights: $\{2 \times 2$ cell array of 1 weight

functions:

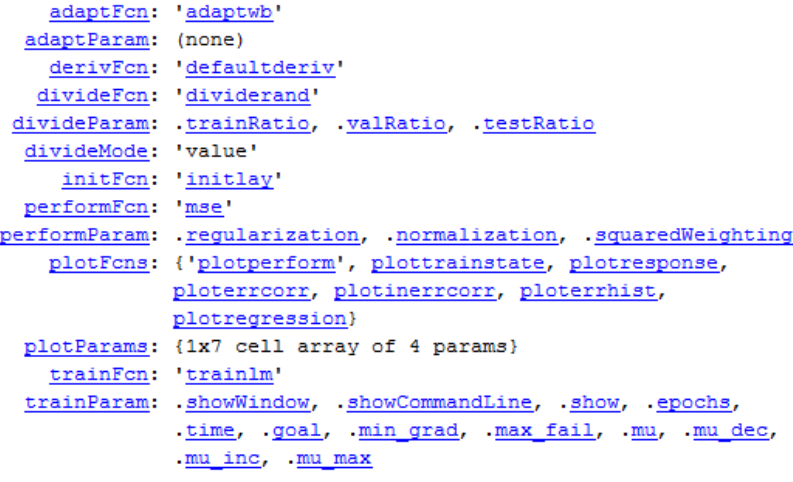

IW: $\{2 \times 1$ cell $\}$ containing 1 input weight matrix

LW: $\{2 \times 2$ cell $\}$ containing 1 layer weight matrix

b: $\{2 \times 1$ cell $\}$ containing 2 bias vectors

methods:

adapt: Learn while in continuous use configure: Configure inputs \& outputs

gensim: Generate Simulink model

init: Initialize weights \& biase

perform: Calculate performance

sim: Evaluate network outputs given inputs

train: Train network with examples

view: View diagram

unconfigure: Unconfigure inputs \& outputs

Configuração básica da rede TDNN utilizada no projeto. 
A figura a seguir mostra a topologias da rede TDNN utilizada no projeto.

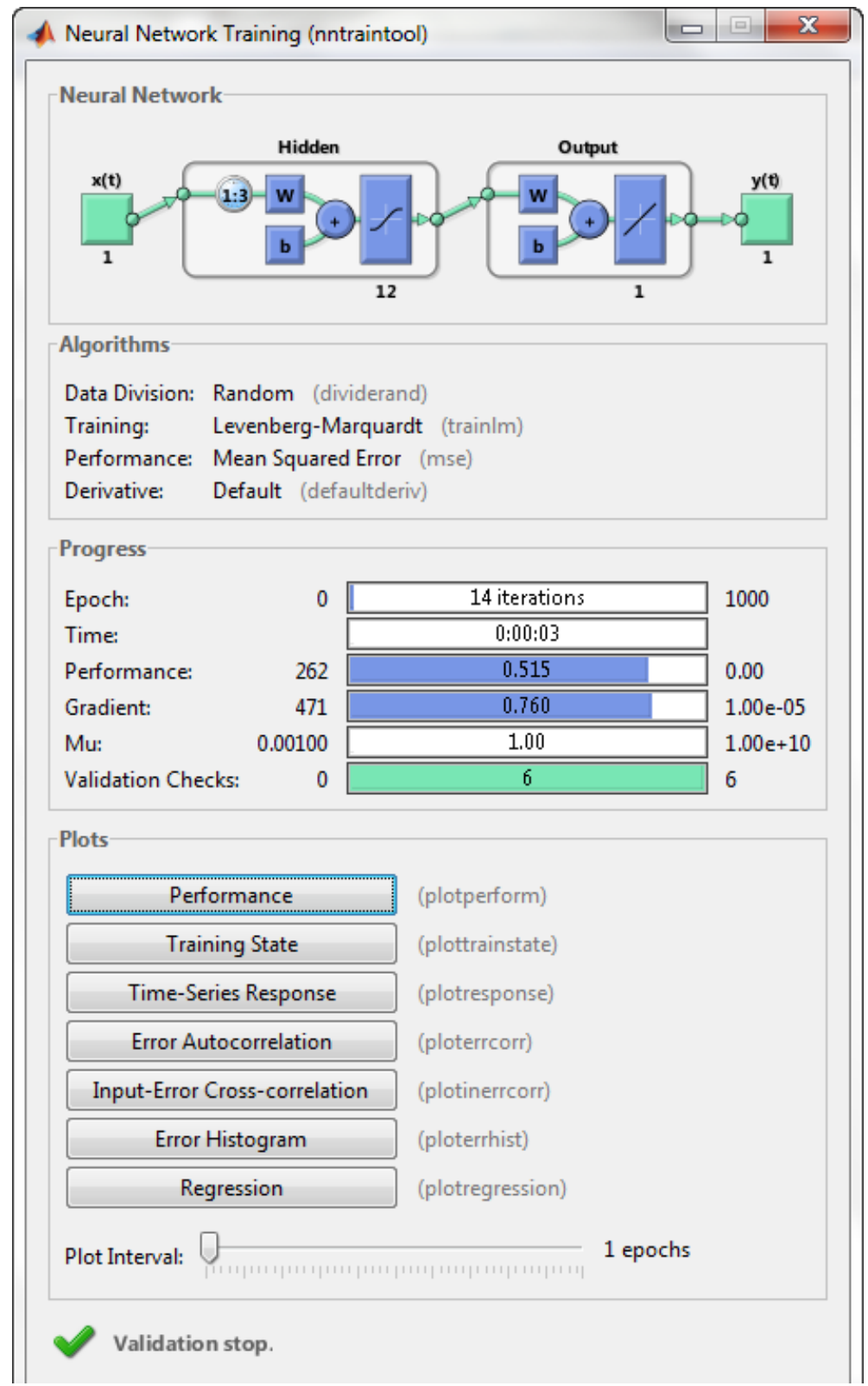

Topologia da rede TDNN 
A figura a seguir mostra a topologias da rede NNARX utilizada no projeto.

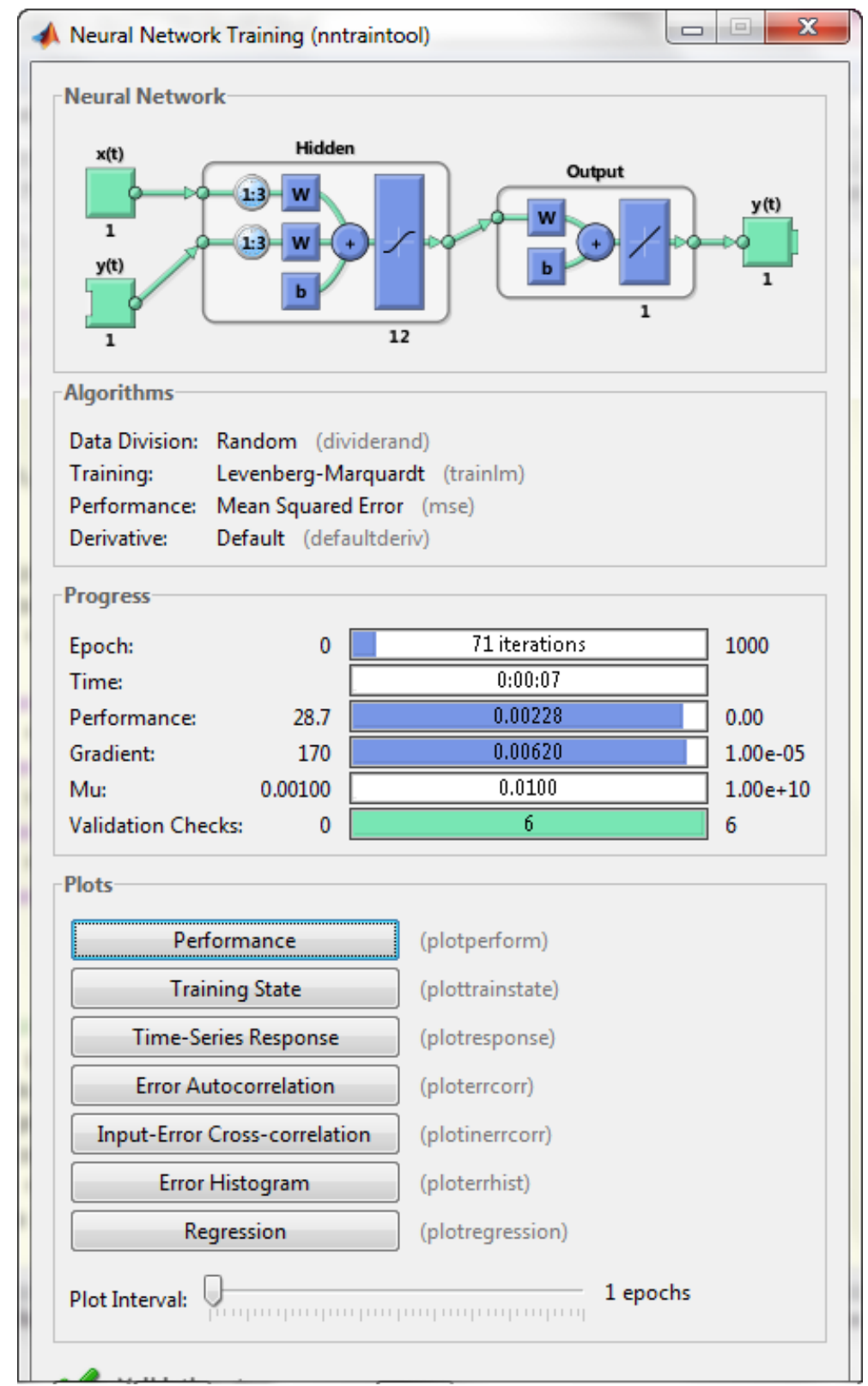

Topologia da rede NNARX 